325

$7 \cdot 31 \cdot 63$

\title{
POWER-BURST FACILITY (PBF) \\ CONCEPTUAL DESIGN
}

A. A. Wasserman, S. O. Johnson,

R. E. Heffner, R. S. Kern, A. H. Spano

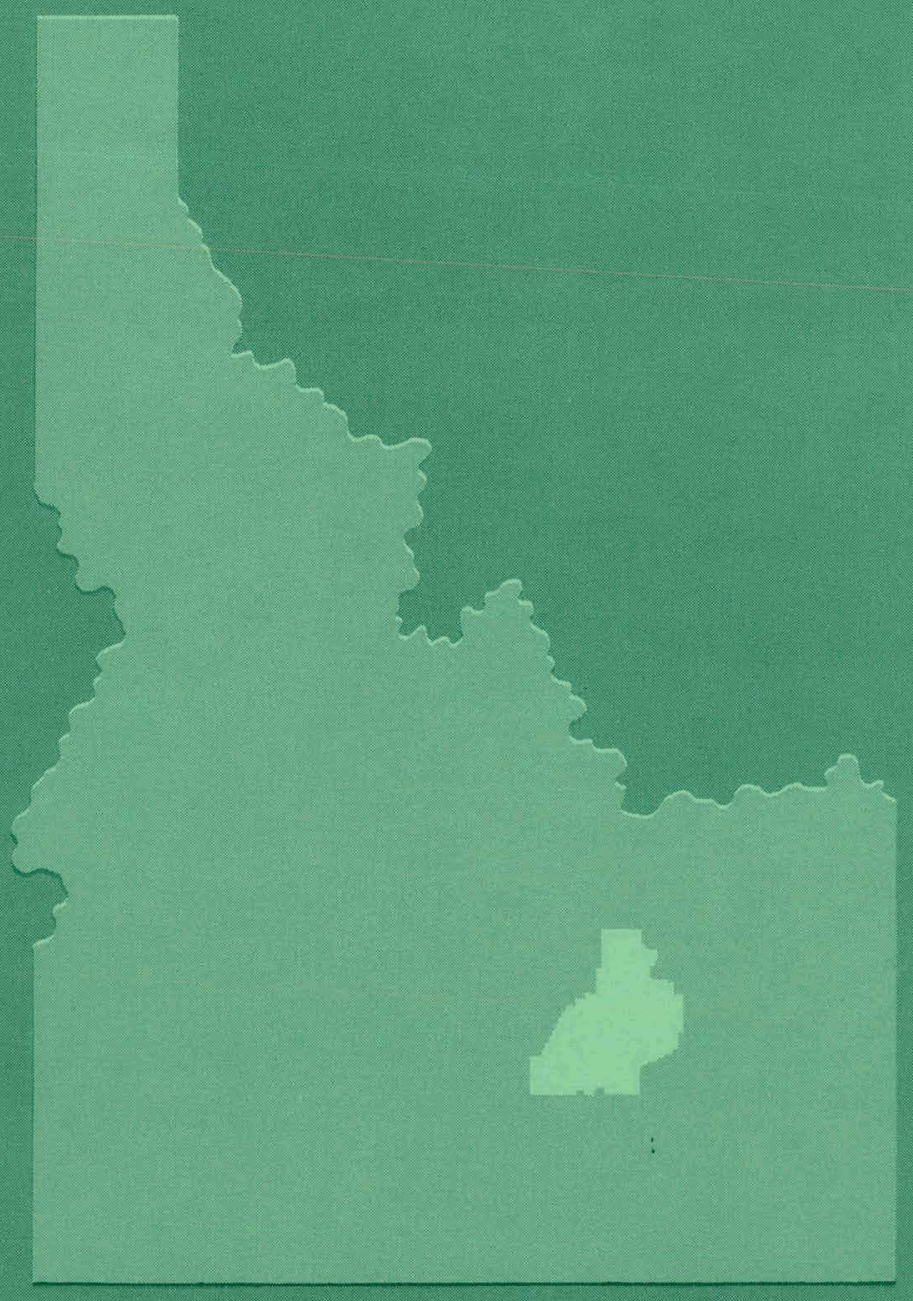

\section{PHILLIPS PEIROLEU M COMPANY}

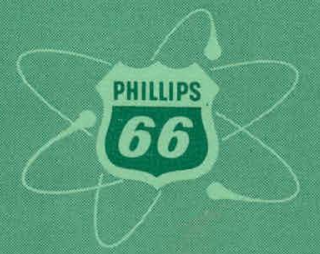

ATOMIC ENERGY DIVISION 


\section{DISCLAIMER}

This report was prepared as an account of work sponsored by an agency of the United States Government. Neither the United States Government nor any agency Thereof, nor any of their employees, makes any warranty, express or implied, or assumes any legal liability or responsibility for the accuracy, completeness, or usefulness of any information, apparatus, product, or process disclosed, or represents that its use would not infringe privately owned rights. Reference herein to any specific commercial product, process, or service by trade name, trademark, manufacturer, or otherwise does not necessarily constitute or imply its endorsement, recommendation, or favoring by the United States Government or any agency thereof. The views and opinions of authors expressed herein do not necessarily state or reflect those of the United States Government or any agency thereof. 


\section{DISCLAIMER}

Portions of this document may be illegible in electronic image products. Images are produced from the best available original document. 


\section{PRICE $\$ 2.75$ \\ Available from the Office of Technical Services \\ U.S. Department of Commerce Washington 25, D. C.}

\section{LEGAL NOTICE}

This report was prepared as an account of Government sponsored work. Neither the United States, nor the Commission, nor any person acting on behalf of the Coumission:

A. Makes any warranty or representation, express or implied, with respect to the accuracy, completeness, or usefulness of the information contained in this report, or that the use of any information, apparatus, method, or process disclused in this report may not infringe privately owned rights; or

B. Assumes any liabilities with respect to the use of, or for damages resulting from the use of any information, apparatus, method, or process disclosed in this report.

As used in the above, "person acting on behalf of the Commission" includes any employee or contractor of the Commission, or employee of such contractor, to the extent that such employee or contractor of the Commission, or employee of such contractor prepares, disseminates, or provides access to, any information pursuant to his employment or contract with the Commission, or his employment with such contractor. 


\section{POWER-BURST FACILITY (PBF)}

\section{CONCEPTUAL DESIGN}

by :

A. A. Wasserman

S. O. Johnson

R. E. Heffner

R. S. Kern

A. H. Spano

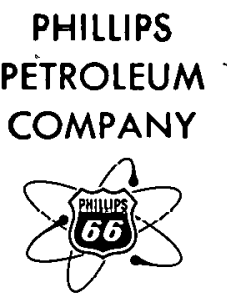

Atomic Energy Division

Contract AT(10-1)-205

Idaho Operations Office

U.S. ATOMIC ENERGY COMMISSION 


\section{POWER-BURST FACILITY (PBF) \\ CONCEPTUAL DESIGN}

CONCEPTUAL DESIGN STAFF

Overall Coordination and Editing

A. A. Wasserman

Detailed Design Supervision

S. O. Johnson, R. E. Heffner, R. S. Kern, and A. H. Spano

Reactor Physics

D. R. Metcalf

A. H. Brown

R. S. Marsden

R. A. Grimesey

R. W. Goin

A. J. Scott

B. J. Goff

Computer Programming and Services

L. A. Marsden

S. Tong

W. A. Hestir

Heat Transfer

J. E. Houghtaling

R. J. Wagner

R. W. Garner
Plant Design and Layout

A. S. Tucker

R. F. Russell

J. N. Brooks

H. M. Sullivan

R. G. Young

D. H. Murphy

H. D. Sweeney

A. L. Watlington

A. N. Schellenberg

E. G. Moshberger

G, M, Davis

G. R. Bohney

M. J. Mortensen

R. D. Pearson

Process Equipment

F. C. Haas

J. H. L. Elkins

D. Martin

N. K. Powell

D. R. Mousseau

Experimental Loops

L. I. Porter

E. L. Morris

F. C. Haas

J. H. L. Elkins

D. Martin

J. Dugone

J. F. Koenig

Electrical Services

B. K. Pope

D. D. Gibson

N. K. Powell

A. L. Smith

Y. A. Yates 


\section{POWER-BURST FACILITY (PBF) \\ CONCEPTUAL DESIGN}

\section{PREFACE}

At the request of the Idaho Operations Office of the U. S. Atomic Energy Commission [1,2], the Atomic Energy Division of Phillips Petroleum Co. has prepared a conceptual design for a new reactor facility called the PowerBurst Facility (PBF). This facility will provide information in direct support of several important facets of the USAEC Nuclear Safety Program, including aspects of reactor kinetics, consequences of fuel assembly meltdown, and containment.

This report on the conceptual design of the PBF is divided into ten sections, which may be grouped roughly into three separate parts. The first part, comprising the first three sections of the report, includes (a) a discussion of the need for and functions of the PBF in the context of the overall Nuclear Safety Program of the Atomic Energy Commission, (b) the general design philosophy for the PBF including the basis for selection of the general concept chosen, and (c) a summary description of the entire facility and its parts. Thus, the first three sections present a general picture of the background and design of the facility.

The second part of the report, comprising Sections IV through VII, includes (a) a detailed discussion of the considerations leading to the particular fuel element design chosen for the PBF; (b) a discussion of the reactor physics calculations leading to the core configuration selected; (c) a detailed engineering description of the entire facility, including site, buildings, reactor, auxiliary facilities, and pressurized water loop; and (d) the proposed division of final design responsibility. Thus, the second part of the report gives the technical basis for the design as presently conceived as well as the basic specifications for the architect-engineer.

The third and final part of the report is comprised of Sections VIII through $X$, which include (a) the list of references, (b) a set of appendices covering supplementary material on the physics design of the facility, and (c) the figures for the report, grouped together for convenience. 


\begin{abstract}
A description is presented of the conceptual design of a new, highperformance, pulsed reactor called the Power Burst Facility (PBF). This reactor is designed to generate power bursts with initial asymptotic periods as short as $1 \mathrm{msec}$, producing energy releases large enough to destroy entire fuel subassemblies placed in a capsule or flow loop mounted in the reactor, all without damage to the reactor itself. The facility will provide a much-needed additional tool for the AEC Nuclear Safety Program. It will be used primarily to evaluate the consequences and hazards of very rapid destructive accidents in reactors representing the entire range of current nuclear technology as applied to power generation, propulsion, and testing. It will also be used to carry out detailed studies of non-destructive reactivity feedback mechanisms in the short-period domain.
\end{abstract}

Because of its ability to achieve very large energy releases during 1-msecperiod power excursions, the initial PBF reactor design makes a major advance over the performance of any existing pulsed reactor. The facility has been designed to be sufficiently flexible to accommodate future cores of even more advanced design. The design for the first reactor core is based upon proven technology; hence, completion of the final design of this core will involve no significant development delays. Construction of the PBF is proposed to begin in September 1964, and is expected to take approximately 20 months to complete. 


\section{POWER-BURST FACILITY (PBF)}

CONCEPTUAL DESIGN

\section{CONTENTS}

PREFACE $: \ldots \ldots \ldots \ldots \ldots \ldots \ldots \ldots \ldots$ iii

ABSTRACT $\ldots \ldots \ldots \ldots \ldots \ldots \ldots \ldots \ldots$ iv

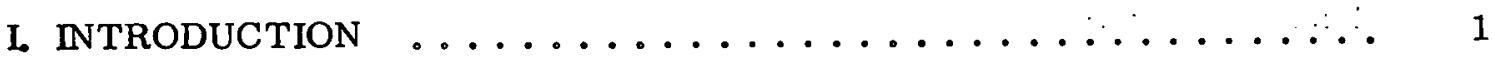

1. REVIEW OF AEC NUCLEAR SAFETY PROGRAM ......... 1

2. NEED FOR THE PBF FOR IN-PILE SUBASSEMBLY TESTING $\ldots \quad 1$

3. EARLIER SUBASSEMBLY TRANSIENT TESTS $\ldots \ldots \ldots \ldots \ldots$

4. FUNCTIONS OF THE PBF .................. 4

5. FLEXIBILITY OF THE FACILITY ............. 4

II. PBF DESIGN PHILOSOPHY $\ldots \ldots \ldots \ldots \ldots \ldots \ldots \ldots \ldots \ldots \ldots \ldots \ldots \ldots$

1. DESIGN OBJECTIVES FOR THE FIRST-GENERATION PBF CORE. 6

2. COMMENTS ON FUTURE-GENERATION PBF CORES $\ldots \ldots \ldots$

3. IMPORTANT FEATURES REQUIRED

TO MEET DESIGN OBJECTIVES ................ 8

3.1 Generation of Sufficient Energy to Melt. Test Assemblies . . . . 8

3.2 Attainment of a One-Millisecond Period of Power Rise . . . . 8

3.3 Provision of Proper Environment in Test Space . . . . . . . . 8

3.4 Prevention of Damage to PBF Core During Meltdown Tests : . 9

3.5 Provision of Sufficiently Large Test Space . . . . . . . . . . 10

3.6 Reduction of Sensitivity of Core

Reactivity to Contents of Test Space . . . . . . . . . . . 10

3.7 Self-Limitation of Power Bursts ............... . . 10

3.8 Provision of High-Duty-Factor Operation ........... 10

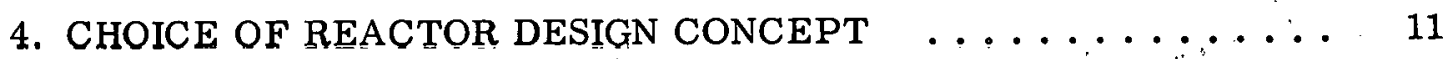

4.1 Review of Capabilities of Existing Pulsed Reactors ...... 11

4.2 Basis for Choice of a Low-Enrichment, $\mathrm{UO}_{2}-\mathrm{H}_{2} \mathrm{O}$ System $\ldots . . \quad 12$

4.3 Limitations of a $\mathrm{UO}_{2}-\mathrm{BeO}-\mathrm{H}_{2} \mathrm{O}$ System $\ldots \ldots \ldots \ldots \ldots \ldots$

5. PROPOSED LOCATION FOR THE PBF . . . . . . . . . . . . 13

III. GENERAL DESIGN FEATURES AND PHILOSOPHY OF OPERATION ${ }^{*}$. 14

1. GENERAL FACILITY DESCRIPTION , ............ 15

2. REACTOR AND PROCESS EQUIPMENT .............. 15 
3. FIRST-GENERATION REACTOR CORE . . . . . . . . . . . . 15

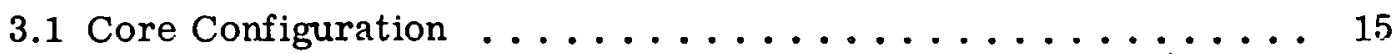

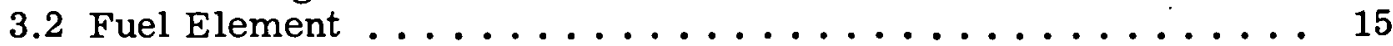

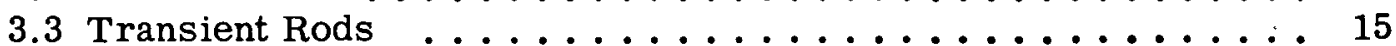

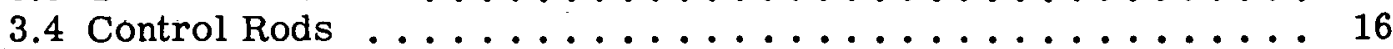

3.5 Safety Rods ......................... 16

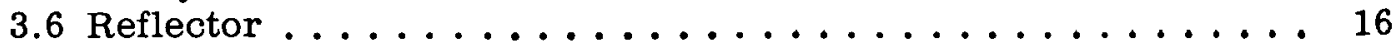

4. EXPERIMENTAL FACILITIES ................. 16

5. PRESSURIZED WATER LOOP $\ldots \ldots \ldots \ldots \ldots \ldots \ldots$

6. PHILOSOPHY OF OPERATION ................. 17

IV. FUEL ELEMENT DESIGN CONSIDERATIONS ............. 19

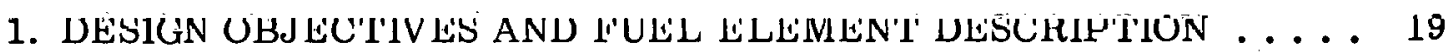

2. PROPERTIES OF FUEL ELEMENT MATERIALS $\ldots \ldots \ldots \ldots$

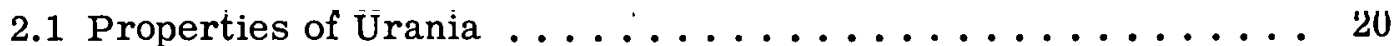

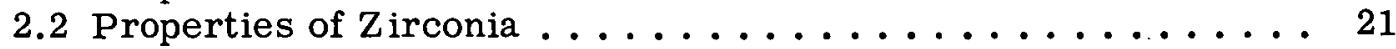

2.3 Properties of the Urania-Zirconia System ........... 22

3. HEAT TRANSFER AND THERMAL STRESS CONSIDERATIONS $\ldots 22$

4. FUel Element testing PROGRAM . . . . . . . . . . . . 26

V. REACTOR PHYSICS OF THE FIRST-GENERATION CORE . . . . . 29

1. PHILOSOPHY AND OBJECTIVES . . . . . . . . . . . . . 29

2. OPTIMIZATION STUDIES $\ldots \ldots \ldots \ldots \ldots \ldots \ldots \ldots \ldots \ldots \ldots$

2.1 Introduction ....................... 32

2.2 Figure-of-Merit and Coupling .................. 33

2.3 Core Radius . . . . . . . . . . . . . . . . . . . 36

2.4 Reactivity Coefficients ..................... 36

2.5 Prompt-Neutron Lifetime Studies ................. 40

3. NEUTRON FLUX AND POWER DISTRIBUTION . . . . . . . . . 40

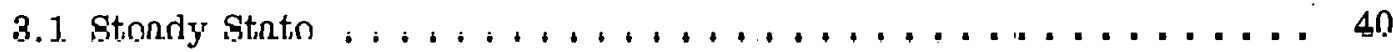

3.2 Transients ........................... 41

4. PERFORMANCE CHARACTERISTICS OF THE OPTIMIZED PBF REACTOR WITH TYPICAL TEST ASSEMBLIES . . 41

5. CONTROL, TRANSIENT, AND SAFETY ROD STUDIES $\ldots \ldots \ldots \ldots$

6. SUMMARY AND RECOMMENDATIONS . . . . . . . . . . . . 45

6.1 Summary of Conceptual Reactor Design . . . . . . . . . 45

6.2 Selection of the Conceptual Design ................ 45

6.3 Recommendation for Further Study . . . . . . . . . . . . . 48 
VI. ENGINEERING DESCRIPTION $\ldots \ldots \ldots \ldots \ldots \ldots$

1. $\operatorname{SITE} \ldots \ldots \ldots \ldots \ldots \ldots \ldots \ldots \ldots \ldots \ldots \ldots \ldots \ldots$

2. CONTROL CENTER ...................... 49

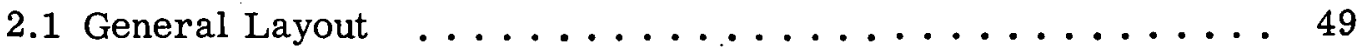

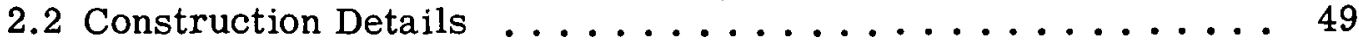

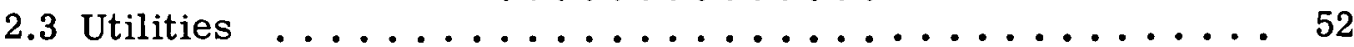

3. REACTOR FACILITY ......................... 54

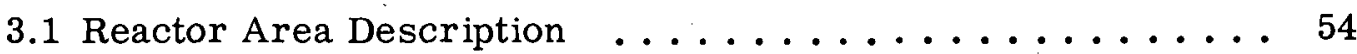

3.2 Reactor Building Layout ... . . . . . . . . . . . . . . . 54

3.3 Reactor Bullding cionstruction vetails ............. 55

3.4 Electrical Services ..................... 56

3.5 Plant Process Instrumentation ............... 66

3.6 Mechanical and Process Equipment ............ 67

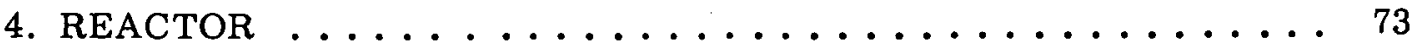

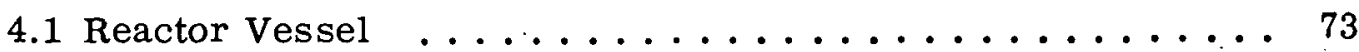

4.2 Core structure ........................ 74

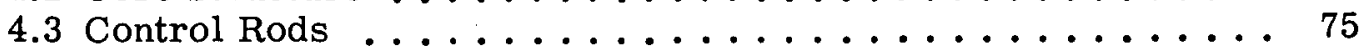

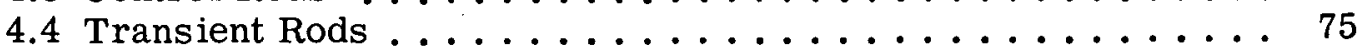

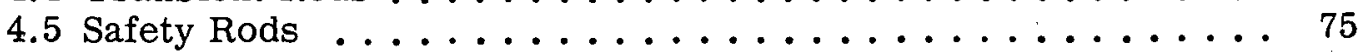

4.6 Control, Safety, and Transient Rod Drives ... . . . . . . 75

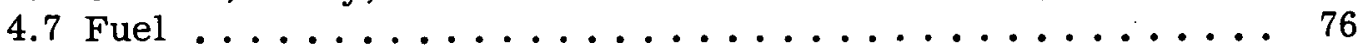

4.8 Stainless Steel Reflector Pins ................ 77

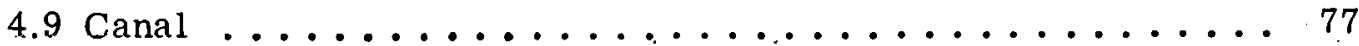

5. EXPERIMENTAL FACILITIES . . . . . . . . . . . . 77

5.1 General ... . . . . . . . . . . . . . . . . . . . 77

5.2 Pressurized Water Capsule .................. 77

5.3 Loop Experiments ....................... 78

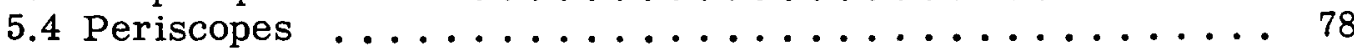

6. PRESSURIZED WATER LOOP . . . . . . . . . . . . 78

6.1 General Description .................... 78

6.2 Operating Philosophy ..................... 79

6.3 General Design Considerations ............... . . 79

6.4 In-pile Tube ......................... 82

6.5 Component Design Considerations ............. 83

VII. DIVISION OF DESIGN RESPONSIBILITY . . . . . . . . . . . . 87

VIII. REFERENCES .......................... 88

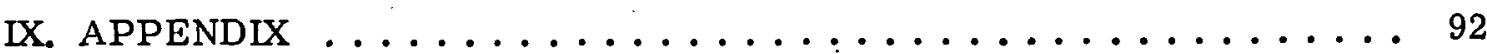

1. PHYSICS CALCULATIONAL METHODS ............... 92

1.1 Introduction . . . . . . . . . . . . . . . . . 92

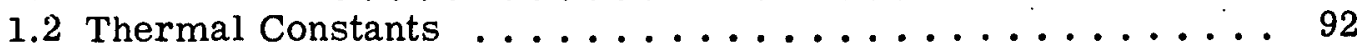


1.3 Fast Constants $\ldots \ldots \ldots \ldots \ldots \ldots \ldots \ldots \ldots \ldots . \ldots . \ldots 2$

1.4 Flux Shape During a Transient and Prompt-Neutron Lifetime . . 93

2. VALIDATION OF PHYSICS CALCULATIONAL METHODS $\ldots \ldots 9$

2.1 Introduction $\ldots \ldots \ldots \ldots \ldots \ldots \ldots \ldots \ldots \ldots \ldots$

2.2 Calculational Methods ................ 94

2.3 Criticality Studies. . . . . . . . . . . . . . . 94

2.4 Prompt-Neutron Lifetime Study. . . . . . . . . . . 95

2.5 Doppler Coefficient of Reactivity Study . . . . . . . . 95

\section{FIGURES}

1. Model for thermal calculations $\ldots \ldots \ldots \ldots \ldots \ldots \ldots \ldots \ldots$ F1

2. Transient temperatures within the fuel pin $\ldots \ldots \ldots \ldots \ldots \ldots$ F2

3. Thermal stress and temperature behavior in the clad $\ldots \ldots \ldots \ldots$ F3

4. Thermal stress and temperature behavior in the clad $\ldots \ldots \ldots \ldots$ F4

5. Temperature distributions within the fuel pin $\ldots \ldots \ldots \ldots \ldots$ F5

6. Effect of $\mathrm{ZrO}_{2}$ insulator thickness on clad surface temperature $\ldots \ldots$ F6

7. Reactor model for optimization studies $\ldots \ldots \ldots \ldots \ldots \ldots \ldots$ F7

8. Effects of metal-to-water ratio and enrichment on figure-of-merit and coupling . ........... F8

9. Effects of metal-to-water ratio and

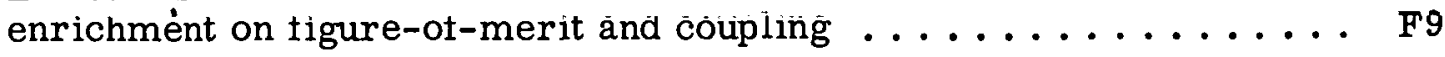

10. Effects of boron concentration in flux suppressor on coupling . . . . F10

11. Effects of boron concentration in flux suppressor on figure-of-merit . F11

12. Effects of metal-to-water ratio and pressure pipe diameter on figure-of-merit and coupling ..........F12

13. Effects of metal-to-water ratio and pressure pipe diameter on figure-of-merit and coupling $\ldots \ldots \ldots \ldots \ldots$ F13

14. Effects of metal-to-water ratio, enrichment, and boron concentration in the flux suppressor on the critical core radius ..... F14

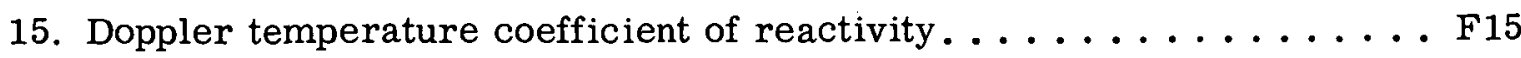

16. Variation of $\mathrm{k}_{\mathrm{eff}}$ with fuel temperature ............. F16

17. Effects of metal-to-water ratio and enrichment on Doppler reactivity (fuel temperature changed from $20^{\circ} \mathrm{C}$ to $2200^{\circ} \mathrm{C}$ ) . . . . F F 17 


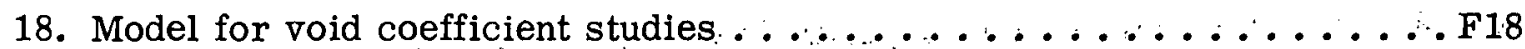

19. Effects of metal-to-water ratio and enrichment on the prompt neutron lifetime ............... F19

20. Four-group neutron flux distribution .................. F20

21. Four-group neutron flux distribution ................... F21

22. Four-group neutron flux distribution . . . . . . . . . . . . F22

23. Power density distributions .................... F23

24. Model for HTGR-type test assembly . . . . . . . . . . . . . . . . F24

25. Rod worth as a function of control rod annulus position . . . . . . . F25

26. Effect of control rod annulus position on the figure-of-merit . . . . . F F26

27. Effects of metal-to-water ratio and enrichment on Doppler reactivity and prompt neutron lifetime . ........... F27

28. Spert general site plan ...................... . F28

29. Spert control center area . . . . . . . . . . . . . . . . . : F29

30. Proposed control center floor plan ..................... F30

31. Proposed control center elevations ........................ F31

32. Proposed control center elevations . . . . . . . . . . . . . F F32

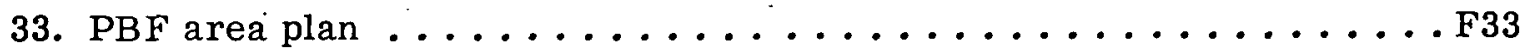

34. Reactor building main floor plan. . . . . . . . . . . . . . F34

35. Reactor building basement floor plan. . . . . . . . . . . . F35

36. Reactor building sub-pile room floor plant ...............F36

37. Reactor building cross section . . . . . . . . . . . . F37

38. Reactor building longitudinal section ................ F38

39. Reactor building elevation . . . . . . . . . . . . . . . F39

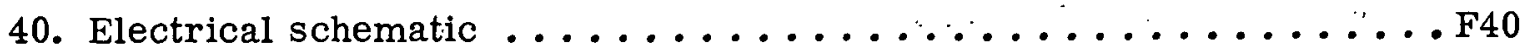

41. Electrical outlets; communications, and warning system . . . . . . F41

42. Electrical outlets, communications, and warning system . . . . . . . F42

43. Reactor process system flow diagram . . . . . . . . . . . F43 
44. Water supply, usage, and disposal flow diagram . . . . . . . . . F F44

45. Make-up demineralizer flow diagram $\ldots \ldots \ldots \ldots \ldots \ldots \ldots \ldots$. . . F45

46. Plant steam system flow diagram ................. F46

47. Heating and ventilating flow diagram $\ldots \ldots \ldots \ldots \ldots \ldots \ldots$ F47

48. Plant and instrument air system flow diagram . . . . . . . . . . F48

49. Liquid waste disposal system flow diagram . . . . . . . . . . . . F49

50. Gaseous waste system flow diagram ................. F50

51. Simplified reactor layout - vertical section $\ldots \ldots \ldots \ldots \ldots \ldots$ F51

52. Reactor core $p l a n \ldots \ldots \ldots \ldots \ldots \ldots \ldots \ldots$ F52

53. Conceptual fuel pin ........................ F53

54. I'ypical pressurized water experiment ................ . F54

55. Pressurized water loop process flow diagram ............ F55

56. Flow diagram of high-pressure demineralized cooling
water system for pressurized water loop $\ldots \ldots \ldots \ldots \ldots \ldots \ldots$. . . . F56

57. Thermal flux in fuel pin ....................... F57

58. Electrical junction box details ................... F58

59. Electrical junction box details .................. F59

60. Electrical junction box details and installation ............ F60

\section{TABLES}

I. Limiting Energy Density for Various Reactor Materials ....... 9

11. PBF Conceptual Design Parameters ................... 14

III. Properties of Urania ... . . . . . . . . . . . . . . 20

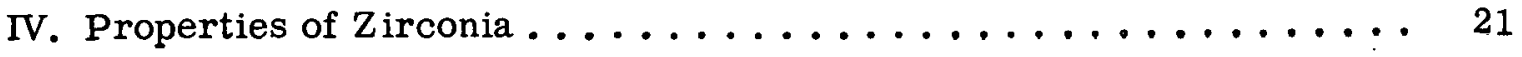

V. Coefficients for Equation 3 Used in the HEAT-1 Program ....... 24

VI. Stainless Steel Pressure Pipe Dimensions ............. . 33

VII. Void Coefficients for the Three Percent Enriched Core With $600 \mathrm{gpm}$ Stainless Steel Assembly in Test Space ...... 38 
VIII. Void Coefficients for the Five Percent Enriched Core with ETR Fuel Assembly in Test Space . . . . . . . . . . 39

IX. Temperature Coefficients for the Five Percent

Enriched Core with ETR Fuel Assembly in Test Space . . . . . ... 40

X. Performance Characteristics of the

Optimized PBF for Typical Test Assemblies . . . . . . . . . . . 42

XI. Summary of PBF Conceptual Reactor Design . . . . . . . . . 45

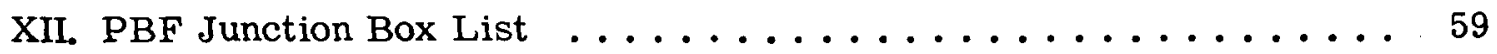

Xill Cable systems specifications ................... 60

XIV. Primary Cooling System Operating Conditions _. . . . . . . . 69

XV. Pressurized Water Loop Design Parameters . . . . . . . . . . 80

XVI Proposed Division of Design Responsibility for PBF $\ldots \ldots \ldots 7$

XVII. Spert I Oxide Core Fuel Rod Parameters . . . . . . . . . . . . . 94 


\section{POWER-BURST FACILITY (PBF) \\ CONCEPTUAL DESIGN}

\section{INTRODUCTION}

\section{REVIEW OF AEC NUCLEAR SAFETY PROGRAM ${ }^{[3]}$}

Nuclear safety is of necessity an overriding consideration in the design, construction, and operation of high-power nuclear systems, whether they be power reactors, test reactors, or reactors for terrestrial or aerospace propulsion. In the absence of adequate information regarding the dynamic capabilities and ultimate hazards of these systems, nuclear reactor design and siting must necessarily be conservative. The AEC nuclear safety program is intended to develop the necessary information to provide a sound technical basis for safe engineering design and reactor siting in the nuclear industry and thereby to contribute to a lowering of the costs involved in the useful application of nuclear energy.

The activities sponsored by the AEC nuclear safety program include a wide range of fundamental experimental and analytical studies in reactor safety and related problems. The overall program may be divided conveniently into three major categories: reactor kinetics, chemical and physical effects associated with fuel meltdown or fuel ignition, and reactor containment. For the purposes of reactor design and prediction of safety behavior, experiments are being carried out to model nuclear excursion behavior, reactor instability, loss of coolant effects, metal-water reactions, and fission product release. Studies in the field of reactor containment include missile and blast effects, energy releases due to loss of coolant, shock effects, and studies related to the evaluation and improvement of advanced containment concepts.

To obtain the needed detailed information on various aspects of reactor kinetics, meltdown effects, and fission-product release, a new pulsed reactor facility is required which is capable of achieving repeated power bursts with periods of the order of $1 \mathrm{msec}$ and with energy releases sufficient to melt down or decompose entire fuel subassemblies of many different types. The PowerBurst Facility has been designed to fulfill this need.

\section{NEED FOR THE PBF FOR IN-PILE SUBASSEMBLY TESTING}

In the early- and mid-1950's, it was recognized that if the utilization of nuclear energy for large-scale power generation, propulsion, and test applications were not to be unduly hampered by uncertainties regarding reactor accident hazards, it was necessary to obtain a better understanding of the interplay of the various dynamic processes involved in reactor transient behavior. Specifically, information was needed on the relation between reactor design parameters and reactor response, both in the non-destructive and in the destructive ranges, in order to permit an evaluation of the safety of proposed nuclear systems and to 
permit the application of safety considerations as a constraint in the engineering design of reactors.

Because of the complex interrelation between the neutronic and thermalhydraulic processes involved in the dynamics of high-power reactor systems, it was evident at the outset that a detailed understanding of the various processes involved had to be obtained, and that "differential" or subassembly tests in a reactor environment were required for this purpose. In such tests the thermal processes can be decoupled from the neutronic processes and studied separately under carefully simulated reactor conditions.

For a number of important reasons, however, it was decided to emphasize first a program of integral-core reactor dynamic testing. Among the reasons for this decision were the following:

First, given the strong impetus to accelerate the development of a nuclear power industry, there was an urgent need for gross answers to a number of basic nuclear safety questions, in advance of the detailed understanding and prediction capability which would follow from a program which included extensive subassembly testing. For example, it was considered necessary to obtain gross demonstrations of:

(1) The inherent stability of reactors of different basic designs when operated at steady state at high power levels

(2) The inherent self-shutdown capabilities of reactors of different basic designs when subjected to step and ramp insertions of reactivity simulating accident conditions of various types

(3) The consequences of destructive transient behavior, both of the excursion and of the stability type.

The second reason for emphasizing integral-core testing initially was that, in order to permit the design of meaningful suhassembly tests and to develop an efficient subassembly test program, it was necessary first to obtain some general "scoping" information, to define in a general way those parameters or processes which were most important in determining the overall behavior of the system in various time-scale domains.

Finally, integral-core test results were needed to provide reference data against which models and predictions based on the detailed information obtained in the subassembly experiments could be tested.

As a result of the integral-core dynamic tests conducted in the past [4-14] a considerable amount of useful information has been developed relating to stability and self-shutdown characteristics of a number of different types of reactors, in addition to a limited amount of valuable information on the consequences of core damage. It is evident that continued studies of this type are necessary. Among the specific achievements of the integral-core tests which strongly pointed up the limitations of those tests unless complemented by a vigorous program of subassembly testing, were:

(1) Demonstration that satisfactory correlations of the nondestructive transient data for a given reactor can be developed on 
the basis of a number of very different physical models. (This finding strongly emphasized the need for subassembly testing to establish uniquely the physical processes actually involved and to obtain a detailed understanding of their dependence on the time scale of the power burst.)

(2) Demonstration that detailed multi-node calculations of the shutdown reactivity due to thermal and radiation-induced expansion effects during short-period, non-boiling transients, using statically measured values of the void coefficients, temperature coefficients, and flux distributions, do not account fully for the observed selfshutdown of plate-type, water-moderated reactors. (This result again pointed up the need for controlled subassembly tests to study the details of transient heat transfer effects and to determine if important mechanisms were missing from the detailed physical models used as a basis for the calculations.)

(3) Establishment of the threshold of reactor period for the transition from non-destructive to destructive behavior in a given class of reactors, approximate determination of the range of asymptotic reactor periods in the destructive domain which are physically realizable, and establishment of the existence of significant threshold effects in the destructive domain. (Again such effects are most efficiently studied in detail in a subassembly test program.)

It remains evident that, to establish a balanced program for obtaining a fundamental understanding of the important mechanisms of energy release, heat flow, pressure generation, and fuel element failure during violent powerexcursion or instability tests of different types of reactor systems, it is necessary to complement the integral-core test program with a strong subassembly test program which will involve the subjection of fuel components to short-period tests with large energy releases. Such an addition to the program will increase the rate at which the desired information is obtained and will materially reduce the total number of the more expensive integral-core tests required.

\section{EARLIER SUBASSEMBLY TRANSIENT TESTS}

Some subassembly testing has been performed during the past few years, both at Spert [7, 15] and at TREAT [14], using an existing power-excursion reactor facility as a driving source for experiments placed in capsules and mounted within or adjacent to the reactor core. As a result of this work considerable experience has been gained in capsule design, instrumentation, and photographic techniques required for effective subassembly testing. In addition, the limited test results obtained thus far have clearly demonstrated the value of subassembly testing for obtaining information on mechanisms of both destructive and nondestructive reactor dynamic behavior in the short-period domain.

(Although the functions of the Power-Burst Facility are somewhat similar to those of the TREAT reactor [14], the TREAT reactor itself would not be suitable for many of the applications considered chiefly because it is limited to periods longer than about $40 \mathrm{msec}$; whereas the rate effects which must be duplicated for an understanding of a BORAX [5], SL-1 [16], or Spert-I [17] 
destructive test require a facility capable of much shorter periods. Further discussion of the limitations of the TREAT and other existing reactors for the present application is given in Section II, 4.1.)

\section{FUNCTIONS OF THE PBF}

The primary purpose of the Power-Burst Facility is to study the various phenomena associated with the rapid destructive heating of fuel assemblies designed for use in a variety of reactor systems. The objective is to obtain a basic understanding of such phenomena as the onset of shock, explosive steam generation, fuel disruption, fission-product release, and metal-water reactions, and their effects on the reactivity of the system. The reactor will also serve as a proof-test facility for confirming analytical predictions of such effects when they are presented in the safety analyses of new reactors.

The second important purpose of the PBF is to carry out in-pile subassembly studies of basic reactivity-feedback mechanisms associated with non-destructive power excursions in reactors of various types. Included here are such mechanisms as fuel and moderator expansion, moderator boiling, Doppler effects in the fuel, rod bowing or other distortion of the fuel geometry, and neutron energy upgrading by bound hydrogen in the fuel. Studies will be made of the effects of various operating parameters (such as, initial system pressure, temperatures, and coolant flow rate) and also of the effects of perturbations in fuel subassembly design (such as, changes in material composition, fuel enrichment, and geometrical configuration).

The third major purpose of the PBF is to make this capability generally available as determined by the needs of the AEC nuclear safety program, and to permit special fuel-element and instrumentation development studies.

\section{FLEXIBILITY OF THE FACILITY}

The PBF is intended to be a flexible facility, designed to accommodate several successive cores, each core yielding an improvement over its predecessor in performance and versatility for subassembly testing.

The performance of the proposed first-generation core far exceeds that of any existing pulsed-reactor facility in achieving large energy releases at very short periods. The design chosen is based upon proven technology and requires no major development program. This is of especial importance in view of the need for a more extensive and more stringent fuel subassembly program than is possible with existing test reactor facilities. The design chosen will permit completion and effective utilization of the PBF at the earliest possible date. Construction of the PBF is proposed to begin in September 1964, and to be completed within approximately 20 months.

Future-generation PBF cores, which will require a significant development effort, may be expected to achieve even larger energy releases at shorter 
periods than the first-generation core. Such cores may also be designed to include variations in the mode of operation of the facility. One such variation would be to decrease the self-shutdown coefficient of the core and to increase the reactivity coupling from the test space to the core. This would permit use of the core as a sensitive reactivity detector to monitor geometrical or other important changes taking place in the experiment during a power burst. Another variation would involve the provision of a fast rather than a thermal neutron flux spectrum in the test space for special tests. The achievement of these and other variations in the mode of operation will require the solution not only of the problems of basic technical design, but also the problems of maintaining the production of large energy releases at short periods, of insuring operational safety, and of establishing the interpretability of the experimental results obtained. It is proposed that study of these advanced concepts be carried on as a continuing design effort for the PBF. 


\section{PBF DESIGN PHILOSOPHY}

\section{DESIGN OBJECTIVES FOR THE FIRST-GENERATION PBF CORE}

To perform its intended functions, the PBF must meet a number of design objectives. The principal design objectives for the first-generation core are to provide a facility which will

(1) Produce power bursts in which sufficient energy is released to cause destruction of a wide range of representative fuel elements or subassemblies placed in a test space within the reactor

(2) Produce power bursts having initial periods as short as one millisecond (in order to permit understanding of destructive behavior in the millisecond time domain characteristic of runaway accident.s)

(3) Provide initial conditions in the test space which simulate as nearly as possible the environment in which the test fuel assemblies arc designed to lue used

(4) Provide a test space of sufficient size to accommodate fuel subassemblies or fuel element clusters representative of the entire range of current and presently planned reactor designs

(5) Permit performance of the destructive subassembly tests without damage to the $\mathrm{PBF}$ reactor itself

(6) Permit design and construction of the facility with a minimum of development delays, in order to meet the present urgent needs for high-performance subassembly testing as rapidly as possible.

In addition to these major design objectives, several important additional constraints have been imposed on the design for the first-generation core in the PBF; namely,

(1) To minimize the neutronic coupling from the test space to the core (ie, the sensitivity of the reactivity of the system to variations of the contents of or the conditions within the test space), so that different test assemblies may be easily subjected to comparable reactor bursts to facilitate interpretation of the trest results, so that the operational characteristics of the reactor (eg, control rod position for criticality) are not markedly altered from one test to another, and to avoid the greater development effort which would be required in a more complex system

(2) To limit the magnitude of short-period power bursts by means of the inherent shutdown mechanisms of the reactor itself, so that programmed scramming of the control rods or some other means of artificially limiting the shortest-period power bursts is not required (although some shaping of power bursts by control rod movement may be performed for longer-period bursts) 
(3) To provide a short cooling time between power bursts so that an appreciable number of tests may be carried out in a single work day.

\section{COMMENTS ON FUTURE-GENERATION PBF CORES}

As indicated earlier, the possibility also has been considered of designing a PBF core to have a variable rather than a fixed neutronic coupling from the test space to the core. ("Coupling" is again defined as the degree to which physical changes within the test space affect the reactivity of the reactor.) Variable coupling would permit two different modes of operation: minimized and maximized coupling.

With minimized coupling (as in the design chosen for the first-generation core), the power pulses produced by the reactor would be precisely reproducible, independent of the nature or condition of the contents of the test space, thus facilitating interpretation and comparison of the results of tests on fuel subassemblies of different types.

With maximized coupling, on the other hand, it might become possible to use the reactor both as a power-burst source and as a reactivity-change detector, serving to measure directly the reactivity changes associated with meltdown or other physical or chemical processes occurring in the test fuel. However, precise interpretation of experiments of this latter type would present difficulties. Even if these difficulties could be overcome (say, by reducing the self-shutdown coefficient of the core itself to a very small value), the design of a reactor to achieve variable coupling is necessarily more complex than one with fixed coupling, and would require a substantial development effort. Furthermore, if the self-shutdown of the core were reduced, this would pose new operational safety problems if the reactivity effects due to changes in the test space were small or positive. Finally, it might prove to be impossible to achieve large power bursts if the reactivity effects due to changes in the test space were large and negative, thus seriously compromising the basic performance of the facility.

Since the reactor with fixed (minimum) coupling between the test space and the core will fulfill most of the present needs for high-performance subassembly testing, and since these needs are urgent, this simpler concept has been selected for the first-generation core. Study of more complex systems for possible use in later-generation cores will be carried on as a continuing design effort.

Among other features which later-generation cores in the PBF facility might embody are provision for creating an epithermal or fast neutron spectrum in the test space (as opposed to the thermal spectrum provided by the first-generation PBF core design). This might be done in order to develop a nuclear environment in the test space similar to that in fast reactors. However, it is not at all certain that a fast neutron environment is necessary for a detailed study of the physical and chemical phenomena involved in fast reactor fuel meltdown. Indeed, some useful fast-reactor fuel-meltdown studies have been carried out in the TREAT reactor, in which the neutron spectrum provided in the test space is highly thermalized. It would appear that the principal limitation of TREAT for fastreactor safety studies has been its inability to achieve periods shorter than 40 $\mathrm{msec}$, rather than its thermal spectrum. For these reasons and, again, because of the immediate need for the PBF, no attempt has been made in the design of 
the first-generation core to achieve a variable neutron spectrum in the test space. (If sound arguments for a variable spectrum are developed, again this concept could be incorporated in future-generation PBF cores for which an extended development program could be justified.)

\section{IMPORTANT FEATURES REQUIRED TO MEET DESIGN OBJECTIVES}

To meet the design objectives listed above for the first-generation PBF core, the reactor concept selected must have certain general features. These features are discussed below as they relate to the appropriate design objectives.

\subsection{Generation of Sufficient Energy to Melt Test Assemblies}

In order to be able to generate sufficient energy in a power burst to melt fuel samples placed in the test space, the prompt reactivity shutdown coefficient of the reactor (ie, the reactivity compensated by the prompt internal shutdown mechanisms in the reactor, per unit of energy generated) must be relatively small. Also, it must be possible to initiate the power bursts from very low starting power levels. This requires a low natural source level in the reactor.

\subsection{Attainment of a One-Millisecond-Period of Power Rise}

In order to achieve periods of power rise as short as one millisecond, either the prompt neutron lifetime of the reactor must be kept relatively short or the injected reactivity must be relatively large. Experience has shown that it is difficult to achieve a step increase in reactivity larger than a few dollars [8]. Hence, it is desirable that the prompt neutron lifetime be kept below about $25 \mathrm{\mu sec}$. (If the prompt-neutron lifetime were $100 \mathrm{\mu sec}$, for example, the required reactivity step to achieve a $1-\mathrm{msec}$ period would be about 12 dollars.) To achieve lifetimes as short as $25 \mu \mathrm{sec}$, the macroscopic absorption cross section and the mean neutron speed in the core must be relatively large and the slowing down time must be short. This dictates a relatively undermoderated core with a hardened neutron spectrum.

The prompt neutron lifetime should not be so short, however, that the reactor period becomes very sensitive to small reactivity changes leading to difficulties in control. Values of lifetime in the vicinity of 10 to $20 \mu \mathrm{sec}$ are considered to provide a satisfactory compromise between the requirements of attaining short periods and of maintaining ease of control.

\subsection{Provision of Proper Environment in Test Space}

Since each type of fuel assembly to be tested is normally used with a specific type of coolant and within some specified ranges of elevated temperature, pressure, and coolant flow rate, it is necessary to provide these same conditions in the tcot opacc of the PBF in order for the meltdown tests to be useful in evaluating safety hazards associated with accidents in reactors using the fuel assemblies tested. This requires that the reactor be designed to accommodate the installation of special capsules and flow loops. It is also important that installation and removal of these capsules and flow loops be achieved safely and conveniently and with a minimum of disturbance to the reactor itself. 


\subsection{Prevention of Damage to PBF Core During Meltdown Tests}

In order to avoid damage to the reactor during power bursts in which fuel samples are melted in the test space, it is important that the energy density required to damage the fuel in the core be large relative to that required to melt (or decompose) the fuel in the test sample. Table I lists a number of fuel element materials of particular interest for the PBF core along with the energy density required to reach the melting (or decomposition) temperature. It is evident that $\mathrm{BeO}, \mathrm{UO}_{2}$, and graphite can sustain the highest energy densities without damage, while aluminum, zirconium hydride, zirconium metal, and beryllium metal are relatively poor in this respect.

\section{TABIE I}

LIMITING ENERGY DENSITY FOR VARIOUS REACTOR MATERIALS [18-24]

\begin{tabular}{lc}
\hline \multicolumn{1}{c}{ Material } & $\begin{array}{c}\text { Watt-sec } / \mathrm{cm}^{3}, 25^{\circ} \mathrm{C} \text { to Melting } \\
\text { or Decomposition Temperature }\end{array}$ \\
\hline Al & 1,800 \\
Zirconium hydride & 3,500 \\
$\mathrm{Zr}$ & 3,700 \\
$\mathrm{Be}$ & 5,500 \\
Fe (stainless steel) & 7,900 \\
UO2 (density $=10.95)$ & 10,400 \\
$\mathrm{C}$ (density $=1.7)$ & 10,500 \\
$\mathrm{BeO}$ & 20,000 \\
\hline
\end{tabular}

Also to avoid damage to the reactor during a meltdown test, it is important that the average energy density developed in the test fuel be large compared with the peak energy density developed in the core fuel. One effective method for achieving this is to use the "flux trap" approach in which the core is kept relatively undermoderated and the test assembly is placed in a hole in the core and surrounded by an annular moderating region. As a result, the thermal neutron flux in the vicinity of the test assembly is substantially peaked as compared with that within the core.

There are two final considerations which are important in avoiding damage to the reactor core. First, if a liquid coolant is employed to remove the heat from a solid-fuel core, it is necessary to keep the peak rate of heat transfer from the fuel elements to the coolant relatively low in order to avoid explosive vaporization of the coolant during or shortly after the power burst. Second, if the core fuel elements are sheathed in some type of cladding, the cladding may have to be thermally insulated from the fuel in order to avoid severe thermal gradients and associated thermal stresses in the cladding during or after the power burst. 


\subsection{Provision of Sufficiently Large Test Space}

In order to provide a test space large enough to accommodate fuel subassemblies representative of the entire range of reactor technology it is necessary that the PBF reactor core itself be relatively large. Typical subassemblies to be tested are about $4-1 / 2$ in. in diameter or smaller. However, the test space must be significantly larger than this in order to accommodate the moderating annulus and the thick-walled pressure capsule or flow loop.

\subsection{Reduction of Sensitivity of Core Reactivity to Contents of Test Space}

The presence of a moderating annulus between the test assembly and the core tends to minimize the sensitivity of the reactor characteristics to the nature of the experiment. To further reduce the sensitivity of the reactor to the experiment, it may be useful to surround the test space by a thermal flux suppressor.

\subsection{Self-Limitation of Power Bursts}

In order for the power bursts to be self-terminated by the internal shutdown mechanisms of the reactor in short-period excursions, it is necessary that the pertinent shutdown mechanisms be essentially prompt in their response to the fission energy release in the core. Mechanisms which fall into this category include fuel expansion in a bare, solid assembly (as in Godiva [4]), moderator expansion when the solid moderator is intimately mixed with the fuel (as in TREAT [14]), direct radiolytic gas formation in a solution of fuel in a liquid moderator (as in KEWB [10]), prompt gamma and neutron heating of the moderator (as in Spert III [7]), hardening of the neutron spectrum by heating of a moderator containing bound hydrogen mixed intimately with the fuel (as in Triga [11]), or Doppler broadening of U-238 resonances by fission heating of a low enrichment fuel (as in the Spert oxide core [25]).

The rcaoon for spccifying self-termination of power bursts is assucialed with the fact that the PDF core must be relatively large footh to provide an adequate test space and to provide a large source of neutrons leaking into the test space). It is impractical, for example, to pass a fuel slug through the core for the purpose of both initiating and terminating a power burst because, in order to provide a large enough reactivity pulse, the fuel slug would have to be unreasonably massive. This point is discussed in greater detail in Section V, 1.

\subsection{Provision of High-Duty-Factor Operation}

In order to provide a short cooling time between power bursts, it is desirable to use a liquid coolant such as water or a liquid metal rather than a gaseous coolant. Since liquid metals are more difficult and more expensive to handle, ordinary water is the preferred coolant, other things being equal.

To minimize the cooling time between bursts it is also necessary to keep the total energy release in the core during the most severe allowable power burst as low as possible. This requires that the core should be no larger than that necessary to provide a sufficiently large test-space. Hence, a suitable neutron reflector should be provided around the core to permit the required excess reactivity in a core of moderate size to be achieved. However, since the lifetime of neutrons in the reflector contributes to the 
total prompt neutron lifetime of the reactor as a whole, the reflector must be chosen to minimize its lifetime contribution while maximizing its reactivity contribution.

\section{CHOICE OF REACTOR DESIGN CONCEPT}

\subsection{Review of Capabilities of Existing Pulsed Reactors}

In an earlier feasibility study for a PBF, it was pointed out that none of the existing pulsed-reactor facilities can meet all of the design objectives specified for the PBF. That discussion is reviewed here briefly as background information relevant to the eolootion of the PDF design cuncepl.

In the case of the TREAT reactor, the 600- 1 sec prompt-neutron lifetime limits the practically achievable period of power rise to about $40 \mathrm{msec}$ or greater, while the limitations of the air cooling system permit only one or at most two power bursts per 8-hr work day.

In the case of the Triga reactor, since the zirconium hydride moderator has a decomposition temperature of $800^{\circ} \mathrm{C}$, the maximum energy density achievable without damage to the reactor is too low to permit destruction of test samples representing the range of present fuel technology (See also Table I). Furthermore, the $80-\mu \mathrm{sec}$ prompt-neutron lifetime is too large by about a factor of three or four to permit attaining a one-millisecond period with a reasonable reactivity insertion.

In the case of the KEWB reactor, the very large shutdown coefficient due to radiolytic gas formation in the fuel solution severely limits the energy which is produced at a given period of power rise, making meltdown experiments impossible except at such short periods that pressure generation by the radiolytic gas would begin to present a containment problem. Furthermore, the $60-\mu \mathrm{sec}$ prompt-neutron lifetime of this system is still sufficiently large that excessive reactivity additions would be required to achieve the short periods needed to obtain the energy releases for meltdown tests. Finally, the small size of the core severely restricts the sizes of the test fuel samples which could be used in the meltdown tests.

For the Godiva fast reactor, the shutdown coefficient due to thermal expansion of the solid fuel sphere (or cylinder) is again so large that the energy releases are much too small to be of value for meltdown studies. Also, although very short periods are easily attainable because of the 0.01-usec prompt-neutron lifetime, the lifetime is so short that the system is very sensitive to minor perturbations, leading to problems of control and safety. Further, the system is so small that, again, only very small samples could be melted in this reactor. Finally, the natural air cooling characteristic of this system again leads to very low duty factor operation.

It was concluded, therefore, (a) that the stringent requirements of the PBF with respect to energy release in the experiment, minimum period, size of experiment, and pulse repetition rate could not be met in any of these existing facilities, (b) that modification of these facilities to meet the PBF design objectives (if indeed possible) would entail a design and development 
effort on a scale comparable to that required for the construction of a new facility, and, therefore, (c) that a new facility must be designed for the PBF which represents a significant improvement over present-generation, pulsedreactor technology.

\subsection{Basis for Choice of a Low-Enrichment, $\mathrm{UO}_{2}-\mathrm{H}_{2} \mathrm{O}$ System}

As discussed in detail in an earlier report [25], power-burst experiments with a small, low-enrichment UO2 core in the Spert I facility resulted in the achievement of periods of power rise as short as $3.2 \mathrm{msec}$ for a reactivity insertion of about $\$ 2$, with no damage to the reactor. The prompt-neutron lifetime of this system was about $25 \mathrm{\mu sec}$. The principal reactivity-compensating mechanism responsible for self-shutdown at periods below about $10 \mathrm{msec}$ was the prompt Doppler broadening of the U-238 capture cross-section resonances with increasing fuel temperature.

In the shortest-period test, the peak power was about $7500 \mathrm{Mw}$, the peak-toaverage neutron flux ratio in the core was about three, and the peuk energy density in the $\mathrm{UO}_{2}$ was about 3300 watt- $\mathrm{sec} / \mathrm{cm}^{3}$ (as compared with a value of about 10,500 watt- sec $/ \mathrm{cm}^{3}$ required to melt a stainless-steel test fuel sample having $200 \mathrm{~g}$ of U-235 per foot of length). Measurements made with a small water channel in the core indicated that the thermal flux developed in the water channel was a factor of three higher than the peak value in the core. The natural-convection water cooling of the core was rapid, permitting a time interval between tests as short as 15 min or less.

From the results of these tests, it was concluded that, with minor improvements in design and with proper optimization, this type of system could meet the initial design objectives for the $\mathrm{PBF}$, and the general directions for the required optimization were, therefore, specified. The present conceptual design has resulted from the execution of that recommended optimization program.

\subsection{Limitations of a $\mathrm{UO}_{2}-\mathrm{BeO}-\mathrm{H}_{2} \mathrm{O}$ System}

Some consideration was given also to a variation of the system discussed in the previous section. As noted in Table $\mathrm{I}, \mathrm{BeO}$ has a higher limiting energy density than $\mathrm{UO}_{2}$ by about a factor of two. Consequently, a fuel element made of a mixture of $\mathrm{UO}_{2}$ and $\mathrm{BeO}$ would seem to have a significant advantage over a fuel element made of pure $\mathrm{UO}_{2}$ in that higher energy densities could be generated in the test fuel assembly without melting of the fuel in the reactor core. However, to achieve a significant gain in this way, so much $\mathrm{BeO}$ would have to be mixed with the $\mathrm{UO}_{2}$ that the neutron spectrum in the vicinity of the $\mathrm{UO}_{2}$ would be severely degraded, rendering the Doppler shutdown mechanism ineffective. In addition, the generation of neutrons by the $(\gamma, n)$ reaction in the beryllium would not permit the achievement of very low starting power levels for the energy bursts. As a result, unnecessarily stringent requirements would be imposed upon the design of the transient rod drive mechanism in order to achieve a true step input of reactivity. Further, the addition of $\mathrm{BeO}$ to the fuel would significantly increase the fuel development costs. For these reasons; as well as the fact that the pure $\mathrm{UO}_{2}$ system appears to be capable of meeting the $\mathrm{PBF}$ design objectives without the addition of $\mathrm{BeO}$, it was decided not to include $\mathrm{BeO}$ in the fuel. 


\section{PROPOSED LOCATION FOR THE PBF}

The PBF will be located in the Spert I area at the National Reactor Testing Station in Idaho, following the planned deactivation of the Spert I reactor in the summer of 1964. 


\section{GENERAL DESIGN FEATURES AND PHILOSOPHY.OF OPERATION}

In this section, a summary description is given of the conceptual design of the PBF including the first-generation core. More detailed descriptions of the reactor facility and its component parts are given in Sections IV, V, and VI. A summary of the conceptual design parameters of the PBF is given in Table II. Final optimization of the core design is not yet complete and it is to be expected that changes in the core configuration and the test facility will occur during final design. Nevertheless, the reactor described here appears capable of fulfilling the objectives of a first-generation core for the PBF.

TABLE II

PBF CONCEPTUAL DESIGN PARAME"I'E'RS

\begin{tabular}{|c|c|}
\hline Reactor type & Open tank \\
\hline Tank size & $15 \mathrm{ft}$ ID by 25 ft high \\
\hline Cure size & 3.6 i't diameter by 3 t't high \\
\hline Experiment space & 8-in.-OD hole through core vertically \\
\hline Moderator-coolant & $\mathrm{H}_{2} \mathrm{O}$ \\
\hline Fuel & $3 \%$ enriched $\mathrm{UO}_{2}$ in pins \\
\hline Metal-to-water ratio & 1.3 \\
\hline Lattice & Triangular, 0.944-in. pitch \\
\hline Fuel pin size & 0.75 i.n. ח \\
\hline Fut'I LIgudiling & 28 mi $\perp$ stainless steel \\
\hline Fuel thermal insulation & $1 / 16$ in. $\mathrm{ZrO}_{2}$ (between fuel and clad) \\
\hline Peak fuel temperature & $\approx 2500^{\circ} \mathrm{C}$ \\
\hline Coolant flow rate & $15,000 \mathrm{gpm}$ \\
\hline
\end{tabular}

The facility has been designed so that future-generation cores, capable of extending the performance of the PBF beyond the present objectives, can be accommodated without major modification of the reactor vessel, process equipment, or building facilities.

As stated in Section VII, Phillips Petroleum Co. has responsibility for final design of the core and associated control equipment. Final design of the reactor is expected to be completed during fiscal year 1964 . 


\section{GENERAL FACILITY DESCRIPTION}

Because of the nature of some of the experiments to be performed in the $\mathrm{PBF}$, the reactor has been designed for remote nuclear operation in a manner similar to that used for the Spert reactors. The facility, therefore, includes two buildings: a reactor building and a control center, as shown on the Spert General Site Plan, Figure 28. The reactor building houses the reactor, as sociated process equipment, experimental facilities, fuel storage and handling facilities, and the controls and instrumentation required for remote operation and experimental measurements. A floor plan of the reactor building is shown in Figure 34 . The control center shown in Figure 30 contains the control room, limited shop facilities, and office space for personnel required to operate the PBF.

\section{REACTOR AND PROCESS EQUIPMENT}

The conceptual PBF first-generation reactor is a light-water-moderated and -cooled, $\mathrm{UO}_{2}$ fueled, open-tank-type reactor. Provision has been made for forced circulation of the coolant in order to control the initial temperature of the water and also to remove the energy released during a power burst. A canal separated from the reactor tank by a removable gate is provided for storage and handling of test assemblies and reactor fuel. The essential features of the reactor are shown in Figures $34,35,36,37,38$, and 51 .

\section{FIRST-GENERATION REACTOR CORE}

\subsection{Core Configuration}

The active reactor core is an approximate right circular cylinder $3 \mathrm{ft}$ high and $3.6 \mathrm{ft}$ in diameter. The test space is a concentric axial hole 8 in. in diameter passing entirely through the reactor. The test hole is surrounded by a 1/4-in.thick stainless steel flux suppressor. The fuel rods are arranged in a triangular lattice having a pitch of 0.944 in., giving a metal-to-water ratio of 1.3. A plan of the core is depicted in Figure 52.

\subsection{Fuel Element}

The conceptual PBF fuel element is a 0.75 -in.-diameter pin having an active length of $3 \mathrm{ft}$. The fuel is $3 \%$ enriched $\mathrm{UO}_{2}$. The fuel is coated with approximately $1 / 16$ in. $\mathrm{ZrO}_{2}$, which serves as a thermal insulator, and is clad with stainless steel. The fuel element is shown in Figure 53.

\subsection{Transient Rods}

Powèr excursions are initiated by rapidly driving three poison rods from the core by means of pneumatic mechanisms. These transient rods are 7.5-in.wide blades having three 2-in. ribs for stiffening as shown in Figure 52. They are made of hafnium and have full length followers of stainless steel. The transient rods are surrounded by a sheath and operate entirely in air in order to minimize drag forces during the rapid motion required to initiate a transient. All transient rods operate simultaneously. 


\subsection{Control Rods}

Control rods are used to adjust criticality of the reactor so that the desired excess reactivity is attained when the transient rods are fully ejected from the core. The geometrical cross section of the control rods is identical with that of the transient rods. Like the transient rods, the control rods will operate in air. The locations of the control rods are shown in Figure 52.

\subsection{Safety Rods}

In order to provide sufficient negative reactivity to rapidly shut down the reactor in the event of an emergency, a set of safety rods has been incorporated into the design. During operation the safety rods are fully withdrawn and are cocked in preparation for scram. The safety rods are of 3/4-in.-diameter hafnium and have full length fuel followers. They operate in water and are located as shown in Figure 52.

\subsection{Reflector}

The conceptual PBF core is surrounded by a stainless steel and water reflector. The stainless steel consists of a single row of rods surrounding the outer periphery of the fuel rods and in the same lattice configuration as the fuel rods. This type of reflector was chosen in order to reduce reflection of thermal neutrons so that a peak in the power density does not occur at the edge of the core. 'The reflector configuration is shown in Figure 52.

\section{EXPERIMENTAL FACILITIES}

From the point of view of the process equipment involved, two general types of experiments are planned for the PBF: Those in which the experiment is placed in a sealed capsule and those in which the experiment is placed in a flow loop.

Though capsule experiments have provision for only minimal conlant flow, they can have provision for elevated temperature and pressure. The basic requirements are that the capsule be capable of withstanding the initial and transient temperatures and pressures associated with a given experiment. Only minor amounts of process equipment are required for capsule experiments. A cross section of a typical pressurized water capsule experiment is shown in Figure 54 .

For those experiments in which flow of the coolant is a parameter, an experimental loop is required. The first loop tests will be made in the pressurized water loop. The proposed design for this loop is included in this report. Since it is intended that experiments be performed with a variety of other coolants, such as liquid metals, gases, or organic fluids, provision is made for two shielded loop cubicles in the reactor building.

In order to perform high-speed stereoscopic photography of events occurring in the test assembly during a power burst, periscopes will penetrate the core at locations which will permit alignment with special windows built into a capsule or flow loop. The techniques involved have been used with success in the past by the Spert Project in connection with capsules pressurized to 2500 psi $[7,15]$. 


\section{PRESSURIZED WATER LOOP}

The PBF pressurized water loop is a facility for destructive testing of a wide variety of experiments in a high-pressure, high-temperature water environment. The loop is capable of operating at temperatures and pressures up to $600^{\circ} \mathrm{F}$ and 2200 psig, respectively. The in-pile tube is designed to withstand transient pressures of $5000 \mathrm{psig}$. The loop is designed to deliver up to $1000 \mathrm{gpm}$ of water flow through a test fuel assembly, with up to 60 psi pressure drop across the assembly. The loop is also designed to permit destructive testing of previously irradiated fuel elements. A process flow diagram for the pressurized water loop is shown in Figure 55.

\section{PHILOSOPHY OF OPERATION}

The PBF first-generation reactor has been designed to be safely self-limiting for power excursions with initial reactor periods as short as $1 \mathrm{msec}$ or less. The magnitude of a power burst is determined by the excess reactivity introduced by ejection of the transient rods and by the shutdown reactivity resulting from Doppler broadening of the U-238 resonances and the prompt heating of the water. For power bursts having a relatively long initial period, the shape of the burst may be controlled by programmed manipulation of the control rods.

The reactor has been designed to be sub-critical with the poison sections of the control and transient rods inserted and the safety rods withdrawn. Thus, the principal steps in a typical operating procedure would be as follows: First the safety rods are withdrawn and cocked. Then the control rods are adjusted to a position which, upon ejection of the transient rods, will result in the desired.initial reactor period. The transient rods are then rapidly ejected and the resultant power excursion allowed to continue until it is terminated by the inherent mechanisms of the reactor. At a convenient time, the control rods are then inserted, constituting termination of the test. Since for short-period power bursts the dominant shutdown mechanisms are prompt and result in a compensating reactivity roughly proportional to the energy released, the shape of the power burst will be approximately symmetric about the power peak.

Both for operational reasons and to facilitate interpretation of test results, it is highly desirable in a facility of this type that the critical position and calibration of the control rods not change during a series of experiments. Toward this end, the core has been designed to minimize the effects of the contents of the experiment space on the reactivity of the core. In addition it is required that the initial reactor temperature be stabilized at a specific value $\left(30^{\circ} \mathrm{C}\right)$ prior to each transient test. Provision for temperature control has therefore been made in the reactor process loop design. The temperature stabilization time will be approximately one hour for the shortest period power burst. For longer period bursts in which a smaller amount of energy is released, the temperature stabilization time will be correspondingly smaller.

The conneptutul PRF first-generation core has been designed so that the peak temperature in the $\mathrm{UO}_{2}$ fuel is slightly less than the melting temperature of $\mathrm{UO}_{2}$ 
during a power burst with a 1-msec period. However, it may prove possible to achieve even shorter periods (and higher energy releases) if some limited melting of the $\mathrm{UO}_{2}$ is permitted. It is planned to test the feasibility of thus improving the performance of the facility by installing some PBF fuel pins in the test space early in the PBF test program and subjecting them to repeated power bursts which cause melting of the $\mathrm{UO}_{2}$ in these pins. 


\section{FUEL ELEMENT DESIGN CONSIDERATIONS}

\section{DESIGN OBJECTIVES AND FUEL ELEMENT DESCRIPTION}

Because of the unique character of a power-burst facility, the design considerations entering into the selection of the fuel element are quite different from those normally encountered in reactor design. The primary fuel element design objectives for the PBF first-generation core are:

(1) To obtain an element capable of withstanding thousands of rapid thermal cycles over the temperature range from ambient to near tho molting point of the fuel

(2) To prevent the rapid escape of heat from the element to the water moderator in order to avoid explosive steam generation.

Secondary objectives have been to obtain an element (a) which can be relatively easily constructed and (b) which does not require a great deal of developmental effort.

The fuel element selected appears capable of satisfying the above objectives.

The conceptual fuel element consists of a 0.75-in.-OD pin having an active length of $3 \mathrm{ft}$. The fuel is uranium dioxide having an oD of $0.553 \mathrm{in}$. The uranium dioxide is coated with a layer of zirconium dioxide approximately $1 / 16$ in. thick. The pin is clad with 0.028 in. of stainless steel. An 8-mil gap between the surface of the zirconium oxide and the inside surface of the clad is provided for thermal expansion of the fuel, but no provision is made to maintain a uniform gap. The fuel element configuration is depicted in Figure 53.

Uranium dioxide was chosen for the fuel because of (a) its high melting point $\left(2800^{\circ} \mathrm{C}\right)$, (b) its relatively high volumetric heat capacity, (c) its relatively low thermal conductivity, and (d) the considerable amount of practical experience which exists with this fuel material at the present time.

The purpose of the zirconium dioxide coating is (a) to prevent the clad from reaching excessive temperatures, (b) to prevent rapid conduction of heat to the water so that explosive steam formation cannot occur, and (c) to reduce the thermal stress in the clad substantially below the yield point of stainless steel. In determining the required thickness of the zirconium oxide coating, no credit was taken for the thermal insulation provided by the gap since no provision is made to maintain a uniform gap between the zirconium dioxide and the clad. It is to be expected that, because of the rapid thermal cycling of the fuel, the fuel will crack; thus it does not appear feasible to maintain a uniform gap.

The 8-mil gap is provided to allow. room for thermal expansion of the fuel. This is necessary to prevent excessive hoop stresses in the clad and to prevent creep after many cycles of operation. If no gap or an insufficient gap were provided then the axial expansion of the fuel, coupled with the friction between the surface of the fuel and the inner surface of the clad, would cause the clad to stretch. Successive thermal cycling of the fuel would result in a 
ratchetting effect in the clad, and the effective life of the fuel would be reduced. This effect has been the cause of failure in the EGCR fuel element under in-pile testing. [26].

\section{PROPERTIES OF FUEL ELEMENT MATERIALS}

The severity of the service to which the fuel elements of the PBF will be subjected requires that the properties of the materials from which the fuel element is constructed be examined in detail. While a considerable amount of information is available about the properties of urania and zirconia, separately and in mixtures, no specific information has been found in the open literature on systems in which urania is clad with zirconia. The available information indicates that the fuel element configuration chosen for this conceptual design is feasible and is capable of meeting the fuel element design objectives. The potential problem areas and the means by which they can be examined are discussiel in Brotion TV, 4.

\subsection{Properties of Urania}

Urania has been used successfully as a fuel in many reactor applications, and it therefore has been subjected to intensive study. An excellent compilation of the properties of uranium dioxide and its nuclear applications is available [27]. Those properties which are of interest in the design of the PBF fuel element. are given in Table III.

A major consideration in the selection of the fuel for the PBF is the energy density required to raise the fuel temperature to the melting point. The combination in urania of a high heat capacity and a high melting point results in a limiting energy density of approximately $10^{4}$ watt-sec/cc. This energy density is as high or higher than all commonly used reactor materials with the exception of beryllia (see Table I, and also section II, 4.3). With respect to this consideration, then, urania is an ideal fuel for a PBF application.

One primary objective of the fuel element design is to retain the heat released in a power burst for as long as possible within the fuel so that explosive boiling of the water does not occur. Retention of the heat within the fuel also

\section{TABIE . III}

TROTRTIES OF URAPIA [27]

Thermal conductivity

Lensity

Specific heat

Thcrmal cxpansion coefficient Melting point

$$
\begin{aligned}
& 0.027 \mathrm{cal} /{ }^{\circ} \mathrm{C}-\mathrm{cm}-\sec \left(\text { at } 20^{\circ} \mathrm{C}\right) \\
& \approx 0.008 \mathrm{cal} /{ }^{\circ} \mathrm{C}=\mathrm{cm}-\sec \left(\text { at }>1000^{\circ} \mathrm{C}\right) \\
& \approx 10 \mathrm{~g} / \mathrm{cc} \\
& 0.063 \mathrm{cal} / \mathrm{g}-{ }^{\circ} \mathrm{C}\left(\text { at } 100^{\circ} \mathrm{C}\right) \\
& 0.082 \mathrm{cal} / \mathrm{g}-{ }^{\circ} \mathrm{C}\left(\text { at } 1500^{\circ} \mathrm{C}\right) \\
& 10^{-5} /{ }^{\circ} \mathrm{C} \\
& \approx 2800^{\circ} \mathrm{C}
\end{aligned}
$$


aids in reducing thermal stresses in the clad and permits maximum utilization of the Doppler broadening of the U-238 resonances as the principal prompt shutdown mechanism. The relatively high heat capacity of urania coupled with its relatively low thermal conductivity makes urania quite satisfactory from this standpoint.

A potential difficulty (inherent in all ceramic materials) is that of spalling or fracturing of the urania when subjected to high thermal gradients. This behavior is the result of the low thermal conductivity and the relatively high thermal expansion coefficient. Fracturing of urania in reactor fuel elements has been encountered previously in reactor applications, but no severe restrictions on reactor operation or performance have resulted. However, because of the type of service envisioned for the PBF (that of repetitive power excursions) and because of the necessity for including a gap between the fuel and the clad, spalling or fracturing of the urania could result in reduced fuel element lifetime. This potential problem will be investigated in the fuel element testing program discussed in Section IV, 4.

\subsection{Properties of Zirconia}

Zirconia is used in many applications as a thermal insulator. The properties of zirconia which are of importance in the PBF fuel element design are listed in Table IV.

\section{TABLE IV}

PROPERTIES OF ZIRCONIA [28]

\begin{tabular}{ll}
\hline Thermal conductivity & $0.006 \mathrm{cal} /{ }^{\circ} \mathrm{C}-\mathrm{cm} \mathrm{sec}$ at $20^{\circ} \mathrm{C}$ \\
Density (a) & $5.4 \mathrm{~g} / \mathrm{cc}$ \\
Specific heat & $0.10 \mathrm{cal} / \mathrm{g}-{ }^{\circ} \mathrm{C}$ \\
Thermal expansion coefficient & $10^{-5} /{ }^{\circ} \mathrm{C}$ \\
Melting point & $2700^{\circ} \mathrm{C}$ \\
& \\
(a) Maximum value. The density of the zirconia insulator will depend \\
$\begin{array}{l}\text { upon the method of fabrication. }\end{array}$
\end{tabular}

Its relatively high heat capacity and extremely low thermal conductivity make zirconia a very effective thermal insulator. In addition, zirconia's great chemical stability, its compatibility with urania, and its high melting point make it a very good insulator for PBF applications. Further, being composed of atoms of relatively low mass number, $\mathrm{ZrO}_{2}$ is not subject to significant radiation heating (as is depleted $\mathrm{UO}_{2}$, which had earlier been considered as a potential thermal-insulator material). Finally, there is considerable experience with $\mathrm{ZrO}_{2}$ in non-nuclear applications. (For example, coatings of $\mathrm{ZrO}_{2}$ have been successfully applied to various materials by flame spraying, and solid $\mathrm{ZrO}_{2}$ components of high strength have been fabricated in a variety of shapes, including cylindrical rings.) 
As previously discussed, the spalling characteristics. inherent in ceramic materials pose a potential problem in maintaining the integrity of the insulator. The problem will be investigated during the fuel element testing.program as discussed below.

Because of changes in crystal structure, the thermal expansion of zirconia is quite peculiar. However, zirconia can be stabilized in a cubic lattice by the addition of small amounts of calcium oxide or other ceramics without significantly reducing the melting temperature of zirconia [28].

\subsection{Properties of the Urania-Zirconia System}

Because the urania and zirconia will be in intimate contact, the properties of the urania-zirconia system are of importance. Fortunately, the eutectic temperature of urania-zirconia is $2550^{\circ} \mathrm{C}$, so that if an eutestic is formed at the urania-zirconia interface no significant restriction will be placed on the operating characteristics of the $\mathrm{PBF}$ as a result of a lowering of the melting puint of the fuel.

The possibility does exist, however, that the insulating properties of the zirconia could be impaired by the diffusion of urania into it. The presence of fissionable material within the insulator would result in energy release directly in the insulator, thus reducing its effectiveness. At the present time, no information is available on the relative diffusion of urania into zirconia. However, it is known that the diffusion coefficient of most oxides at the melting point is of the order of $10^{-7} \mathrm{~cm}^{2} / \mathrm{sec}$ [27]. If a diffusion coefficient of this order applies at the zirconia-urania interface, then, after maintaining a PBF zirconia-clad fuel pellet at the melting point for one day, the concentration of urania halfway through the zirconia coating would be $2-1 / 2 \%$. Moreover, the self-diffusion coefficient of oxides falls rapidly with decreasing temperature [27]. For example, at $1700^{\circ} \mathrm{C}$ the self-diffusion coefficient of urania is $6 \times 10^{-4} \mathrm{~cm}^{2} / \mathrm{sec}$, while at. $1450^{\circ} \mathrm{C}$ the coefficient is down to $5 \times 10^{-15} \mathrm{~cm}^{2} / \mathrm{sec}$. Finally, the fuel temporaturc will be ncar the melting point for only a few seconds after each maximum power burst. For these reasons, the destruction of the effectiveness of the insulator by diffusion of urania does not appear to be a problem at the present time. However, this effect will be studied during the fuel element testing program discussed in Section IV, 4.

\section{HEAT TRANSFER AND THERMAL STRESS CONSIDERATIONS}

As indicated in Section IV, 1 the major design objectives for the PBF require a fuel rod which can withstand many extreme temperature cycles, which will release its internal energy to the surrounding water slowly enough to prevent explosive steam formation, and which will not require an extensive testing program. The results of a recent series of tests in the Spert I reactor facility $\{25\}$ indicate that these requirements may be satisfied with a modified, stainless steel clad, uranium oxide pin. In the Spert I tests, the core was constructed of stainless steel clad, compacted uranium dioxide rods $(0.5$ in. OD, 0.028-in. clad thickness, 67-in. active length, 4\% enriched) similar 
to those used in the N. S. Savannah core. As mentioned earlier, periods as short as 3 milliseconds were achieved with no evidence of damage to the core. In the most severe tests the peak energy density in the $\mathrm{UO}_{2}$ was about 3300 watt$\mathrm{sec} / \mathrm{cm}^{3}$. The natural-convection water cooling of the core was relatively rapid, permitting a time interval between tests as short as 15 minutes. The rod surface temperature increased from ambient to a steady-state value of about $100^{\circ} \mathrm{C}$ shortly after the nuclear burst and remained near $100^{\circ} \mathrm{C}$ until the energy stored in the fuel rods had escaped. At no time did steam formation become sufficient to block coolant channels or to eject large volumes of water from the core.

Calculations have indicated that in the Spert Ioxide reactor energy densities in the fuel substantially higher than 3300 watt-sec/ $/ \mathrm{cm}^{3}$ could not have been attained without rupture of the clad as a result of excessive thermal stresses. Since the maximum specific energy release in the PBF is expected to be about 10,000 watt-sec/ $\mathrm{cm}^{3}$, steps have been taken in the present design to insulate the clad from the fuel, as discussed above. Calculations described below indicate that zirconium dioxide is a very effective insulator for this purpose and that no difficulty should occur as long as the maximum fuel temperature is kept below the urania-zirconia eutectic temperature $\left(2550^{\circ} \mathrm{C}\right)$.

A brief study of thermal behavior in several low-enriched uranium dioxide rods with and without insulating annuli has been performed by numerical solution of the heat diffusion equation for one-dimensional cylindrical geometry. Solutions were obtained by means of the HEAT-1 program for the IBM 650 computer [29]. The geometric model, shown in Figure 1, consisted of an inner heat-source region of $\mathrm{UO}_{2}$, an insulating annulus of zirconia, a clad region of stainless steel, and a water region. The heat source distribution in the $\mathrm{UO}_{2}$ due to fission by slow and fast neutrons was obtained by a four-group neutron diffusion calculation using Muft- and Sofocate-derived constants $[30,31]$. Prompt heating effects in the rod and moderator due to neutron slowing down and prompt gamma absorption were included in the calculation by using the gross formulation that the fractional prompt gamma source in the $\mathrm{i}^{\text {th }}$ region is given by

$$
\epsilon_{i}^{\gamma}=\frac{7.5}{192} \frac{A_{i}}{\Sigma_{i} A_{i}} \sigma_{i}
$$

where

$A_{i}$ is the cross-sectional area of the region, and

$\sigma_{i}$ is the relative stopping power of the region,

and that the fractional neutron slowing-down contribution in the water is given by

$$
\epsilon_{\mathrm{H}_{2} O}^{\mathrm{n}}=\frac{5}{192}=2.6 \%
$$

For each time step, the program computed temperature-dependent input values for the conductivity (X) and specific heat (Y) of each region by solving equations of the form 


$$
X=\frac{A}{\theta}+B+C \theta+D \theta^{2}
$$

and

$$
Y=A+B \theta+C \theta^{2}+D \theta^{3}
$$

where the coefficients of the respective equations for conductivity and specific heat vs temperature $(\theta)$ were obtained by a least-squares fit of each equation to published experimental data. Values for the conductivity of $\mathrm{UO}_{2}$ as a function of temperature were taken from Kingery's data [32] with extrapolation to higher temperature made by means of Bates' radiation heat transfer approximation [33]. The corresponding values for $\mathrm{ZrO}_{2}$ were taken from Ryshkewitch's data [34]. The coefficients of Firution (3) which wero uood in the program are presenied in Table $\mathrm{V}$.

\section{'LALL' V}

\begin{tabular}{|c|c|c|c|c|c|}
\hline \multicolumn{6}{|c|}{ Thermal Conductivity (calories $/ \mathrm{cm}-\mathrm{sec}-{ }^{\circ} \mathrm{C}$ ) } \\
\hline & & $\mathrm{A} \cdot$ & $B$ & $\mathrm{C}$ & $\mathrm{D}$ \\
\hline $\mathrm{UO}_{2}$ & 4.913 & $\times 10^{-1}$ & $1.495 \times 10^{-2}$ & $-1.385 \times 10^{-5}$ & $4.7985 \times 10^{-9}$ \\
\hline $\mathrm{ZirO}_{2}$ & & .0 & 4. $\times 10^{-3}$ & $1 . \quad \times 10^{-6}$ & 0.0 \\
\hline S.s. & & .0 & $3.91 \times 10^{-2}$ & $2.23 \times 10^{-5}$ & 0.0 \\
\hline $\mathrm{H}_{2} \mathrm{O}$ & & .0 & $1.435 \times 10^{-3}$ & 0.0 & 0.0 \\
\hline \multicolumn{6}{|c|}{ Specific Heat (calories $/ \mathrm{cm}^{3}-{ }^{\circ} \mathrm{C}$ ) } \\
\hline $\mathrm{UO}_{2}$ & 5.6 & $\times 10^{-1}$ & $4.37 \times 10^{-4}$ & $-1.83 \times 10^{-7}$ & 0.0 \\
\hline $\mathrm{ZrO}_{2}$ & 4.125 & $\times 10^{-5}$ & $1.16 \times 10^{-4}$ & 0.0 & 0.0 \\
\hline S.S. & 8.83 & $\times 10^{-1}$ & $\times 10^{-4}$ & 0.0 & 0.0 \\
\hline $\mathrm{H}_{2} \mathrm{O}$ & 9.98 & $x 10^{-1}$ & 0.0 & 0.0 & 0.0 \\
\hline
\end{tabular}

COEFFICIENTS FOR EQUATION 3 USED IN THE HEAT-I PROGRAM

The HEAT-1 program has been successfully used ${ }^{[35]}$ to prenict the temperature behavior observed during Spert $I$ tests from clad-surface and central- $\mathrm{UO}_{2}$ thermocouples for an appreciable range of initial reactor periods ( $\left.\tau_{0} \leq 200 \mathrm{msec}\right)$. From results of the digital calculations, it was computed that maximum heat fluxes from a rod into the surrounding water reached about $2 \times 10^{6} \mathrm{BTU} / \mathrm{hr}-\mathrm{ft}^{2}$ for a brief period following the shortest-period ( $\tau_{U}=3.2 \mathrm{msec}$ ) Spert I oxide core test, and that the clad stress reached a maximum value of $9.5 \times 10^{4}$ psi, exceeding the ultimate strength reported for soft-annealed type 304 stainless steel. However, subsequent hardness tests and microstructure analysis revealed that the (initially) cold worked clad retained a minimum ultimate strength of $1.5 \times 10^{5} \mathrm{psi}$, and that at no place did it show any loss of its cold-worked microstructure, even in the region adjacent to the $\mathrm{UO}_{2}$ fuel. It may be concluded that reactor excursions with initial periods below about $2 \mathrm{msec}$ might 
have resulted in permanent clad deformation of some of the fuel rods used in the Spert I oxide core.

Four proposed rod configurations for the PBF were studied using the digital approach: these were 0.75 -in. and 1.0-in.-OD rods, each with $1 / 16$-in. and $1 / 32$-in. insulating annuli of zirconia. All rods were clad with 0.028 -in. stainless steel. A metal-to-water ratio of 1.0 was selected for all calculations together with an arbitrary symmetric power burst with a $0.1-\mathrm{msec}$ initial period and sufficient magnitude to generate integrated energy densities of $\sim 10^{4}$ watt$\mathrm{sec} / \mathrm{cm}^{3}$ in the fuel, since this should present a reasonably severe test of the fuel rods.

The results of the calculations are shown in Figures 2 to 6 . In Figure 2; the time behavior of the temperatures at the rod center and at all interfaces is shown for a $0.75-i n .-O D$ rod with a $1 / 16-i n$. insulator. This is typical of the shapes observed for the other rod configurations in the study, although the change in temperature at the rod surface was about twice as rapid for the rods with a 1/32-in. insulator. Figures 3 and 4 show heat flux into the water, temperature difference across the 28-mil clad, resulting thermal hoop stress in the clad, and clad surface temperature as functions of time. The hoop stress, $\sigma_{\theta}$, was calculated by numerical integration of the formula

$$
\sigma_{\theta}=\frac{\alpha E}{1-v} \frac{1}{r^{2}}\left[\frac{r^{2}+a^{2}}{b^{2}-a^{2}} \int_{a}^{b} \operatorname{Tr} d r+\int_{a}^{r} \operatorname{Tr} d r-\operatorname{Tr}^{2}\right]
$$

where

$\mathbf{r}$ is the radius at the point in question,

a is the inner clad radius,

$\mathrm{b}$ is the outer clad radius,

$\alpha$ is the coefficient of thermal expansion $=17.1 \times 10^{-6} /{ }^{\circ} \mathrm{C}$,

$E$ is modulus of elasticity $=29 \times 10^{6} \mathrm{lb} / \mathrm{in}^{2}$, and

$\nu$ is Poisson's ratio $=0.305$.

The heat flux into the water was computed from

$$
\frac{d Q}{d t}=\frac{E(t+h)-E(t)-S(t+h)}{[(t+h)-(t)] A}
$$

where

$E$ is the total energy in the water coolant,

$S$ is the prompt source of energy in the water ( $\gamma$ and neutron moderation), 
$A$ is the surface area per unit length of clad, and

$\mathrm{h}$ is the time increment.

Time increments were selected sufficiently small that energy changes in the water were relatively small during any time step.

The maximum clad stress observed shortly after the onset of boiling appears to be safely lower than the peak value observed in the Spert I oxide core during a $3-\mathrm{msec}$ excursion, and indicates that there is no apparent limitation due to hoop stresses on the number of such stress cycles which this fuel rod can undergo. Maximum heat flux into the water also occurs shortly after the onset of boiling, and is also considerably (about a factor of two) below the peak value calculated for the Spert oxide core. The provision of forced coolant flow in the PBF (which could not be accommodated with the calculational approach used) should further widen this margin of safety.

'I'hree radial temperature profiles for the $3 / 4-$ in. fuel rod with a $1 / 16$-in. insulator are presented in Figure 5 , with time as a parameter. The effects of prompt heat sources on the profile at a time near the peak of the burst $\left(t=10^{-3}\right.$ sec) are evident in regions 2,3 , and 4 . With in about 2 sec the profile is sccn to approach its asymptotic relaxation shape.

Figure 6 shows the clad-surface temperatures at a time shortly after the burst has subsided, for each of the four rods studied, with the thickness of the $\mathrm{ZrO}_{2}$ insulator as a parameter. The merit of the increased thickness of the insulator is readily apparent when one considers that the surface temperature rise at the selected time is superimposed upon the prompt heating of the clad during the power burst (about $55^{\circ} \mathrm{C}$ in all cases). At the same time after the 3.2-msec-period burst, the rate of rise of clad surface temperature (both experimental and calculated) for the Spert I oxide fuel rod was about a factor of 5 greater than that calculated for the insulated rods. Figure 6 clearly shows the advantage of using as thick a $\mathrm{ZrO}_{2}$ annulus as possible, consistent with the other requirements discussed above.

\section{FUEL ELEMENT TESTING PROGRAM}

The fuel proposed for the PBF is unique in that an inert insulating shield will be used between the active fuel and the stainless steel cladding for reasons explained in Section IV, 1. Although a literature search and calculations performed on the characteristics of the $\mathrm{UO}_{2}-\mathrm{ZrO}_{2}$ system indicate feasibility of the design, it will be necessary to perform a limited fuel testing program in order to verify the calculations and references. Possible fuel element problems are (a) the diffusion of $\mathrm{UO}_{2}$ into the $\mathrm{ZrO}_{2}$ insulator; (b) axial ratchetting of the clad, (c) the loss of $\mathrm{ZrO}_{2}$ spalling into the air gap, and (d) determination of a satisfactory method of fabrication.

Extensive diffusion of $\mathrm{UO}_{2}$ into the $\mathrm{ZrO}_{2}$ would negate the desired effect of the $\mathrm{ZrO}_{2}$ insulator. While the indications are that diffusion will not be extensive in the PBF (see Section IV, 2), no experimental information on this type of $\mathrm{ZrO}_{2}-\mathrm{UO}_{2}$ system is presently available. Hence, one portion of the 
fuel element development program is the investigation of the diffusion of $\mathrm{UO}_{2}$ into $\mathrm{ZrO}_{2}$.

Axial ratchetting of the clad, caused by thermal expansion of the fuel, has been known to result in substantial axial growth of the clad and eventual clad failure [26]. The conceptual PBF fuel pin has incorporated a gap between the $\mathrm{ZrO}_{2}$ and clad in order to avoid ratchetting effects. However, because of the type of service to which the PBF fuel elements will be subjected, substantial cracking of the fuel is expected, and it is not clear whether the gap will eliminate the ratchetting phenomenon. In addition, it is desirable to minimize the gap size in order to obtain a high overall fuel density in the reactor and to minimize the possibility of insulator loss by spalling. Thus, a proof test of the PBF fuel element design is necessary.

During maximum bursts in the $\mathrm{PBF}$, the $\mathrm{ZrO}_{2}$ insulator will develop very high thermal stresses and may tend to spall. The presence of a gap between the insulator and the clad permits potential axial motion of $\mathrm{ZrO}_{2}$ flakes, and portions of the fuel may come into contact with the clad. Such an occurrence could result in an intolerable thermal stress in the clad. The extent to which spalling and displacement of the $\mathrm{ZrO}_{2}$ occurs must be determined during the fuel element testing program.

Of secondary importance from the reactor standpoint but of equally great concern from the fabrication and procurement view is the method of fabricating a practical fuel pin. Two methods appear feasible at the present time. These include forming the $\mathrm{ZrO}_{2}$ layer by the powder-spray technique or sintering slip fit rings of $\mathrm{ZrO}_{2}$ to mate with sintered $\mathrm{UO}_{2}$ pellets. phases:

The testing program as presently visualized would consist of the following

Phase 1: Ten sintered pellets and twenty full scale fuel pins of each fabricating method will be manufactured by potential fabricators of the full core.

Phase 2: The ten sintered pellets of each fabricating method are to be furnace heated to a steady state temperature roughly equivalent to the calculated $\mathrm{UO}_{2}-\mathrm{ZrO}_{2}$ interface temperature and held at that temperature for varying lengths of time to determine the diffusivity constant for each fabricating method. Diffusivity will be measured by destructive analysis of the pellets. Integrity of the $\mathrm{ZrO}_{2}-\mathrm{UO}_{2}$ system can be evaluated at this time.

Phase 3: The fuel pins are to be subjected to several hundred power bursts in a test reactor in order to proof-test the pins with respect to clad ratchetting and insulator flaking. It is planned that the enrichment of the fuel in the pins be so adjusted that design maximum operating conditions of the pin can be attained at the longer periods and/or lower fluxes available in other pulsed reactors. (Note that the long thermal time constant of the $\mathrm{UO}_{2}$ and $\mathrm{ZrO}_{2}$ makes it possible to obtain meaningful results from tests in an existing reactor like TREAT which is limited in the minimum period it can achieve, but which can produce substantial energy release in a power burst.) 
On the basis of the results of the above program, the final selection of fuel for the PBF will be made. 


\section{REACTOR PHYSICS OF THE FIRST-GENERATION CORE}

\section{PHILOSOPHY AND OBJECTIVES}

The purpose of the Power-Burst Facility is to provide a test reactor in which typical reactor fuel assemblies can be tested to destruction during shortperiod power excursions and under initial conditions which closely simulate the operating environment for which the fuel has been designed. In order to achieve this purpose, design objectives have been specified for various aspects of the facility design. From the point of view of the nuclear design of the reactor, there are three primary objectives for the first-generation core:

(1) During a maximum burst the energy density achieved in the fueled regions of the assembly under test must be sufficient to melt the fuel, while the energy density released in the fuel element of the core must be less than that required to raise the fuel temperature to the melting point.

(2) In order to test the fuel assemblies under conditions which simulate a severe accident, the reactor must be capable of achieving an initial reactor period of the order of one millisecond.

(3) The facility must provide a test space large enough to accommodate full-size fuel assemblies typical of those used throughout the industry, or (in the case of very large fuel assemblies) to accommodate partial assemblies of sufficient size to constitute a meaningful experiment.

Consideration of the need for flexibility in the experimental program and for convenience of operation has resulted in several secondary objectives for the first-generation core. Among these are:

(1) Variation of the contents of or the conditions within the test space should have a negligible effect on the reactivity of the core. This objective is necessary in order to be able to subject various test assemblies to comparable transients and to ensure that the placing of the various types of experiments within the test space does not markedly alter the characteristics of the reactor.

(2) The power burst should be self limiting by means of an inherent prompt shutdown coefficient, in order to obviate the need for a programmed scram or other means of artificially limiting a power burst at the shorter periods.

(3) Consistent with obtaining the necessary energy release within the experiment, the energy release in the core should be as small as possible, in order to minimize the heat removal requirements.

The first of the primary objectives, that of achieving a sufficiently high power density in the fuel in the test assembly with respect to that in the core, leads to the following considerations: While it is permissible (and in some cases 
necessary) to produce a high power density in a test assembly by increasing the fuel density in the assembly, such an approach is inconvenient and in certain cases not possible. Therefore, the approach taken in the design of the PBF reactor has been to provide a large thermal flux peak in the test space. Accordingly, the test space is located along the central axis of a cylindrical core to take advantage of the natural peaking due to geometric effects. In addition, the core is designed to operate with a rather high fast-to-thermal flux ratio in order to provide a current of fast neutrons to the test space. The fast neutrons are thermalized in a moderating annulus surrounding the test assembly, thus producing a large thermal flux peak in the test space. While the neutron spectrum within the test space may be quite different from that in which the assembly undergoing test is normally expected to operate, this difference is of no major consequence since the primary concern is with the thermal and mechanical effects resulting from very high power and energy densities within the fuel elements.

The objective that the reactor should be cavable of initial perinds of the order of $1 \mathrm{msec}$ dictates that the prompt neutron lifetime be of the order of 10 to $20 \mu \mathrm{sec}$. A lifetime substantially longer than this would require reactivity additions of a magnitude which would be difficult to achieve. On the other hand, lifetimes substantially shorter than this would make the reactor so sensitive to small reactivity changes that control would be difficult.

With rcgard to the third primary objective (a sufficiently large test space) a review of the various reactor designs in the United States Atomic Energy program has indicated that the most common cross sectional dimension for fuel elements is approximately 3 by $3 \mathrm{in}$. While there is considerable variation from this dimension, with some assemblies being as large as $7-1 / 2$ by $7-1 / 2$ in., the larger fuel assemblies normally consist of bundles of rods, and hence, meaningful experiments can be run on partial bundles. Moreover, since a large portion of the increase in power density in the test assembly over that in the core is produced by the thermalization of neutrons, there is a tendency toward substantial power density variations within the test assembly. As a result, meaningful experiments involving assemblies much larger than about 3 to 4 in. in diameter are not feasible. Thus, for very large fuel assemblies it is necessary to use partial assemblies. For these reasons, a 3 by 3 in. cross section was chosen as the basis for optimization of the test space size. This consideration resulted in a diameter for the test space of 8 in., within which the test assembly, pressure container, and moderating annulus must be placed. With a pressure in the container of 2500 psi, test assemblies as large as 4 in. square or $4-1 / 2$ in. in diameter can be accommodated without undue reduction in the maximum power density achievable within the test assembly. The height of the core has been specified as $3 \mathrm{ft}$. This imposes no undue restriction on the axial length of the experiment; pressure effects resulting from very long channels can be studied by positioning the test assembly such that the flux peak occurs at the desired axial location along the test assembly.

The secondary design objectives of the PBF first-generation core stem from a variety of considerations. For reasons of safety and operating convenience, it is desirable that the condition and contents of the test space have a negligible effect upon the reactivity of the core. For example, if the insertion or removal of a fuel-containing capsule from the test space were to cause a large change in reactivity, a safety hazard could exist in the changing of experiments. If, further, the substitution of one experiment for another caused a large change in the core 
reactivity, an operational inconvenience would arise from the resultant changes in critical position and calibrations of control and transient rods. Such a situation would require the performance of extensive critical experiments after the insertion of each new test assembly. Finally, if the changing conditions within the experimental capsule during a transient (for example, the generation of voids) were to cause a large change in the reactivity of the core, two difficulties would result. If, the reactivity change were positive, a safety hazard could be created, but, if the change in reactivity were negative it could affect the shape of the power burst and thus cause difficulties in interpreting comparative experiments. For these reasons, one guideline in the conceptual design of the $\mathrm{PBF}$ core has been that the reactivity coupling between the experiment and the core should be as small as possible consistent with meeting the primary objectives.

One possible method for producing a power burst in a reactor is to pass a fuel slug at high speed through the reactor. In the present case this approach does not appear to be practical since the fuel slug would have to be very large to be sufficiently effective. In addition, the presence of the test space at the center of the core eliminates the optimum location for such a fuel slug. As a result, in order to ensure that severe azimuthal perturbations in the flux during a transient be avoided, several such fuel slugs would have to be moved through the core in symmetrical locations, simultaneously, and at high speed. The practical difficulties involved in such a scheme are considerable. Therefore, the approach taken in the conceptual design of the PBF core has been that transients will be initiated by ejection of poison-type "transient" rods and will be limited by inherent shutdown mechanisms. Because transients will typically be initiated from very low power levels, the speed of the transient rods need not be excessive. The principal shutdown mechanisms in the present case are the prompt Doppler effects in uranium-238 and the prompt gamma and neutron heating of the water moderator.

The magnitude of the prompt shutdown effect must be such that the maximum allowable burst (that which causes the hot spot in the fuel to reach $\approx 2500^{\circ} \mathrm{C}$ ) is achieved at an initial reactor period of approximately $1 \mathrm{msec}$. If the magnitude of the shutdown effect were too small, then the maximum allowable burst would be achieved at an initial period longer than $1 \mathrm{msec}$. If the magnitude were too large, then a shorter initial period would be required to achieve the maximum burst. However, because of the speed required of the transient rods, periods substantially shorter than $1 \mathrm{msec}$ would be difficult to achieve. Thus, the magnitude of the reactivity effects resulting from Doppler broadening of U-238 resonances and prompt heating of the water is crucial, and core design parameters such as fuel enrichment, test space size, metal-to-water ratio, etc, must be adjusted in the design to yleld the desired amount of reactivity compensation.

Radial flattening of the power distribution in a reactor of the PBF type has an advantage only if it increases the ratio of the average power density in the experiment to the maximum power density in the core. If power flattening does not increase this ratio, then excessive amounts of energy are released without resulting in any advantage from the point of view of the experiment. Therefore, in the conceptual design of the PBF core, the approach has been taken that the peak-to-average power density ratio within the core should be as high as possible consistent with obtaining a power density in the test assembly which is high with respect to that in the core. 
In Sections $V, 2$ through $V, 5$ the results of calculations made to obtain a preliminary optimization of the core design are presented and discussed. While the design obtained as a result of these calculations is a conceptual rather than a final design, it appears fully capable of meeting the objectives of a first-generation power-burst facility. In Section V, 6 the results developed in Sections V, 2 through V, 5 are summarized, the resulting conceptual core design is outlined, and recommendations are made for further physics studies leading to the final core design.

\section{OPTIMIZATION STUDIES}

\subsection{Introduction}

From the above discussion, it is apparent that in order to meet the objectives of the PBF the various core parameters must be nntimized with respect to several measures of core performance. In addition to such measures as the prompt-neutron lifetime, reactivity coefficients, power distribution, etc, two quantities having special meaning with respect to the performance of a PBF core have been defined:

First, as a measure of the ability to destroy a test fuel element without damage to the core, a "figure-of-merit" has been defined as the ratio of the average power density in the experiment to the peak power density in the core. (This quantity is defined more precisely in Section $V, 2.2$ ).

Second, as one measure of the effects of the contents of the experiment space on the reactivity of the reactor, the "coupling" has been defined as the change in the eigenvalue (essentially the reactivity) whioh results when the test fuel assembly and its capsule are removed from the test space and replaced with water.

In ordex to reduce the number of plyssics calculations required to obtain a preliminary optimization for conceptual design purposes, a number of simplifying approximations have been made. These are as follows:

Since the shape of the core can be closely approximated by a cylinder, all of the optimization studies were made with the aid of one-dimensional diffusion theory codes using cylindrical geometry. For simplicity, these studies were done with the control rods and transient rods completely removed from the core and replaced by fuel, as shown in Figure 7. Calculational studies of the Spert I UO $\mathrm{UO}_{2}$ core [25] and of the MARTY core [36], summarized in Appendix A, indicate that for a just critical arrangement an eigenvalue of about 1.02 should be obtained. Thus, for about $3 \%$ excess reactivity in the PBF core, the calculated eigenvalue should be about 1.05 . The core radius was adjusted with each parameter change in order to obtain this eigenvalue.

The Spert III fuel assembly [7] was chosen arbitrarily as the test element in the optimization studies. The effect of varying other reactor parameters was then studied at an eigenvalue of 1.05 with the Spert III assembly in the test space. An aluminum ETR assembly [37], two stainless steel assemblies with different U-235 concentrations, a gas-cooled assembly of the HTGR type [38], and various arrays of PBF fuel pins were then considered to be 
inserted successively into the test space in place of the Spert III assembly in order to determine the changes in eigenvalue and to obtain the power distributions with these experiments. There was no special reason for using the Spert III assembly rather than some other type of fuel assembly as the test fuel for the bulk of the optimization calculations. Indeed, the results of the calculations obtained with other fuel assemblies in the test space showed that the optimum values of the design parameters of the core were not a significant function of the type of test fuel assembly used in the calculations.

Since cylindrical geometry was used for all the calculations it was necessary to approximate the test fuel assembly as a cylinder of cross-sectional area equal to the actual fuel assembly area. Thus, for rectangular fuel assemblies, corner effects were neglected.

For studies in which the diameter of the test space was varied, it was assumed that the stainless steel pressure pipe must be strong enough to contain a pressure of $5000 \mathrm{psi}$ at a temperature of $400^{\circ} \mathrm{F}$. The necessary wall thickness for various pipe diameters was then computed by means of the membrane theory. The pipe outer diameter, wall thickness, and inside diameter as used in the one dimensional computations are given in Table VI.

\section{TABLE VI}

STAINLESS STEEL PRESSURE PIPE DIMENSIONS

\begin{tabular}{cccc}
\hline $\begin{array}{c}\text { Outer Diameter } \\
(\text { in. })\end{array}$ & $\begin{array}{c}\text { Outer Radius } \\
(\mathrm{cm})\end{array}$ & $\begin{array}{c}\text { Wall Thickness } \\
(\mathrm{cm})\end{array}$ & \begin{tabular}{c}
$\begin{array}{c}\text { Inside Radius } \\
(\mathrm{cm})\end{array}$ \\
\cline { 2 - 3 } 6
\end{tabular} \\
\cline { 2 - 3 } 7 & 7.62 & 1.369 & 6.251 \\
8 & 10.16 & 1.598 & 7.292 \\
9 & 11.43 & 1.826 & 8.334 \\
10 & 12.70 & 2.055 & 9.375 \\
12 & 15.24 & 2.284 & 10.416 \\
\hline
\end{tabular}

In the following paragraphs the effects of change in the reactor design parameters upon each measure of performance are treated. The reactor configuration selected for the conceptual design and the reason for its selection are given in Section V, 6.

\subsection{Figure-of-Merit and Coupling}

The figure-of-merit has been defined earlier as the ratio of the average power density in the experiment to the peak power density in the core. This ratio has been chosen as a measure of reactor performance because it indicates the potential ability to destroy a test fuel assembly without damaging the core.

During short power bursts, the storage of heat in the core fuel pins and in the fueled portion of the experiment is essentially adiabatic. Hence, the 
most meaningful power densities for use in determining the figure-of-merit are based upon the actual fuel volumes rather than the total metal (and/or oxide) volume: The power density in the core has been determined on this basis.

In certain types of experiments, however, it has been necessary to use a somewhat different definition of the power density for the following reason: The present study has been performed using one-dimensional diffusion theory in cylindrical geometry. Plate-type test assemblies have been represented by homogeneous cylindrical regions. Consequently, effects due to geometrical differences among fuel assemblies have been ignored, and fuel assemblies having the same metal-to-water ratio, materials, and fuel loading, but differing in geometry, are represented in exactly the same way. In order, therefore, to obtain a conservative value for the figure-of-merit, the power density for plale-lype fuel assemblies has been determined by using the entire metal volume (including structural parts; such as, side plates) as the power producing volume.

To obtain a measure of the effect of the experiment upon the core, a coupling parameter has been defined. "Coupling" has been defined as the change in $\mathrm{k}_{\text {eff }}$ resulting from removing the experiment and its stainless steel pressure pipe from the test space and replacing them with water. In all cases studied the eigenvalue was higher where the experiment was present than when it was replaced with water. The optimization studies have therefore been directed toward obtaining both a high value for the figure-of-merit and a low absolute value for the coupling.

To achieve these two objectives, several reactor variables were investigated. These included the core metal-to-water ratio (the ratio of the total fuel pin volume to the water volume), the fuel enrichment, the boron concentration in a thermal flux suppressor surrounding the experiment capsule, and the reflector composition.

2.21 Effects of Variation in Core Metal-to-Water Ratio and Enrichment. The effects of variations of the metal-to-water ratio and fuel enrichment upon the figure-of-merit and coupling are shown in Figures 8 and 9 . Variation of the enrichment has a relatively large effect on the coupling but only a small effect on the figure-of-merit. Variation of the metal-to-water ratio has a significant effect on both the coupling and the figure-of-merit. Figures 8 and 9 indicate that the core should have a high metal-to-water ratio in order to maximize the figure-of-merit and a low fuel enrichment in order to minimize the coupling. However, in both figures the $3 \%$ enrichment curve indicates that there is a maximum attainable value of the figure-of-merit for a given enrichment. Hence, for a given tolerable value of coupling, the figure-of-merit can be increased by the simultaneous increase of the enrichment and the metal-to-water ratio:

2.22 Effects of Variation in Thermal Flux Suppressor Poison. A parametric study has been made of the effect of an annular thermal neutron flux suppressor placed between the pressure pipe and the core to reduce the reactivity effect of the experiment on the core. The flux suppressor consisted of a 1/4-in.-thick boron-stainless steel cylinder surrounding the test space as shown schematically in Figure 7. Flux suppressors with four boron concentrations were considered: (a) a "heavy boron" suppressor with $2.85 \times 10^{21}$ 
atoms of B-10 per $\mathrm{cm}^{3}$, (b) a "medium boron" suppressor with $0.95 \times 10^{21}$ atoms of B-10 per $\mathrm{cm}^{3}$, (c) a "light boron" suppressor with $0.29 \times 10^{21}$ atoms of B-10 per $\mathrm{cm}^{3}$, and (d) a stainless steel suppressor containing no boron.

It was postulated that, by eliminating the transfer of thermal neutrons between the core and the test space, the effect of the experiment on the reactivity of the core as measured by the coupling would be decreased. However, as shown on Figure 10, the study indicated that as the boron concentration in the flux suppressor was increased, the coupling first increased, reached a maximum, and then decreased.

A possible explanation for this behavior is that the coupling is the sum of two opposing effects. The removal of fuel from the test space removes a source of fast neutrons and results in a loss in reactivity. However, the associated removal of the pressure pipe eliminates some thermal neutron poison and results in an increase in reactivity. The addition of a thermal neutron poison such as boron to the flux suppressor reduces the positive effect of removing the pipe. Since the negative effect predominates in this core, an increase in poison results in a larger absolute value of the coupling. However, if sufficient boron is added to cause significant absorption of epithermal neutrons by the flux suppressor, the negative effect due to the removal of the fast-neutron source represented by the test fuel is decreased, resulting in an overall decrease in the absolute value of the coupling. As is indicated on Figure 11, the figure-of-merit is largest when there is no boron in the flux suppressor. The gain in coupling and figure-of-merit (to be realized by use of a nonborated stainless steel flux suppressor) is also apparent when Figure 9 is compared with Figure 8 . Figure 8 represents a core with a heavy boron flux suppressor while Figure 9 represents a core with a stainless steel flux suppressor. Therefore, the main functions of the flux suppressor are: to limit the reactivity effects of removing the experiment capsule, to reduce the power peaking at the edge of the core, and to act as a guide for inserting the experiment capsule.

2.23 Effects of Variation in Pressure Pipe Diameter. The effects of the size of the pressure pipe on the coupling and figure-of-merit are shown in Figures 12 and 13 , for $3 \%$ and $5 \%$ enriched fuel. These figures indicate that for metal-to-water ratios less than 1.8 the optimum pipe OD is about 7 in. However, for a metal-to-metal ratio of 1.3 , the coupling is substantially reduced with very little reduction in the figure-of-merit by increasing the pipe $O D$ to 8 in. A further increase in the pipe size, however, substantially reduces the figure-of-merit.

2.24 Effects of Variation in Reflector Composition. The effect of the reflector composition was studied by varying the relative amounts of stainless steel and water in a $2-\mathrm{cm}$ annulus adjacent to the periphery of the core. The results show that variation of the proportions of stainless steel and water in the reflector has very little effect on the reactivity and figure-of-merit. Specifically, in changing the reflector annulus material from pure water to $80 \%$ stainless steel and $20 \%$ water, the keff is lowered $0.6 \%$ while the figureof-merit is increased $2 \%$. For this same change in annulus material, the ratio of maximum core power density to average core power density is increased by about $8 \%$. However, the ratio of peak core power density to the density adjacent to the reflector changes from 1.3 with the pure water reflector to 3.0 with the $80 \%$ stainless steel, $20 \%$ water reflector. 
To investigate the feasibility of reflector control of the PBF reactor, the effect of replacing a 2-cm-thick annulus of water adjacent to the periphery of the core by heavily borated stainless steel was examined. This change lowered the $\mathrm{k}_{\text {eff }}$ by only $1.8 \%$. Since $1.8 \%$ is considerably less than the amount of control required in this system, it was concluded that reflector control is not feasible.

\subsection{Core Radius}

The core radius required to attain an eigenvalue of 1.05 is plotted in Figure 14 as a function of metal-to-water ratio, with fuel enrichment and boron concentration in the flux suppressor as parameters. Figure 14 indicates that, at low values of fuel enrichment, the core radius is strongly dependent upon the metal-to-water ratio.

\subsection{Reactivity Coefficients}

2.11 Doppler Effect Studics. For power bursts having an initial peiviu of the order of $1 \mathrm{msec}$, the principal prompt shutdown mechanism is that resulting from Doppler broadening of the U-238 resonances. The long thermal time constant of the fuel element selected for the conceptual PBF core is such that during a short-period power burst essentially all of the heat released in the $\mathrm{UO}_{2}$ remains in the $\mathrm{UO}_{2}$. Thus, in order to calculate the effective Doppler temperature coefficient during short-period bursts, all regions other than the $\mathrm{UO}_{2}$ fuel are considered to be at room temperature. The GAM-1 code [39], which takes into account the Doppler broadening of the U-238 absorption resonances, was used to obtain fast group constants for various values of the $\mathrm{UO}_{2}$ temperature. These constants were used with the room-temperature, flux-weighted thermal constants to obtain the change in keff resulting from a change in fuel temperature.

The Doppler temperature coefficient as a function of temperature is shown in Figure 15 for a core having a metal-to-water ratio of 1.3 and a fuel enrichment

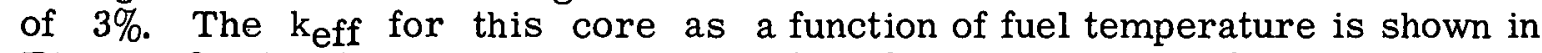
Figure 16. The change in reactivity resulting from changing the fuel temperature from $20^{\circ} \mathrm{C}$ to $2200^{\circ} \mathrm{C}$ is shown in Figure 17 as a function of metal-to-water ratio and U-235 enrichment.

All of the above results were obtained assuming a uniform temperature distribution throughout the core. The more realistic case of a non-uniform temperature distribution was studied by considering the average power density in each of eight radial regions of the core. The temperature, taken at the peak of the power burst in the radial region with the highest power density, was $1300^{\circ} \mathrm{C}$. The temperature in each of the other regions of the core was assumed to be proportional to the average power density in that region. Fast constants were determined for the various radial core regions by interpolation of GAM-1 results obtained at several temperatures. The calculated eigenvalue for this $\mathrm{UO}_{2}$ temperature distribution was 0.9749 . For this same temperature distribution, the average $\mathrm{UO}_{2}$ temperature in the core was $996^{\circ} \mathrm{C}$. Using fast constants determined for this average temperature, the resultant eigenvalue was 0.9764 . The eigenvalue for the base case $\left(20^{\circ} \mathrm{C}\right.$ uniform core temperature) for this model was 0.9942 . The results of these calculations indicate that the negative Doppler effect for the non-uniform $\mathrm{UO}_{2}$ temperature distribution is roughly $8 \%$ higher than that for the uniform temperature distribution. 
The studies described in Section. V, 2.2 indicate that the best overall operational characteristics are obtained if there is no boron in the flux suppressor. However, the calculated Doppler effects described above were obtained for the case of the heavily-borated flux suppressor. To determine whether these results were equally valid for the non-borated flux suppressor case, a few calculations of the Doppler effect for the core with the non-borated suppressor were made. The results of these calculations showed that the Doppler effect was relatively insensitive to changes in the boron concentration in the flux suppressor; the Doppler effect decreased by $4 \%$ when the boron was removed from the heavily-borated suppressor.

The average Doppler temperature coefficient between $20^{\circ} \mathrm{C}$ and $400^{\circ} \mathrm{C}$ is $-2.3 \times 10-5 /{ }^{\circ} \mathrm{C}$ for the $\mathrm{PBF}$ core with metal-to-water ratio of 1.3 and fuel enrivininent of $3 \%$.

2.42 Void Coefficient Studies. Because of the high peak power levels to be attained in the PBF and the consequent possibility of void formation, void coefficients for void volumes ranging between 5 and $95 \%$ of the water volume were obtained throughout the experiment and core regions. The studies were made on two cores: one containing 3\% enriched fuel in the fuel pins and the other containing $5 \%$ enriched fuel in the fuel pins. The metal-to-water ratio in both cores was 1.3. In both cases, the $2-\mathrm{cm}$ annulus of the reflector adjacent to the core perimeter consisted of $80 \%$ stainless steel and $20 \%$ water.

The experimental fuel assembly used with the $3 \%$ enriched core was a stainless steel assembly containing $600 \mathrm{~g}$ of U-235. For the studies of the $5 \%$ enriched core, the experimental assembly was a standard aluminum ETR fuel assembly containing $400 \mathrm{~g}$ of $\mathrm{U}-235$. For both cores studied, the pressure pipe OD was 8 in. Most of the studies were made with the heavily borated flux suppressor surrounding the test space; however, several calculations were also performed with the unborated stainless steel flux suppressor in order to determine the effect of the boron on the void coefficient in the test space and in the core.

All calculations were based on four neutron-energy groups. Fast constants were obtained with the GAM [39] code, and thermal constants were averaged over a Wigner-Wilkins spectrum and flux weighted as described in Section IX, 1 . A homogeneous void was introduced into a particular region by reducing the density of the water in that region. In all cases where a 95\% void was introduced into a region (ie, the water density was reduced by $95 \%$ ), a zero value of the vertical buckling was used in that region in order to avoid an excessively large value of end leakage. Since there will be some end leakage, the use of a zero vertical buckling results in an eigenvalue which is too large and, consequently, yields a void coefficient which is algebraically greater (eg, less negative) than the true coefficient.

The results of these studies are given in Tables VII and VIII. For both cores studied, the overall void coefficient of the cores is negative. The void coefficient associated with voids in the water annulus surrounding the test assembly, however, is positive. The void coefficient within a test assembly may be either positive or negative, but in all cases it is quite small.

The removal of boron from the flux suppressor results in a substantial increase in the positive void coefficient associated with the water annulus in 
VOID COEFFICIENTS FOR THE THREE PERCENT ENRICHED CORE WITH $600 \mathrm{gm}$ U-235 STAINLESS STEEL ASSEMBLY IN TEST SPACE

\begin{tabular}{|c|c|c|c|c|c|}
\hline Description of Voided Region & $k_{\text {eff }}$ & $\Delta k / k_{\text {eff }}$ & $\Delta k / k_{\text {eff }} / \%$ void & $\begin{array}{r}\Delta \mathrm{k} / \mathrm{k}_{\mathrm{et} \mathrm{t}^{\prime}} / \phi \\
\text { vold } / \mathrm{cm}^{2}(\mathrm{a}) \\
\end{array}$ & Comments \\
\hline \multirow{5}{*}{$\begin{array}{l}\text { Void in entire water filled } \\
\text { test region (No test assembly } \\
\text { in test space) }\end{array}$} & 1.06693 & & & & No vold base case \\
\hline & 1.06709 & $+1.6 \times 10^{-4}$ & $+3.1 \times 10^{-5}$ & $+1.4 \times 10^{-7}$ & $5 \%$ vold \\
\hline & 1.06728 & $+33.3 \times 10^{-4}$ & $+3.3 \times 10^{-5}$ & $+1.5 \times 10^{-7}$ & $10 \%$ vold \\
\hline & 1.06799 & $+10.0 \times 10^{-4}$ & $+4.0 \times 10^{-5}$ & $+1.8 \times 10^{-7}$ & $25 \%$ vold \\
\hline & 1.08044 & $+127.2 \times 10^{-4}$ & $+13.4 \times 10^{-5}$ & $+6.1 \times 10^{-7}$ & $95 \%$ vold \\
\hline \multirow[t]{5}{*}{ Void in test aosembly only } & $1.0706 \Omega$ & & & & Ho volia base case \\
\hline & 1.07065 & $+0.2 \times 10^{-4}$ & $+0.5 \times 10^{-3}$ & $+0.8 \times 10^{-T}$ & 59. void \\
\hline & 1.07064 & $+0.2 \times 10^{-4}$ & $+0.2 \times 10^{-5}$ & $+0.3 \times 10^{-7}$ & $10 \%$ void \\
\hline & 1.07060 & $-0.2 \times 10^{-4}$ & $-0.1 \times 10^{-5}$ & $-0.1 \times 10^{-7}$ & $25 \%$ void \\
\hline & 1.07007 & $-5.2 \times 10^{-4}$ & $-0.7 \times 10^{-5}$ & $-1.3 \times 10^{-7}$ & $95 \%$ void \\
\hline \multirow{5}{*}{$\begin{array}{l}\text { Vold in both test assembly } \\
\text { and water annulus ( } 600 \mathrm{gm} \text {, } \\
\text { stainless steel) }\end{array}$} & 1.07062 & & & & No vold base case \\
\hline & 1.07098 & $+3.3 \times 10^{-4}$ & $+6.7 \times 10^{-5}$ & $+3.1 \times 10^{-7}$ & $5 \%$ vold \\
\hline & 1.07132 & $+6.5 \times 10^{-4}$ & $+6.5 \times 10^{-5}$ & $+3.0 \times 10^{-7}$ & $10 \%$ vold \\
\hline & 1.07240 & $+16.6 \times 10^{-1}$ & $+6.6 \times 10^{-5}$ & $+3.0 \times 10^{-7}$ & $25 \%$ void \\
\hline & 1.08077 & $+94.8 \times 10^{-4}$ & $+10.0 \times 10^{-5}$ & $+4.6 \times 10^{-7}$ & $95 \%$ void \\
\hline \multirow{3}{*}{$\begin{array}{l}\text { Void in both test assembly } \\
\text { and water annulus (No boron } \\
\text { in flux suppressor) }\end{array}$} & 1.08143 & - & & & No void base case \\
\hline & 1.08454 & $+31.1 \times 10^{-4}$ & $+12.4 \times 10^{-5}$ & $+7.9 \times 10^{-7}$ & $25 \%$ vold \\
\hline & 1.09596 & $+145.3 \times 10^{-4}$ & $+15.3 \times 10^{-5}$ & $+9.8 \times 10^{-7}$ & $95 \%$ vold \\
\hline
\end{tabular}

(a) $\Delta k / \mathrm{k}_{\text {eff }} / \phi$ void $/ \mathrm{cm}^{2}$ refere to void coefficient per square $\mathrm{cm}$ of area in the region specified.

the test space; however, there is no significant effect on the void coefficient within the core.

To determine the radial variation of void worth, the core containing $5 \%$. enriched fuel was divided into five regions of equal volume, as shown in Figure 18, and a 25\% homogeneous void was introduced separately into each region. F'or both cores, the void coefficient is positive in the water annulus surrounding the experiments. The core as a whole and all five individual regions of the core possess negative void coefficients. The largest negative void coefficient with the boron flux suppressor present occurs in region 6 of the reactor core (Figure 18). 
VOID COEFFICIENTS FOR THE FIVE PERCENT ENRICHED CORE WITH ETR FUEL ASSEMBLY IN TES'I' SPACE

\begin{tabular}{|c|c|c|c|c|c|}
\hline Description of Volded Region & $k_{\text {eff }}$ & $\Delta k / k$ eff & $\Delta k / k_{\text {eff }} / \%$ void & $\begin{array}{l}\Delta \mathrm{k} / \mathrm{k}_{\text {eff }} / \mathrm{s} \\
\mathrm{vold} / \mathrm{cm}^{2}(\mathrm{a})\end{array}$ & Conments \\
\hline \multirow[t]{4}{*}{ Void in test assemblies only } & 1.03837 & & & & No vold base case \\
\hline & 1.03833 & $-0.4 \times 10^{-4}$ & $-0.08 \times 10^{-4}$ & $-1.3 \times 10^{-7}$ & $5 \%$ void in experiment \\
\hline & 1.03828 & $-0.9 \times 10^{-4}$ & $-0.09 \times 10^{-4}$ & $-1.5 \times 10^{-7}$ & $10 \%$ void in experiment \\
\hline & 1.03811 & $-2.5 \times 10^{-4}$ & $-0.10 \times 10^{-4}$ & $-1.7 \times 10^{-7}$ & $25 \%$ void in experiment \\
\hline \multirow{4}{*}{$\begin{array}{l}\text { Homogeneous vold throughout } \\
\text { core }\end{array}$} & 1.03837 & & & & No void base case \\
\hline & 1.01840 & $-192.4 \times 10^{-4}$ & $-38.48 \times 10^{-4}$ & $-10.4 \times 10^{-7}$ & $5 \%$ void \\
\hline & 1.00187 & $-351.6 \times 10^{-4}$ & $-35.16 \times 10^{-4}$ & $-9.5 \times 10^{-7}$ & $10 \%$ void \\
\hline & 0.93800 & $-966.6 \times 10^{-4}$ & $-38.66 \times 10^{-4}$ & $-10.4 \times 10^{-4}$ & $25 \%$ vold \\
\hline \multirow[t]{3}{*}{ Void in water annulus only } & 1.03837 & & & & No void base case \\
\hline & 1.03938 & $+9.7 \times 10^{-4}$ & $+1.94 \times 10^{-4}$ & $+12.2 \times 10^{-7}$ & $5 \%$ void \\
\hline & 1.04357 & $+50.1 \times 10^{-4}$ & $+0.20 \times 10^{-4}$ & $+1.3 \times 10^{-7}$ & $25 \%$ void \\
\hline \multirow[t]{6}{*}{$25 \%$ void in 5 core sections } & 1.03837 & & & & No void base case \\
\hline & 1.01851 & $-191.3 \times 10^{-4}$ & $-7.65 \times 10^{-4}$ & $-10.3 \times 10^{-7}$ & Void in region 5 \\
\hline & 1.01179 & $-256.0 \times 10^{-4}$ & $-10.24 \times 10^{-4}$ & $-13.8 \times 10^{-7}$ & Void in region 6 \\
\hline & 1.01893 & $-187.2 \times 10^{-4}$ & $-7.49 \times 10^{-4}$ & $-10.1 \times 10^{-7}$ & Vold in region 7 \\
\hline & 1.02353 & $-142.9 \times 10^{-4}$ & $-5.72 \times 10^{-4}$ & $-7.7 \times 10^{-7}$ & Vold in region 8 \\
\hline & 1.03004 & $-80.3 \times 10^{-4}$ & $-3.21 \times 10^{-4}$ & $-4.3 \times 10^{-7}$ & Void in region 9 \\
\hline \multirow{2}{*}{$\begin{array}{l}25 \% \text { void in core region } 5 \\
\text { (No boron in flux suppressor) }\end{array}$} & 1.06959 & & & & Base case \\
\hline & 1.04875 & $-194.9 \times 10^{-4}$ & $-7.79 \times 10^{-4}$ & $-10.5 \times 10^{-7}$ & $25 \%$ void \\
\hline
\end{tabular}

For voids in the test space, the largest positive void coefficient is obtained with an unborated flux suppressor and no experiment in the test space. The values in Table VII indicate that for this case a positive reactivity of about $2 \%$ would be obtained with a $95 \%$ void in the test space.

2.43 Temperature Coefficient Studies. With 5\% enriched fuel in the core, the temperature coefficients in the ETR fuel assembly, the water annulus, and the core were determined individually by changing the temperature from $20^{\circ} \mathrm{C}$ to $90^{\circ} \mathrm{C}$ only in the region under study. The model used for these studies is shown in Figure 18. As indicated in Table IX, a negative temperature coefficient was obtained in both the experiment and the core, but a positive coefficient was obtained in the water annulus. Thus, from Table IX a power burst generating sufficient prompt gamma radiation to raise the core and experiment temperature $20^{\circ} \mathrm{C}$ will reduce the $\Delta \mathrm{k} / \mathrm{k}$ eff of the core by about $0.23 \%$. Since this reactivity loss is prompt, it must be included with the Doppler shutdown coefficient in computing the total prompt shutdown coefficient of the core, 
TABLE IX

TEMPERATURE COEFFICIENTS FOR THE FIVE PERCENT ENRICHED CORE WITH ETR FUEL ASSEMBLY IN TEST SPACE

\begin{tabular}{|c|c|c|c|c|}
\hline Problem Description & $k_{\text {eff }}$ & $\Delta \mathrm{k} / \mathrm{k}$ eff & $\Delta k / k_{\text {eff }}$ & $\Delta \mathrm{k} / \mathrm{k}_{\mathrm{eff}} /{ }^{\circ} \mathrm{C} / \mathrm{cm}^{2}$ \\
\hline Base case, $20^{\circ} \mathrm{C}$ & 1.03837 & & & \\
\hline $90^{\circ} \mathrm{C}$ in experiment & 1.03797 & $-3.9 \times 10^{-4}$ & $-0.056 \times 10^{-4}$ & $-0.95 \times 10^{-7}$ \\
\hline $90^{\circ} \mathrm{C}$ in water annulus & 1.03925 & $+8.4 \times 10^{-4}$ & $+0.12 \times 10^{-4}$ & $+0.75 \times 10^{-7}$ \\
\hline $90^{\circ} \mathrm{C}$ throughout core & 1.02588 & $-120.2 \times 10^{-4}$ & $-1.72 \times 10^{-4}$ & $-0.46 \times 10^{-7}$ \\
\hline
\end{tabular}

\subsection{Prompt-Neutron Lifetime Studies}

The prompt-neutron lifetime for the $\mathrm{PBF}$ reactor was calculated by computing the change in eigenvalue when a $1 / \mathrm{v}$ absorber was added to all reactor regions. The calculational details are given in Section IX, 1. The promptneutron lifetime is dependent primarily upon the core composition, ie, metalto-water ratio and fuel enrichment. Other variables, such as the composition of the reflector, the diameter of the test space, the boron content of the stainless steel flux suppressor, etc, have only a minor effect on the lifetime. The dependence of prompt-neutron lifetime on metal-to-water ratio and fuel enrichment is shown in Figure 19. The lifetimes obtained in this study are generally within the 10 to $20 \mu \mathrm{sec}$ range specified as desirable for a PBF core.

\section{NEUTRON FLUX AND POWER DISTRIBUTION}

\subsection{Sleady Slate}

Three typical sets of four-group radial flux distributions, illustrating the effects of changes in the reflector and flux suppressor compositions, are shown in Figures 20,21, and 22. These distributions were obtained for a core with a metal-to-water ratio of 1.3 and a fuel enrichment of $3 \%$. The test space contained a Spert III fuel assembly. In all cases, the core radius was adjusted to obtain an eigenvalue of 1.05. The three sets of flux distributions were all normalized to the same maximum core power density. The power distributions curresponding to the three sets of flux distribution are shown in Figure 23.

The effect on the flux distribution of changes in the reflector composition is illustrated by a comparison of Figure 20 with Figure 21. The removal of the stainless steel from the 2-cm-thick annulus surrounding the core results in a substantial increase in the thermal flux distribution near the outer edge of the core. The associated power density near the core periphery is also increased, as illustrated in Figure 23. In the core interior and test space, however, the flux and power distributions are not significantly altered by the change in the reflector composition. In addition, the core radius required for an eigenvalue of 1.05 is not changed. 
The effects of changing the boron concentration in the flux suppressor are illustrated by a comparison of Figure 20 with Figure 22 . It is evident that the removal of boron from the flux suppressor substantially increases the thermal flux within the test space. As indicated in Figure 23, the increase in the thermal flux in the test space results in an increase in the power density. in the test assembly. The removal of boron from the flux suppressor also reduces the core size.

In all three cases the spatial variation of the power density within the test assembly is significant. This variation is a consequence of the use of the flux trap principle to obtain the required average power density in the test assembly. Since the neutrons supplied to the core are thermalized in the water annulus, the outermost fuel in the test assembly effectively shields the fuel in the center of the test assembly. Although large spatial variation of the power density within an experiment is not generally desirable, the variations indicated in Figure 23 do not preclude the performance of meaningful experiments. In fact, in many experiments (particularly in those in which a photographic record of the experiment is desired) it is advantageous to produce the maximum power density in the outermost fuel.

\subsection{Transients}

As discussed in Section IX, 1, the flux distribution for a reactor in which the power is increasing exponentially with time can be approximated by the addition of a $1 / \mathrm{v}$ absorption cross section to all regions of the reactor. The flux distribution is then computed in the usual manner. In a typical case, the addition of the amount of poison required to simulate an exponential period of $1 \mathrm{msec}$ results in a reduction of the figure-of-merit by about 5\%. Thus, the flux distribution when the reactor power is increasing on an asymptotic period is not significantly different from the steady-state distribution.

4. PERFORMANCE CHARACTERISTICS OF THE OPTIMIZED PBF REACTOR WITH TYPICAL TEST ASSEMBLIES

As is discussed in detail in Section $V, 6$, the results of the optimization studies described in Section $\mathrm{V}, 2$, indicate that optimum performance is obtained when the core has the following characteristics: a metal-to-water ratio of 1.3 , a fuel enrichment of 3\%, and an 8-in.-diameter test space surrounded by an unborated, stainless steel flux suppressor.

In order to further evaluate the performance capabilities of this core, the figure-of-merit and coupling have been calculated with various test assemblies in the test space. These included four different highly enriched, plate-type assemblies, three different sizes of PBF fuel pin clusters, and two gas-cooled fuel elements of the HTGR type with different fuel loadings. The results of these calculations are given in Table $\mathrm{X}$.

For all the plate-type assemblies studied, the figures-of-merit were satisfactorily high. The lowest figure-of-merit obtained (1.24 for the stainless steel assembly containing $300 \mathrm{~g}$ of $\mathrm{U}-235$ ) is approximately $50 \%$ greater than that required to raise the average temperature of the test assembly to the 
TABLE X

PERFORMANCE CHARACTERISTICS OF THE OPTIMIZED PBF(a)
FOR TYPICAL TEST ASSEMBLIES

\begin{tabular}{|c|c|c|c|c|c|}
\hline $\begin{array}{c}\text { Type of } \\
\text { Tcst Assembly }(b)\end{array}$ & $\begin{array}{l}\text { Metal- } \\
\text { to-Water } \\
\text { Ratio } \\
\end{array}$ & Coupling & $\begin{array}{l}\text { Pigure of } \\
\text { Merit ('l'otal } \\
\text { Metal Basis) }\end{array}$ & Eigenvalue & $\begin{array}{l}\text { Tutal Metal- } \\
\text { to-Fuel Plate } \\
\text { Volume Ratio } \\
\end{array}$ \\
\hline $\begin{array}{l}\text { Spert III, stainless steel } \\
(638-g \mathrm{U}-235)\end{array}$ & 0.298 & 0.0072 & 3.26 & 1.0500 & 1.73 \\
\hline $\begin{array}{l}\text { Stainless steel assembly } \\
(300-8 \mathrm{U}-235)\end{array}$ & 0.429 & 0.0048 & 1.24 & 1.0476 & 1.13 \\
\hline $\begin{array}{l}\text { Stainless st.eel assembly } \\
(600-\mathrm{g}(\mathrm{J}-235)\end{array}$ & 0.4 .09 & 0.0064 & $\varepsilon .00$ & 1.0492 & 1.13 \\
\hline EIIK, aluminum (400-g U-235) & 0.644 & 0.0075 & 2.76 & 1.0503 & 1.47 \\
\hline $\begin{array}{l}\text { PBF, 3\% enriched fuel } \\
\text { (radius }=1.27 \mathrm{~cm} \text { ) }\end{array}$ & 1.3 & $0.00 \Omega 5$ & ع. $4,1,1$, & 1.0453 & 1.00 \\
\hline $\begin{array}{l}\text { PBF, 3\% enricined luel } \\
\text { (radius }=4.3 \mathrm{~cm} \text { ) }\end{array}$ & 1.3 & 0.0059 & 1.37 & 1.0487 & 1.00 \\
\hline $\begin{array}{l}\mathrm{PBF}, 3 \% \text { enriched fuel } \\
\text { (radius }=6.0 \mathrm{~cm} \text { ) }\end{array}$ & 1.3 & 0.0099 & 1.15 & 1.0527 & 1.00 \\
\hline $\begin{array}{l}\text { HTGR element, as designed } \\
(29.1-g \mathrm{U}-235+ \\
178-\mathrm{g} \mathrm{Th}-232)\end{array}$ & 一 & 0.0016 & 0.67 & 1.0444 & - \\
\hline $\begin{array}{l}\text { HTGR modified element } \\
\text { ( } 207-\mathrm{g} \text { U-235, no thorium) }\end{array}$ & 一 & 0.0045 & 2.53 & 1.0473 & - \\
\hline $\begin{array}{l}\text { (a) Optimized PBF design par } \\
8-i n .- \text { Diameter test spac } \\
49.6 \mathrm{~cm} \text {. }\end{array}$ & $\begin{array}{l}\text { neters: } \\
\text {; Unbora }\end{array}$ & \multirow{2}{*}{\multicolumn{4}{|c|}{$\begin{array}{l}\text { Metal-to-water ratio }=1.3 \text {; Fuel enrichment }=3 \% \text {; } \\
\text { ted stainless steel flux suppressor; Core radius } \\
\text { 3-ft-long test assemblies. }\end{array}$}} \\
\hline (b) Indicated U-235 loadin & & & & & \\
\hline
\end{tabular}

melting point of stainless steel during a maximum power burst (ie, a burst in which the peak temperature in the core reaches the $\mathrm{UO}_{2}-\mathrm{ZrO}_{2}$ eutectic temperature). Further, for the plate-type assemblies, the figure-of-merit is determined from a power density based on the entire metal volume rather than just the fuel volume, and hence may be considered to be somewhat conservative (see Section V, 2.2).

To evaluate the performance of the conceptual PBF reactor with respect to slightly enriched $\mathrm{UO}_{2}$ fuel assemblies, calculations of the figure-of-merit and coupling have been made for three different sizes of clusters of the conceptual PBF fuel pins as the test fuel. These pins, while not truly typical of the slightly enriched fuel elements in current. use in the nuclear industry, were chosen for this portion of the design evaluation for two reasons. First, the presence of $\mathrm{ZrO}_{2}$ in the fuel pin dilutes the fuel (in the homogeneous model) and thus results in a severe test of the performance capabilities of the conceptual reactor. Second, one probable use of the first generation core will be to aid in the development of fuel elements for a second generation PBF core having 
substantially improved performance characteristics. Thus, the ability to perform destructive tests on PBF fuel elements is a highly desirable goal for the first generation core. As indicated in Table $\mathrm{X}$, the figure-of-merit obtained with PBF fuel pins in the test space is satisfactory if the cluster size is not excessive. (In Table $\mathrm{X}$, the PBF test fuel assembly radius of $6 \mathrm{~cm}$ corresponds roughly to a cluster containing 22 pins.) Note that the figure-of-merit could be increased by increasing the enrichment of the fuel in the test assembly.

To evaluate the conceptual PBF reactor performance with respect to gas-cooled fuel elements, calculations were performed with an HTGR fuel element in the test space. The calculational model used was necessarily different from that used for the other test assemblies, and is shown in Figure 24. For the unmodified HTGR element, the computed figure-of-mer it $(0.67)$ is rather unsatisfactory. This low value is a result of the very low fuel density in the element. If the thorium carbide in the fuel annulus of the HTGR element were replaced by highly enriched uranium carbide, calculation indicates that a very satisfactory figure-of-merit of 2.5 could be obtained. Such a substitution of U-235 for thorium should not significantly affect the validity of the test results, except possibly with respect to certain chemical reactions which might accompany a meltdown.

In all cases considered, the coupling and the change in reactivity which occurs when one test assembly is replaced by another (indicated in Table $\mathrm{X}$ by the eigenvalue) are satisfactory.

\section{CONTROL, TRANSIENT, AND SAFETY ROD STUDIES}

To determine the optimum positions in the core for control poison and an estimate of the amount of control poison required, a series of reactivity calculations based upon one-dimensional diffusion theory was performed. Since one-dimensional diffusion theory is generally not adequate for the accurate determination of control rod worths, the results discussed below should be taken as being only qualitatively correct, but indicative of important trends.

The reactor model used in this study had a metal-to-water ratio of 1.3 , a fuel enrichment of $3 \%$, an 8 -in.-OD pressure pipe containing a Spert III fuel assembly, and a reflector consisting of a 2-cm-thick annulus of $60 \%$ stainless steel and $40 \%$ water adjacent to the core and surrounded by water.

The control and transient rods were located in an annulus $2.09 \mathrm{~cm}$ thick, corresponding to the width of a single row of fuel pins. The control and transient rods were assumed to be made of hafnium and to operate in air inside a stainless steel sheath. For calculational purposes these materials were homogenized within the control rod annulus. The control and transient rods were assumed to have full-core-length aluminum followers.

The safety rods, consisting of 3/4-in.-diameter pins of hafnium with full-core-length fuel pin followers, were placed in another annular region of the core. From the reactor physics standpoint, an optimum rod configuration is obtained with the safety rod annulus placed inside the control rod annulus. However, for mechanical reasons, it may be more desirable to place the safety 
rod annulus outside the control rod annulus. Such a change in rod configuration would not substantially alter the conclusions resulting from this study.

Core radii corresponding to an eigenvalue of 1.05 were determined for several radial positions of the control rod annulus. These calculations were made assuming the fuel follower sections of the safety rods and the aluminum follower sections of the transient and control rods to be in the core. For various radial positions of the control rod annulus, the computed core radius varied from about 54.3 to $55.4 \mathrm{~cm}$, indicating that the reactivity of the core with all rods withdrawn is relatively insensitive to the control rod annulus position.

The control and transient rod worths, with the safety rods withdrawn and replaced by fuel followers, are shown in Figure 25 as a function of the control rod annulus position. (For convenience, rod worth has been defined in this study as the change in eigenvalue which results when the rod followers are replaced by the poison sections of the rods.) The optimum annulus position is at a radius of $30 \mathrm{~cm}$ from the center of the core. For this configuration the indicated total reactivity worth is approximately $11.8 \%$. The rod worth required for adequate reactor control is estimated to about 6 to $8 \%$.

The worth per unit weight of the rods is important with respect to the force required to eject the transient rods. In the present design, the total control and transient rod weight is proportional to the radius of the control rod annulus. With respect to the worth per unit weight, then, the optimum location of the control rod annulus is at a radius of 28 to $29 \mathrm{~cm}$. In this position, the indicated total worth is well above that required for adequate control of the core.

As shown in Figure 25, the safety rod worth is also maximized when the safety rod annulus is placed at a radius of $30 \mathrm{~cm}$. The indicated worth of $14.5 \%$ is well in excess of the 5 to $6 \%$ considered adequate for safety rods in the PBF. While the results shown were obtained with the control rod annulus placed at a radius of $48.4 \mathrm{~cm}$, other results have indicated that the safety rod worth is reduced by not more than $1.5 \%$ as the control rod annulus is moved toward the center of the core.

Also shown in Figure 25 is the total rod worth with the control rods located at a near-optimum position. Again, the worth obtained is much larger than that required for adequate control.

The location of the control rod annulus has an effect on the figure-of-merit, as shown in Figure 26. The reduction in the figure-of-merit when the control rod annulus is placed at the optimum position for rod worth is the result of a thermal flux peak which occurs in the fuel adjacent to the annulus when the rods are withdrawn. This detrimental effect can be eliminated by a slight increase of the thermal absorption cross section of the control and transient rod followers (eg, the use of stainless steel rather than aluminum). Since the results discussed above indicate that the control and transient rod worths are more than adequate, the resultant loss in rod worth would be of no concern. 


\section{SUMMARY AND RECOMMENDATIONS}

\subsection{Summary of Conceptual Reactor Design}

The results of the physics calculations discussed above have permitted an initial optimization of the reactor design with respect to the objectives outlined in Section V, 1. This optimization constitutes the conceptual design of the PBF reactor. The pertinent design parameters of the conceptual reactor are summarized in Table XI, and a plan view of the reactor is shown in Figure 52. Since many of the physics calculations have necessarily been approximate, it is to be expected that the final reactor design will differ somewhat from the conceptual design. The studies described in Section IX, 2, however, have shown that the calculational methods used are sufficiently accurate for conceptual design purposes, and all indfcations are that the design selected is capable of meeting the design objectives.

\section{$\underline{\text { TABLE XI }}$}

SUMMARY OF PBF CONCEPTUAL REACTOR DESIGN

\begin{tabular}{|c|c|}
\hline Core height & $3 \mathrm{ft}$ \\
\hline Core diameter & $3.6 \mathrm{ft}$ \\
\hline Test space & $\begin{array}{l}\text { 8-in.-diameter vertical hold } \\
\text { through center of core }\end{array}$ \\
\hline Fuel & $3 \%$ enriched, sintered $\mathrm{UO}_{2}$ \\
\hline Moderator & $\mathrm{H}_{z} \mathrm{O}$ \\
\hline Fuel element & 0.75 -in.-OD pins (See Figure 53) \\
\hline Clad & $28 \mathrm{mil}$ stainless steel \\
\hline Expansion gaps & 8-mil annulus, 0.5-in. axial \\
\hline Thermal insulation & $\approx 1 / 16-\mathrm{in} \cdot \mathrm{ZrO}_{2}$ \\
\hline Lattice & Triangular, 0.944 in. pitch \\
\hline Control and transient rods & $\begin{array}{l}\text { Ribbed hafnium blades with stain- } \\
\text { less steel followers (See Figure } 52 \text { ) }\end{array}$ \\
\hline Safety rods & $\begin{array}{l}0.75 \text {-in.-diameter hafnium pins with } \\
\text { fueled followers }\end{array}$ \\
\hline Flux suppressor & $\begin{array}{l}\text { 1/4-in.-unborated stainless steel } \\
\text { surrounding test space }\end{array}$ \\
\hline Refflestinr & $\begin{array}{l}\text { Water with eingle row of otainlcos } \\
\text { steel pins surrounding core }\end{array}$ \\
\hline
\end{tabular}

\subsection{Selection of the Conceptual Design}

As in all reactor designs, optimization is the result of a series of compromises made in order to best satisfy the design objectives. In this section, the principal results obtained in Section V, 2 are summarized, and the compromises leading to the conceptual design and the reasons for them are briefly discussed. 
As shown in Figures 8 and 9 , an increase in the metal-to-water ratio tends to increase the figure-of-merit and to reduce the coupling. (Both are desired effects.) For a fuel enrichment of $3 \%$, however, there is a maximum in the figure-of-merit at a metal-to-water ratio of 2.3 and a further increase in the metal-to-water ratio would decrease the figure-of-merit. For higher values of fuel enrichment, maxima in the figure-of-merit are apparently obtained at metal-to-water ratios substantially greater than 2.8. The maxima in the figure-of-merit obtainable at these higher enrichments are much greater than those attainable with a fuel enrichment of $3 \%$. With respect to maximizing the figure-of-merit, then, Figures 8 and 9 indicate that the metal-to-water ratio should be as large as possible, and that the fuel enrichment should be $5 \%$ or greater.

Also shown on Figures 8 and 9 is the effect of the metal-to-water ratio and the enrichment on the coupling. Evidently, the coupling is a rather weak function of the metal-to-water ratio, and hence the value of the metal-to-water ratio is unimportant with respect to minimizing the coupling. An increase in the fuel enrichment, however, produces a substantial increase in the coupling. Thus, with respect to minimizing the coupling, any reasonable value of the metal-to-water ratio is satisfactory, but the enrichment should be as low as is feasible.

The results shown in Figure 14 indicate that a low fuel enrichment and a high metal-to-water ratio can result in an excessively large reactor. Since one of the design objectives is that the total energy released in the core should be as small as possible in order to reduce heat removal requirements, a large core size is undesirable. As indicated in Figure 14, the core size may be reduced by increasing the fuel enrichment and reducing the metal-to-water ratio.

The major inherent prompt shutdown mechanism in a slightly-enriched, water-moderated reactor is the Doppler broadening of the U-238 absorption resonances. Since the magnitude of the power bursts is to be limited by inherent reactivity mechanisms, a major consideration in the selection of a core design is the amount of reactivity compensated by Doppler broadening. It can be shown that the compensating reactivity required to terminate a short-period power burst (ie, to stop the power increase) is:

$$
\rho=\alpha \Lambda
$$

where $\alpha$ is the initial asymptotic inverse reactor period and $\Lambda$ is the prompt neutron lifetime. Thus, the amount of compensating reactivity required is a function of the prompt neutron lifetime, which, in turn, is a function of the metal-to-water ratio and enrichment. The amount of compensating reactivity obtained is dependent upon the Doppler coefficient, which is also a function of the metal-to-water ratio and the enrichment.

The functional relationships among the metal-to-water ratio, the enrichment, the prompt neutron lifetime, and the compensating reactivity resulting from Doppler broadening are indicated in Figure 27. Since Figure 27 was constructed on the basis of heating the fuel from $20^{\circ} \mathrm{C}$ to $2200^{\circ} \mathrm{C}$, a conversion factor must be applied to obtain the Doppler reactivity resulting from heating the fuel from $20^{\circ} \mathrm{C}$ to $1000^{\circ} \mathrm{C}$ (the estimated average fuel temperature at the time of peak power during the maximum burst). This conversion factor $(\approx 0.7)$ may be obtained from Figure 16. The relationship between the required compensating reactivity and the prompt neutron lifetime (given by Equation 1) can be represented in Figure 27 
by a straight line passing through the origin. In the present case the desired maximum value of $\alpha$ is $1000 \mathrm{sec}^{-1}$, and the relationship is very nearly approximated by a straight line from the origin through the intersection of the $5 \%$ fuel enrichment curve with the 1.1 metal-to-water ratio curve.

For combinations of fuel enrichment and metal-to-water ratio which lie on the straight line between the origin and the point representing $5 \%$ enrichment and a 1.1 metal-to-water ratio, the maximum power burst is obtained when the initial inverse period is $1000 \mathrm{sec}^{-1}$. For combinations above this line, an inverse period larger than $1000 \mathrm{sec}^{-1}$ would be required in order to obtain the maximum power burst. These considerations, then, indicate that desirable combinations would be, for example, a fuel enrichment of $5 \%$ and a metalto-water ratio of 1.1 or a fuel enrichment of $3 \%$ and a metal-to-water ratio slightly less than $1 . \dot{3}$.

As suggested in Section V, 1, the prompt neutron lifetime of the reactor should be approximately 10 to $20 \mu \mathrm{sec}$ in order that the reactivity required to initiate bursts and to control the reactor is neither too small nor too large. The lifetimes obtained for all combinations of fuel enrichments and metal-towater ratios shown in Figure 27 are satisfactory in this regard.

Consideration of the shutdown reactivity from Doppler broadening dictates that the metal-to-water ratio should be 1.3 or less. If a higher metal-to-water ratio were chosen, the required reactivity compensation could be obtained only by reducing the fuel enrichment, and, as a result, an excessive core size would be required for criticality. Since at metal-to-water ratios less than 1.8 the figure-of-merit is insensitive to the fuel enrichment, and since the figureof-merit increases with metal-to-water ratio, the metal-to-water ratio should be as high as possible, ie, about 1.3. With a metal-to-water ratio of approximately 1.3, Doppler coefficient and coupling considerations both indicate that the fuel enrichment should be approximately $3 \%$.

Having fixed the metal-to-water ratio and fuel enrichment, Figure 12 indicates that the figure-of-merit is maximized by a test space diameter of about 7 in. However, the coupling can be reduced without a substantial reduction of the figure-of-merit by a slight increase in the test space diameter. Therefore, an 8-in.-diameter test space has been selected for the conceptual design.

Figures 10 and 11 indicate that the smallest values of the coupling and the largest values of the figure-of-merit are obtained when the flux suppressor surrounding the test space is unborated, and an unborated flux suppressor has been tentatively selected for the conceptual design. However, as indicated in Table VII, the reactivity effects of voids within the test space are reduced when the flux suppressor contains boron, and further studies of the flux suppressor composition are requircd before the final selection is made.

As indicated in Section V, 2 and V,3, the relative amounts of stainless steel and water in the reflector have a significant effect only on the flux and power distributions near the core periphery. To reduce the power peak at the core periphery and the energy released during a burst, a single row of stainless steel rods have been placed around the core periphery, as shown in Figure 52.

The peak power of the conceptual PBF first-generation core during a 1-msecperiod power burst is approximately $500,000 \mathrm{Mw}$. The total energy release is 
approximately $2000 \mathrm{Mw}$-sec. The peak thermal neutron flux in the test space is strongly dependent upon the nature of the contents of the test space. With no experiment installed (ie, the test space filled with water only) the peak thermal neutron flux is calculated to be in excess of 1018 neutrons $/ \mathrm{cm}^{2}-\mathrm{sec}$.

\subsection{Recommendation for Further Study}

As previously mentioned, the calculational techniques used in developing the conceptual reactor design, while quite appropriate for parametric studies, were necessarily approximate in many respects. For example, the representation of the control and transient rods by a homogenized annular region in the core is a rather gross approximation and, while the calculational results are expected to be qualitatively correct, the quantitative evaluation of rod worth could be considerably in error. Thus, as is the usual procedure in reactor design, the calculalluns performed by approximate methods to obtain near-optimization of the design must be repeated using more sophisticated methods (eg, using two- and three-dimensional diffusion theory rather than one dimensional; Monte-Carlo methods for determining the resonance escape probability, etc).

In addition to a repetition of previous calculations with more sophisticated techniques in order to better evaluate control rod worth. corner effects in square or rectangular test assemblies, etc, several possible methods of improving the reactor performance should be investigated further. Among these are the following:

From the previous section, it is apparent that the reactor design is to a large extent determined by the required magnitude of the Doppler coefficient of reactivity. As a result, the metal-to-water ratio in the present design cannot be larger than 1.3, and the figure-of-merit which results is considerably smaller than that which could be achieved if the metal-to-water ratio were increased. It may be possible to increase the metal-to-water ratio without changing the Doppler coefficient by reducing the amount of U-238 in the core without changing the amount of U-235. This could be accomplished by increasing the enrichment of the $\mathrm{UO}_{2}$ and then diluting it with $\mathrm{ZrO}_{2}$. (The properties of fuel materials consisting of mixtures of $\mathrm{UO}_{2}$ and $\mathrm{ZrO}_{2}$ have been studied extensively [40]). This approach will be investigated during the final design.

Since the magnitude of the Doppler cuefficient is crucial, it would be highly desirable to have some means of adjusting it in the actual PBF reactor. One possible approach would be to construct two types of fuel pins, one containing undiluted $\mathrm{UO}_{2}$ and the other containing a mixture of $\mathrm{UO}_{2}$ and $\mathrm{ZrO}_{2}$. The Doppler coefficient would then be adjusted by changing the relative numbers of the two types of fuel pins in the core. During the final design, an investigation of this and other physical methods for adjusting the Doppler coefficient will be investigatèd.

As mentioned in Section V, 6.2, the composition of the flux suppressor surrounding the test space requires further study during the final design effort. 


\title{
VI. ENGINEERING DESCRIPTION
}

\author{
1. SITE
}

The PBF will be located at the National Reactor Testing Station (NRTS) near Arco, Idaho. The PBF Reactor Building will be constructed in the Spert I area, and the PBF Control Center will be constructed at the Spert Control Center area. A general site plan for the Spert area is shown in Figure 28.

The Spert I reactor will be deactivated prior to the beginning of the construction of the PBF. The existing Spert I area electrical substation, the single road presently serving spert $I$, and the three-strand barbed wire fence surrounding the area will be utilized for the PBF. Use of the road providing access to the area will be controlled from the Control Center area.

\section{CONTROL CENTER}

\subsection{General Layout}

The PBF Control Center building is an $88-\mathrm{ft}$ by $62-\mathrm{ft}$ single story pumice block building which is to be located in the present Spert Control Center area as shown in Figure 29. Space is provided in this building for the reactor console, control consoles for those operations of the reactor plant and test loops which require remote controllabilityduring nuclear tests, data gathering systems for the experiments, necessary office space for operating and experimenting personnel, health physics office space, a conference room, and a minimal amount of space for experiment pre-assembly and electronic instrumentation maintenance. Rest room facilities in accordance with Idaho Operations Office Standard Health and Safety Requirements are included. The Control Center Building plan and elevations are shown in Figures 30,31, and 32. In addition, fallout shelter space will be provided for 450 people, in accordance with the requirements of fallout criteria established in AEC Manual Appendix 6316.

\subsection{Construction Details}

General. All building construction shall conform to the Type I classification of the Uniform Building Code by Pacific Coast Building Officials' Conference as required by Section 9.02, Part A, of the Idaho Operations Office Standard Health and Safety Requirements. The occupancy classification as referred to in the Uniform Building Code shall be Group F, Division 2.

Footings. Spread footings for columns, certain walls, grade beams, etc, shall be in accordance with accepted engineering practice. Main load bearing sections such as column footings shall be carried to undisturbed soil. In the event that excavations are required below the level required for footings, concrete shall be used for fill to the required grade.

Floors. Floor slabs shall be reinforced concrete, adequate to support a minimum superimposed live load of $150 \mathrm{lb} / \mathrm{ft}^{2}$. The floor shall be smoothly finished and treated to reduce dusting. All floors, except those in the shop 
area, furnace room, control room, and tape system and instrumentation room, shall be covered with asphalt tile. The shop area and furnace room floors shall be left bare.

The floors in the control room and the tape system and instrumentation room shall be heavy duty free access floors similar to those furnished by the Harford Metal Products, Inc. The subflooring shall be concrete and provide a minimum clearance of 12 in. beneath the finished floor. The floor system shall not have any exposed metal on the surface. The finished surface shall be vinyl floor covering. All of the removable floor system shall be of materials which are fire resistant in final assembled form. The floor system shall be designed and constructed to support a uniformly distributed load of at least $250 \mathrm{lb} / \mathrm{ft}^{2}$ and a concentrated load of $1000 \mathrm{lb} / \mathrm{ft}^{2}$ at any point of the removable panel. Panel strength shall enable the making of cable cut-outs in any portion of the panel without placing additional underfloor reinforcing members to carry the load. The weight of the removable panels, including the vinyl floor covering, shall not exceed $6 \mathrm{lb} / \mathrm{ft}^{2}$. The panels shall not be fastened to the framing system in any way and shall be capable of removal by means of a surface lifting device without disturbing adjacent panels and without permanently breaking the bond between the vinyl floor covering and the metal panel. The panels shall not be smaller than four square feet nor larger than nine square feet. The entire floor system shall be capable of leveling to within $1 / 16$ in. with no slope $\epsilon$ xceeding $1 / 16 \mathrm{in}$. in $10 \mathrm{ft}$.

Walls. All exterior walls shall be 12-in. pumice block or equal. The interior surface of the pumice block walls shall be painted to match the interior wall portions.

The interior walls of the furnace room shall be a minimum of 8 -in. pumice block extending to the roof.

The interior walls surround the shop area shall be of pumice block extending to the roof. 'I'he size of the blocks shall be as necessary to provide a stable wall section.

The interior walls surrounding the men's and women's rooms shall be of 4-in. pumice block.

All other interior walls shall be of movable gypsum-type construction with a fire rating of one hour and a minimum sound reduction of 35 decibels. Both sides of the wall sections shall be faced with $5 / 8$-in. thick by 2 -ft-wide gypsum board face panels, finished on one side. The face panels shall be seeparated and bonded to a core composed of 1-in.-thick by 6-in.-wide gypsum board ribs spaced on 1-ft centers. The walls shall be fastened to the floor and ceiling with the use of non-exposed metal runners.

The exposed surfaces of all interior walls, with the exception of the furnace room, shall be painted.

Doors.' The three exterior entrance doors shall be steel doors with safety glass upper light. These doors shall be equipped with panic hardware inside, thumb latches for outside actuation, and outside locks keyed to the Spert master key system. The east entrance door shall be $4 \mathrm{ft}$ wide and the other two $3 \mathrm{ft}$ wide. 
The door on the furnace room shall be a 4-ft-wide, hollow metal, all steel door and shall have fixed louvers sized to admit sufficient furnace combustion air.

The large truck door in the shop area shall be a 12 -ft by 12 -ft, all metal, motor operated, overhead roll door provided with adequate weather-stripping.

The two interior doors on the rest rooms and the one between the shop area and office hallway shall be solid wood paneled doors. The door between the shop area and the store room shall be a solid wood, sectioned, Dutch door with a 12-in.-wide shelf on the lower half. All of these doors shall be $3 \mathrm{ft}$ wide, except for the door between the shop area and the office hallway. This door shall be $4 \mathrm{ft}$ wide or a double door.

The control room door shall be a 4-ft-wide, wood paneled door: with DSA glass upper light. The door between the tape system and instrumentation room and the adjacent office shall be a 3 -ft-wide, wood paneled door with DSA glass upper light.

All other interfor doors shall be $3-\mathrm{ft}$-wide wood doors with DSA glass upper light and fixed louvered lower light.

Windows. All exterior windows shall be glazed with DSB glass, bedded in putty, and secured with glazing clips. Opening-type steel frames will be used throughout the building. All windows shall have clear glass except for the rest rooms. 'These windows shall have frosted glass. Exterior windows shall be sized to provide adequate lighting and ventillation.

The interior window in the control room is for visual access to the control room from the hall and should be sized accordingly. It shall be of the nonopening type with a metal frame and glazed with DSB glass. The bottom of this window shall be approximately $4 \mathrm{ft}$ from the floor.

A sliding glass window shall be provided in the tape system and instrumentation room wall above the CEC island for vocal communication between the rooms. It shall have metal frames and be glazed with DSB glass. In addition, metal access doors shall be furnished below the window to provide access in the tape system and instrumentation room to the back of the CEC island.

Ceiling. The ceiling shall be of framed type. The ceiling height for the entire building shall be $9 \mathrm{ft}$ except in the furnace room and shop area. These areas shall not have a ceiling. The underside of the ceiling shall be painted with an off-white flat paint.

Any walkways provided in the space between the ceiling and the roof shall be constructed of non-combustible material.

Roof. The roof shall be of reinforced concrete beam design capable of supporting a future second floor and a minimum superimposed live load of $150 \mathrm{lb} / \mathrm{ft}^{2}$. The concrete beams shall be covered with a non-combustible vapor barrier, two 1-in. layers of rigid asphalt impregnated fiber insulation board, and a 5-ply built-up asphalt impregnated rag-felt roofing.

The roof beams shall span the building in the east-west direction. The beams may be either continuous span or a double span with one section spanning 
the shop area. Columns should be kept out of the office area in order not to restrict the movable partition versatility. All of the columns used for roof support shall be of fire resistant construction.

\subsection{Utilities}

Lighting. Adequate and well designed fluorescent lighting shall be located in all areas of the building. Illumination shall conform to the provisions of Illuminating Engineers Society 1961 Standards, as required by the Idaho Operations Office Standard Health and Safety Requirements. In the areas where ceilings. exist, fixtures may either be of the recessed or hung type.

Electrical Power Distribution. All installations of electrical wiring and equipment shall be in accordance with the National Electrical Code as required by Section 2.11 of the Idaho Operations Office Standard Health and Safety Requirements.

A minimum of one 110-volt electrical outlet. shall he provider on each wall of the various offices, control room, and conference room. Where the walls are exceptionally long, additional outlets shall be provided at reasonable intervals. Outlets should also be provided in hallways, rest rooms, and furnace room.

Outlets shall be provided on all walls of the shop area and electronic shop at 1 -ft intervals.

All of the above outlets shall be of the 125-volt, 15-ampere, Duplex type that will take either a 3-blade NEMA grounding plug or a standard 2-blade plug. Wiring for rcceptacles located on movable partitions, with the exception of the electronic shop walls, shall be run within the partitions. All other wiring shall be carried in plug-in strips.

Two 480-volt, 3-phase, 30-ampere wall plugs shall be provided on the east wall of the shop area.

A 25-kva isolation transformer shall be provided to supply 110-volt instrument power to the control room and electronic shop. Circuit panels shall be provided in both these areas.

Communication. Telephone conduit and wiring shall be run to each office, the control room, the conference room, the electronic shop, and the shop area. The location of the outlets will be specified at the time the architect-engineer's Title I drawings are being prepared.

Fire Protection. The following fire protection equipment shall be provided and suitable hangers installed at locations shown in Figure 30.

(1) One 1-1/2-in. fire hose station with $75 \mathrm{ft}$ of hose.

(2) Five 20-1b ABC Type fire extinguishers.

Heating, Ventilating, and Air Conditioning. Heating shall be provided by a forced circulation, warm air, oil-fired furnace to maintain the building air temperature at $70^{\circ} \mathrm{F}$. Heat load calculations shall be based on good engineering 
practice as recommended by The American Society of Heating and Ventilating Engineers, using the following design criteria. The outside design temperature and wind velocity shall be $-20^{\circ} \mathrm{F}$ and $8 \mathrm{mph}$ from the southwest, respectively. Approximately 7 air changes per hour should be supplied to each room. About $45 \%$ of the supply air is returned for recirculation. The excess air is to be released through roof ventilators located over the rest rooms and shop area.

The distribution system shall consist of main supply headers with branch ducts routed to each room and the shop area. Each branch duct shall be equipped with manually adjustable dampers located in the supply register. Overhead return air ducts shall be located in the hallways.

The heating and ventillating equipment shall be located in the furnace room and consists of manually adjustable, outside and return air louvers and an oil-fired, forced-air heater equipped with washable high efficiency filters. The heater fan shall be provided with a manual on-off switch to control forced ventilation of unheated air in the building during warm weather periods. Automatic heat control is to be maintained by use of a tamper-proof thermostat located in the main hallway near the hose station.

A buried 3000-gallon fuel oil storage tank shall be located adjacent to the building near the furnace room. Location of the tank, with respect to the building, shall be according to standard IDO safety practice.

An adequately sized water-cooled air conditioner shall be located in the control room as shown in Figure 30 to handle the heat load from the instruments. This shall include the instruments located in the tape system and instrumentation room. Cooling ducts shall be provided, if required, and may be carried above the ceiling or under the floor.

Sanitary Facilities and Plumbing. Adequate sanitary drains, a septic tank, and a drain field shall be provided to handle the original installation and future expansion. A service sink in the men's rest room, lavatories, water closets, floor drains, and the drinking fountain shall be connected to the sanitary drain. The cooling water out of the air conditioner may be tied into the drainage system downstrean frum the septic tank.

The water supply for the building may be obtained from the 4-in. Spert I water line located near the north end of the building. Adequately sized water piping shall be installed and connected to the equipment as required. A 2-in. line is required for the supply to the fire hose station.

A room with a cot is to be provided adjacent to the women's rest room.

Summary of Basic Utility Requirements. The following is a summary of the basic utility requirements for the PBF Control Center Building.

Electric Power

General use; 110 volt, 1 phase; as required

General use; 480 volt, 3 phase; as required

Instrument use; 110 volt, 1 phase; 25 kva (isolation) 


\section{Water}

Raw water as required for fire protection and general use

Fuel Oil

Underground 3000-gal tank for No. 2 fuel oil

\section{REACTOR FACILITY}

\subsection{Reactor Area Description}

The site selected for the PBF Reactor Building is shown in Figure 28, and a proposed plot plan of the area is shown in Figure 33. The architect-engineer shall obtain topographical and subsurface data as required to locate the PBF Reactor Building to minimize excavation cost and provide adequate drainage.

Equipment and facilities located outside the PBF Reactor Building include the acid tank, electric substation, 10,000-gallon fuel oil storage tank, sanitary septic tank, chemical waste leaching pond, process water waste leaching pond, and the cubicle exhaust stack. Equipment items such as the heat exchanger and oil storage tank shall be located as feasible to minimize cost. The chemical waste leaching pond shall be located as feasible to minimize cost and at a minimum of $100 \mathrm{ft}$ down prevailing wind from the PBF Reactor Building. The process water disposal lake shall be located as feasible to minimize cost and a minimum of 200 ft from the reactor area. Surfaced roadways shall be provided to service the outside equipment and provide vehicle parking facilities.

\subsection{Reactor Ruilding Layout}

The proposed PBF Reactor Bullding is a 79- $x$ 84-ft building divided into two wing annexes, a main reactor room, basement, and sitb-pile room as indioated in Figures 34, 35, 36, 37, 38, and 39. The figures are intended to convey only the approximate space requirements and the general layout desired. The architectengineer is to investigate the space requirements of the varinus equipment items and revise the layout as required. It is essential that experimental instrumentation be located on the opposite side of the building from electrical switchgear and motor control equipment.

The east wing of the building includes an electronic work area (No, 1). experimentai instrumentation room (No. 2), test loop control room (No. 3), and mechanical work area (No. 4). The west wing of the building includes a furnace and equipment room (No. 6), process room (No. 7), office (No. 8), and change room (No. 9). The experimental instrumentation room, test loop control room, process control room, and areas near each of the bridge tracks on the eastwest centerline of the reactor are to be interconnected with instrumentation raceways such as cable trenches or hollow subflooring. Internal doors leading to these rooms must have the capability of being sealed against the admittance of water vapor.

The main reactor room (No. 5) shall contain the reactor vessel and canal. Rails shall extend along each side of the reactor vessel and canal to support 
and guide a reactor control bridge and two working bridges. Structural members are to support the rails sufficiently to withstand a total load of 6000 . pounds carried to wheels on 4-ft centers at any location along the length of the rails, except for the sections $10 \mathrm{ft}$ on either side of the reactor east-west centerline. This $20-\mathrm{ft}$ section of rail must be capable of supporting a total load of 300,000 pounds applied either up or down and carried by wheels on $6-\mathrm{ft}$ centers. The entire area of the main reactor room is to be serviceable by a 15-ton traveling crane with a 35-ft minimum hook height. A $6-$ by $6-\mathrm{ft}$ hatch shall be constructed in the floor as a dry dock area in which the control rod drive cluster may be set for check-out and maintenance. A hatch or hatches of sufficient size shall also be constructed in the floor to allow installation and removal of the equipment located in the basement.

The basement shall include a process equipment room (No. 12), two loop cubicles (No. 10 and 13), and a waste gas blower room (No. 11). The process equipment room shall house the reactor process equipment. Escape ladders are to be provided from the process equipment room to the process control room and from the test loop equipment area to the test loop control room. Access shall also be provided to the process equipment room from the main reactor room by means of a stairway.

Loop cubicle (No. 10) consists of a shielded room of sufficient size to house the equipment shown in Figure 55. Loop cubicle (No. 13) is to be of equal size. The walls and ceiling are to be a minimum of $2 \mathrm{ft}$ thick.

The waste gas blower room consists of a shielded room of sufficient size to house the exhaust blowers shown in Figure 50.

A sub-pile room is to be provided below the reactor vessel to allow access for removal and insertion of experimental in-pile assemblies. Access to the subpile room is provided through a water tight door by way of an access pit from the process equipment room. A warm sump and strainer shall be localed below the floor of the access pit to enable the removal of highly radioactive particles from the reactor vessel. Sufficient access shall be provided to the strainer to enable its removal in a cask.

A hot waste tank is also located below the basement level in order to provide drainage for the experimental loops. Access must be provided for removal of this tank. Two-foot-thick shielding walls must separate the area occupied by the warm sump and hot waste tank from the sub-pile room and access pit.

\subsection{Reactor Building Construction Details}

It is proposed to use pumice block construction above grade and reinforced concrete construction below grade for the PBF Reactor Building. Previous experience indicates this type of construction economically fulfills the building requirements for the prevalent weather conditions. Special consideration is to be used in constructing the building to be as "dustproof" as is economically feasible.

All building construction shall conform to the Type I classification of the Uniform Building Code by Pacific Coast Building Officials' Conference as required by Section 9.02 , Part A, of the Idaho Operations Office Standard 
Health and Safety Requirements. The occupancy classification as referred to in the Uniform Building Code shall be Group F, Division 2.

Spread footings for columns, curtain walls, grade beams, etc, shall be in accordance with accepted engineering practice. Main load bearing sections such as column footings shall be carried to undisturbed soil. In the event that excavations are required below the level required for footings, concrete shall be used for fill to the required grade.

Floor slabs shall be reinforced concrete adequate to support a minimum superimposed live load as indicated in Figures 34,35, and 36. The floors shall be smoothly finished and treated to reduce dusting.

All exterior walls shall be 12-in. pumice block ui equal.

The interior walls of the furnace room shall he a minimum of 8 -in. pumice block extending to the roof.

All other interior partition walls shall be of pumice block extending to the roof. The size of the blocks shall be as necessary to provide a stable wall section.

The exterior entrance doors shall be steel doors with safety upper light. These doors shall be equipped with panic hardware inside and thumb latches for outside actuation.

The outside door on the furnace room shall have fixed louvers sized large enough to admit sufficient furnace combustion air.

The large truck doors at each end of the high bay shall be 14-ft 8 -in. wide by 16-ft 7-in. high, all metal, motor operated, overhead roll doors provided with adequate weatherstripping.

All exterior windows shall be glazed with DSB glass, bedded in putty, and secured with glazing clips. Opening-type steel frames will be used throughout the building. All windows shall have clear glass except for the change room. These windows shall have frosted glass. Exterior windows shall be sized to provide adequate lighting and ventilation.

The interior windows shall be of the non-opening type with metal frames and glazed with DSB glass. The bottom of these windows should be approximately $4 \mathrm{ft}$ friom the llour.

The roof shall be structurally supported for a minimum superimposed live load of $50 \mathrm{lb} / \mathrm{ft} 2$. The structural beams shall be covered with a non-combustible vapor barrier, two 1-in. layers of rigid asphalt impregnated fiber insulation board, and a 5-ply, built-up, asphalt impregnated, rag-felt roofing.

All of the columns used for roof support shall be of fire-resistant construction.

\subsection{Electrical Services}

3.41 General. Adequate and well designed fluorescent lighting shall be located in all areas of the building. Illumination shall conform to the provisions 
of the Illuminating Engineers Society 1961 Standards, as required by the Idaho Operations Office Standard Health and Safety Requirements. An electrical schematic drawing is shown in Figure 40.

All installations of electrical wiring and equipment shall be in accordance with the National Electrical Code as required by Section 2.11 of the Idaho Operations Office Standard Health and Safety Requirements.

A minimum of one 125-volt electrical outlet shall be provided on each wall of the office, change room, process control room, furnace and equipment room, test loop control room, experimental instrumentation room, and process equipment room. Where the walls are exceptionally long, additional outlets shall be provided at reasnnahle intervals. Outlets shall be provided on all walls of the mechanical work area and the electronics work area at 4-ft intervals. All of the outlets shall be of the 125-volt, 15-ampere, Duplex type that will take either a 3-blade NEMA grounding plug or a standard 2-blade plug.

The preferred locations for 120-volt, single-phase, ac convenience outlets are shown in Figure 41 . When located near the reactor pools or on the reactor bridge, the outlets shall be a weatherproof type. In addition to the standard convenience outlets, several outlets shall be provided which are controlled by 120 -volt, ac relays located in the motor control center. Relay control wiring of the 120-volt relays will not be included as part of this contract.

Several 480-volt, 3-phase, ac convenience outlets for welders shall be provided. These shall consist of a 60 -amp and a 30-amp receptacle at each station. In addition, one 480-volt, 3-phase, 30-amp relay controlled outlet shall be provided for motorized equipment. The relay control coil shall be 120 volt, ac.

\subsection{Interconnecting Cables and Junction Boxes}

The PBF reactor will normally be operated remotely from the control center and most of the information obtained will be recorded at the control center. Therefore, the method for transmitting information between the reactor building and the control center must receive very careful consideration. The operating personnel of the Spert facilities have investigated this problem repeatedly over the past eight years and have developed an effective system for transmitting the required information over a distance of several thousand feet. This system includes transmitting cables and terminating junction boxes. In order that the PBF may benefit from previous Spert experience with signal and data transmission systems, the detailed design of the intercabling system, including terminating junction boxes, has been completed and is presented in this section.

(1) General. In order to operate the reactor and process equipment and to record plant and reactor parameters, a great many cables must be run between the reactor building and the control building. These cables must be suitable for direct underground burial as described in Figure 33. The general philosophy to be used for all interconnecting cabling is that each cable will terminate at a permanent wall-mounted junction box in a professional manner. All shielded cables shall be terminated in such a manner as to keep the length of nonshielded conductor to an absolute minimum. Each cable and wire shall have a number assigned and attached to it. Each wire and shield shall have separate terminations in the junction box. Shields will never be made common unless specified. 
The construction contractor shall wire beyond the terminating junction boxes only on those systems for which the architect-engineer is providing the complete design. Wiring beyond the junction boxes for the remaining systems will be completed by the operating contractor at a later date.

All cables between the reactor building and the control building shall be continuous runs without splices.

A cable and wire numbering system has been developed for the PBF facility. The system gives a number to each cable and wire used for signal or control purposes and identifies (signal trench or control trench) routing and termination of the cable.

Spare numbers have been left at the end of the numbcring sequence fur use hy the architect-enginter In 1dentifying cables and wires sperifien by him.

Table XII is a list of the rernired junction boxcs, their luaklium, ynd the typo of valules terminating in them. This table also identifies the detail drawing for each junction box. The junction box installation requirements are shown in Figure 60 . The architect-engineer may make use of spare junction box locations for terminating cables specified by him as part of the plant process instrumentation, radiation monitoring instrumentation, and pressurized water loop process instrumentation. He shall, however, specify the cables to be run.

Table XIII is a list of the cables to be installed for reactor control and transient measurements. The cables for the radiation monitoring instrumentation, plant process instrumentation, and pressurized water loop process instrumentation, have not been specified. Such cables are to be specified by the architect-engineer.

(2) Cable Numbering System. The number for each cable will start with the prefix " $\mathrm{C}^{n}$ or " $\mathrm{S}$ " denoting routing between the reactor building and control building, 1e, laid in signal trench, S, or control trench, C. The next two sets of numbers will be those of the two terminating junction boxes and the last set of numbers will be a numerical list of all PBF and control cables.

Example:

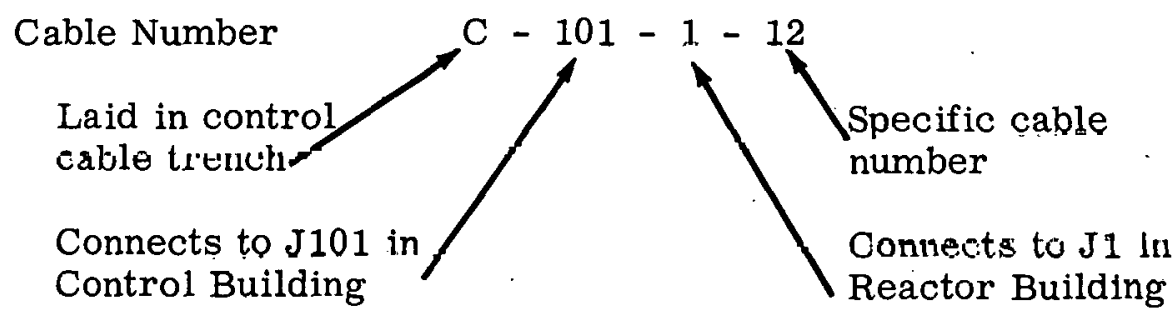

(3) Wire Numbering System. The wire numbering system will identify on each wire the cable of which it is a part. Wire numbers will run numerically starting with the number 1 for each cable. Shields will also receive a number followed by the letter "S". The shield number will always follow the wire numbers it shields. Where shielded and unshielded wires in a single cable are used the unshielded wires will be assigned the highest wire numbers in the particular series. Coaxial and triaxial shields will receive only cable numbers. 
TABLE XII

PBF JUNCTION BOX LIST

\begin{tabular}{|c|c|c|c|}
\hline $\begin{array}{l}\text { Junction } \\
\text { Box No. }\end{array}$ & Location & Box Drawing & Type Cables \\
\hline 1 & Transient instrument room & Figure 58, panel type $I$. & Signal - coaxial \\
\hline 2 & Transient instrument room & Figure 58 , panel type II & Signal - coaxial and triaxial \\
\hline 3 & Transient instrument room & Figure 58, panel type III & Signal - STP(a) \\
\hline 4 & Transient instrument room & Figure 59, panel type IV & Signal - STP \\
\hline 5 & Transient instrument room & Not installed & \\
\hline 6 & Transient instrument room & Not installed & \\
\hline 7 & Transient instrument room & Architect-Engineer to specify & Architect-Engineer to specify \\
\hline 8 & Loop process control room & Architect-Engineer to specify & Control \\
\hline 9 & Loop process control room & Architect-Engineer to specify & Signal \\
\hline 10 & Loop process control room & Figure 59, panel type III & Control - 19-conductor \\
\hline 11 & Loop process control room & Figure 58, panel type V & Signal - STP \\
\hline 12 & Plant process control room & Not installed & \\
\hline 13 & Plant process control room & Figure 59, panel type $V$ & Control - 19-conductor \\
\hline 14 & Plant process control room & Figure 58, panel type III & Signal - STP \\
\hline 15 & Plant process control room & Not install leer & . \\
\hline 16 & Spare numbers & Not installed & $\therefore$ \\
\hline 17 & Spare numbers & Not installed & \\
\hline 18 & Spare numbers & Not installed & \\
\hline 19 & Spare numbers & Not installed & \\
\hline 20 & Spare numbers & Not installed & \\
\hline 101 & Tape room & Figure 58 , panel type I & Signal - coaxial \\
\hline 102 & Tape room & Figure 58, panel type II. & Signal - coaxial and triaxial \\
\hline 103 & Tape room & Figure 58, panel type III & Signal - STP \\
\hline 104 & Tape room & Figure 59, panel type VI & Signal - STP coaxial and triaxial \\
\hline 105 & Control room & F'igure 59 , panel type $\mathrm{V}$ & Control = 19-conductor \\
\hline 106 & Control room & Figure 59, panel type $\mathrm{V}$ & Control - 19-conductor \\
\hline 107 & Control room & Figure 58, panel type III & Signal - STP \\
\hline
\end{tabular}

Examples:

$14-1$

$14-2$

Cable number $\begin{aligned} & \text { Specific } \\ & \text { wire } \\ & \text { number }\end{aligned} \quad \begin{aligned} & \text { Indicates shield } \\ & \text { for wires No. }\end{aligned}$

(4) Plant and pressurized water loop process control cabling. All cabling required by the plant and pressurized water loop process control equipment shall be specified by the architect-engineer. It is, however, requested that the same type of cables described in the previous section be used, if suitable. The numbering system and general philosophy of termination described previously shall be used by the architect-engineer in designing the process control and signal cabling. 
TABLE XIII

CABLE SYSTEMS SPECIFICATIONS

\begin{tabular}{|c|c|c|c|c|c|c|}
\hline & Terminating $J$ & tio & on Boxes & & & \\
\hline Cabl, , No. & $\begin{array}{r}\text { Control } \\
\text { Building }\end{array}$ & & $\begin{array}{l}\text { Reactor } \\
\text { Building }\end{array}$ & Type Cable & $\begin{array}{c}\text { Type Terminations } \\
\text { Io be Used }\end{array}$ & \\
\hline $\begin{array}{l}S-101-1-1 \\
\text { thru } \\
S-101-1-80\end{array}$ & J101 & & JI & Coaxial RG $8 \mathrm{~A} / \mathrm{U}$ & See footnote $(a)$ & \\
\hline $\begin{array}{c}S-102-2-81 \\
\text { thru } \\
S-102-2-90\end{array}$ & $\mathrm{~J} 102$ & & J2 & Coaxial RG $8 \mathrm{~A} / \mathrm{U}$ & Coaxial (b) & \\
\hline $\left.\begin{array}{c}s-104-2-91 \\
\operatorname{thru} \\
3-104-2-1000\end{array}\right\}$ & $\mathrm{J} 104$ & & 32 & Coaxial RG $8 \dot{A} / U$ & (Inaxiail (b) & \\
\hline $\begin{array}{l}S-104-2-101 \\
\text { thru. } \\
\text { S.10h } 2105\end{array}$ & $\mathrm{~J} 104$ & & T? & $\begin{array}{l}\text { Triaxial amphenol 2l-583 } \\
5 ? \mathrm{shm}\end{array}$ & Triarial $(0)$ & \\
\hline $\begin{array}{l}s-102-2-106 \\
\text { thru } \\
\text { s-102-2-110 }\end{array}$ & $\mathrm{J} 102$ & & $\mathrm{~J} 2$ & $\begin{array}{l}\text { Triaxial amphenol, } 21-583 \\
52 \mathrm{olm}\end{array}$ & $\operatorname{Triaxial}(c)$ & \\
\hline $\begin{array}{c}S-102-2-111 \\
\text { thru } \\
s-102-2-115\end{array}$ & $\mathrm{~J} 102$ & & $\mathrm{~J} 2$ & $\begin{array}{l}\text { Triaxial amphenol } 21-529 \\
75 \text { ohm }\end{array}$ & Triaxial (c) & \\
\hline $\left.\begin{array}{c}\mathrm{s}-104-2-116 \\
\operatorname{thru} \\
\mathrm{s}-104-2-120\end{array}\right\}$ & $\mathrm{J} 104$ & & J2 & $\begin{array}{l}\text { Triaxial amphenol 21-529 } \\
75 \text { ohm }\end{array}$ & $\operatorname{Triaxial}(c)$ & \\
\hline $5-103-3-121$ & JIO3 & & J3 & STP - 19 pair no. $16(d)$ & $\begin{array}{l}\text { Terminal strip cinch } \\
\text { Jones Beries } 140\end{array}$ & - \\
\hline$s-103-3-122$ & J103 & & J3 & STP - 19 pair no. $16(d)$ & $\begin{array}{l}\text { Terminal strip cinch } \\
\text { Jones series } 140\end{array}$ & - \\
\hline $5-104-3-123$ & $\mathrm{~J} 104$ & & $\sqrt{3}$ & STP - 1,9 pair no. $16(d)$ & $\begin{array}{l}\text { Terminal strip cinch } \\
\text { Jones ocries } 140\end{array}$ & - \\
\hline$s-104-3-124$ & $\mathrm{~J} 104$ & & $\mathrm{J3}$ & STP - 19 pair no. $16(\mathrm{~d})$ & $\begin{array}{l}\text { Terminal strip cinch } \\
\text { Jones series } 140\end{array}$ & - \\
\hline S-107-10-125 & J107 & & JII & STP - 19 pair no. $16(d)$ & $\begin{array}{l}\text { Terminal strip cinch } \\
\text { Jones series } 140\end{array}$ & - \\
\hline$S-107-10-126$ & $\mathrm{J107}$ & & $\mathrm{Jll}$ & STP - 19 pair no. $16(d)$ & $\begin{array}{l}\text { Terminal strip cinch } \\
\text { Jones series } 140\end{array}$ & $\therefore$ \\
\hline s-103-104-127 & $\mathrm{J} 103$ to $\mathrm{JlO} 4$ & & & STP - 19 pair no. 16(d) & $\begin{array}{l}\text { Terminal strip cinch } \\
\text { Jones series } 140\end{array}$ & - \\
\hline $\left.\begin{array}{c}5-.102-104-128 \\
\text { thru } \\
s-102-104-132\end{array}\right\}$ & $\mathrm{Jl}, 0$ ? & & & Coaxial RO $58 \mathrm{c} / \mathrm{U}$ & Coaxial $(e)$ & \\
\hline $\left.\begin{array}{c}s-102-104-133 \\
\text { thru } \\
s-102-104-137\end{array}\right\}$ & $\mathrm{J} 102$ to $\mathrm{JlO} 4$ & & & Coaxial RG $59 \mathrm{~A} / \mathrm{U}$ & Coaxial $(e)$ & \\
\hline $5-3-14-138$ & & J3 & 3 to $\mathrm{J} 4$ & STP - 19 pair no. 16 & $\begin{array}{l}\text { Terminal strip cjuch } \\
\text { Jones series } 140(d)\end{array}$ & - \\
\hline$S-3-10-139$ & & $\mathrm{~J} 3$ & 3 to $J 11$ & STP - 19 pair no. 16 & $\begin{array}{l}\text { Terminal strip cinch } \\
\text { Jones series } 140(d)\end{array}$ & - \\
\hline $\begin{array}{c}-140 \\
\text { thru } \\
\text { S- } \quad-149\end{array}$ & & . & -5 & $\begin{array}{l}\text { pare signal cable numbers } \\
\text { continued) }\end{array}$ & 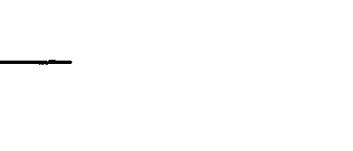 & \\
\hline
\end{tabular}


TABLE XIII (Continued)

Terminating Junction Boxes

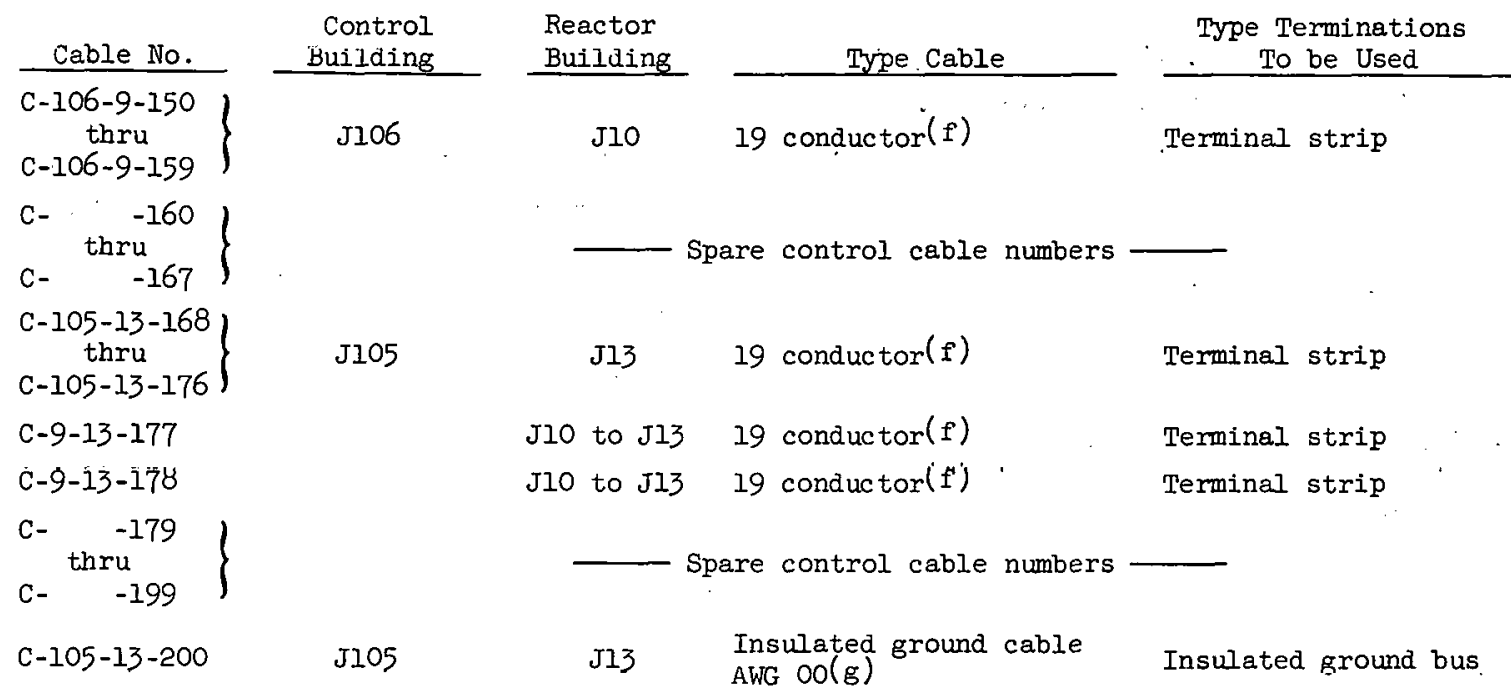

(a) Cables to be teminated on lerminal slrips ds indicated in Figure 50, panel ty'je I.

(b) Cables to be terminated with connector UG $290 \mathrm{~A} / \mathrm{U}$ (or approved substitute) mounted on insulating board (See Figure 58, panel type 11 ).

(c) Cables to be terminated with triaxial panel jack or IPC connector: 53125 mounted on insulating board (See Figure 58, panel types I and II).

(d) Multiple pair shielded (STP) - 19 individually shielded and insulated twisted pair. Each wire to be AWG 16 stranded. Insulation between conductors or conductor to shield to be greater than 109 ohms per thousand feet. Each pair to have drain wire. Cable to be overall shielded and insulated for direct burial.

(e) Cablcs to be tcrminated as indicated in Figure 58, panel types I and II, with coaxial panel. jarks.

(f) Nineteen conductor overall shielded cable. Each conductor to be AWG 16 stranded with insulation color coded and rated at 600 volts. Outer insulation suitable for direct burial.

(8) Ground cable to be AWG 00 stranded with overall insulation suitable for direct burial.

The architect-engineer shall specify in which cable trench the process cables shall run (signal or control). However, in no case may cables carrying alternating current be laid in the signal cable trench.

\subsection{Special Power Requuirements.}

(1) Experimental instrumentation room (No. 2). A special power supply is required for electronic instruments which will be installed in Room 2 of the reactor building following acceptance of the facility. For this purpose, 120-volt, ac, single-phase, power shall be supplied to a breaker panel in the room by means of a transformer directly connected to the 13.8-kv line. The breaker panel shall contain twelve amp breakers. Power from each breaker shall be run to twistlock convenience outlets located above the intended instrument rack locations as indicated in Figure 41. This power shall be switched to emergency power upon failure of the 13.8-kv line (area plot plan, Figure 33).

(2) Reactor control power. A source of power is required at the reactor building for operating the reactor control rod drives and other equipment. A 480volt, 3-phase, 100-amp branch circuit terminating in a breaker shall be included in the process control room (No. 7) exclusively for this purpose. This circuit 
must be switched to emergency power upon power outage (see electrical schematic drawing, Figure 40).

3.44 Controlled Convenience Outlets. Individually controlled convenience outlets are required to which the power is individually controlled by means of relays. Several outlets of this type for obtaining 120-volt, single-phase ac power, and 480-volt, 30-amp, 3-phase power shall be located as shown in Figures 41 and 42 . The relays for controlling the power to these outlets shall have 120-volt, ac control coils and shall be installed in the motor control center (Room No. 7). Relay control wiring will not be accomplished as part of this contract.

3.45 Warning Lights and Horns. Two warning horns, one inside the reactor building and one outside the reactor building, located as shown in Figure 41. are included in the design. Power to the horns shall be supplied by means of 120 -volt ac relays located in the motor control center (Room No. 7). Relay control wiring will not be accomplished as part of this contrast. Power to the horns must be supplied through effective filters to stop high frequency noise from feeding back into the power line. The specifications for the horns are as follows:

Inside Horn: Faraday Industrial, No. 133L, $120 \mathrm{v}$, ac with loop protection or approved equal.

Exterior Horn: Faraday Industrial, weatherproof, No. 136, $120 \mathrm{v}$, ac or approved equal.

Bix flashing red lights located in and about the reactor building as shown in Figures 41 and 42 shall also be included in the design. Wiring shall be run from the lights to a flasher unit. The flasher unit shall be mounted in the motor control center (Room No. 7). Cinntrol wiring for the flasher will not be included as part of this contract. This system shall have a filter to stop high frequency interference in other. systems. The specifications for the lights and flasher units are as follows:

Lights: Crouse Hinds - Vapor Light Industrial Lighting Fixture, bracket type VGR 216 , form 200 with red globe (VO 205) and guard (V 912), or approved equal.

Flasher: Flasher unit, Reco silver contact type, one cycle per second, Catalog No. LDBS-4 with cabinet for wall mounting (GE Supply Catring No. 102 WP-p.811), or approved equal.

3.46 Scram Switches. Eight outlet boxes containing face mounted switches are included in the design and located as shown in Figures 41 and 42 . Wiring shall be run from the switches to one side of a terminal strip located in the motor control center (Room No. 7). The specifications for the outlet boxes and switches are as follows:

Boxes: Outlet box, $3 \times 3 \times 3$ in. minimum, sized to accommodate switches.

Switches: Allen-Bradley, push button switch, mushroom head, red button, one normally closed and one normally open 
circuit, w/o name plate, type DGA (Bulletin 8007), or approved equal.

3.47 Radiation Monitoring Systems. Three systems for radiation monitoring are included in the design as follows: (a) a constant air monitoring system, (b) a gamma radiation monitoring system, and (c) two portal monitoring systems for detecting radioactive contamination transported by personnel.

(1) Constant air monitors. The three constant air monitors are located as shown in Figures 41 and 42 and are portable radioactive air monitors of commercial design similar to Nuclear Measurements Corporation, Model Am-2, or approved equal. Each unit is a complete installed system supplied with the necessary equipment to accomplish the following objectives: (a) provide an integrally mounted recorder by means of which the air activity may be read directly, (b) provide alarm circuits which give an audible signal in the event of high air activity, and (c) provide a remotely located recorder on the control center building process panel from which the air activity may be read directly. The constant air monitor located on the main floor provides the necessary signal from high radiation levels to automatically close an air damper in the cold air return to the furnace from the main reactor room. The fans and blowers in the heating and ventilating system (Figure 47) are automatically shut down upon coincident high radiation level signals from the main floor monitor and one basement monitor.

(2) Gamma radiation monitoring system. The gamma radiation monitoring system is a complete system consiting of seven sensing units with built-in calibration sources, a basic control and readout unit, and a remote readout station. The seven sensing units (chambers) are located as shown in Figures 41 and 42 . The basic control and readout unit is located in the experimental instrumentation room (Room No. 2) of the reactor building, and the remote readout station is located on the process control panel at the PBF control center building.

\section{General Specifications.}

Basic system: Tracerlab remote area monitoring system or approved equal. The basic system provides a seven-channel gamma sensing unit which may be located up to $200 \mathrm{ft}$ from a basic control unit consisting of a power supply and the necessary cabinet space for the seven-channel control unit. There is also a seven-channel remote readout station unit to be located approximately $3000 \mathrm{ft}$ from the basic control unit. The 3000-ft cable assembly between the basic control unit and the remote-readout unit will be supplied by the contractor. This cable will consist of a 19-conductor, overall shielded cable with No. 16 AWG conductors. Provision should be made for adding three additional monitoring chambers and associated readout equipment at a future time. All cabling and necessary couplings between the sensing units and the oontrol unit are to be specified by the vendor.

Materials and workmanship. The equipment supplied must be new and of first-class design. Construction, workmanship, and materials must be of the best quality, free from any defect that would render the equipment inoperative or inaccurate.

Adjustments. The design of the remote area monitoring system shall be such as to make all parts readily accessible for ordinary adjustments, repair, and cleaning. 
Instruction and operation. The vendor shall furnish operator's instruction manuals and.schematics in duplicate for the proper installation, adjustments, and operation of the system. This manual shall include a complete replacement parts list.

\section{Sensing Unit.}

Sensitivity. The sensing units shall be halogen quenched GM-tubes sensitive to gamma radiation and capable of operation in fields from $0.1 \mathrm{mr} / \mathrm{hr}$ to $100 \mathrm{r} / \mathrm{hr}$. The sensing units shall be gamma energy independent within plus or minus $10 \%$ for gamma ray energies between $80 \mathrm{kev}$ and $1.2 \mathrm{Mev}$.

The probe may be subjected to high fields of radiation for short intervals of time. The instrument indicator must be able to rise above fill scale and to a maximum of $2 \times 10^{5} \mathrm{r} / \mathrm{hr}$ for short pcriods of time. When the probe is returned to fields within its range, the calibration must still be correct.

Ambient onvironment. The selislng units shail be of waterprof design and capable of operation under ambient ronditions of 0 to $150^{\circ} \mathrm{F}$, up to $95 \%$ humidity, and at an altitude of approximately $5000 \mathrm{ft}$ above sea level.

Calibration. Each sensing unit shall include a self-contained, remotely operated calibration source. Calibration must be indcpendent of cable length.

Cabling. The vendor shall supply the cable assemblies for use between sensing units and the basic control unit. These cables shall be supplied with connectors at both the sensing unit and the basic control unit. The comnector's at the sensing units shall be splash proof. The cables shall bc supplied in $200-\mathrm{ft}$ lengths.

Alarms. There shall be a light and an audible bell at each probe,

Basic Control Unlt.

General: Tho basic control unit shall Include a 115-volt, 60-cycle power supply to operate the complete system, meters indicating the dose rate at each sensing chamber, controls for the calibration sources, calibration adjustment for each channel, audible bell alarm, recorder output for each channel, and a multipoint recorder having one point for each channel. The basic control shall be capable of being rack mounted in a standard 19-in. relay rack.

Response. The system shall have a speed of response sufficient to provide an indication change from initinl dnge rate to $90 \%$ of the now dosc rate within 8 sec or less.

Indicating meters. The seven meters for indicating the dose rate at the sensing chamber's shall have decade logarithmic scales, which shall be designated from $0.1 \mathrm{mr} / \mathrm{hr}$ to $100 \mathrm{r} / \mathrm{hr}$. Thcsc meters shall have adjustable set points so that the alarm can be set to ring at any point on the mcter scale.

Calibration. Each channel shall have separate calibration adjustments and remote control of the calibration source. Each channel shall be calibrated by the vendor over its appropriate range to within $\pm 20 \%$ of the true dose rate. 
Ambient environment. The control system shall be capable of continuous service operation in ambient temperatures between 50 and $110^{\circ} \mathrm{F}$.

Recorder provisions. Each channel shall have an output of at least $10 \mathrm{mv}$ which can be used as an input to a recorder. A multipoint recorder having one point for each channel shall be provided.

Remote readout unit. The remote readout unit shall consist of seven meters with decade logarithmic scales. All of these meters shall indicate dosage rates of $0.1 \mathrm{mr} / \mathrm{hr}$ to $100 \mathrm{r} / \mathrm{hr}$. These meters shall provide readings within $\pm 20 \%$ of the true dose rate at the sensing units. Each of the meters shall provide simultaneous indication with the meters at the control unit, and the corresponding meters must agree to within the nominal accuracy of the meters with the $3000 \mathrm{ft}$ of cable described above included in the system. The seven readout meters shall be supplied on a 19-in. panel for rack mounting. This panel shall have a height of $3-1 / 2$ in.

(3) Portal radiation monitors. Two independent portal radiation monitors shall be installed on the two doorways indicated in Figure 41. The equipment to be supplied shall be quintector units complete with the necessary associated items, such as manufactured by Eberline Instrument Division or approved equal. The unit shall be constructed for installation on door frames for the purpose of detecting radioactive contamination on personnel or articles passing through these exit doors. Each monitor shall be equipped with an audible alarm actuated when radioactive clothing, tools, etc, are passed through the doorways.

(4) Health Physics Emergency Generator. The Health Physics emergency generator will provide power for continuous radiation monitoring for the protection of personnel working in the reactor area in the event of a commercial power failure. This generator will consist of a small compact power generator that will automatically start on loss of commercial power. The evacuation alarm located at the reactor building also will be connected to this emergency power source.

3.48 Intercommunications System. The architect-engineer shall include in the design the necessary cable, station boxes, etc, which are part of a portable intercommunications system to be completed by the operating contractor following acceptance of the facility. The design shall provide for installing the following: (a) one central station terminal box, (b) eleven intercom station boxes, and (c) conduit and communications cable between the central station terminal box and the eleven intercom station boxes. The communications cable will not be connected to the additional portable equipment required to complete the system either in the central station box or the individual intercom boxes.

The central station terminal box and the eleven intercom station boxes shall be located as shown in Figures 41 and 42 . One cable consisting of six shielded pairs shall be pulled from the central station terminal box to each of the intercom stations. This cable shall be run in conduit installed exclusively for this use; ie, no other wiring will be run in these same conduits.

The specifications for equipment are as follows: 
(1) Central Station Terminal Box:

(2) Intercom Station Boxes:

(3) Intercom Cable:
Square " $D$ " circuit breaker box No. MH-41 with front No. DF$142 \mathrm{~F}$, or approved equal.

Appleton Unilet Box, Type FDCDeep No: 16636 with blank metal vapor-tight cover and gasket No. 7986, or approved equal.

Intercom cable, Beldon No. 8768,6 individual shield and insulated pairs.

\subsection{Plant Process Instrumentation}

Since remote operation of the nuclear reactor from the central control area is essential, it is required that the plant instrumentation be designed to permit operation of certain plant equipment and control of certain process parameters from the PBF control building. The instrumentation designed by the architectengineer shall provide for the remote control of process parameters and the remote operation of plant equipment as follows: (a) control of the reactor pool temperature (heat exchanger outlet) from 70 to $90^{\circ} \mathrm{F}$, (b) control of the reactor pool drain, and (c) control. of the reactor pool water inlet flow rate (that is, control of the pool water height).

Both the pool water height and temperature distribution influence reactor behavior, and it is therefore necessary to record or indicate both parameters at the control center. The recording or indicating of other information which is considered by the architect-engineer to be necessary for the safe remote operation of plant equipment shall also be included.

It is not considered essential that the pool purging operation or pool cleanup be âccomplished at the same time that reactor operation is in progress; therefore, control of the equipment associated with these functions is required only from the reactor building. The architect-engineer shall select the necessary instrumentation to permit normal operation of this equipment based on this criterion.

The deionized water system shall be designed for manual operation and regeneration. The minimum information considered necessary for proper operation and quality control is effluent conductivity, effluent pH, effluent flow rate, and the capacity remaining in each bed. Since it is necessary that. the quality of the water in the pool and canal be closely controlled, it is proposed that the $\mathrm{pH}$ and conductivity indicators used to monitor the deionizer effluent also be used to check the quality of the water in the reactor pool and canal by providing pH and conductivity calls in all three places and a three-point selector switch.

The method of control of the heat exchanger exit water temperature shown in Figure 43 is schematic only. It is recommended that the architect-engineer investigate other methods of control.

The architect-engineer shall include in his instrument specifications a thorough instrument check-out procedure to be followed to insure that all 
instruments are in proper calibration and in operating condition upon completion of plant construction.

\subsection{Mechanical and Process Equipment}

3.61 General. The mechanical and process equipment to be installed in the reactor building shall be sized by the architect-engineer according to best engineering practices. In all cases where feasible, each item shall be of a standard manufacturer's design and all identical items shall be of the same make and model to simplify maintenance and spare parts stores. The manufacturer of each piece of equipment will furnish certified prints of the equipment, operating manuals, spare parts lists, and maintenance manuals. The architect-engineer will furnish a loose leaf type Plant Operations Manual which shall be in sufficient detail to assure safe operating procedures. The equipment shall be located so that acess for maintenance is provided. For those pieces of equipment which may require changeout, a method of removing the piece of equipment and replacing it with the new equipment shall be provided.

3.62 Crane. The overhead traveling crane design prepared by the architectengineer shall provide for the following operating requirements:

(1) Service requirements

Capacity - 15 ton

Span - Approximately $36 \mathrm{ft}$

Hook lift - $35 \mathrm{ft}$ (min)

Duty - the crane shall raise the designed load the full hook height at lowest speed without stopping.

Speeds - Two speeds at full load capacity as follows:

Hoist - 6 and $25 \mathrm{ft} / \mathrm{min}$

Bridge - 20 and $60 \mathrm{ft} / \mathrm{min}$

Trolley -20 and $60 \mathrm{ft} / \mathrm{min}$

(2) Crane controls. The crane shall be furnished with two plug-in control stations located on opposite sides of the reactor pool. A single push-button type pendant controller with a $45-\mathrm{ft}$ extension cable shall be supplied. The pendant cable shall be equipped with suitable quick disconnect plugs for rapid connection to either of the two plug-in stations for operation of the crane.

3.63 Water Supply, Usage, and Disposal (Figure 44). The chlorinated raw water for the $\mathrm{PBF}$ shall be supplied by a new 8-in. line to be run from the raw water distribution pumps in the Spert Control Center Area to the PBF. This line will furnish raw water for the fire protection system, domestic and sanitary uses, air conditioner cooling, air compressor cooling, reactor primary heat exchanger secondary cooling, reactor emergency fill, and influent for the demineralizer system, the steam plant, and the experimental loops. 
The secondary cooling water for the main heat exchanger is pumped from a small surge tank through the exchanger to waste. This precludes any possible contamination of the raw water supply. All other connections between the raw water supply and possible contaminated water are mechanically isolated to prevent contamination of the raw water supply.

A demineralized water system serves the reactor, canal, experimental loops, and the steam plant. Water from the mixed bed demineralizing units is stored, then distributed for use as needed from a pump.header. Regeneration waste from the demineralizer flows directly to the corrosive waste leaching pond.

Raw water from the Spert fire protection system is available at a fire hydrant and hose house outside the reactor building. Hose stations are located inside the building.

3.64 Makeup Demineralizer (Figure 45). Demineralized water with a specific conductivity of less than two micrnmhns is produced by flowing raw water down through two 3-ft-diameter, plastic lined, 100-psig-design, mixed bed demineralizers. The system is designed for either continuous (alternating regeneration) or parallel operation or for continuous operation by alternating regeneration of the units. Each 50-gpm unit will run approximately $5 \mathrm{hr}(15,000$ gal) or longer per regeneration and require $4 \mathrm{hr}$ for the manual regeneration process. Water from the demineralizers is piped to an insulated type 304 stainless steel, 10,000-gal storage tank located outside the reactor building. The stored water temperature is maintained at $60^{\circ} \mathrm{F}$ by two temperature controlled 3-kw electric heaters. The tank is equipped with an overflow, a water level indicator, and high- and low-level alarms. The demineralized water service pump $(75 \mathrm{gpm}$, $230 \mathrm{ft}$ TDH, $5 \mathrm{hp}$ ) supplies demineralized water at $100 \mathrm{psig}$ to the stainless steel plant demineralized water system.

Connentrated sulphuric acid for regeneration is supplied from an existitig 500-gal portable carbon steel tank which is filled from the MTR acid supply. The acid is transferred to a mixing drum by pressurizing the tank with low pressure instrument air when necessary. Flake caustic is mixed with demineralized water to provide the caustic dose for regeneration. Acid and caustic regeneration doses are mixed in separate open-top 55-gal. plastic lined drums and diluted through separate eductor valves during regeneration of the beds.

\subsection{Reactor Process System.}

(1) Primary Loop. The reactor primary system provides the necessary facilities to remove the energy generated during the power burst as well as providing flow velocities through the core sufficient to prevent excessive boiling after a maximum power burst. The flow diagram for the reactor primary system is shown in Figure 43. Primary cooling system operating conditions are listed in Table XIV.

The primary pumps draw reactor water from the bottom of the reactor vessel at a point outside of the flow skirt. The pumps discharge up to $15,000 \mathrm{gpm}$ through manually operated flow control valves to a heat exchanger. The positions of the control valves are set prior to start-up. Since only steady flow conditions are required, only minor adjustments of these valves should be required during operation. Water flow is measured between 500 and $15,000 \mathrm{gpm}$ by conventional meter runs. The reactor inlet coolant temperature is controlled by a temperature recorder-controller which automatically positions two control valves. The position 
Maximum burst energy

Heat cycle for temperature stabilization after maximum energy burst

Reactor coolant stabilization temperature

Reactor inlet temperature

Reactor exit temperature

Measurable reactor flow rate

Number of primary coolant pumps
$3000 \mathrm{Mw}-\mathrm{sec}$

$1 \mathrm{hr}$

$86^{\circ} \mathrm{F}$

83 to $93^{\circ} \mathrm{F}$

88 to $98^{\circ} \mathrm{F}$

500 to $15,000 \mathrm{gpm}$

3

of the control valves determines the fraction of primary flow which passes through the heat exchanger. The water is then returned to the bottom of the reactor at a point inside the flow skirt. Flow through the reactor core is upward. All primary piping is series 300 stainless steel.

The reactor temperature is increased to $86^{\circ} \mathrm{F}$ prior to a power burst by use of pump heat and the line heaters. The reactor temperature is maintained at $86^{\circ} \mathrm{F}$ prior to a power burst, and the heat from the power burst is removed by the primary heat exchanger. The maximum power burst will add about 3000 $\mathrm{Mw}-\mathrm{sec}\left(2.8 \times 10^{6} \mathrm{Btu}\right)$ of energy to the system. (For design purposes, this number has been taken $50 \%$ higher than that obtained from physics calculations.) This energy is removable from the system within one hour. The architectengineer will prepare a study of other ways of maintaining the reactor temperature at $86^{\circ} \mathrm{F}$ and arrive at the most economical design.

(2) Codes and Specifications. The reactor process system piping is to be designed, inspected, and tested according to the latest revision of the ASA piping code. The system vessels and heat exchangers are to be designed, constructed, and tested according to the latest revision of the ASME Pressure Vessel Code. Code stamping is required.

All welding in the reactor process system shall be in accordance with Phillips Petroleum Co. Specification PPCS-243, entitled "Manual Welding of Austenitic Stainless Steel in Nuclear Reactor Experiment Systems". All piping welds shall be inspected in accordance with Phillips Petroleum Co. Specification PPCS-244, entitled "Acceptance and Quality Control Standard for Manual Welding of Austenitic 
Stainless Steel in Nuclear Reactor Systems". All piping radiography shall be done in accordance with Phillips Petroleum Co. Specification PPCS-253, entitled "Radiographic Technique Requirements for the Inspection of Piping". All welder operators utilized in the welding of the process equipment and piping shall be qualified in accordance with Phillips Petroleum Co. Specification PPCS-245, entitled "Welders Qualification Procedure for Austenitic Stainless Steel". The required number of copies of the above Phillips Petroleum Co. specifications will be furnished to prospective architect-engineers upon request.

(3) Heat Exchanger. The proposed primary heat exchanger is a single-pass counterflow heat exchanger designed for a maximum heat load of $3.9 \times 10^{6}$ $\mathrm{Btu} / \mathrm{hr}$. A maximum of $500 \mathrm{gpm}$ raw water is to be used for the secondary cooling water. However, other methods of cooling are to be studied by the architectengineer in order to determine the most economical design. This study should include the possibility of designing one system to take care of hoth the reactor and the pressurized water loop cooling requirements. All metal parts of the primary heat exchanger in contact with the primary water are stainless steel.

(4) Primary Pumps. The three primary pumps are single-stage, 5000-gpm, 100-ft T $\overline{D H}$, deep-well-type, centrifugal pumps driven by 150-hp, 2400-v, 3-phase motors. 'The pumps shall be located so that flow can be established when the reactor water is at any level between one foot above the core and the scum drain level.

3.66 Reactor and Canal Fill, Drain, and Cleanup Systems. Separate 2-in. lines from the demineralized water system are used for filling the reactor and canal. The 1-1/2-in. drain lines are routed from the reactor and canal to a common header and then to the warm sump.

A continuous purge stream is added to the reactor and canal. The reactor purge is estimated to be $15 \mathrm{gpm}$. The canal purge is estimated at $7 \mathrm{gpm}$. The purge water is removed through scum drains. Four drains, one in each quadrant, are located in the reactor. Two scum drains are located in the canal.

In the cleanup systems for the reactor and the canal, continuous side streams are pumped through cartridge filters. A $15-\mathrm{gpm}, 100-\mathrm{ft}$ TDH, 1/2-hp pump is provided for each system.

3.67 Steam Plant (Figure 46). One 2000-lb/hr heating boiler is located in the furnace and utility room. The boiler supplies 15-psig steam to the heating coils. The boiler is a package unit, equipped with the conventional safeties and controls, and is fired with No. 2 diesel nil. Demineralized water is supplied for makeup. A potable water line for makeup is also provided for emergencies.

Auxiliary equipment includes a 100-gal condensate tank and two boiler feed pumps (each $4.5 \mathrm{gpm}, 125 \mathrm{ft} \mathrm{TDH}, 1 / 2 \mathrm{hp}$ ). A chemical addition station is also provided to treat the boiler water with phosphates for $\mathrm{pH}$ control and sodium sulfite for residual oxygen removal.

A fuel oil transfer pump (0.5 gpm, $200 \mathrm{ft} \mathrm{TDH,} \mathrm{1/2} \mathrm{hp)} \mathrm{and} \mathrm{a} \mathrm{duplex} \mathrm{fuel}$ oil strainer are located in the furnace and utility room. This system supplies clean oil to the boiler from the 10,000-gal fuel oil storage tank buried outside 
the building. This storage volume is sufficient to fire the boiler at a maximum rate for approximately 30 days. Oil is trucked to the storage tank.

3.68 Heating and Ventilating System (Figure 47). The heating and ventilating system is designed to provide $100 \%$ fresh air at $50^{\circ} \mathrm{F}$ to the reactor building when needed, eg, during experimental runs. A damper, capable of being remotely controlled from the control room, can be opened during other times to provide for recirculation of part of the reactor room air. All fresh air passes through flow sensitive louvers and a filter, then over a finned preheat coil into a supply plenum. The air temperature in the plenum is controlled by automatically positioned air deflectors in front of the preheat coil. The preheat coil has a constant supply of $15-1 b$ steam with the flow regulated by a standard trap. A pressure switch on the preheat coil trips relays to stop the three supply blowers on low steam pressure. Remote thermostats which actuate steam control valves to the respective tempering coils on the three discharge ducts from the preheated supply plenum as provided in each wing and the reactor room.

The reactor room is provided with a separate heating and ventilating supply system discharging about four air changes per hour to the reactor room which is maintained at $70^{\circ} \mathrm{F}$. This air is exhausted to the atmosphere by two electric exhaust fans located on the reactor room roof. The roof exhaust fans and supply blower are wired to constant air monitors located on the reactor building main floor and basement. The fans and blower will shut off after the main floor monitor and one basement monitor have alarmed, allowing the flow sensitive dampers to close, and forcing all air to be discharged through the waste gas system. Remote control of the fans and blower, overriding the monitor alarms, is provided in the control rooms.

Separate heating and ventilating units furnish about eight air changes per hour to each wing of the reactor building, also maintained at $70^{\circ} \mathrm{F}$. The distribution system consists of main ducts from which branch ducts are routed to each room. Manual dampers are provided on each branch duct. Air flows from the wing rooms into the reactor room. This air is then routed to the process equipment room, experimental cubicles, and sub-pile room for exhausting through the waste gas system.

In addition to the normal start-stop controls for the three blowers, emergency start-stop switches are located in the reactor control room.

A $7-1 / 2-h p$ refrigerated air conditioner is provided in the loop instrumentation room.

3.69 Plant and Instrument Air System (Figure 48). One 60-scfm, singlestage, oil-less, reciprocating air compressor delivers air at 150 psig to a $350-\mathrm{ft}^{3}$ receiver. The one-inch plant air header is supplied directly from the receiver through a motor valve which automatically closes if the receiver pressure drops to 100 psig. An adequate air supply is thus preserved in the receiver at all times to operate instruments and motor valves. Plant air, on leaving the receiver, is reduced to $100 \mathrm{psig}$ by means of a pressure-controlled motor valve. The instrument air is dried by a dual-tower, electrically regenerated dryer. The instrument air, after leaving the dryers, is reduced to $50 \mathrm{psig}$ by means of a pressure-controlled motor valve and routed via a one-inch air header throughout the building. Instrument air is further reduced to $20 \mathrm{psig}$ by small locally mounted reducing valves. 
3.70 Liquid Waste Disposal Systems (Figure 49). The sanitary waste disposal system is sized for approximately 10 persons, and consists of a conventional septic tank and leaching pit system with adequate drainage.

The acid and caustic regeneration wastes from the demineralizer flow directly to the corrosive waste leaching pond in a separate corrosion-resistant line.

Spent cooling water from the air compressor, air conditioner, and primary heat exchanger flows (approximately $600 \mathrm{gpm}$ ) directly to the fenced leaching pond approximately 40,000 . square feet in area. Spent cooling water from the primary heat exchanger can be alternately routed to the warm sump or the hot waste tank.

The reactor and canal main and scum drains and the building floor drains all flow by gravity to the warm sump. The experimental loops can also be drained to the warm sump. All water entering the warm sump passes through a strainer. A sump pump ( $300 \mathrm{gpm}, 70 \mathrm{ft} \mathrm{TDH}, 7.5 \mathrm{hp}$ ) pumps the waste to the leaching pond. Continuous flow proportional sampling is provided for the monitoring of the radiation level of the waste effluent stream. Contents of the warm sump can be pumped to the hot waste tank if necessary.

The experimental loops can be drained through a strainer into the 1000-gal stainless steel hot was te tank. A sump pump (10 gpm, $70 \mathrm{ft} \mathrm{TDH}, 1 / 2 \mathrm{hp})$ transfers the hot waste into an existing shielded tank truck for transport and final disposal at ICPP. Contents of the hot waste tank can be circulated for mixing and sampling prior to disposal. The hot waste tank design will include provision for periodic sampling of the crud from the bottom of the tank.

3.71 Waste Gas System (Figure 50). All air from the proness pit, experiment cubicles, and sub-pile room is routed to the waste gas blower room where it is filtered by a roughing filter and a high-eftisiensy filter (minimum DOP efficiency of $99.97 \%$ at 0.3 micron). It is then exhausted to atmosphere by a blower (500 cfm, $10 \mathrm{hp})$ through an 80-ft-high, 12-in.-diameter, carbon steel stack. The vent line from the hot waste tank ties directly into the waste gas header upstream of the filters. Spent filters will be handled with existing NRTS solid waste disposal facilities. The filters shall be designed so that the high activity collected on the filters does not create a personnel radiation exposure problem during the removal of the filters. The pressurized water lonp vapor header ties into the waste gas header downstream of the blower. The gaseous waste discharge is monitored for gaseous and particulate activity. Activities are recorded in the process control room. A manual start-stop switch for the blower is lncnten in the reactor control room.

In the event of air activity in the reactor room and basement, the reactor room heating and ventilating fan and the reactor room roof exhaust fans are automatically shut down hy the constant air monitors. Then all air.flows from the work spaces into the reactor room, from there to the process equipment room, experimental cubicles and the sub-pile room, and then through the waste gas system, provided that the remotely controlled damper for recirculation of reactor room air has been closed. 
3.72 Solid Waste Disposal. The. existing NRTS burial ground is adequate for the small amount of solid waste expected from this facility. Handling equipment for this waste is also adequate.

3.73 Communications. A commercially installed and serviced telephone system connected to the existing NRTS commercial system provides for primary operational communications. In addition, an intercom system with two-way units located in all normal working areas and a master station in the reactor control room serves the reactor building area. This master control unit can speak to all locations collectively or selectively and can transfer a call from one working area to another. This total system can be overridden by an emergency unit at the control center, establishing communication between the control center and the reactor building intercom stations.

Manual-automatic coding fire alarm systems are installed at the control center and the reactor building and consist of alarm boxes connected to centralized relay and terminal strip units. The coded fire alarm annunciates at the Spert security station and at the NRTS central fire station as well as at the reactor and control center areas.

An evacuation siren is located in the reactor area. It can be actuated from the reactor building and from the control center.

3.74 Electrical (Figure 40). The reactor site is supplied with $13.8-\mathrm{kv}$ commercial electrical power from the Spert substation. A separate 13.8-kv to 2400-v, 3-phase, 750-kva transformer furnishes power to the three 150-hp primary pumps. A power bus supplied by a 13.8-kv, 480-v, 3-phase, 750-kva transformer distributes the main plant loads. A step down transformer $(13.8-\mathrm{kv}-$ $120 / 240-v, 3-p h a s e, 75-k v a)$ supplies lighting and general purpose requirements from this bus. Battery-powdered standby light packages furnish an emergency light source. A separate isolation transformer $(13.8-\mathrm{kv}, 120 / 240-\mathrm{v}, 1-$ phase, 25-kva) normally furnishes all transient instrumentation requirements direct from the main $13.8-\mathrm{kv}$ supply line.

An engine-generator set $(480-v, 3$-phase, 60-kva) is supplied. The engine will be started and running under no load on a governor controlled throttle prior to every reactor test. In the event of a commercial power failure, the waste gas blower and the control rod drive and instrument loads will be automatically switched to the emergency bus. All instrumentation will be served from this emergency bus through a 480-120/240-v, 1-phase, 25-kva transformer. The sole purpose of the emergency bus is to ensure control of the reactor at all times by providing a source of power to shut down the reactor in the event of a commercial power failure. Such power failure will automatically scram the reactor and stop any experiment in progress.

\section{REACTOR}

\subsection{Reactor Vessel}

The reactor vessel is an open top tank, constructed of stainless steel, $15 \mathrm{ft}$ ID by $29 \mathrm{ft}$ deep (Figure 51) with a $2: 1$ elliptical bottom head. The vessel has a minimum shell and head thickness of $1 / 2 \mathrm{in}$. The reactor vessel is 
designed and constructed in accordance with the latest revision of the ASME Pressure Vessel Code to withstand pressure surges of up to $100 \mathrm{psig}$, plus the static water head of $29 \mathrm{ft}$ and temperature variations of $50^{\circ} \mathrm{F}$. The vessel is to be code stamped. A level indicator is installed on the reactor vessel.

A 6- by 10-ft watertight removable gate designed to withstand 50-psig pressure surges and an expansion joint to compensate for differential movement serves to separate the reactor vessel from the canal. The gate is designed to enable the vessel or canal to be drained or filled independently. Removal of the gate and use of the building crane permits the underwater transfer of radioactive equipment and materials between the vessel and canal under water.

The bottom nozzle located in the center of the vessel is for loop penetration. The nozzle has an 8.075-in. ID with 150-1b ASA flanges and a 1-in. drain. The side nozzles are also for loop penetrations and are 10-in. standard pipe with 150lb flanges. The loop nozzles are blind flanged. All final vessel penetration specifications will be supplied to the architect-engineer hy Phillips Petroleum Co. after the core design has been finalized.

The reactor vessel has a 3-in. bottom drain and scum drains. Coolant nozzles and other additional openings are located and installed to satisfy the requirements shown in Figure 43. The 3-in. reactor vessel bottom drain and the bottom loop nozzle drain are provided with remotely operated valves controlled from the Reactor Building Process Control Panel.

The top of the core support ring is located $19 \mathrm{ft} 6 \mathrm{in}$. down from the vessel rim. The support $r i n g$ is designed to withstand a total core load of $70,000 \mathrm{lb}$, either up or down, imposed by four I-beams. (This figure will be verified when the core design has been finalized.)

The reactor vessel support ring is designed to carry the load of the veseel filled with water, plus the 70,000-lb core load.

The reactor vessel, core and vessel rings, all nozzles, and other equipment exposed to the demineralized water are constructed of 304,321 , or 347 stainless steel. All shell and head seams are double butt welded. All welds, including support ring and nozzle welds, are to be radiographed wherever possible. Welds which cannot be radiographed are to be dye-penetrant and/or ultrasonic tested. All welding, weld inspection, and radiography shall be in accordance with Phillips Petroleum Co. Specifications PPCS-243, PPCS-244, PPCS-253, and PPCS-245 (See Section 3.65).

\subsection{Core Structure}

The reactor core structure, as shown in Figure 51, consists of a lower grid, two intermediate grids, an upper grid, a pin hold down mechanism, a flow diverter, control and transient rod guides, and a removable flux suppressor.

The stainless steel lower grid supports the 44 -in-diameter by 36 -in.-high $\mathrm{UO}_{2}$ core. The lower grid, as well as the flow skirt, is supported by an I-beam bridge which is mounted on the reactor vessel walls. Coolant to the core is admitted through the lower grid by broached holes that also act as the lower support for the fuel pins. The upper face of the lower grid, furnished with 0.760 -in.-diameter holes bored $3 / 4$ in. deep on a $0.944-$ in. triangular pitch, also furnishes lateral retention of the individual fuel pins. 
The flow skirt is used to direct the coolant flow through the core. The flow skirt is also used to support the two aluminum intermediate grids, the aluminum upper grid, and the fuel pin hold down mechanism. The four grids restrict lateral movement of the fuel pin. Each grid fuel pin hole is broached in order to permit coolant flow through the grid.

Control and transient rod guide tubes are used to guide the control and transient rods when they are moved. The guides are attached to the lower and upper grids. Since the guide tubes extend above the upper grid, the upper ends of the guide tubes are interconnected to prevent any lateral movement.

A removable stainless steel flux suppressor, 8 in. ID, is placed in the center of the core structure as shown in the plan view of the core, Figure 52.

\subsection{Control Rods}

The control rods are stiffened blades having a cross section as shown in Figure 52. Hafnium is used as the control material. The three control rods are individually driven and utilize a magnetic latch and gravity drop. The control rods have full length stainless steel followers to provide flux suppression.

\subsection{Transient Rods}

The three transient rods are essentially inverted control rods with the stainless steel portion above the poison section. In order to obtain a reproducible burst, the transient rods are yoked together and are driven by a single drive unit. The transient rods operate in air in order to reduce drag forces during scram.

\subsection{Safety Rods}

There are six safety rod sets in addition to the control rods. These rods are the poison fuel-follower type. Each safety rod set consists of five fuel pins and poison sections. Each rod set is individually driven and utilizes a magnetic latch and gravity drop.

\subsection{Control, Safety, and Transient Rod Drives}

The control rod drives and safety rod drives consist of variable-speed motor-driven inverted worm screws for positioning a standard magnetic latch. Shock absorbers are used on each rod drive to decelerate the rods at the end of their free travel. A full complement of indicators is used to indicate rod position, magnet contact, upper and lower limit, etc, for each rod. The control motors are controlled such that any combination of rods may be moved simultaneously or singly.

Control rod drive characteristics are as follows:

1. Speed of withdrawal - 6 to $12 \mathrm{in.} / \mathrm{min}$

2. Scram time (36 in. travel) $-\mathbf{3 0 0} \mathrm{msec}$

3. Effective travel -36 in.

4. Release mechanism - electromagnet 
5. Mounting - control bridge

6. Shock absorber - integral

The transient rod drive has an unbalanced pneumatic piston drive with lead screw positioning. Ejection is effected by rapidly discharging the air on the bottom side of the piston and using the energy of the compressed air on the top side of the piston for acceleration. One drive is used to actuate all transient rods. The shock absorber for deceleration is an integral part of the drive system. Approximately one foot of "pre-run" will be required to attain the velocities necessary for a step insertion of reactivity in the 1-msec period region. A full complement of indicators is used to indicate rod position, piston contact, upper and lower limit, etc, for the rods.

Transient rod drive characteristics are as follows;

1. Speed of withdrawal - 6 to $12 \mathrm{in.} / \mathrm{min}$

2. Scram time (36 in. travel) - $40 \mathrm{msec}$

3. Effective travel -36 in. (64 in. total travel)

4. Release mechanism - air release

5. Mounting - control bridge

6. Shock absorber - integral

\subsection{Fuel}

Fuel for the PBF consists of 3/4-in.-OD $x$ 36-in.-long fuel pins as shown in Figure 53. The lower beveled end rests in the lower grid gulde holes. The physics of the fuel was discussed fully in Section IV. The following are the mechanical characteristics of the fuel pins:

Outside diameter -0.75 in.

Cladding material - type 304 cold-drawn stainless steel

Cladding thickness -0.028 in.

End cap material - 304 stainless steel

Insulation clearance -0.008 in.

Fuel end clearance -0.500 in.

Insulation.material - $\mathrm{ZrO}_{2}$ (sprayed or sintered)

Insulation thickness -0.062 in.

Fuel - sintered enriched $\mathrm{UO}_{2}$ pellets

Enrichment - 3\% 


\subsection{Stainless Steel Reflector Pins}

Stainless steel pins, having the same external dimensions as the fuel pins, are used to surround the active core and act as a fast neutron reflector. Placement of these reflector pins is shown in Figure 52. The additional unused holes in the grids outside of the stainless steel reflector pin ring are plugged to prevent coolant flow through this portion of the grid.

\subsection{Canal}

The 8- x 16- $\times 20-\mathrm{ft}$-deep canal is constructed of reinforced concrete and is completely lined with stainless steel (see Figures 34 and 37). The north end of the canal is $32 \mathrm{ft}$ deep to allow the experiment to be removed from the in-pile tube after being removed from the reactor to this area. A means should be provided for covering this deep section of the canal at the $20-\mathrm{ft}$ depth. The canal floor is designed to withstand $2500 \mathrm{lb} / \mathrm{ft}^{2}$. The canal has provisions for storing the 6- $\times 10-\mathrm{ft}$ gate in its south end. The canal has 3-in. bottom drains and scum drains.

\section{EXPERIMENTAL FACILITIES}

\subsection{General}

The 8-in.-diameter through hole in the center of the reactor core is designed to accommodate a wide variety of experiments ranging from single fuel plates or pins to complete fuel subassemblies. The environmental conditions for these experiments can be varied to include any desired pressure, temperature, flow rate, or type of coolant, independent of the reactor core conditions.

Two types of experiments are planned for the PBF: those in which the experiment is placed in a sealed capsule and those in which the experiment is placed in a flow loop.

\subsection{Pressurized Water Capsule}

Among the first experiments planned for the PBF are the pressurized water capsule type. The cross section of a typical pressurized water capsule is shown in Figure 54. This cross section is also typical of the in-pile portion of a pressurized water flow loop.

The capsule consists of a pressure container and a thin outer shell. A gas annulus between the outer shell and the pressure container serves as a thermal insulator so that excessive thermal stresses are not developed in the pressure container when the contents of the capsule are at elevated temperatures. 'The gas in the annulus is pressurized to insure that water does not leak into the annulus.

The pressure container is designed to withstand operating pressures of $2500 \mathrm{psi}$ at $650^{\circ} \mathrm{F}$ or $5000 \mathrm{psi}$ at $400^{\circ} \mathrm{F}$. The fittings required for positioning the fuel assembly to be tested and for instrumentation are included in the pressure container. All connections to the capsule for instrumentation and for post-burst cooling are made at the top of the capsule so that the capsule can be both inserted and removed from the top of the core. 
Transparent windows are provided at specified locations on the capsule in order to permit high-speed photography of the events occurring within the capsule during the power burst.

Following completion of a severe test the capsule in its entirety is removed from the test hole and transferred to the reactor building canal. Depending on the extent of the inspection required, the capsule may then be transferred to a hot cell for radiolytic gas analysis, metallurgical examination, and any other examinations that may be indicated.

\subsection{Loop Experiments}

The loop experiments permit destructive testing of fuel assemblies in a flow environment. A pressurized water loop is to be designed and constructer as an integral part of the PBF. Two shielded cubicles are located in the reactor basement area for placement of loop out-of-pile equipment. The pressurized water loop will initially occupy one of these cubicles. The other cubicle will be used for future loops involving coolants other than water. Testing with such coolants as liquid metals, gases, and organic fluids is being considered. The amount of equipment required for testing with any of these coolants is comparable to that of the pressurized water loop, and the total cost of each of the loops would be in the same range as the cost of the pressurized water loop.

\subsection{Periscopes}

High-speed photography of the events occurring within the capsule during the power burst will be useful in determining and evaluating the results of an experiment. For this purpose, periscopes which penetrate the core at locations which permit alignment with windows in the capsule or in-pile loop are required. Periscope penetrations of the core can be made between the two intermediate grids at $60^{\circ}$ azimuthal intervals. The periscope penetration is made by removing the regular fuel pins along the radius on which the periscope is to be located. Partial length fuel pins are then inserted above and helow the desired location of the periscope.

The provision for placing periscopes at $60^{\circ}$ azimuthal angles permits the stereoscopic examination of events within the capsule by means of monoscopic periscopes. The feasibility of a single stereoscopic periscope. will also be examined.

\section{PRESSURIZED WATER LOOP}

\subsection{General Description}

The PBF pressurized water loop is a facility for destructive testing of a wide range of experiments in a high-pressure and high-temperature water environment. The process flow diagram for the loop is given in Figure 55.

The loop is capable of operating at a temperature and pressure of $600^{\circ} \mathrm{F}$ and 2200 psig, respectively. The in-pile tube is designed to withstand transient pressures of 5000 psi without damage to the tube. The loop is capable of delivering up to $1000 \mathrm{gpm}$ of high-purity water through a test fuel assembly with up to $60 \mathrm{psi}$ pressure drop across the assembly. 
The major equipment contained in the primary loop consists of a primary circulating pump, line heaters, a primary heat exchanger, a pressurizer vessel, and an in-pile tube.

\subsection{Operating Philosophy}

Most of the experiments to be run in the pressurized water loop do not present a radiation problem. However, the loop does have the capability for the testing of previously irradiated fuel assemblies. Ion exchange columns, a strainer, and decontamination equipment are included for cleaning the system following fission-product release resulting from the testing of such an element. However, because of the infrequency of this type of a test, a low shielding approach has been used in the layout of equipment and in the routing of lines.

Normally an experiment will be removed from the in-pile tube without removing the in-pile tube from the reactor. When highly radioactive elements are to be removed from the in-pile tube, the in-pile tube will be transferred from the reactor to the canal through the canal gate. The tube will be lowered into the deep section of the canal where the experiment will be lifted out of the tube. The experiment will then be placed in a transfer cask for shipment to other areas. The reverse procedure will be followed for the insertion of a highly radioactive fuel element into the in-pile tube. As transfer casks are normally available at other areas at the NRTS for moving fuel assemblies between different areas of the NRTS, a transfer cask is not included in the design of the pressurized water loop. If a particular experiment is to be run that requires a special cask, this cask will be included in the design of the experiment.

The pressurized water loop has been designed to provide a basic facility for conducting a wide variety of experiments. However, no attempt has been made to include all instrumentation and equipment that might conceivably be necessary for conducting special tests. As the loop cubicles have been sized for the inclusion of additional equipment, such items can be added as required for special tests.

When it is necessary to shut down the pressurized water loop for repairs, for addition of equipment or instrumentation, or for decontamination, the in-pile tube will be removed from the reactor. During such periods, the reactor can be used for capsule experiments or for experiments in a (future) loop using a nonaqueous coolant. This can be accomplished by appropriate scheduling of the loop work. Because this can be done and because the operating time required for a power burst test is short compared to the operating time in a static high-power test reactor, the duplication of equipment and instrumentation that is required in some parts of pressurized water loops in static test reactors is not necessary in the PBF pressurized water loop.

During the execution of loop experiments the loop will be controlled from the $\mathrm{PBH}$ Control Center. Adequate instrumentation will be located at the Control Center to meet the experiment requirements and to meet loop safety requirements. However, such operations as loop start-up, shutdown, cleanup, and decontamination will be conducted at the reactor building. Alarms at both the reactor and the control center will alert the operators of abnormal conditions.

\subsection{General Design Consideratons}

6.31 Design Codes. The loop process system piping shall be designed, inspected, and tested according to the latest edition of the ASA piping 1 code. All 
vessels shall be designed and constructed according to the latest edition of the ASME Pressure Vessel Code, and code stamping is required.

All welding in the loop process system shall be in accordance with Phillips Petroleum Co. Specification PPCS-243, entitled "Manual Welding of Austenitic Stainless Steel in Nuclear Reactor Experiment Systems". All piping welds shall be inspected in accordance with Phillips Petroleum Co. Specification PPCS-244, entitled "Acceptance and Quality Control Standard for Manual Welding of Austenitic Stainless Steel in Nuclear Reactor Systems". All piping radiography shall be done in accordance with Phillips Petroleum Co. Specification PPCS-253, entitled "Radiographic Technique Requirements for the Inspection of Piping". All welder operators utilized on the welding of the process equipment and piping shall be qualified in accordance with Phillips Petroleum Co. Specification PPCS-245, entitled "Welders Qualification Procedure for Austenitic Stainless Steel". The required number of copies of the above Phillips Petroleum Co. specifications will be furnished prospective architect-engineers upon request.

In addition to the cleaning and testing of components required by the codes mentioned above, the entire loop system shall be pressure-tested and flushed in order to remove any foreign material.

6.32 Equipment and Piping Design. The primary loop equipment and piping is designed according to the design parameters listed in Table XV.

\section{TABLE XV}

\section{PRFGSITRTYRT WATER LOOP DESIGN PARAMETERS}

Controllable flow rate

Design pressure

Design temperature

In-pile tube differential pressure at $1000 \mathrm{gpm}$

Maximum burst energy released in the experiment
100 to $1000 \mathrm{gpm}$
2500 psig
$670^{\circ} \mathrm{F}$
$80 \operatorname{psi}(\mathrm{a})$
$50 \mathrm{Mw}-\mathrm{sec}$

(a) This figure will be verified when the design of the in-pile tube is finalized.

The process equipment shall be sized by the architect-engineer according to good engineering practices. The piping and equipment sizes indicated in Figure 55 are presented only to show the basis of this conceptual design. In all cases where feasible, each item shall be of standard manufacturers' design and all identical items shall be of the same make and model to simplify maintenance and spare parts stores.

All equipment surfaces in contact with the process coolant shall be made of type 321 or 347 stainless steel because of the resistance of these materials to decontaminating solutions. All piping shall be seamless and shall be made of type 321 or 347 stainless steel. 
6.33 Equipment Arrangement. The primary loop equipment and piping, the pressurizer, and the cleanup equipment are located within the basement cubicle. Low pressure equipment that is not to contain radioactive coolant shall be located outside the shielded cubicle. Equipment arrangement must be such that any major component can be installed or removed without affecting adjacent equipment.

Care must be taken in the layout of the loop piping because of expansion problems resulting from high-temperature operation. A detailed stress analysis of the piping shall be performed to establish the piping supports needed.

Dead legs or pockets which can trap corrosive or radioactive products must be avoided in the primary piping layout. The piping should be laid out so as to minimize the number of low spots and high spots. All low spots shall be equipped with a drain line, and all high spots shall be equipped with a vent line. All drains and vents shall be of the double-block-and-bleed type.

Provisions are included so that the venting, draining, cleanup, degassing, and decontaminating operations can be conducted from outside the shielded cubicle. Past experience indicates that reach rods extending through the cubicle walls to the critical valves is a satisfactory method of operating these valves.

The loop must be as leak-tight as possible. Therefore the use of flanges should be reserved only for those pieces of equipment which must be removed from the loop frequently. No leakage at design conditions shall be allowed across the seat of block valves located in lines connected to the primary loop system.

6.34 Instrumentation. Since remote control of the loop from the central control area is essential, it is required that plant instrumentation be designed to permit adjustment of certain operating conditions from the PBF Control Center. The instrumentation designed by the architect-engineer shall provide for remote control of loop temperature, pressure, flow, and pressurizer level. The recording or indicating of other information which is necessary for safe remote operation shall also be included. Alarms at both the reactor and the control center shall be included to alert the operators to abnormal conditions.

The instruments recording loop temperature, pressure, flow, and pressurizer level will be equipped so that they can be tied into the reactor control circuitry when needed.

Instrumentation at the control center for such operations as start-up, shutdown, cleanup, and decontamination is not necessary, since these operations will be conducted at the reactor building.

Those instrument transmitters which are in direct contact with the loop process coolant are located in an exhausted cabinet outside the shielded cubicle, With this arrangement it will be possible to work with the instrumentation without entering the shielded cubicle.

Pressure safety valves shall be located on all primary piping containing a heat source which may be isolated from the rest of the system. 'The safety valve shall be isolated from the process water by a rupture disc. A rupture disc leak will be detected by a pressure switch which will actuate the alarm system. 
The architect-engineer shall include in his instrument specifications a thorough instrument check-out procedure to be followed in order to insure that all instruments are in proper calibration and in operating condition upon completion of plant construction.

6.35 Cubicle. In order to facilitate the decontamination of the cubicle in the event of a spill of contaminated water, the floor, walls, and ceiling of the cubicle shall be treated to produce a smooth surface and shall be coated with an impervious paint. All piping in the cubicle shall be a minimum of 18 in. above the floor to facilitate draining and decontamination.

'The cubicle shall include an overhead monorail for equipment maintenance.

All a.reas where lnnp prnness conlant is contained shall be oxhauotod to the gaseous waste system. These areas include the shielded cubicle, the sampling glovebox, and the transmitter cabinet. A minimum face velocity of $150 \mathrm{ft} / \mathrm{min}$ at any opening is required in all evacuated areas.

The cubicle ambient temperature shall be less than $130^{\circ} \mathrm{F}$. Refrigeration may be necessary in order to meet this requirement.

6.36 Operating Manual. A detailed manual containing the philosophy, procedures, etc, necessary for safely carrying out all loop operations shall be supplied by the architect-engineer. Included in the manual shall be an analysis of system behavior and protection provided in the event of power failure or component failure. This report shall also include an analysis of system capabilities.

6.37 Information to be Supplied the Reactor Operator. The reactor operator shall be supplied with the following information in order to maintain and nperate. the experimental equipment safely and economically:

(1) One copy of all design calculations

(2) Three copies of a list of all purchase order numbers and the suppliers

(3) Reproducible "as-built" drawings of all facilities and equipment

(4) Five copies of recommended spare parts lists and maintenance manuals for all equipment, including vendor drawings

(5) Three certified copies of all inspection reports on components

(6) Ten complete, detailed copies of the operating manual for the loop

- (7) Five copies of all specifications

\subsection{In-pile Tube}

The initial in-pilc tube for the pressurized water loop is of the top reentrant type, ie, the coolant will enter and leave from the top of the tube. The tube will be designed for 2500 psig and $670^{\circ} \mathrm{F}$. In addition, that section of the tube 
which is in the core region will be designed for transient pressures of 5000 psig without damage to the tube. The tube shall be designed to accept a 4-1/2-in.OD sample surrounded by a water annulus approximately one inch thick. Those portions of the tube in contact with the loop cooling water will be constructed of 347 stainless steel. Insulation between the pressure tube and the reactor cooling water will be necessary to prevent boiling of the reactor cooling water. All in-pile tube welding will conform to the Phillips Petroleum Co. welding specifications listed in section 6.31 .

Experiments will be inserted into the in-pile tube through the top. Experiment instrumentation will leave the tube from the top. A particle trap will be built into the bottom of the tube. The initial in-pile tube will not contain a periscope window.

As the in-pile tube is a part of the reactor vessel internals, it will be designed, procured, and installed by Phillips Petroleum Co. In order to facilitate the removal of the tube from the reactor, the inlet and outlet lines will contain flanges. These flanges will be supplied by the architect-engineer. The exact location of the flanges will be established during the detailed design of the reactor vessel internals.

\subsection{Component Design Considerations}

6.51 Flow Control. The primary circulating pump has a capacity of 100 to $1000 \mathrm{gpm}$ while operating at water temperatures ranging from 70 to $670^{\circ} \mathrm{F}$. The pump is of the canned rotor type because of the minimum leakage requirement. High-pressure demineralized water is provided for pump cooling. The pump is automatically shut down on low pump cooling water flow. A flush stream of demineralized water can be injected into the pump to protect the bearings during loop decontamination. A shutdown switch for the pump is installed at the control center and at the control panel in the Reactor Building.

The coolant flow through the in-pile tube is controllable from 100 to $1000 \mathrm{gpm}$ by a flow control valve positioned by a hand controller. Primary flow is monitored using a flow tube. The flow transmitter is temperature compensated.

6.52 Temperature Control. The coolant temperature is automatically controlled from 150 to $600^{\circ} \mathrm{F}$ by varying the primary coolant flow through the primary heat exchanger. Electric line heaters are provided to heat the loop water to operating temperature.

The primary heat exchanger is to be sized to cool the primary system (excluding the pressurizer) from 670 to $150^{\circ} \mathrm{F}$ in two hours. The primary heat exchanger cooler shall be constructed to withstand high thermal expansion and shock. A " $U$ " tube or spiral type of design should be evaluated.

The line heater capacity is sufficient to heat the primary system from 70 to $670^{\circ} \mathrm{F}$ in eight hours. Heaters of both the internal and clamp-on types are to be evaluated.

6.53 Pressure Control. The purpose of the pressurizer is to provide a means for (a) controlling the pressure in the primary loop from atmospheric to $2200 \mathrm{psig}$, (b) totally containing the expanded volume of loop coolant from 70 to $600^{\circ} \mathrm{F}$, and (c) degassing the coolant. Pressure is maintained by steam generation. Heat for the steam generation is supplied either by externally or internally 
mounted electric heaters. The heaters are sized to raise the pressurizer temperature from 70 to $650^{\circ} \mathrm{F}$ in eight hours.

Pressure is automatically controlled by means of the pressure controller which actuates the pressurizer heaters in a manner which will insure the mixing of the water in the pressurizer vessel. Automatic shutdown of the pressurizer heaters will occur on low pressurizer level, high pressurizer pressure, high pressurizer temperature, and high heater element temperature. Temperature measurements are made at six points in the tank. All instrumentation pertinent to the operation of the pressurizer have their in-service switches interlocked with the pressurizer heater breakers.

The water level is measured by means of a system which will accurately detect the level regardless of water density changes. The level will he controlled automatically by using the makeup pump. In the event of a high level, water can be drained from the loop by a remote, manually controlled drain valve.

A degassing line from the primary flow loop to the top of the pressurizer serves for coolant degassing and system depressurization. The approximate rate for degassing is $2.5 \mathrm{gpm}$. The rate for depressurizing is $10 \mathrm{gpm}$. An auxiliary heat interchanger may be necessary to control thermal shock to the pressurizer vessel, since the temperature of the depressurizing stream may be as low as $150^{\circ} \mathrm{F}$.

6.54 Makeup System. The makeup system supplies the high-purity demineralized water for the loop. The makeup system consists of a fill pump, decontamination tank, and makeup pump. This equipment is located outside the shielded cubicle.

The loop system can be filled directly from the plant demineralized water system or from the decontamination tank. A small ion exchange unit consisting of a deoxygenating resin column followed by a mixed resin column can be used to condition the plant demineralized water before it is introduced into the lonp. A helium blanket in the decontamination tank is provided to keep oxygen from the water. The makeup pump is used for loop pressure testing and for adding water to the loop during loop operation. The makeup pump will be a positive displacement pump with a capacity sufficient to maintain a safe level in the pressurizer.

The decontamination tank serves not only as a makeup tank but as a tank for mixing and heating of decontamination solutions. The tank should be sized to contain liquid volume equal to the volume of the loop excluding the pressurizer volume. The fill pump can be used to charge demineralized water into the loop or to charge decontamination solutions into the loop. This pump is sized to completely fill the loop in $15 \mathrm{~min}$.

Check valves are to be provided in the water supply and water transfer systems to prevent loop water from entering the demineralized water system.

6.55 Cleanup System. The purpose of the cleanup system is threefold. It provides a facility for controlling the water chemistry of the loop, for cleanup of the loop water following a power burst, and for taking of loop water samples. The system consists of a cleanup loop interchanger, a cleanup cooler, ion- 
exchange columns, and a sample bomb. All of these pieces of equipment will be located inside the shielded cubicle with the exception of the sample bomb.

The cleanup system is designed for a maximum flow rate of $2 / 3$ of the primary system volume (excluding the pressurizer volume) per hour. The size of the ion exchange columns shall be designed so that the contamination level in the total primary loop volume can be reduced by a factor of 350 in eight hours. The type of resin placed in the ion exchange columns will depend upon the experiment to be run. Because of the temperature requirements of the resins, the temperature at the inlet to the ion exchange columns cannot exceed $140^{\circ} \mathrm{F}$.

Uncontaminated demineralizer regeneration liquids are drained to the chemical waste leaching pond. Contaminated demineralizer regeneration liquids are drained to the warm drain or hot waste tank. Highly radioactive resins are flushed from the ion exchange columns to a shielded cask for disposal. This cask is considered as part of the design.

The sample bomb is to be sized to contain a one-pint sample. The sampling equipment is in a glove box located outside the shielded cubicle. A coolant sample can be procured and contained at the system operating pressure. A bypass is installed around the sampling location for the purpose of flushing the sample lines. The sample bomb can also be used for the injection of chemicals into the primary loop.

6.56 Auxiliary Cooling Water System. The cooling water for the primary heat exchanger, the primary pump, and the cleanup cooler can be supplied by a high-pressure demineralized cooling water system. The flow diagram for this system appears in Figure 56.

The piping material of the demineralized water cooling system can be of carbon steel if the water is treated with chemicals to minimize corrosion. Water in the high-pressure demineralized cooling system is cooled in a heat exchanger supplied with cooling water from an atmospheric cooling tower. Water for the cooling tower system is from the PBF raw water supply header. The cooling tower circulating system is constructed of carbon steel. The cooling water in the cooling tower is treated with corrosion inhibitor and sulfuric acid as required. As stated in the section describing the reactor cooling water requirements (Section VI, 3.65), the architect-engineer is to study methods of satisfying the cooling requirements of both the reactor and the loop in order to determine the most economical design. It may be that one system can take care of the requirements of both the reactor and the loop.

6.57 Strainer. A Y-type strainer in the primary system is located in the outlet line from the in-pile tube. This standard mesh strainer will be used for collection of particles in the loop. The strainer drain piping will be designed so that the particles can be flushed to the hot waste tank, to the warm drain, or to the shielded cask.

6.58 Crossover System. Two removable spool pieces are provided in the primary loop such that by replacing them with spool pieces of a different design it will be possible to reverse the coolant flow through the in-pile tube.

6.59 Fission Product Monitor. A fission product water monitor (such as the Tracer Lab MWPIA monitor) will be provided. The sample stream to the 
monitor will pass through a pressure reducer and a sample cooler before entering the monitor. The sample, approximately two gallons per hour, will be drained to the hot waste tank. The monitor is located outside of the shielded cubicle. 
In the construction of a specialized reactor facility there are of necessity certain areas in which the architect-engineer must assume prime responsibility for design and other areas in which the reactor designer must assume prime responsibility. Table XVI presents the breakdown of design responsibility for the PBF along with the pertinent interfaces between the work of the architectengineer and that of the reactor designer.

\section{TABLE XVI}

\section{DIVISION OF DESIGN RESPONSIBILITY FOR PBF}

\begin{tabular}{|c|c|c|c|c|}
\hline Division & Destgn & Procurement & Installation & Meeting Point \\
\hline Basic buildings & Architect-Engineer & Architect-Engineer & Arch1 tect-Engineer & None \\
\hline Process equitpment & Architect-Enginecr & Architect-Englncer & Architect-Bnginecr & None \\
\hline $\begin{array}{l}\text { Services (except high } \\
\text { pressure air) }\end{array}$ & Architect-Engineer & Archi tect-Engineer & Architect-Engineer & None \\
\hline H1gh pressure air system & Philifps Petroleum Co. & Architect-Engineer & Archltect-Engineer & Brtdges \\
\hline Reactor vesacl & Architect-Dngineer & Architect-Engineer & Architect-Ingineer & $\begin{array}{l}\text { Core structure mounts integral } \\
\text { w1th vessel }\end{array}$ \\
\hline $\begin{array}{l}\text { Reactor fuel, control } \\
\text { rods, and transient rods }\end{array}$ & Phillips Petroleum Co. & Phillips Petroleum Co. & Phillips Petroleum Co. & None \\
\hline Core structure & Phillips Petroleum Co. & Phillips Petroleum Co. & Phillips Petroleum Co. & $\begin{array}{l}\text { Core otructure mounto to mect } \\
\text { mounts integral with vessel }\end{array}$ \\
\hline Control bridge & Phillips Petroleum Co. & Phillips Petroleum Co. & Phillips Petroleum Co. & Floor-mounted ralls for bridge \\
\hline $\begin{array}{l}\text { Control and transient rod } \\
\text { drive units }\end{array}$ & Pbillips Petroleum Co. & Phillips Petroleum Co. & Pbilllps Petroleum Co. & None \\
\hline $\begin{array}{l}\text { Reactor control circuitry } \\
\text { and console }\end{array}$ & Ph1llips Petroleum Co. & Phillips Petroleum Co. & Phillips Petroleum Co. & Junction boxes in control room \\
\hline Signel and control cables & Fhlll1ps Petroleum Co. & Arch1tect-Eng1neer & Architect-Engineer & $\begin{array}{l}\text { Junction boxes in reactor, con- } \\
\text { trol, and instrument rooms }\end{array}$ \\
\hline $\begin{array}{l}\text { Transient instrumentation } \\
\text { (1ncluding data-recording } \\
\text { e.quifment.) }\end{array}$ & Phillips Petroleum Co. & Phillips Petroleum Co. & Phililps Petroleum Co. & $\begin{array}{l}\text { Junction boxes in } \\
\text { instrument rooms }\end{array}$ \\
\hline Intercomunication system & Arch1tect-Engineer & Architect-Engineer & Architect-Engineer & None \\
\hline In-plle tube & Fh1Il1ps Petroleum Co. & Phtllips Petroleum Co. & Fhillips Petroleum Co. & $\begin{array}{l}\text { Flow inlet and outlet flanges } \\
\text { at reactor vessel face }\end{array}$ \\
\hline
\end{tabular}


1. Letter from E. W. Bosse, Director of the Reactor Division of the Idaho Operations Office of the USAEC, to J. R. Huffman, Assistant Manager of the Atomic Energy Division, Phillips Petroleum Company, dated October 2, 1961.

2. Letter from E. W. Bosse, Director of the Reactor Division of the Idaho Operations Office of the USAEC, to J. R. Huffman, Assistant Manager of the Atomic Energy Division, Phillips Petroleum Company, dated May 1, 1962 .

3. J. A. Lieberman and S. A. Szawlewicz, Kesearch and Development Activities in Nuclear Safety, Paper presented at the Annual Conference of the Atomic Industrial Forum, Chicago, Illinois, November 6-9, 1961.

4. T. F. Wimett, et al, "Godiva II - An Unmoderated Pulse-Irradiation Reactor", Nucl. Sci. and Eng., $\underline{8}, 691,-708$ (1960).

5. J. R. Dietrich, Experimental Determination of the Self-Regulation and Safety of Operating Water-Moderated Reactors, First U. S. Internat. Conf. on Peaceful Uses of Atomic Energy, Geneva, Paper 481 (June, 1955).

6. B. S. Maxon et al, Reactivity Transients and Steady-State Operation of a Thoria-Urania-Fueled Direct-Cycle Light Water Boiling-Reactor (Borax IV), ANL-5733 (February, 1959).

7. J. C. Haire, Jr., "A Summary Description of the SPERT Experimental Program", Nuclear Safety, 3, 15-23 (1961).

8. F. Schroeder, "Review of Power Excursion Studies", Proc. of 1960 Idaho Conf. on Reactor Kinetics, Sun Valley, Idaho, IDO-16791, (July, 1962).

9. R. R. Smith et al, A Mechanism Explaining the Instability of EBR-I, MARK II, ANL-6354 (September, 1961).

10. J. W. Flora, Ed., Kinetic Experiments on Water Boilers - 'A' Core Report Part I - Program History, Facility Description, and Experimental Results, NAA-SR-5415 (to be issued).

11. R. S, Stone, "Transient Behavior of TRIGA, A Zirconiun-Hydride, WaterModerated Reactor", Nucl. Sci. and Eng., 6, 255-259 (1959).

12. J. A. DeShong, Jr., and W. D. Lipinski, Analysis of Experimental PowerReactivity Feedback Transfer Functions for a Natural Circulation Boiling Water Reactor, ANL-5850 (July, 1958).

13. C. W. Griffin and J. G. Lundholm, Jr., Measurement of the SRE Power Coefficients and Reactor Parameters Utilizing the Oscillation Techniques, NAA-SR-3763 (November, 1960).

14. R. Kirn, et al, Reactor Physics Measurements in TREAT, ANL-6173 (October, 1960). 
15. Spert Project Quarterly Reports: 1st Qtr, 1959, J. A. Norberg, ed, IDO16539 (November, 1959); 2nd Qtr, 1959, J. C. Haire, ed, IDO-16584 (April, 1960); 2nd Qtr, 1960, F. Schroeder, ed, DO-16640 (April, 1961); 3rd Qtr, 1960, F. Schroeder, ed, IDO-16677 (May, 1961); 4th Qtr, 1960, F. Schroeder, ed, IDO-16687 (June, 1961).

16. IDO Report on the Nuclear Incident at the SL-1 Reactor, January 3, 1961, at the . National Reactor Testing Station, IDO-19302, (January, 1962).

17. A. H. Spano, et al, "Report on Spert I Destructive-Test Program", Trans. Am. Nucl. Soc. 6 (1), June, 1963 (to be published).

18. Taylor Lyman, Ed., Metals Handbook, 7th Ed., American Society for Metals (1948).

19. Clifford A. Hampel, Ed., Rare Metals Handbook (1954).

20. E. R. Tipton, Jr., Ed., Reactor Handbook-Materials, 2nd Ed., Vol. 1, USAEC (1960).

21. W. D. Wilkinson and W. F. Murphy, Nuclear Reactor Metallurgy (1958):

22. H. H. Hausner, Data Book on Physical and Engineering Properties of Materials for Nuclear Fuel Elements, Sylvania-Corning Nuclear Corporation (1959).

23. Alvin Glassner, The Thermochemical Properties of the Oxides, Fluorides, and Chlorides to $2500^{\circ} \mathrm{K}$, ANL-5750 (1957).

24. T. B. Douglas and A. C. Victor, Physical Properties of High Temperature Materials, Part II, WADC-TR-57-374 (August, 1957).

25. A. H. Spano et al, Self-Limiting Power Excursion Tests of a Water-Moderated Low-Enrichment $\overline{\mathrm{UO}} 2$ Core in Spert I, IDO-16751 (February, 1962).

26. W. R. Martin and J. R. Weir, Dimensional Behavior of the Experimental Gas-Cooled Reactor Fuel Element at Elevated Temperatures, ORNL-3103 (August, 1961).

27. J. Belle, Ed., Uranium Dioxide: Properties and Nuclear Application, Naval Reactors, Division of Reactor Development, United States Atomic Energy Commission (July, 1961).

28. E. Ryshkewitch, "Metal-Oxide Ceramics", Internat. Sci. and Tech., No. 2, 54-61 (February, 1962).

29. R. J. Wagner, "General One Dimensional Heat Conduction Code for the IBM-650", MTR-ETR Technical Branches Quarterly Report, Third Quarter, 1961, IDO-16733 (December, 1961).

30. R. A. Grimesey et al, Muft, Revision, A Fast Neutron Spectrum Code for the IBM-650, IDO-16735 (March, 1962). 
31. R. J. Wagner, 650 Sofocate - A Code to Determine Thermal Constants on the IBM-650, IDO-16758 (March, 1962).

32. W. D. Kingery et al, "Thermal Conductivity - Part X: Data for Several Pure Oxide Materials Corrected to Zero Porosity", Journal American Ceramic Society, 37, p 107 (1954).

33. J. L. Bates, "Thermal Conductivity of $\mathrm{UO}_{2}$ Improves at High Temperatures", Nucleonics, 19, 83-85 (June, 1961).

34. E. Ryshkewitch, Oxide Ceramics: Physical Chemistry and Technology, New York, Academic Press, p 378 (1960).

35. J. E. Houghtaling et al, Calculation and Measurements of the Transient 'Temperature in a Low-Enrichment UO2 Fuel Rod During Large Power Excursions, IDO-16773 (May, 1962).

36. R. M. Ball et al, MARTY Critical Experiments - Summary of $4 \%$ Enriched $\mathrm{UO}_{2}$ Cores Studied for NMSR, BAW-1216 (May, 1961).

37. R. S. Marsden et al, Reactor Physics Studies for the Final Conceptual Design of the Advanced Test Reactor, IDO-16668, (March, 1961).

38. Letter from H. B. Stewart, General Atomic Division of General Dynamics Corporation, to A. A. Wasserman, Spert Project of the Atomic Energy Division of Phillips Petroleum Co., dated June 18, 1962.

39. G. D. Juanuu, J. S. Dudek, GAM-I: A Consistant $P 1$ Multigroup Code for the Calculation of Fast Neutron Spectral and Multigroup Constants, GA-1850 (June, 1961).

40. I. Cohen, B, E. Shaner, A Metallographic and X-ray Study of the UO2-ZrO2 System, WAPD-T-1418 (April, 1962).

41. J. Weil and P. Cabral, $\mathrm{P}_{3}$ Flux Distribution, Phillips Petroleum Co. 650 Program Library, File Number 8.2.014.

42. D. G. Ott, Calculation of Prompt Neutron Generation Time from Reactivity of $\frac{1}{\mathrm{~V}}$ Absorber, Internuclear Company Report INT-DGO-56-1 (1956).

43. E, J, Leshan et al, Diffusion Multigroun Multiregion, DMM, Phillips Petroleum Co. 650 Program Library, File Number 8.2.015.

44. S. Tong, Modification to DMM-I, Phillips Petroleum Co. 650 Program Library, File Number P.P.Co. 00.094.

45. W. R. Cadwell, PDQ-4 - A Program for the Solution of the NeutronDiffusion Equations in Two Dimensions on the Philco-2000, WAPD-TM-230 (June, 1961).

46. MTR-ETR Technical Branches Quarterly Report, 1st Qtr, 1962, DO-16781 (June 1962). 
47. H. P. Flatt and D. C. Baller, AIM-6 Code, NAA Program Description (January, 1961).

48. A. H. Spano, Phillips Petroleum Co., Spert Project, Idaho Falls, Idaho, Unpublished Notes (March, 1962). 


\section{APPENDIX}

\section{PHYSICS CALCULATIONAL METHODS}

\subsection{Introduction}

The reactor physics calculations for the PBF conceptual design have been based entirely upon four-neutron-energy-group, one-dimensional diffusion theory. It is realized that the diffusion theory approximation is subject to question for systems that have regions of widely differing nuclear properties and dimensions of the order of the neutron mean free path. However, comparison of the results of calculations and experiments performed with systems similar to the PBF reactor, summarized in Section X, 2 below, have indicated that diffusion theory is sufficiently accurate for purposes of the conceptual design of such systems. The few-group constants for the diffusion calculations were obtained using exioting oomputor programo. Void, tcmpcraturc, and Doppler effeets as weil as lifetime and control studies were made by determining eigenvalue changes for complete reactor systems.

\subsection{Thermal Constants}

Constants for the thermal energy group were obtained by using the 650 SOFOCATE [31] program. For the core region, the assumption was made that the spatially independent average thermal spectrum seen by the core was the Wigner-Wilkins spectrum calculated by homogenizing the atom densities throughout the core volume. The cross sections $\Sigma_{\mathrm{a}}, \Sigma_{\mathrm{t}}$, and $\Sigma_{\mathrm{S}}$, for each of the regions of $\mathrm{UO}_{2}$ fuel, $\mathrm{ZrO}_{2}$ insulator, stainless steel cladding, and surrounding moderator, were obtained by averaging the measured energy-dependent crosssections over the spectrum obtained for the homogenized core. These constants were then used with a cylindrical-geometry, $P_{3}$ spherical harmonics program [41] to obtain the thermal flux distribution in the fuel pin and surrounding moderator. A typical thermal flux distribution, for a fuel enrichment of $3 \%$ and a metalto-water ratio of 1.3 , is shown in Figure 57. The thermal macroscopic absorption and fission cross sections, $\Sigma_{\mathrm{a}}$ and $\Sigma_{\mathrm{f}}$, were then flux weighted by this distribution. The thermal diffusion coefficient was determined by utilizing the homogenizedcore thermal spectrum. The determination of the flux-weighted thermal constants and the diffusion coefficient allowed the core to be considered as a homogeneous region with respect to thermal neutrons.

The thermal constants for hydrogen-moderated regions other than the fueled region were obtained with the 650 SOFOCATF program by homogenizing the atom densities and performing the standard Wigner-Wilkins spectrum calculation. The procedure for pure metal regions, such as the pressure pipe surrounding the experimental region, was to average the constants over either the spectrum obtained for the homogenized core or the spectrum obtained for water, depending upon the surrounding environment.

\subsection{Fast Constants}

An IBM 7090 code, GAM-1 [39], was used to obtain the fast group constants. This code was written specifically for lumped, low enrichment fuels similar to the type under consideration for the PBF reactor. One important feature of this code is that the temperature to be used in computing the Doppler broadening of the U-238 absorption resonances is specified as an input. 'Therefore, 
the fast constants which result have been adjusted for the resonance absorption in the U-238 as well as the localized geometry effects of lumped fuel surrounded by moderator.

The fast constants for regions other than the core region were determined in a manner similar to that described above for the thermal constants. For example, constants for stainless steel were obtained by averaging over the spectrum appropriate to the surrounding environment.

\subsection{Flux Shape During a Transient and Prompt-Neutron Lifetime}

During extremely rapid transient conditions, the neutron flux distribution in a reactor is somewhat different from that under steady state conditions. Since, in the PBF reactor, a change in the flux shape during a transient could reduce the figure-of-merit, it is important to estimate the magnitude of such a change. The flux distribution under transient conditions may be estimated by assuming the reactor power to be increasing with an asymptotic exponential period. This assumption is represented in static calculations by the addition of a fictitious absorption cross-section to all regions of the core. The magnitude of the fictitious cross-section is $\alpha / \mathrm{v}$, where $\alpha$ is the inverse asymptotic period and $\mathrm{v}$ is the neutron speed. The flux shape during the transient condition is then obtained by performing the normal static calculation with the fictitious absorption present in all reactor regions.

The change in eigenvalue produced by the addition of an $\alpha / v$ absorption cross-section to all regions of the reactor can be used to evaluate this prompt neutron lifetime in the reactor [42]. If one defines the reactivity $(\rho)$ by

$$
\rho \equiv \frac{\lambda_{0}-\lambda}{\lambda_{0} \lambda}
$$

where $\lambda$ is the eigenvalue obtained with addition of the $\alpha / v$ cross-section, and $\lambda_{o}$ is the eigenvalue obtained without the added $\alpha / v$ cross-section, then the prompt-neutron lifetime $(\Lambda)$ can be obtained from

$$
\Lambda=\frac{\rho}{\alpha}
$$

\section{VALIDATION OF PHYSICS CALCULATIONAL METHODS}

\subsection{Introduction}

In order to test the validity of the calculational methods used in the conceptual design of the PBF reactor, physics calculations have been carried out for the Spert I Oxide Core [25] and the MARTY critical experiment [36]. Both of these cores were constructed of fuel rods having the parameters summarized in Table XVII. These cores were similar to that proposed for the PBF in that they were water-moderated and-reflected, low-enrichment, $\mathrm{UO}_{2}$ cores employing cylindrical fuel rods. The specific studies which were done included criticality, prompt-neutron lifetime, and Doppler coefficient of reactivity calculations. Agreement with experimentally determined values 
was good in each case, thereby supporting the validity of the calculational methods used in the PBF conceptual design.

\section{TABLE XVII}

\section{SPERT I OXIDE CORE FUELL ROD PARAMETERS [25]}

Total length of rod

Active length

Outside diameter of rod

Cladding thickness (stainless steel)

Fuel

Fuel enrichment

Effective $\mathrm{U}_{2}$ densily

Maes $\mathrm{UO}_{2}$ per fuel rod

Center-center fuel pin spacing

Metal-to-water ratio
71.5 in:

66.9 in.

0.5 in.

0.028 in.

Cumpressed $\mathrm{UO}_{2}$ powder

4.02 wt\% U-235

$9.45 \mathrm{~g} / \mathrm{cc}$

$1600 \mathrm{~g}$

$0.663 \mathrm{in}$.

0.81

\subsection{Calculational Methods}

Insofar as possible, the same calculational methods were applied as those used for the PBF; ie, the fast and thermal reactor constants in group diffusion equations were obtained from the GAM-1 [39] and SOFOCATE [31] codes, respectively. In the diffusion-theory calculations the core was treated as being homogeneous once the flux-weighted thermal constants were obtained, as described in Sootion $Y, 1$. Thermal constants for the rontronl rnd hlades (aluminum-boron alloy) of the SPERT Oxide Core were obtained by, using blackness theory, while the fast constants were obtained by adding a $1 / \mathrm{v}$ absorber to the absorption cross section of pure aluminum as follows:

$$
\Sigma_{a}(1 / v)=N(B-10) \sigma_{a}^{t h}(B-10) v\left(2200 \frac{m}{\mathrm{sec}}\right) /(\bar{v})^{i}
$$

where

$(\bar{v})^{i}=$ average speed of neutrons in group $i$, and

$\dot{N}(B-10)=$ atom density of boron-10 in control rod blades.

$\sigma_{\text {th }}(\mathrm{B}-10)=$ thermal microscop1c absurption cruss seclion of boron-10, taken to be 4010 barns at $2200 \mathrm{~m} / \mathrm{sec}$.

\subsection{Criticality Studies}

It was determined from the MARTY Critical Experiments [36] that 408 fuel pins (of the type indicated in Table XVII) arranged in cylindrical geometry with essentially infinite water reflection were necessary to achieve criticality. 
A four-group, one-dimensional, criticality calculation was made for this using MDMM-1 [43, 44]. The core radius used in the problem was $19.19 \mathrm{~cm}$. With an axial buckling of $0.0003 \mathrm{~cm}^{-2}$ corresponding to the $66.9 \mathrm{in}$. core height, the resulting eigenvalue was 1.021 .

In criticality experiments with the operational, unconstrained SPERT I Oxide Core, the critical control rod insertion depth was found to be 43.5 in. To calculate an eigenvalue for this insertion depth, a conventional flux synthesis technique was employed using PDQ-4 [45] and MDMM-1 [44]. Specifically, the procedure was as follows: Two four-group, 2500-mesh-point PDQ problems were run, each representing radial planes of the reactor in the two dissimilar vertical regions of the core; ie, "rods in" and "rods out" sections. A groupindependent axial core buckling was used such that each problem was near critical. The group-dependent radial core bucklings calculated by PDQ were then used in a four-group, axial MDMM-I problem, in conjunction with the FLUSY [46] program to calculate the group-dependent axial core bucklings. Using these bucklings as input to $\mathrm{PDQ}-4$, the iterative procedure was repeated. The converged eigenvalue obtained by this method was 1.015 .

As a check on the validity of four-group diffusion calculations for this type of core, an eighteen group AIM-6 [47] problem was also run for the MARTY Core. The resulting eigenvalue of 1.0193 indicated that insofar as criticality is concerned, four-group calculations are adequate for the PBF.

\subsection{Prompt-Neutron Lifetime Study}

Using PDQ-4 [45], a prompt neutron lifetime calculation was made for the vertical section of the SPERT I Oxide Core containing no control rods. The method used was identical to that used for the PBF; ie, a $1000 /\left(\bar{v}_{r}\right)^{i}$ absorption cross section was added to each region of the problem, where:

$$
\begin{aligned}
& \left(\bar{v}_{\mathbf{r}}\right)^{\mathbf{i}}=\text { average neutron velocity for group i in region } r \\
& 1000=\text { the inverse asymptotic reactor period in } \mathrm{sec}^{-1} .
\end{aligned}
$$

Addition of the poison resulted in a reactivity change of 0.02633 , where the reactivity $(\rho)$, is defined as in Section $X, 1$. The resultant prompt neutron lifetime was $26.3 \mathrm{\mu sec}$. From step-transient tests on the unconstrained Spert I Oxide Core $[24]$, an experimental value of $\Lambda / \beta$ eff was determined to be $3.61 \pm 0.05 \mathrm{msec}$. The value of $\beta$ eff is estimated to be 0.008 [48], so that:

$$
\begin{aligned}
& \Lambda=28.9 \text { microsec (experimental) } \\
& \Lambda=26.3 \text { microsec (calculated) }
\end{aligned}
$$

Considering the approximations involved in the calculation, the $9 \%$ discrepancy is well within the expected range of agreement.

\subsection{Doppler Coefficient of Reactivity Study}

An experimental average Doppler coefficient of reactivity for the SPERT Oxide Core was found to be $2.2 \times 10^{-5} /{ }^{\circ} \mathrm{C}[24]$. This value, determined for the $3.2 \mathrm{msec}$ period test, was based upon the assumption that the energy produced to peak power was generated and contained only in the "rods out" section of the core and that $\beta$ eff $=0.0080$. If one also assumes, as a first approximation, that 
the energy is uniformly distributed throughout the $\mathrm{UO}_{2}$ in the "rods out" section of the core, then the resulting temperature rise is calculated to be approximately $600^{\circ} \mathrm{C}$. Therefore, an average Doppler coefficient of reactivity for temperatures up to $600^{\circ} \mathrm{C}$ was calculated using the MDMM-I and GAM programs as discussed in Section $V, 2.4$. One difference from the PBF calculational procedure was that the diffusion calculations were performed in the axial rather than the radial directions, the base problem being the converged axial problem of the flux synthesis series. Inserting core constants calculated by the GAM program for a U-238 temperature of $600^{\circ} \mathrm{C}$ into the "rods out" region of the base problem resulted in a $\Delta \mathrm{k}_{\text {eff }}$ of -0.0137 , giving a calculated value of $-2.19 \times 10^{-5} \Delta \mathrm{k} / \mathrm{k}$ per degree centigrade for the average Doppler coefficient of reactivity. 


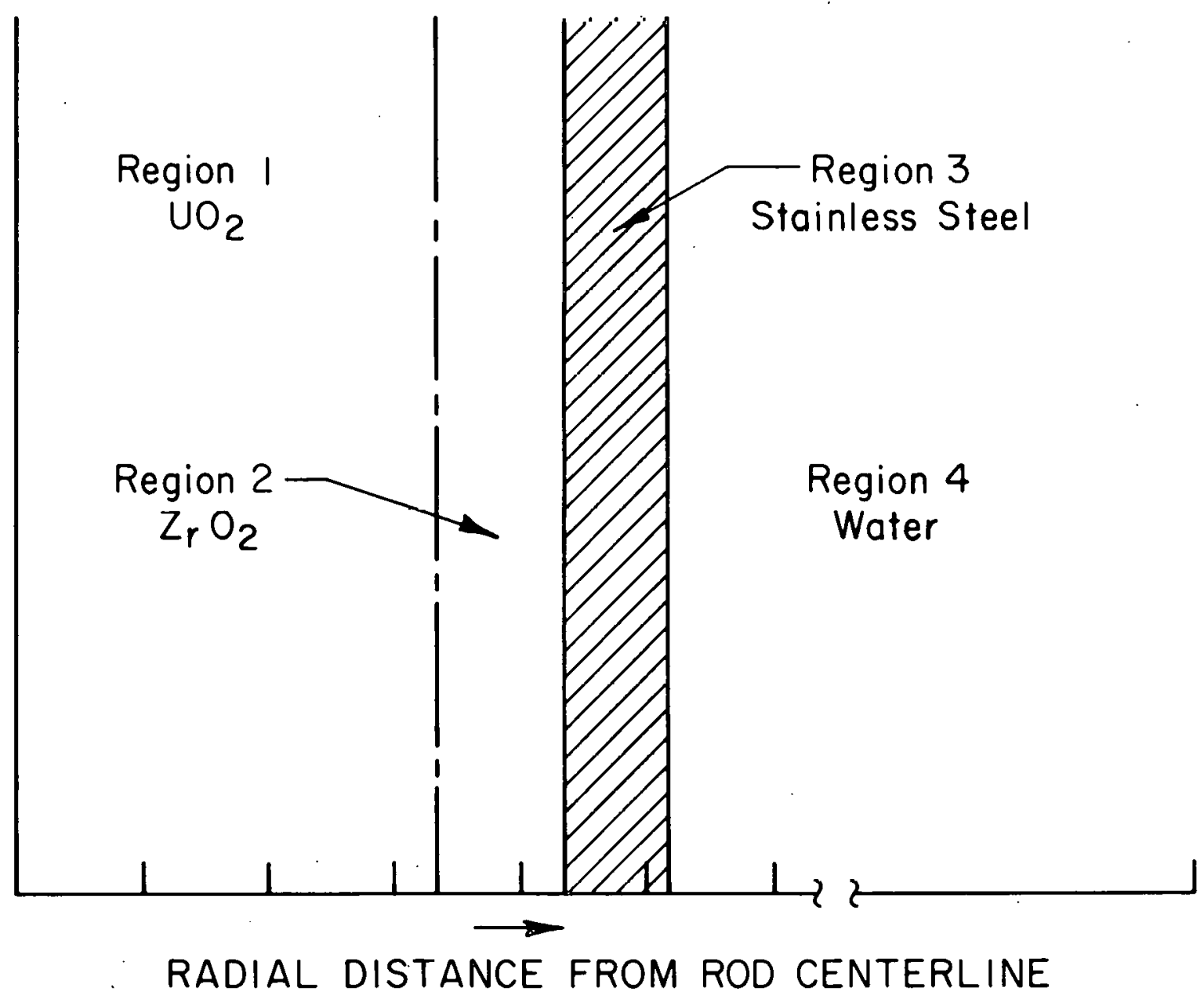

FIG, I MODEL FOR THERMAL CALCULATIONS, 


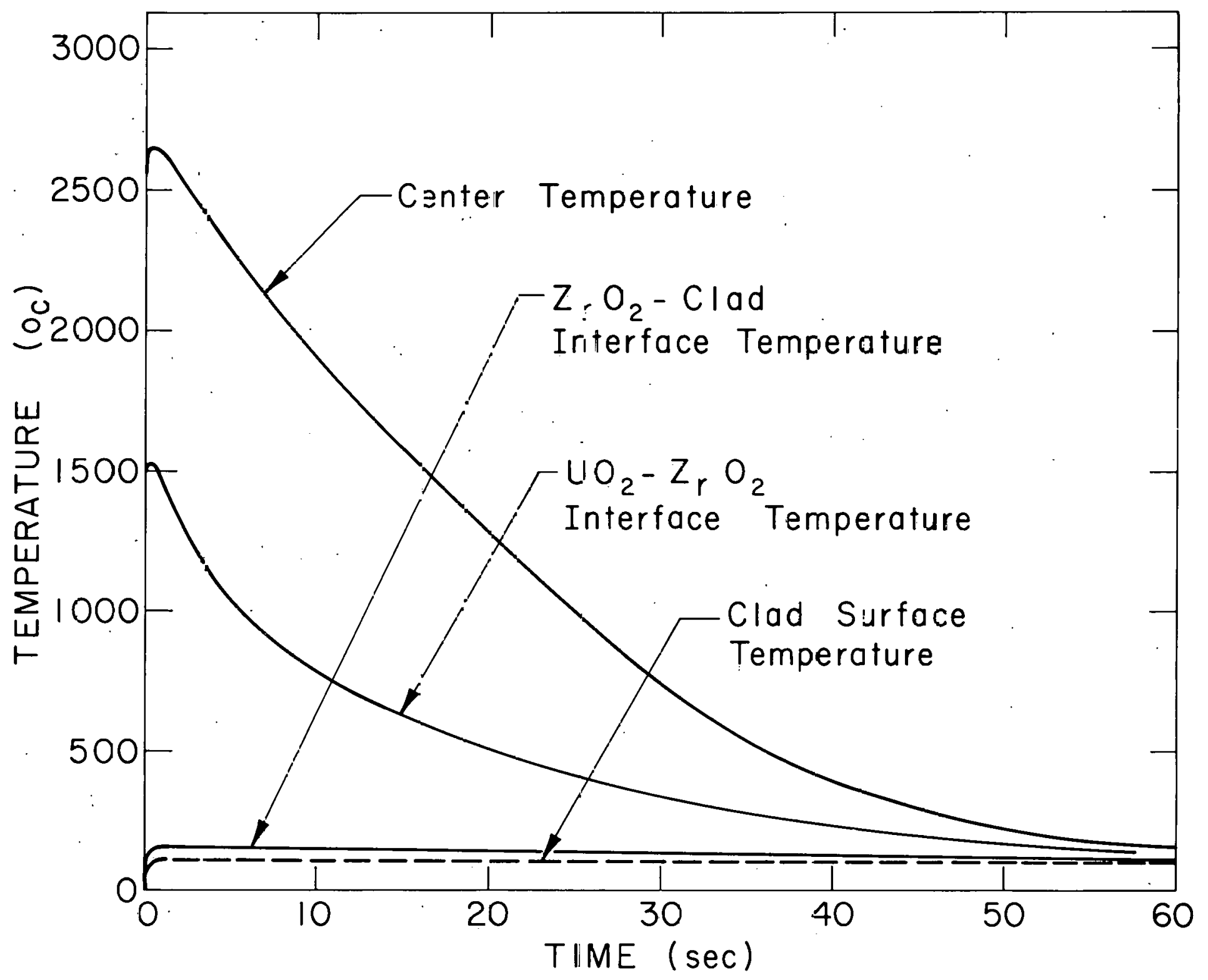

FIG. 2 TRANSIENT TEMPERATURES WITHIN THE FUEL PIN. 


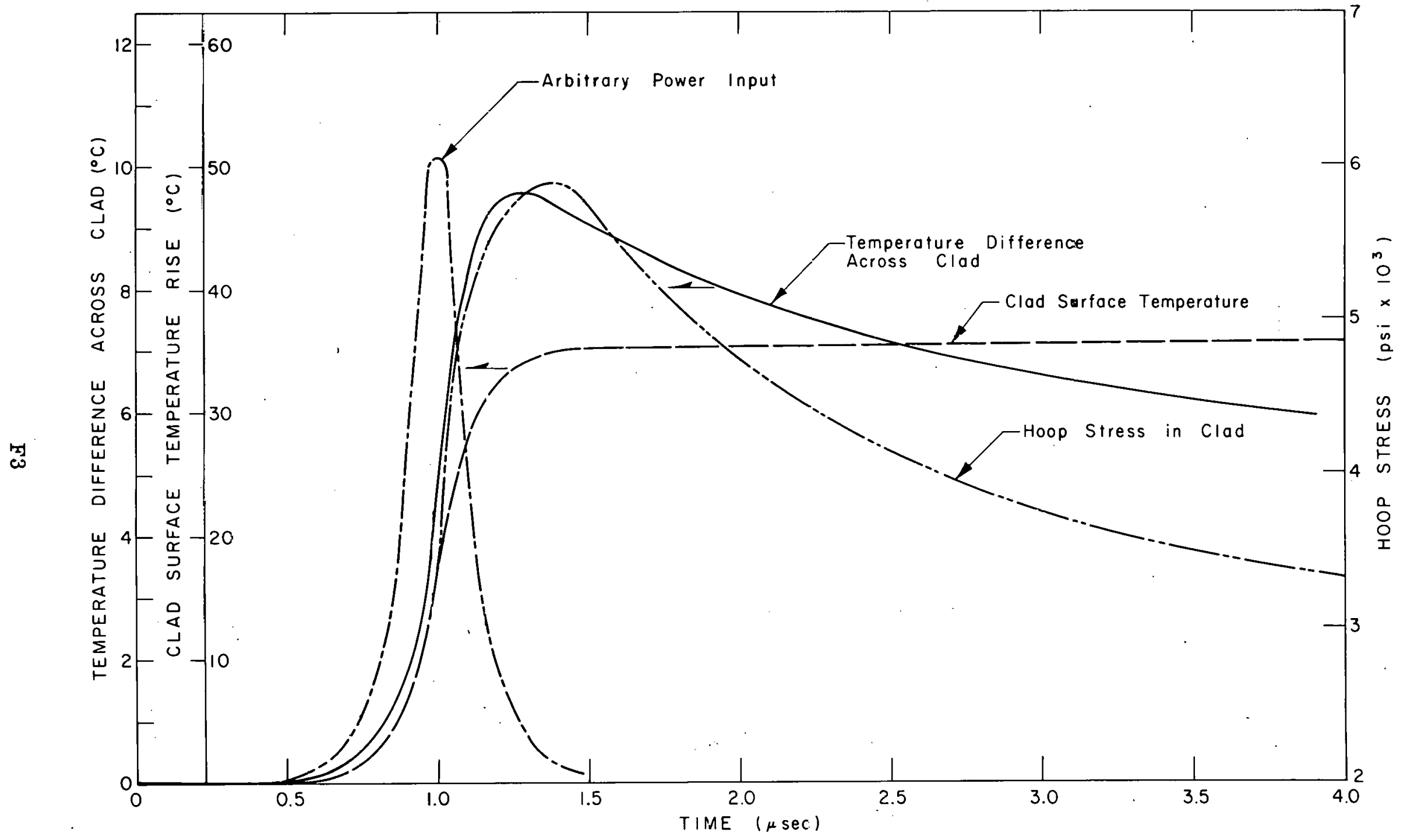

FIG. 3 THERMAL STRESS AND TEMPERATURE BEHAVIOR IN THE CLAD. 


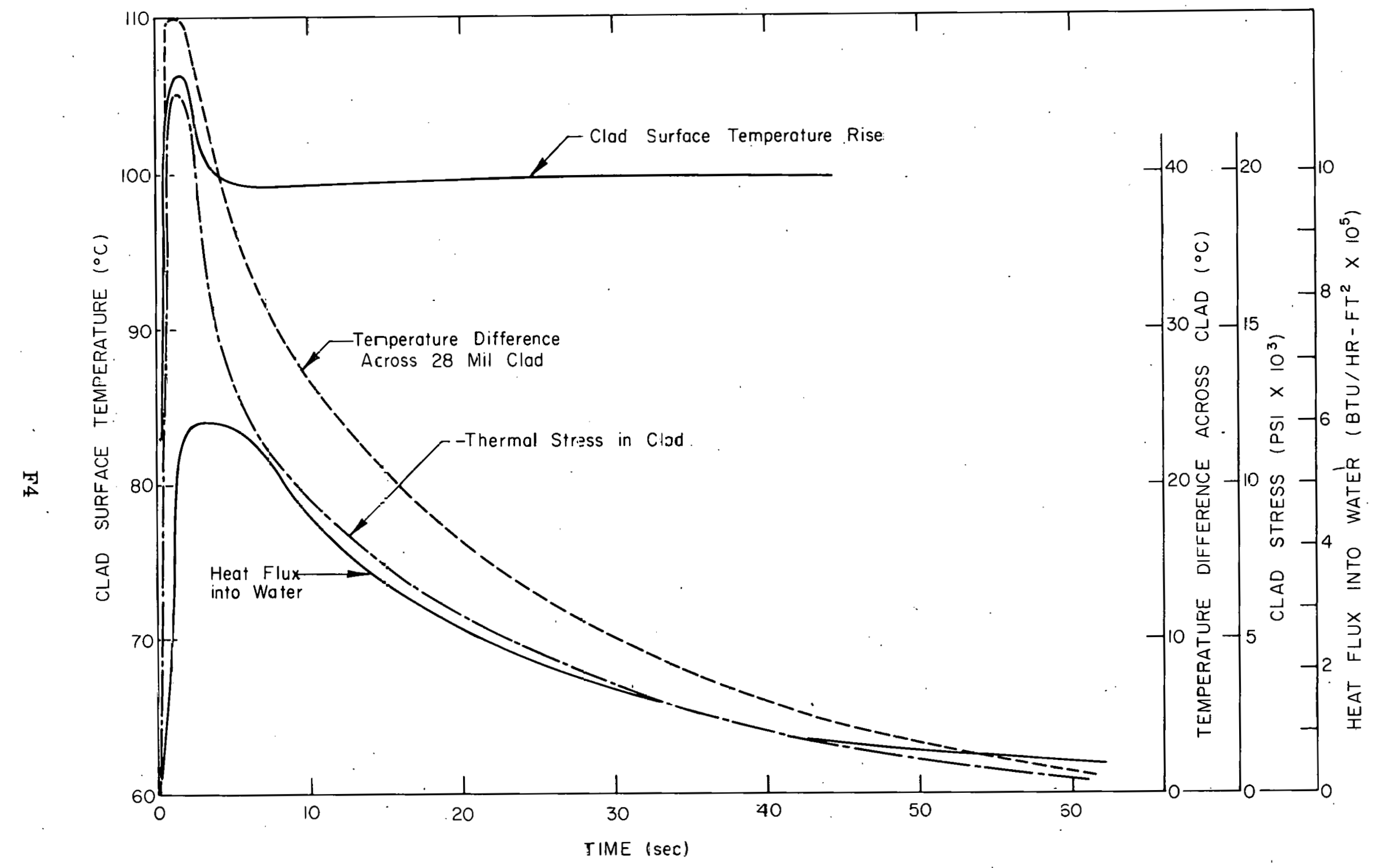

FIG. 4 THERMAL STRESS AND TEMPERATURE BEHAVIOR IN TH I CLA.D. 


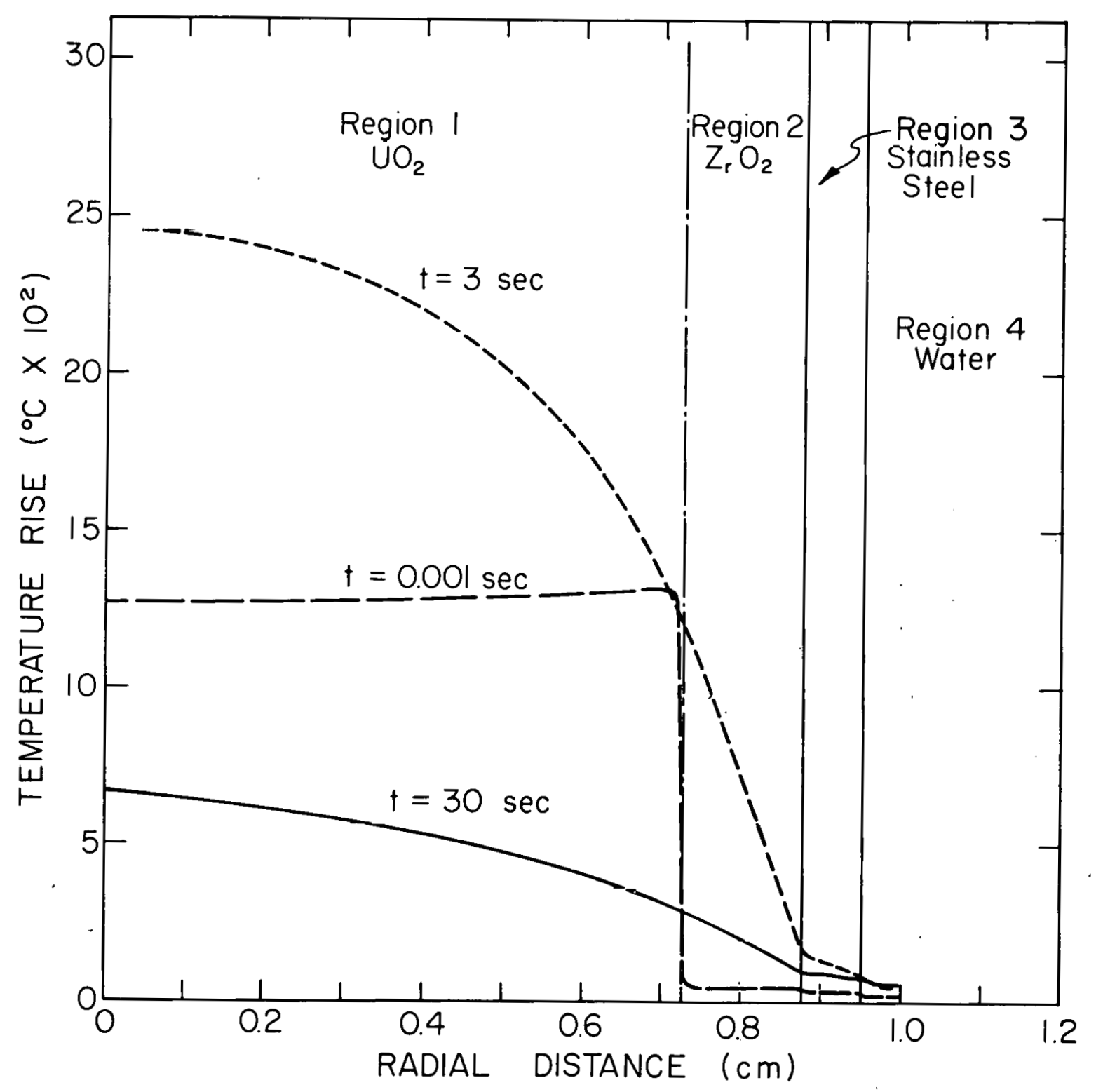

FIG. 5 TEMPERATURE DISTRIBUTIONS WITHIN THE FUEL PIN. 


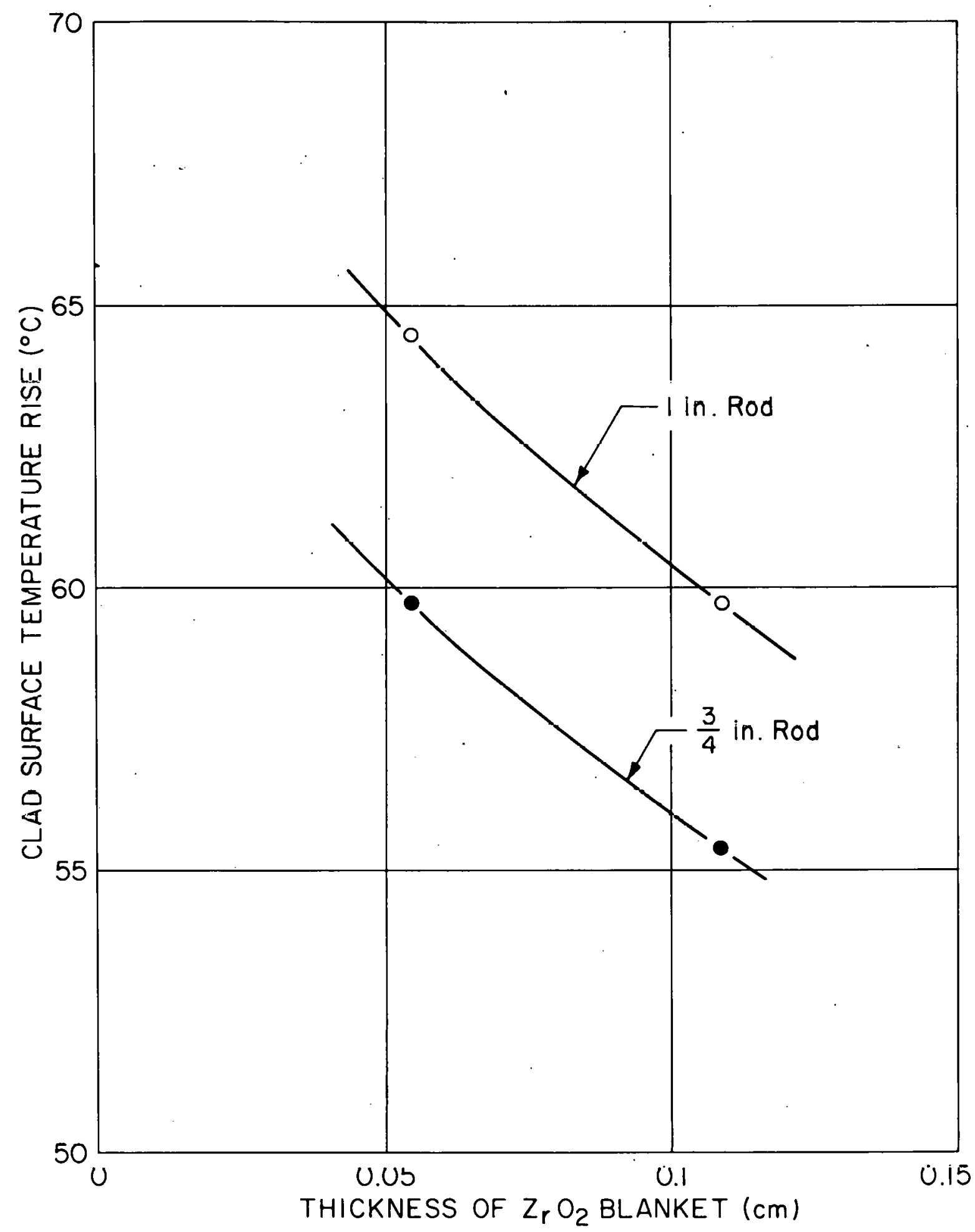

FIG. 6 EFFECT OF $Z_{r} \mathrm{O}_{2}$ INSULATOR THICKNESS ON CLAD SURFACE TEMPERATURE. 


\section{Experiment \\ REGION}

2. $\mathrm{H}_{2} \mathrm{O}$

3. Pressure Pipe - Stainless Steel Constants Averaged Over $\mathrm{A}_{2} \mathrm{O}$ Spectrum

4. Pressure Pipe - Stainless Steel Constants Averaged Over A Core Spectrum

5. Boron - Stainless Steel Flux Suppressor

6. Core

7. Stainless Steel $-\mathrm{H}_{2} \mathrm{O}$ Reflector

8. $\mathrm{H}_{2} \mathrm{O}$ Reflector

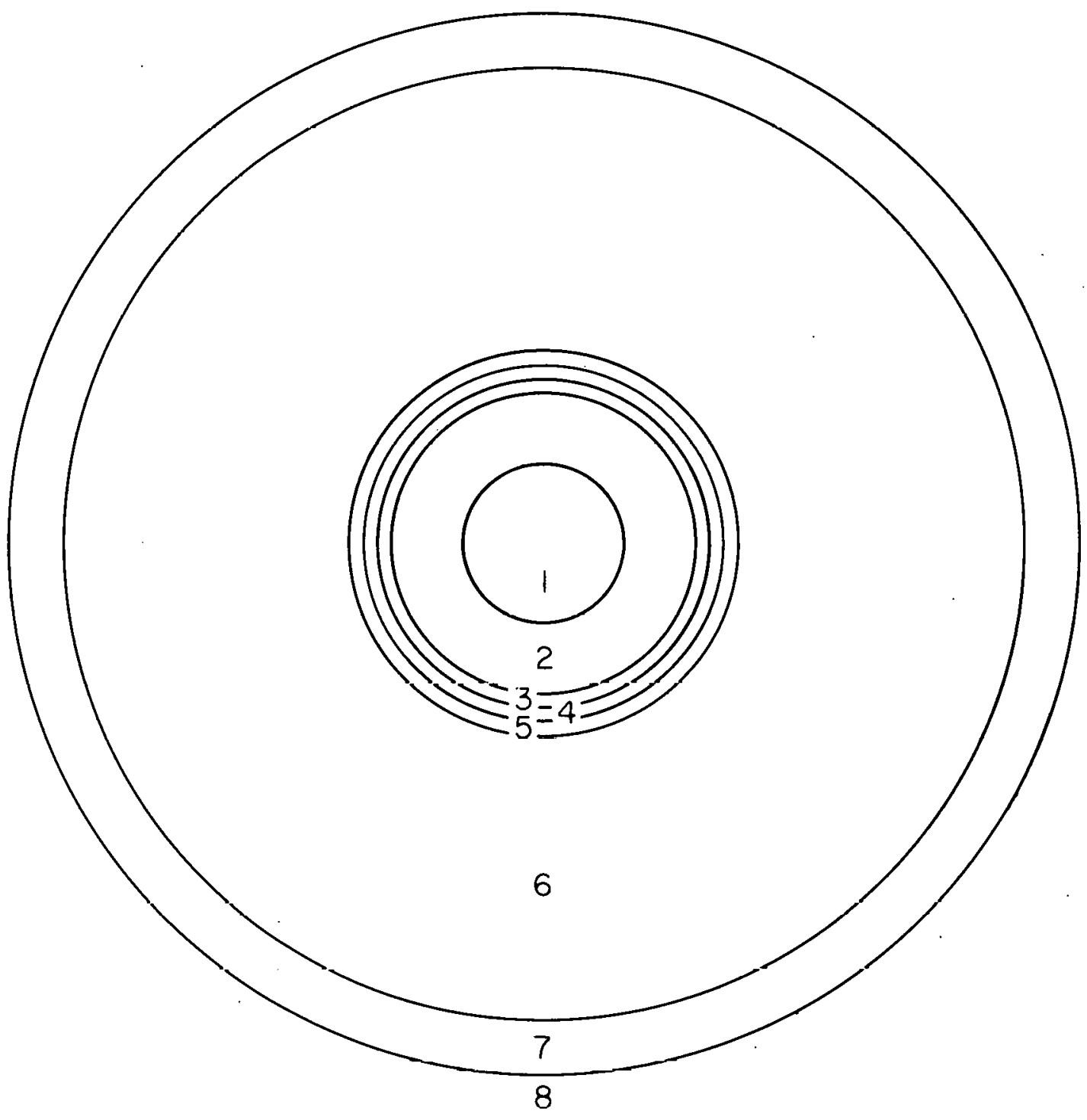

FIG. 7 REACTOR MODEL FOR OPTIMIZATION STUDIES. 


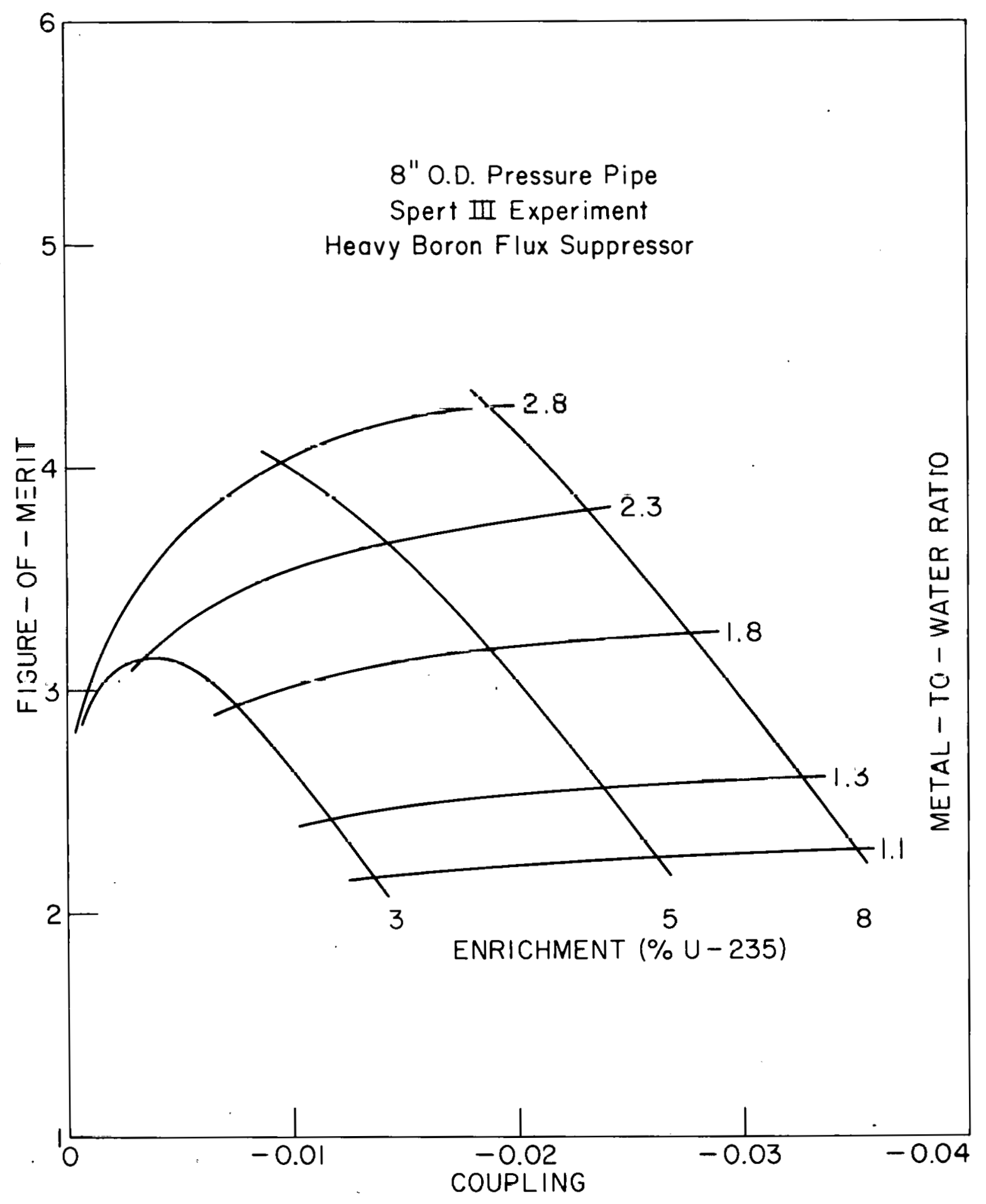

$761-8888-45-706-071278$

FIG. 8 EFFECTS OF METAL-TO-WATER RATIO AND ENRICHMENT ON FIGURE-OF-MERIT AND COUPLING. 


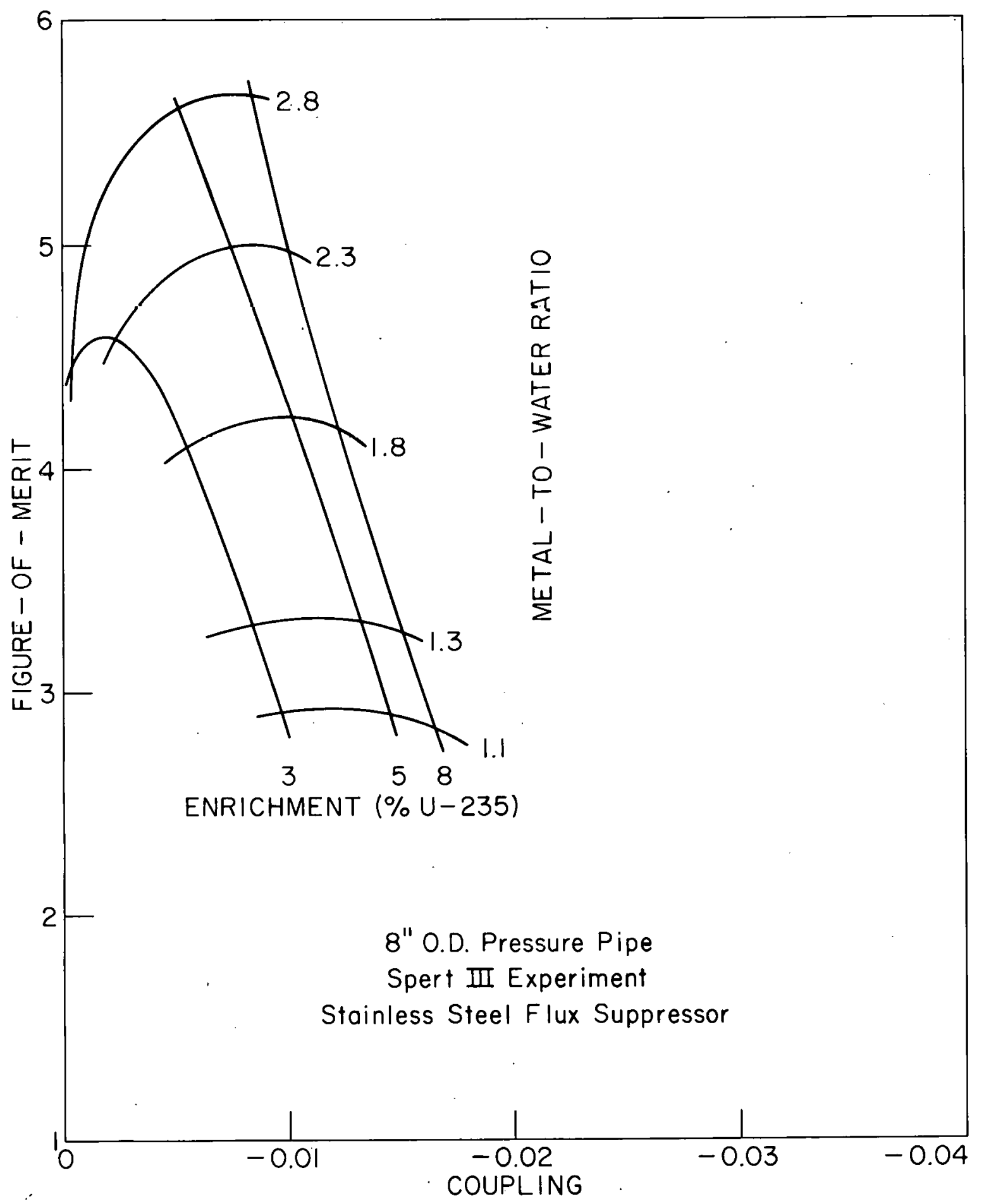

$761-8888-45-706-071281$

FIG. 9 EFFECTS OF METAL-TO-WATER RATIO AND ENRICHMENT ON FIGURE-OF-MERIT AND COUPLING. 


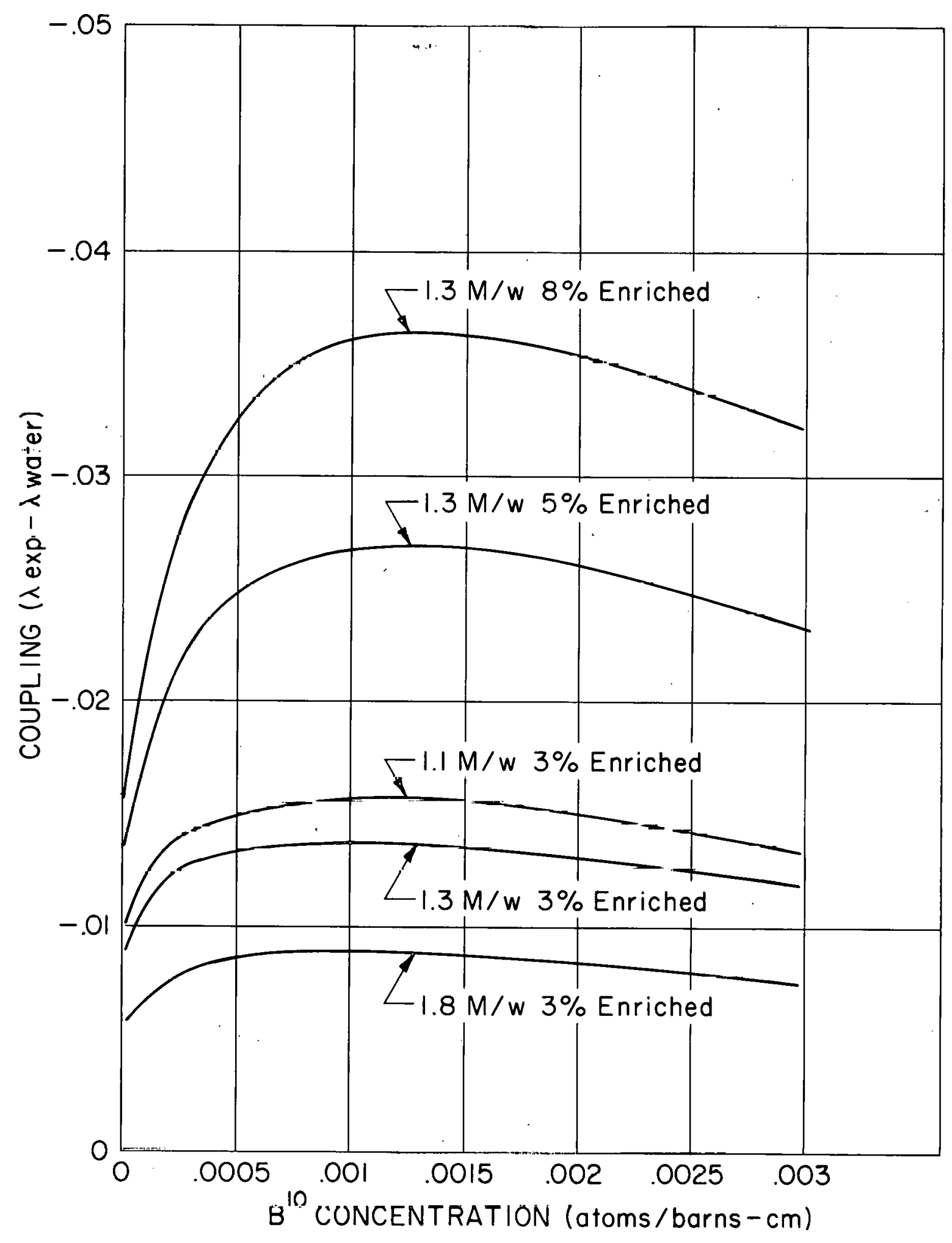

$761-8888-45-706-071279$

FIG. 10 EFFECTS QF BORON CONCENTRATION IN FLUX SUPPRESSOR ON COUPLING. 


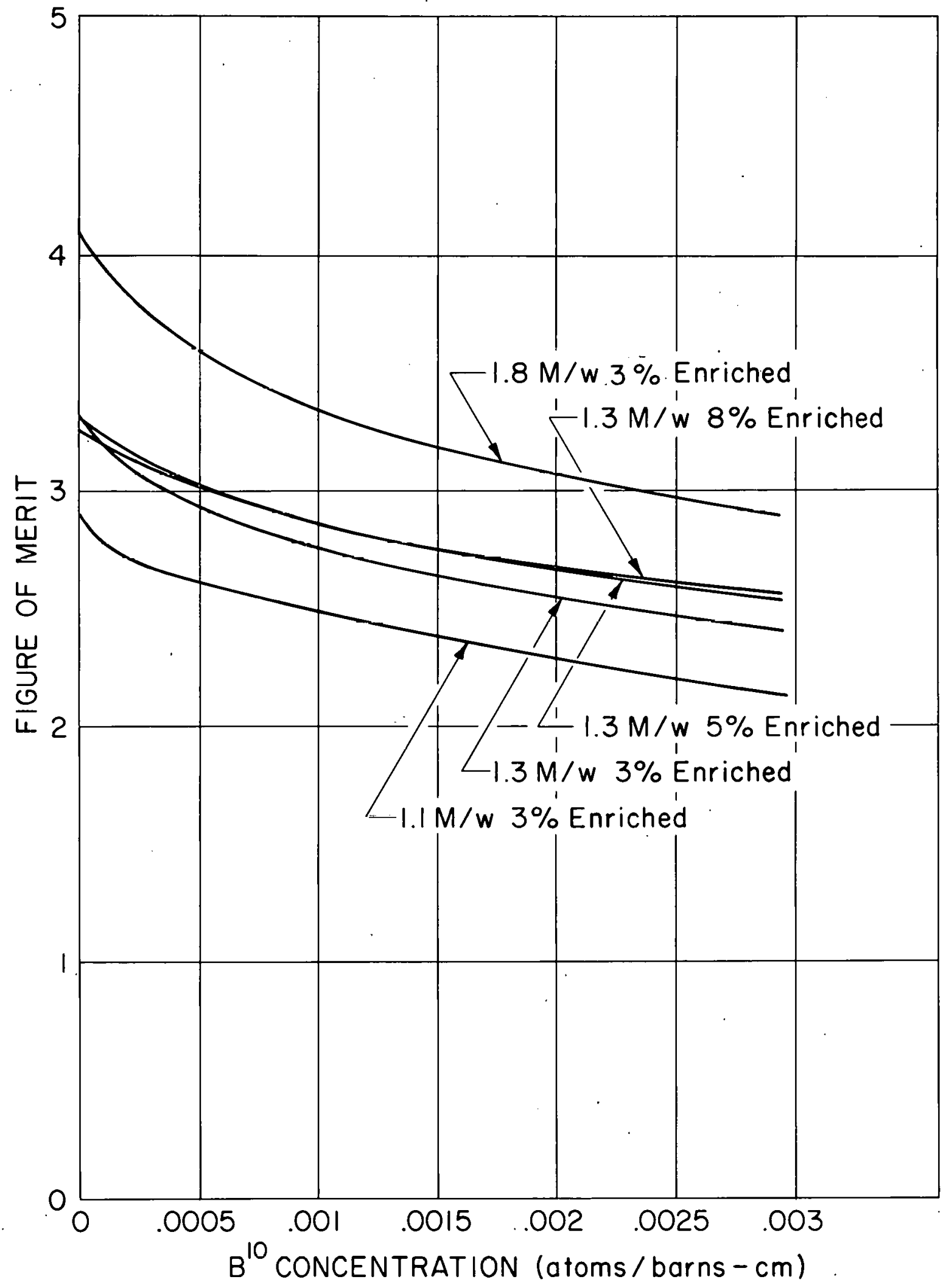

$$
761-8888-45-706-071280
$$

FIG. II EFFECTS OF BORON CONCENTRATION IN FLUX SUPPRESSOR ON FIGURE-OF-MERIT. 


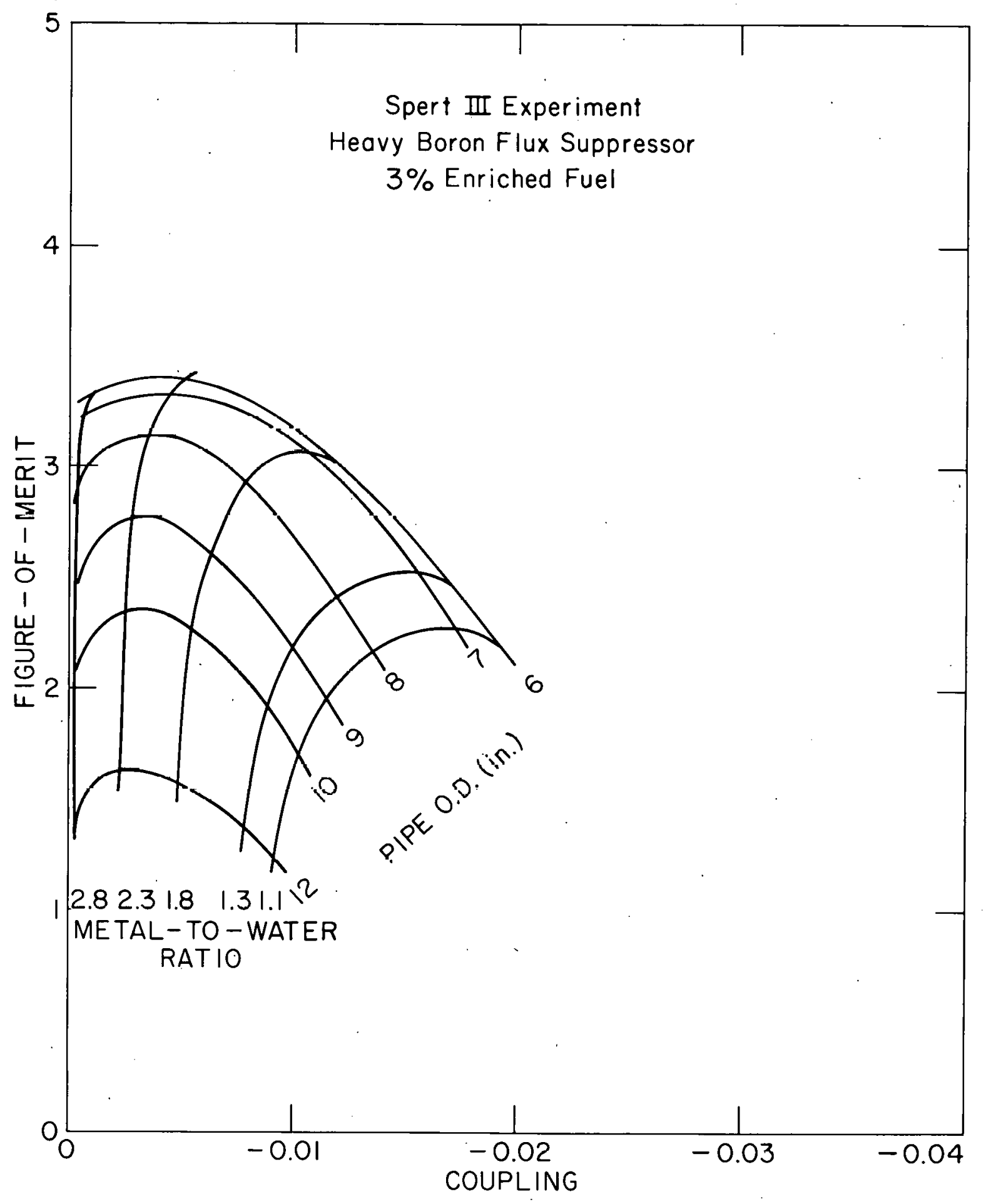

$$
761-8888-45-706-071282
$$

FIG. 12 EFFECTS OF METAL-TO-WATER RATIO AND PRESSURE PIPE DIAMETER ON FIGUREUR-MERIT" AND CUUPLING. 


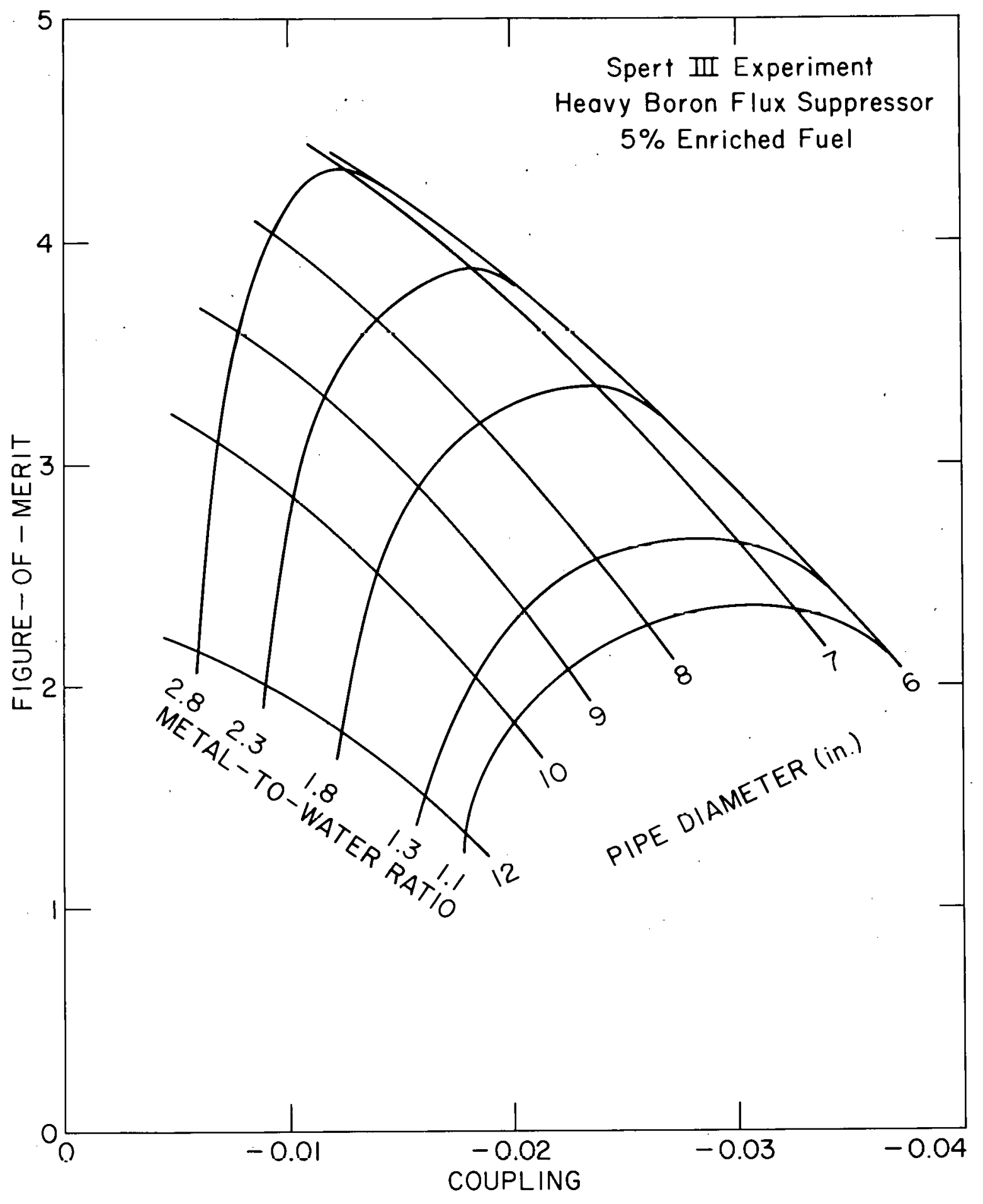

$$
761-8888-45-706-071283
$$

FIG. 13 EFFECTS OF METAL-TO-WATER RATIO AND PRESSURE PIPE DIAMETER ON FIGUREOF-MERIT AND COUPLING. 


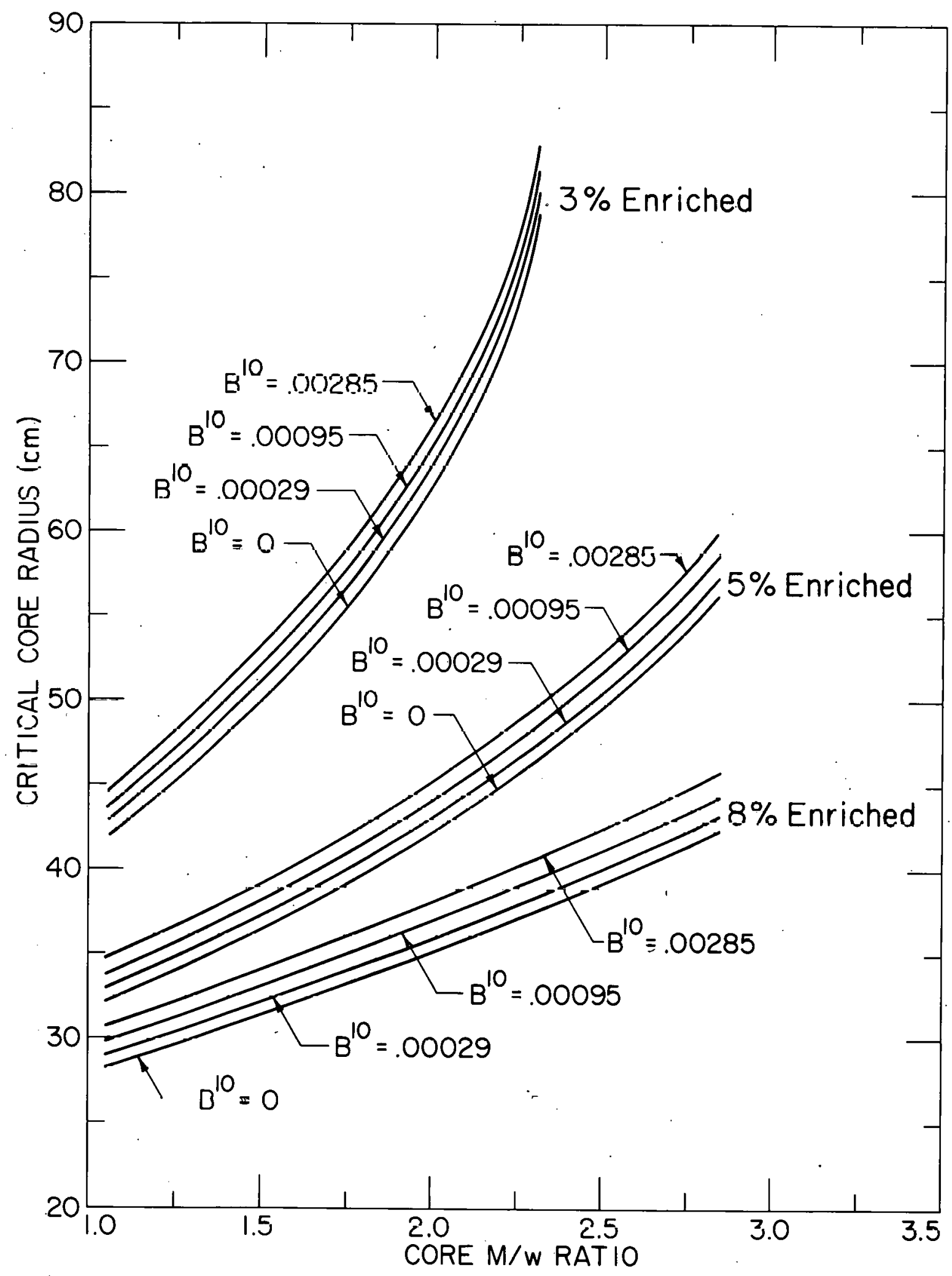

$761-8888-45-706-071284$

FIG. 14 EFFECTS OF METAL-TO-WATER RATIO, ENRICHMENT, AND BORON CONCENTRATION IN THE FLUX SUPPRESSOR ON THE CRITICAL CORE RADIUS. 


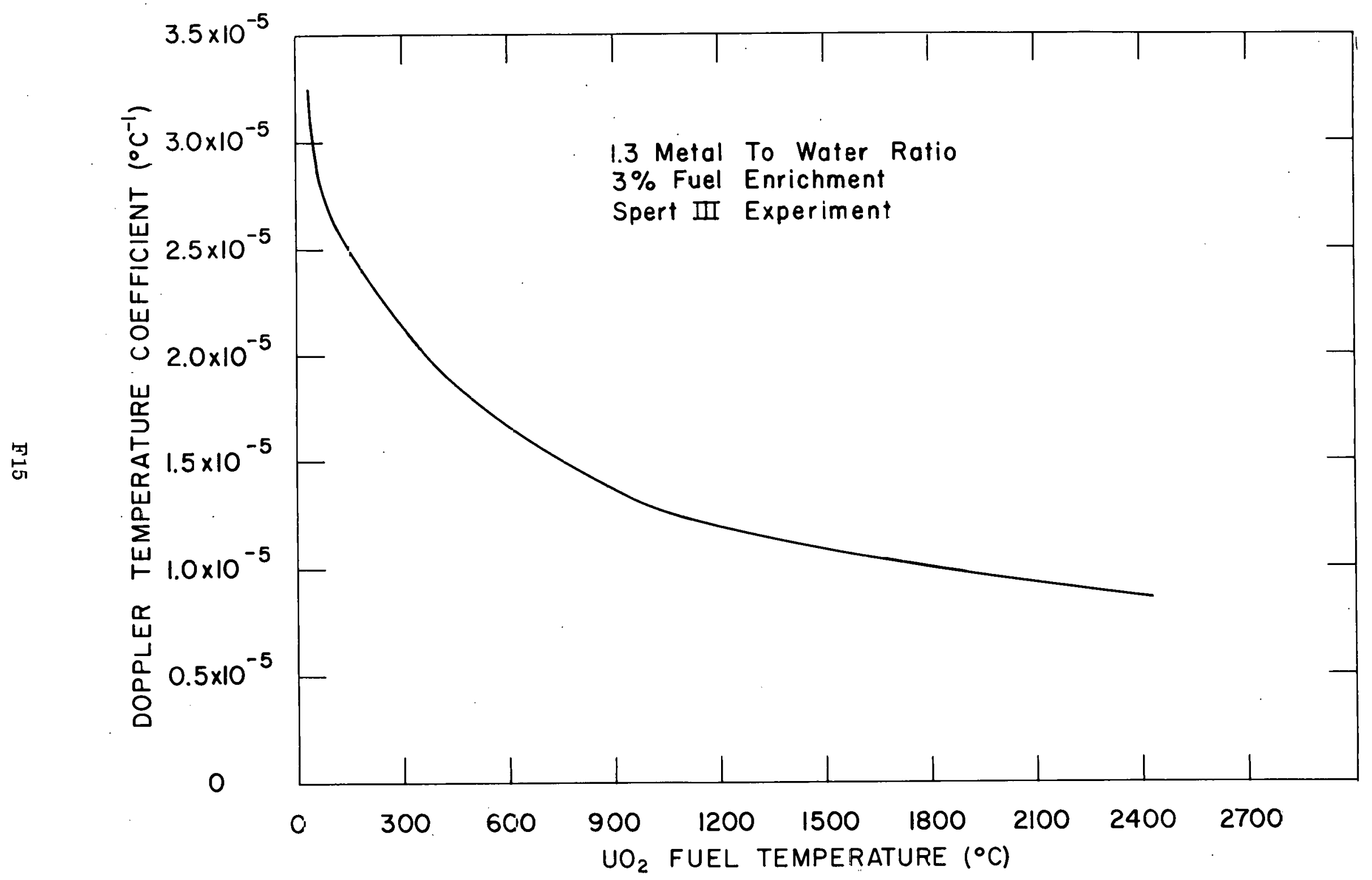

FIG. 15 DOPPLER TEMPERATURE COEFFICIENT OF REACTIVITY. 761-8888-45-706-071286 


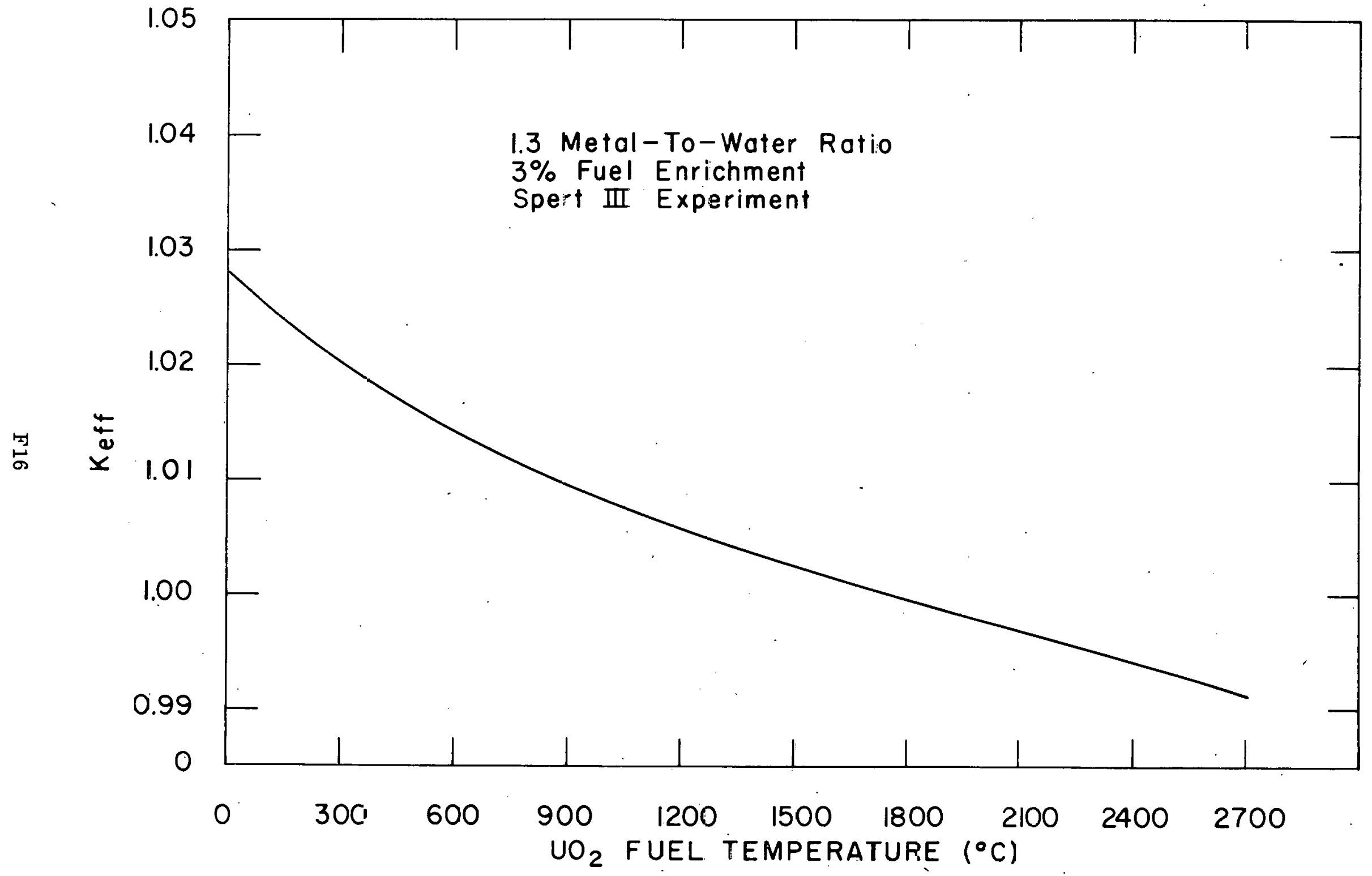

Fig. 16 VARIation of KEFF WITH FUEL TEMPERATURE. 761-8888-45-706-071287 


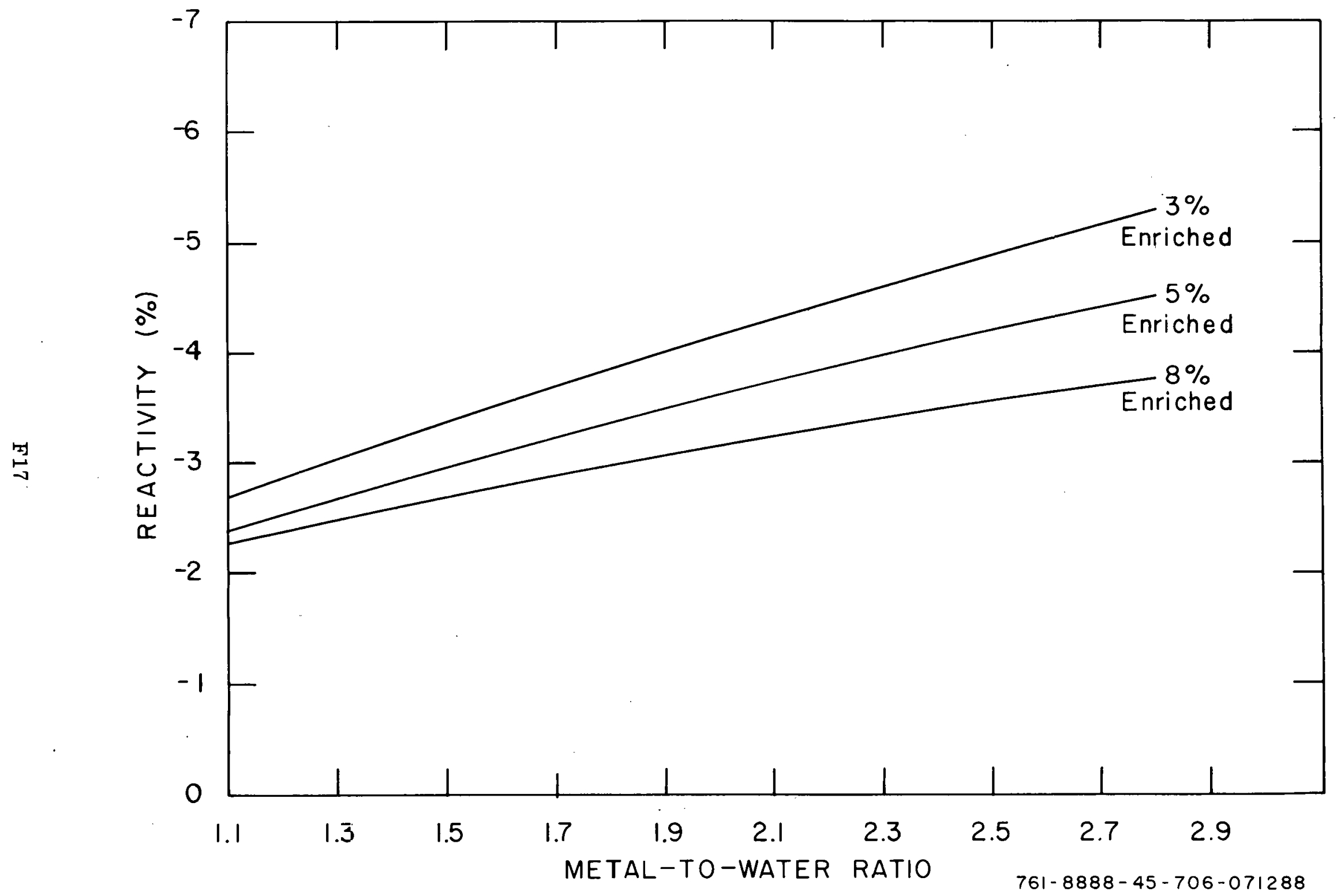

FIG. 17 EFFECTS OF METAL-TO-WATER RATIO AND ENRICHMENT ON DOPPLER REACTIVITY (FUEL TEMPERATURE CHANGED FROM $20^{\circ} \mathrm{C}$ TO $22.00^{\circ} \mathrm{C}$ ). 


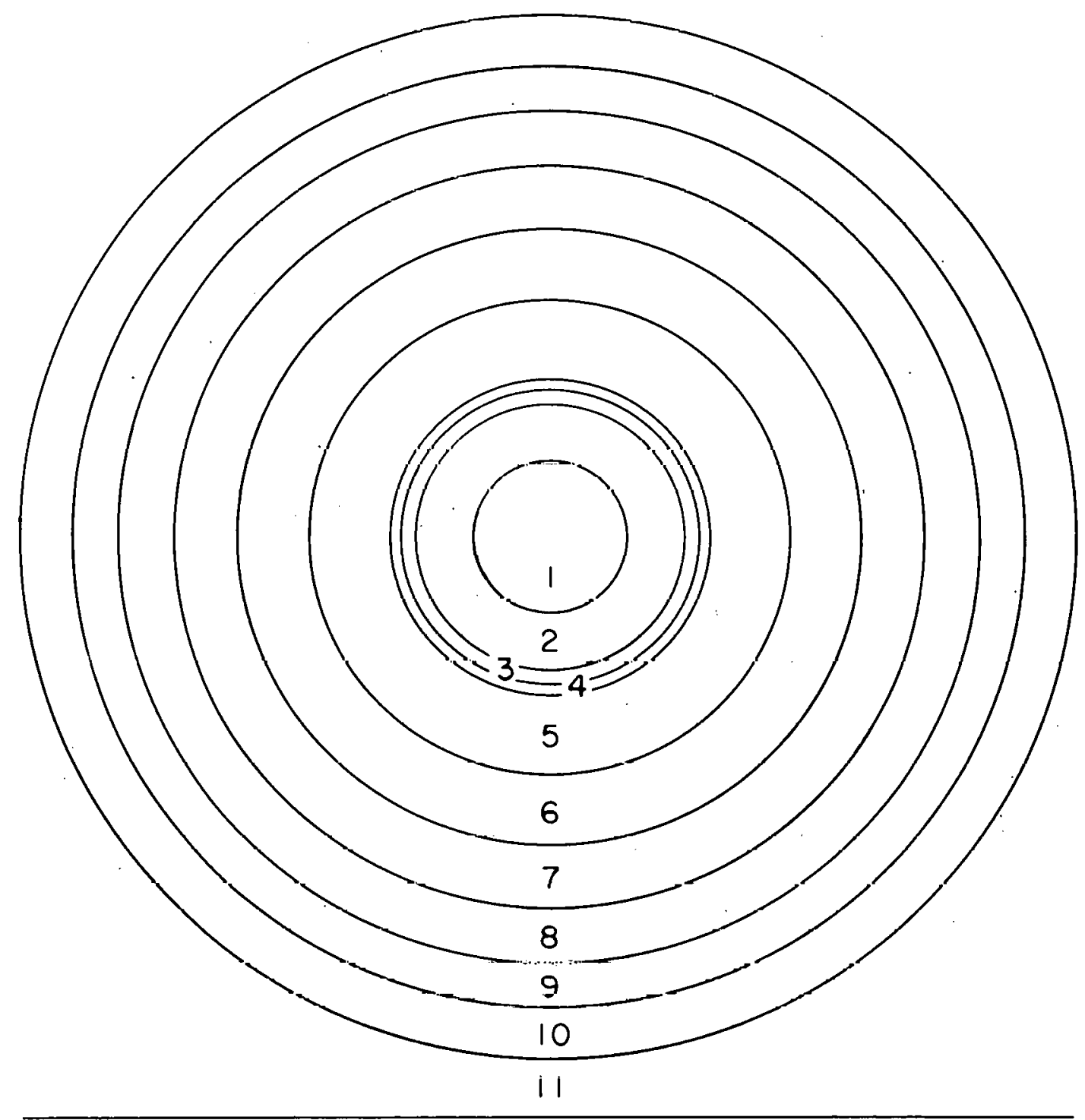

\section{REGION}

\section{Experiment}

2. Water Annulus

3. Stainless Steel Pressure Pipe

4. Flux Suppressor

5. Core
6. Core

7. Core

8. Core

9 Core

10. $80 \%$ Stainless Steel 8 $20 \%$ Wuler

11. Water Reflector

$761-8888-45-706-071296$

FIG. 18 MODEL FOR VOID COEFFICIENT STUDIES. 


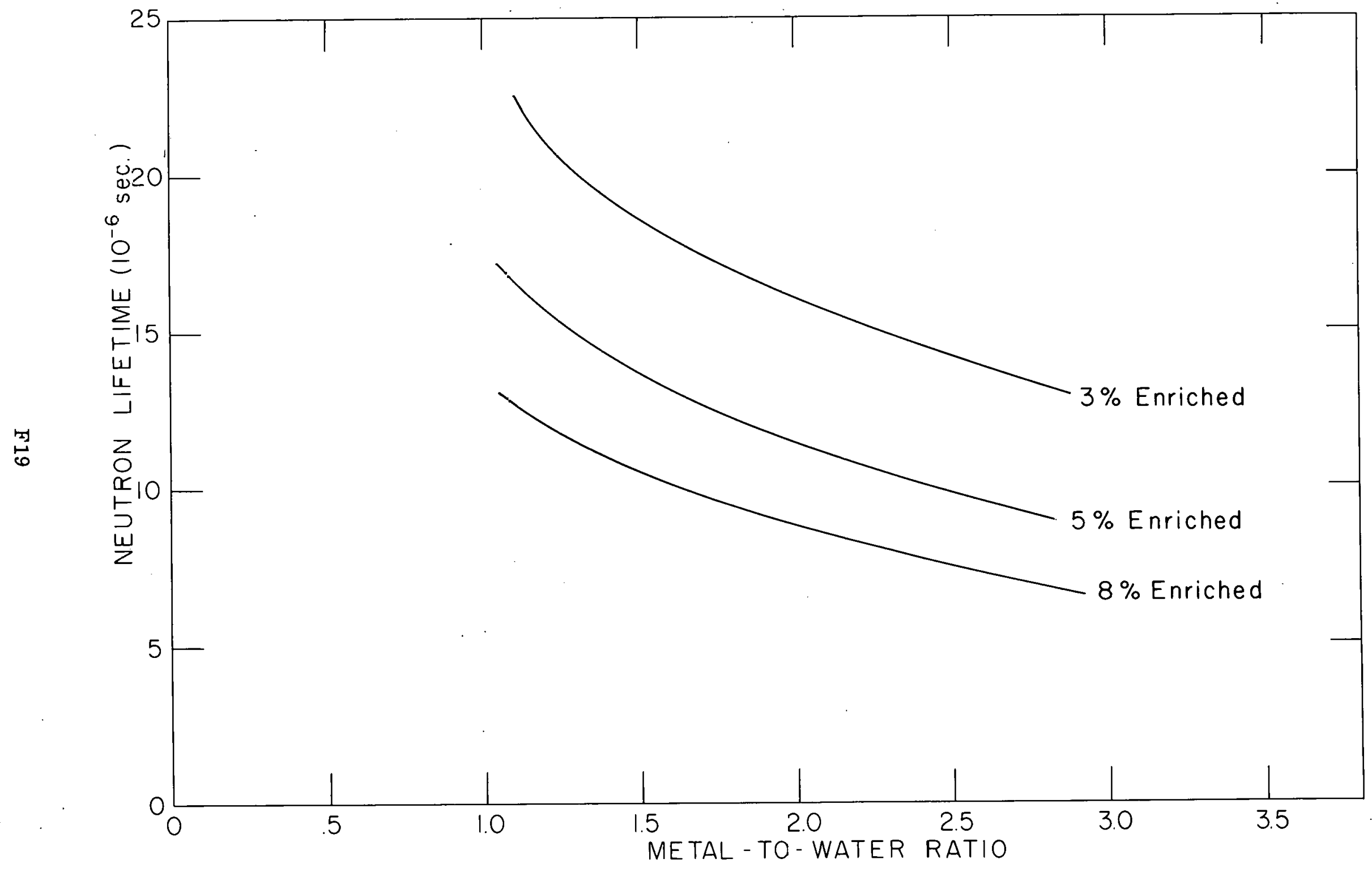

FIG. 19 EF=ECTS OF METAL-TO-WATER RATIO AND ENRICHMENT ON THE PROMPT NEUTRON LIFETIME. 


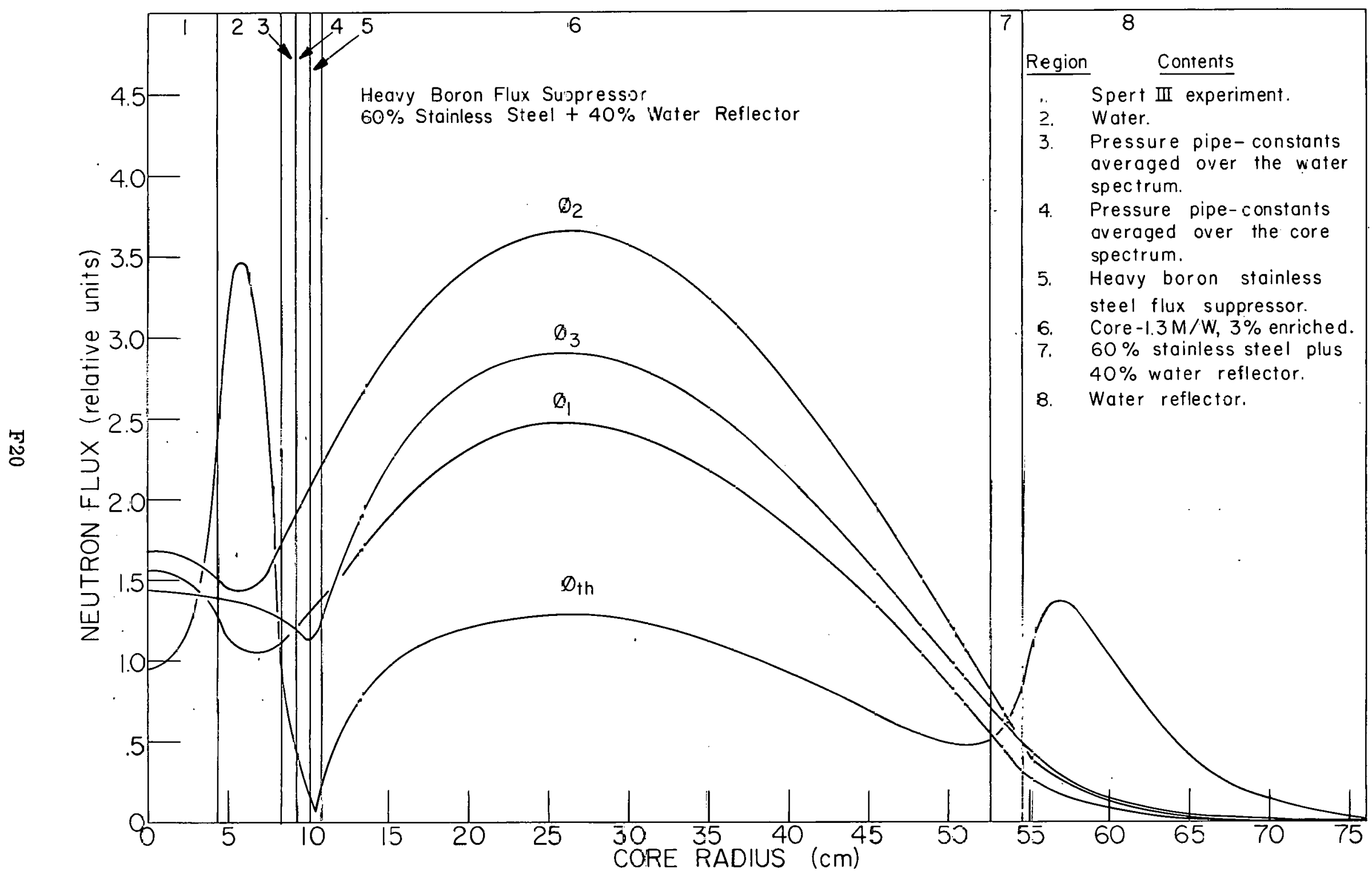

FIG. 20 FOUR-GROUP NEUTRON FLUX DISTRIBUTION, 


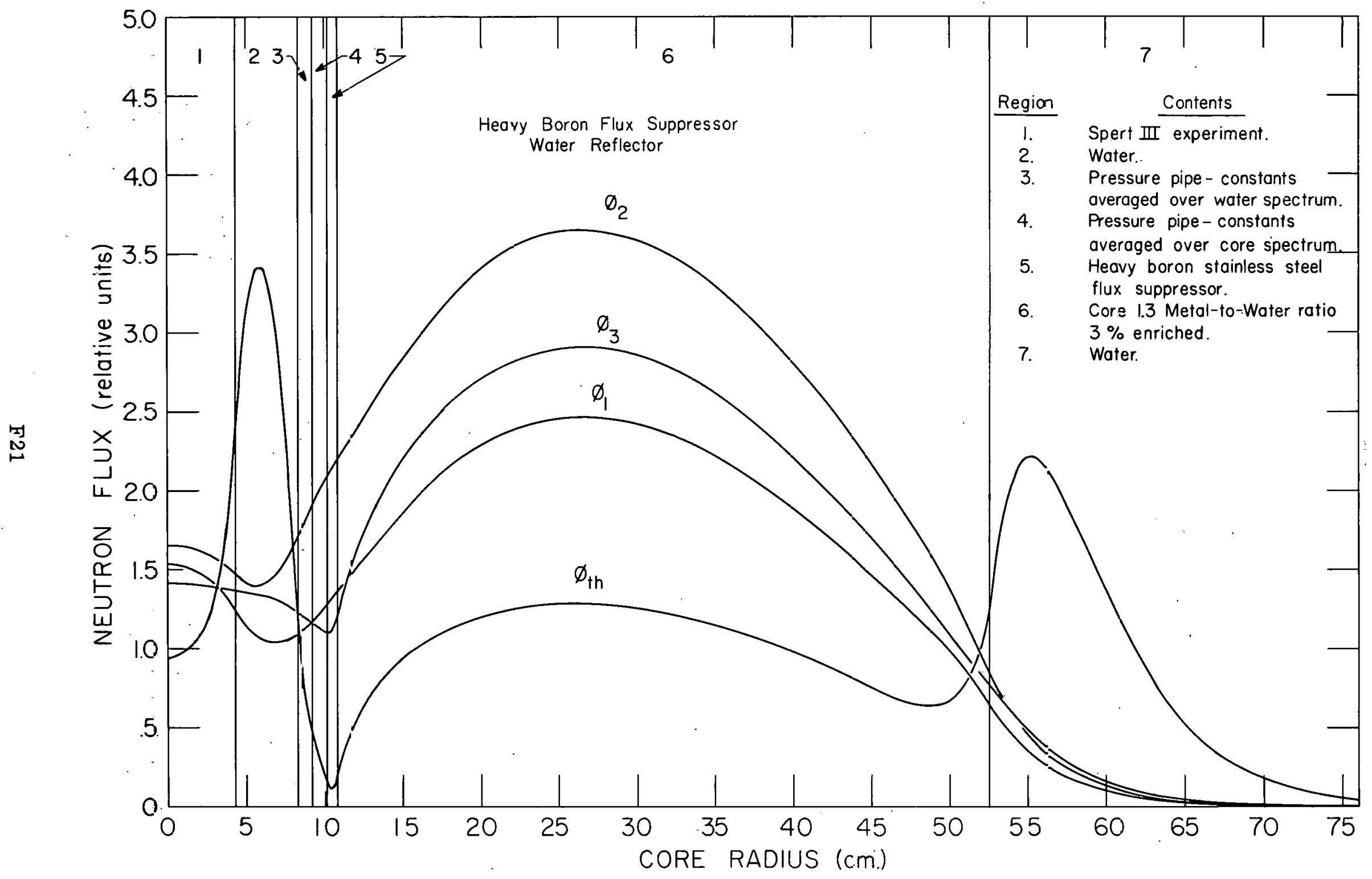

FIG. 21 FOUR-GROUP NEUTRON FLUX DISTRIBUTION. 


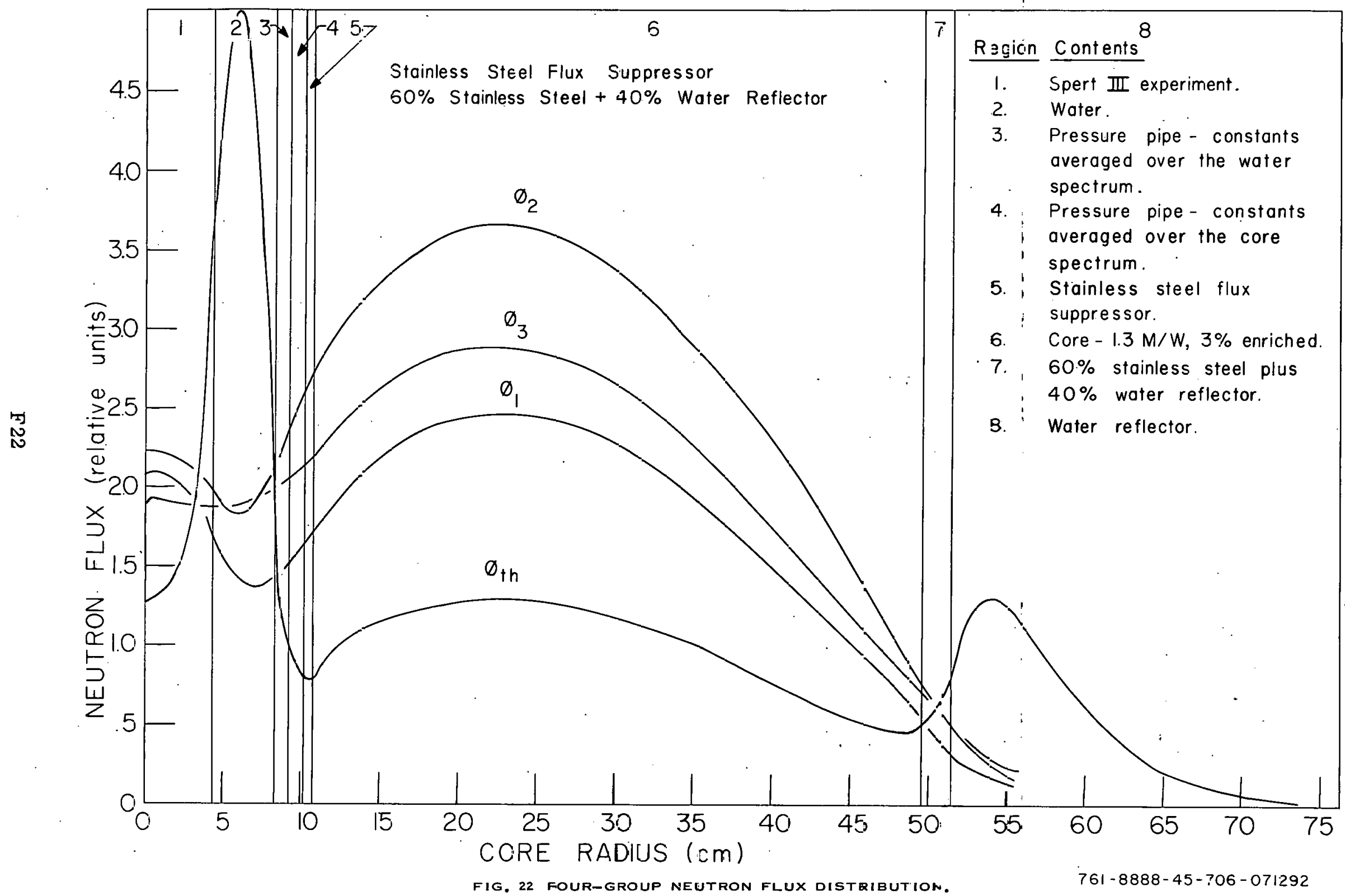




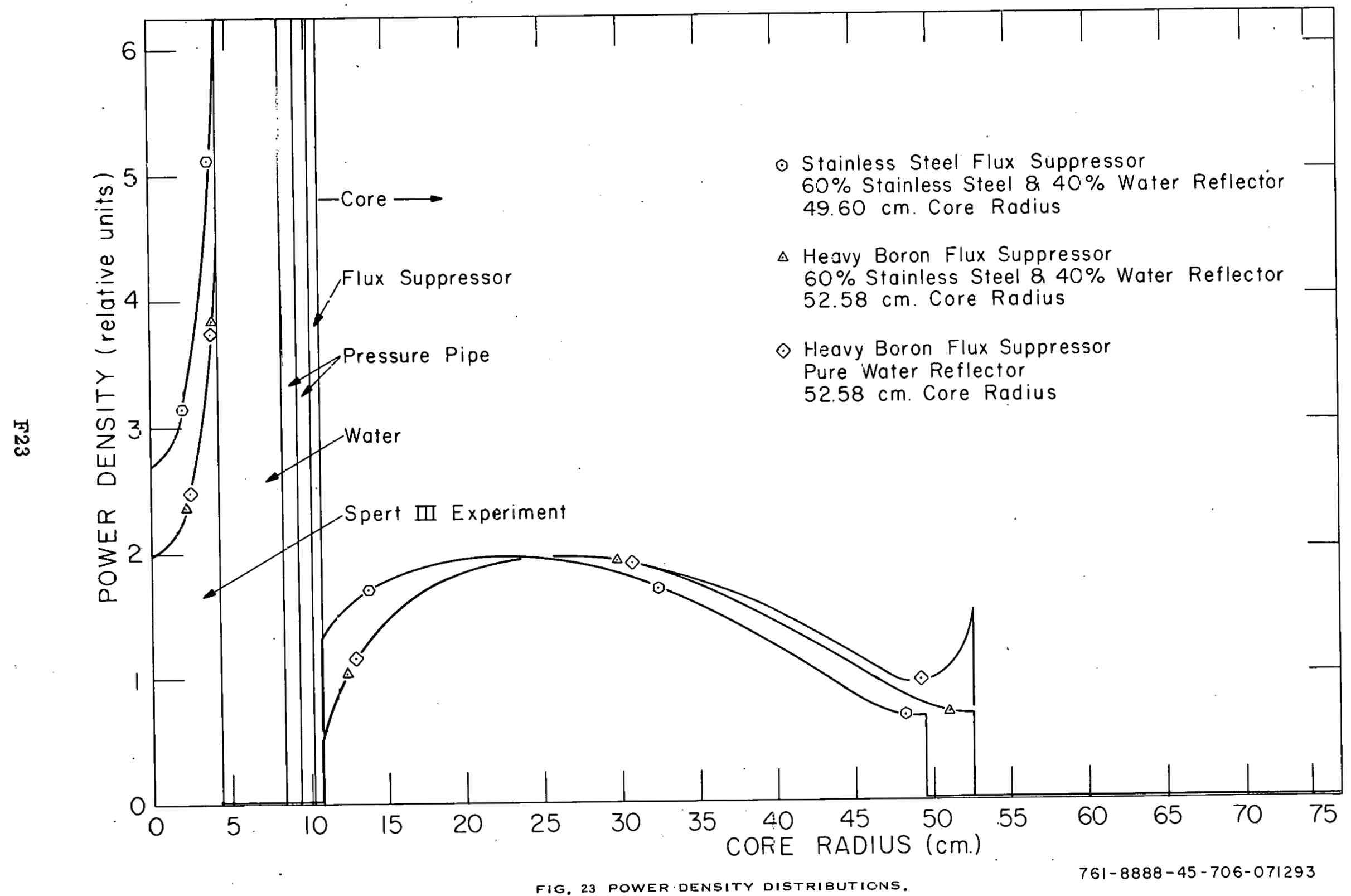




\begin{tabular}{c|l} 
REGION No. & \multicolumn{1}{|c}{ COMPOSITION } \\
\hline 1 & Graphite \\
2 & Graphite And Fuel \\
3 & Graphite \\
4 & Void \\
5 & Stainless Steel (Constants Averaged Over $\mathrm{H}_{2} \mathrm{O}$ Spectrum) \\
6 & H2O \\
7 & Stainless Steel (Constants Averaged Over $\mathrm{H}_{2} \mathrm{O}$ Spectrum) \\
8 & Stainless Steel (Constants Averaged Over Core Spectrum) \\
9 & Core (Out To A Radius Of $52.58 \mathrm{~cm})$. \\
& Balance Of Model Same As Shown On Figure 7
\end{tabular}

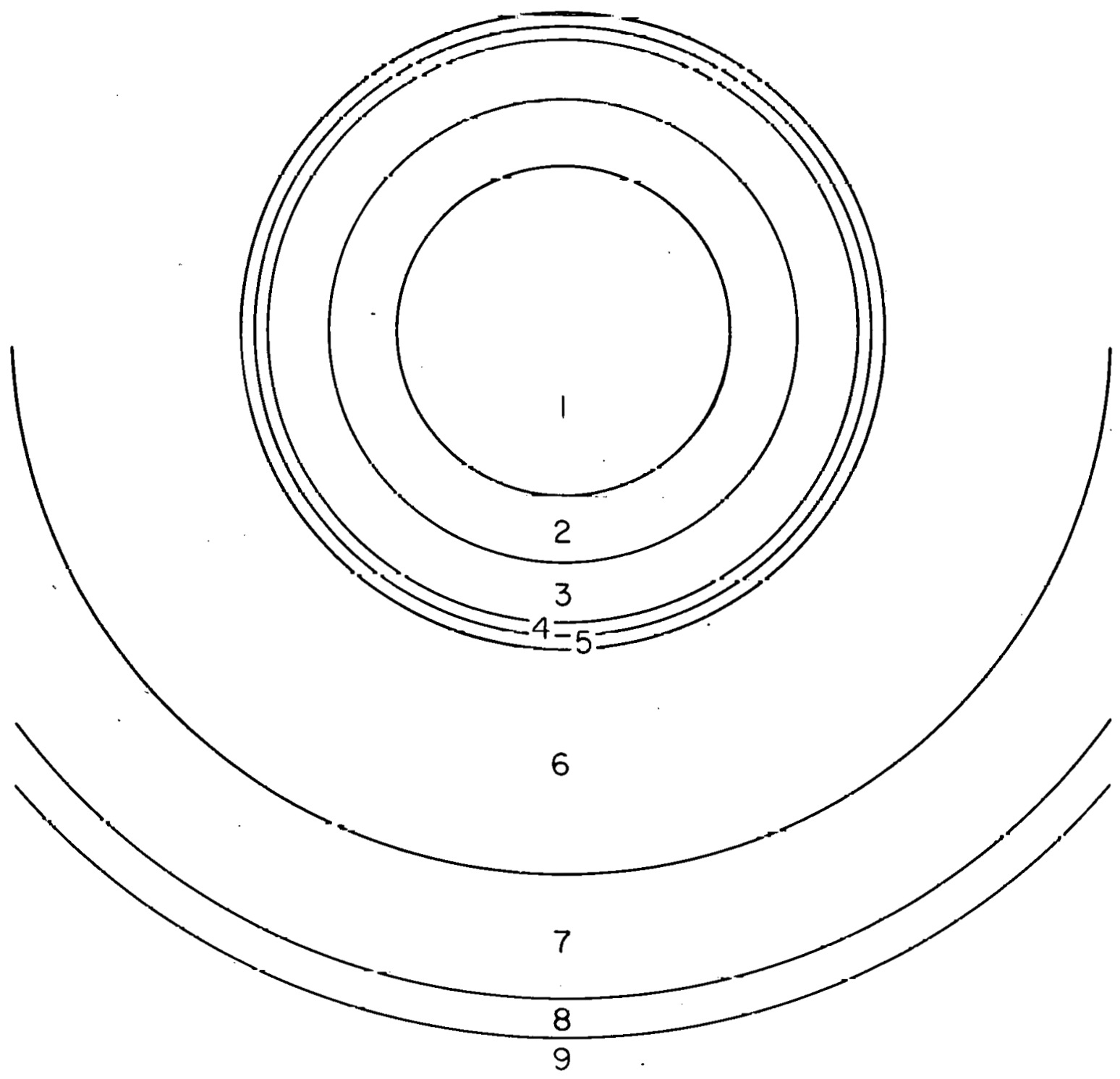

Fig. 24 MOdEL For hTGR-TyPE TEST ASSEMBLy. 


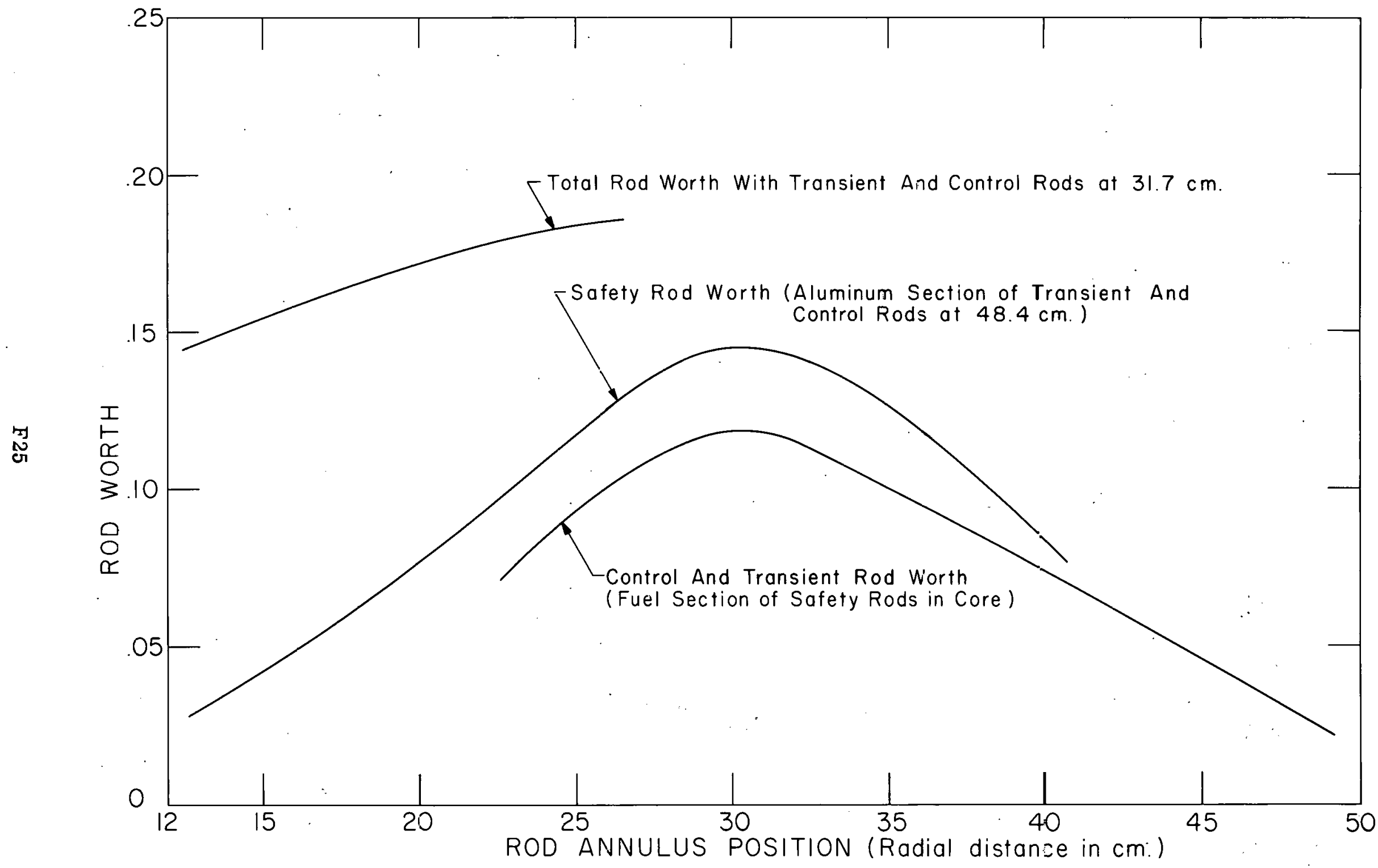

FIG. 25 ROD WORTH AS A FUNCTION OF CONTROL ROD ANNULUS POSITION.

$76 \mid-8888-45-706-071294$ 


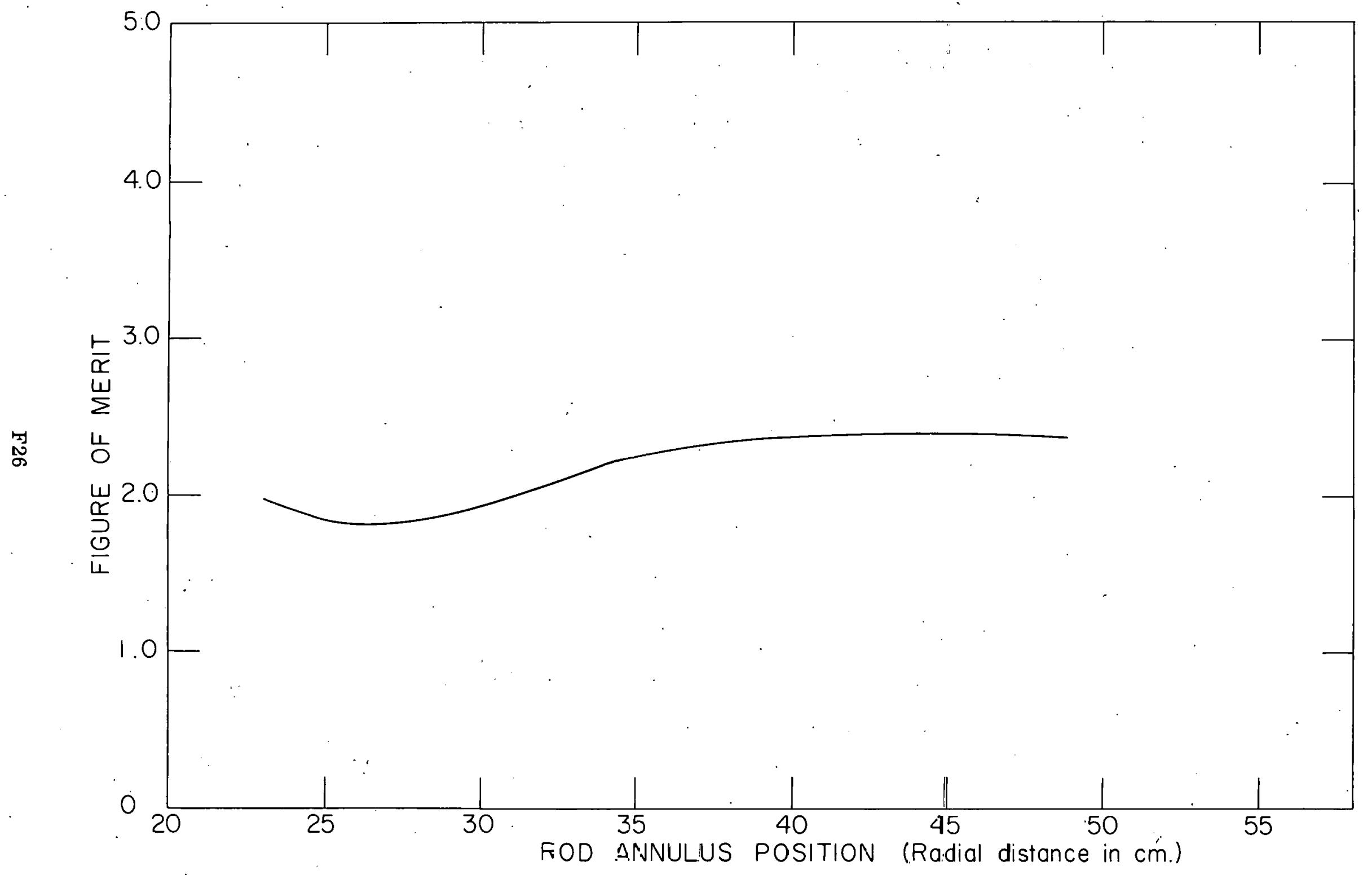

FIG. 26 EFFECT OF CONTROL ROD ANNULUS POSITION ON THE FIGUPE-OF-NJERIT.

$761-8888-45-706-071295$ 


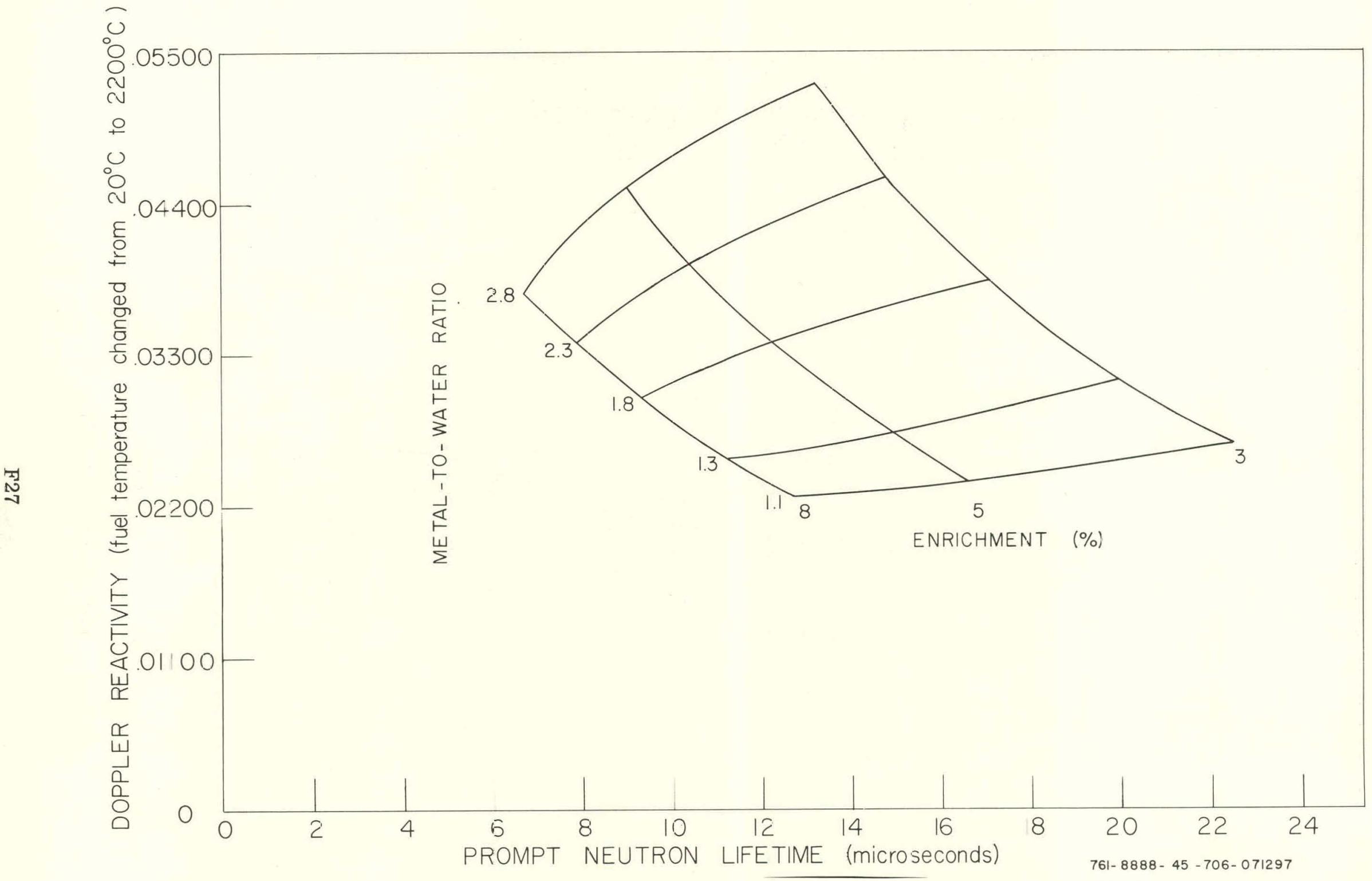

FIG. 27 EFFECTS OF METAL-TO-WATER RATIO AND ENRICHMENT ON DOPPLER REACTIVITY AND PROMPT NEUTRON LIFETIME. 


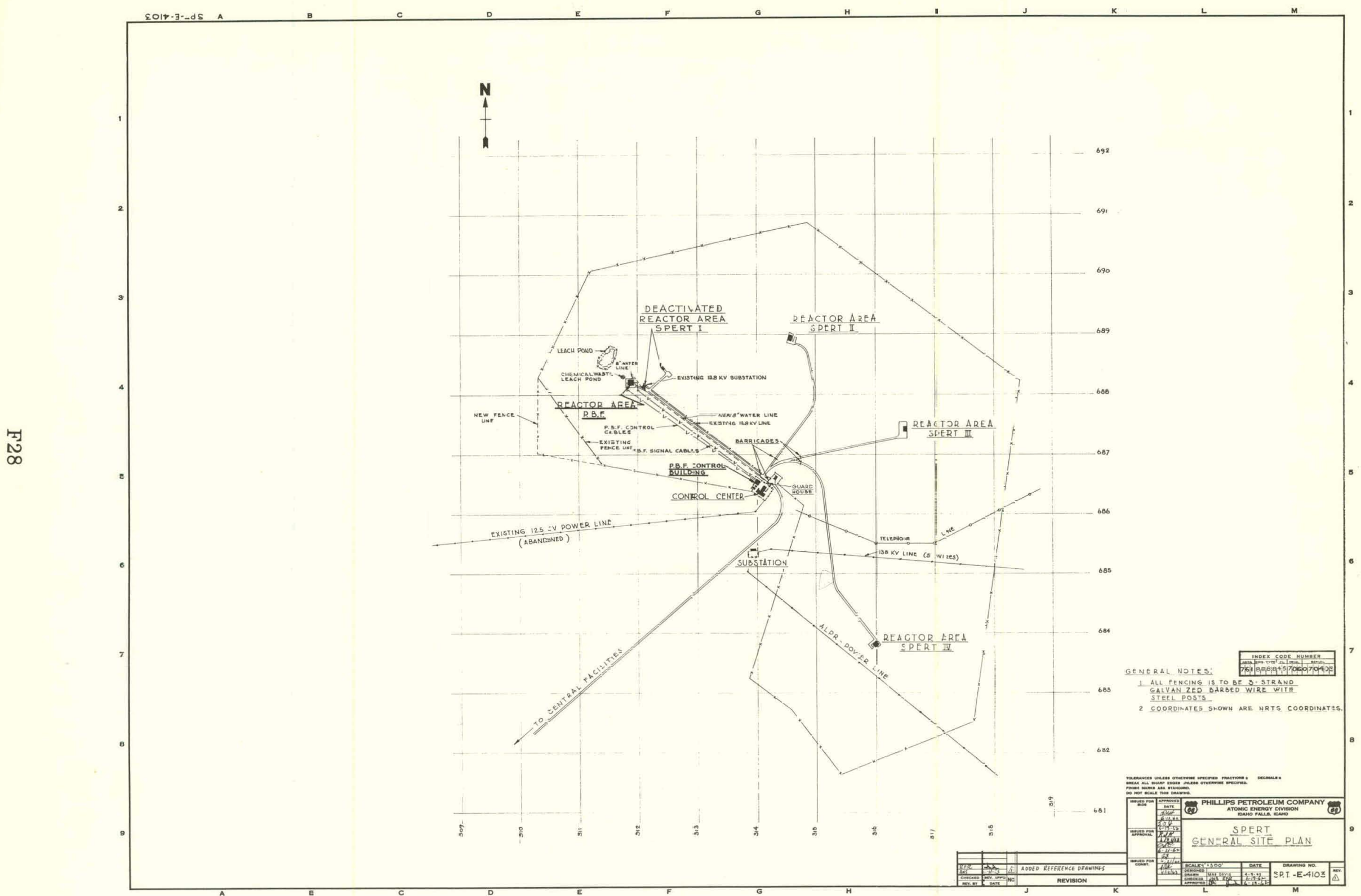

FIG. 28 SFERT GENERAL SITE PLAN, 


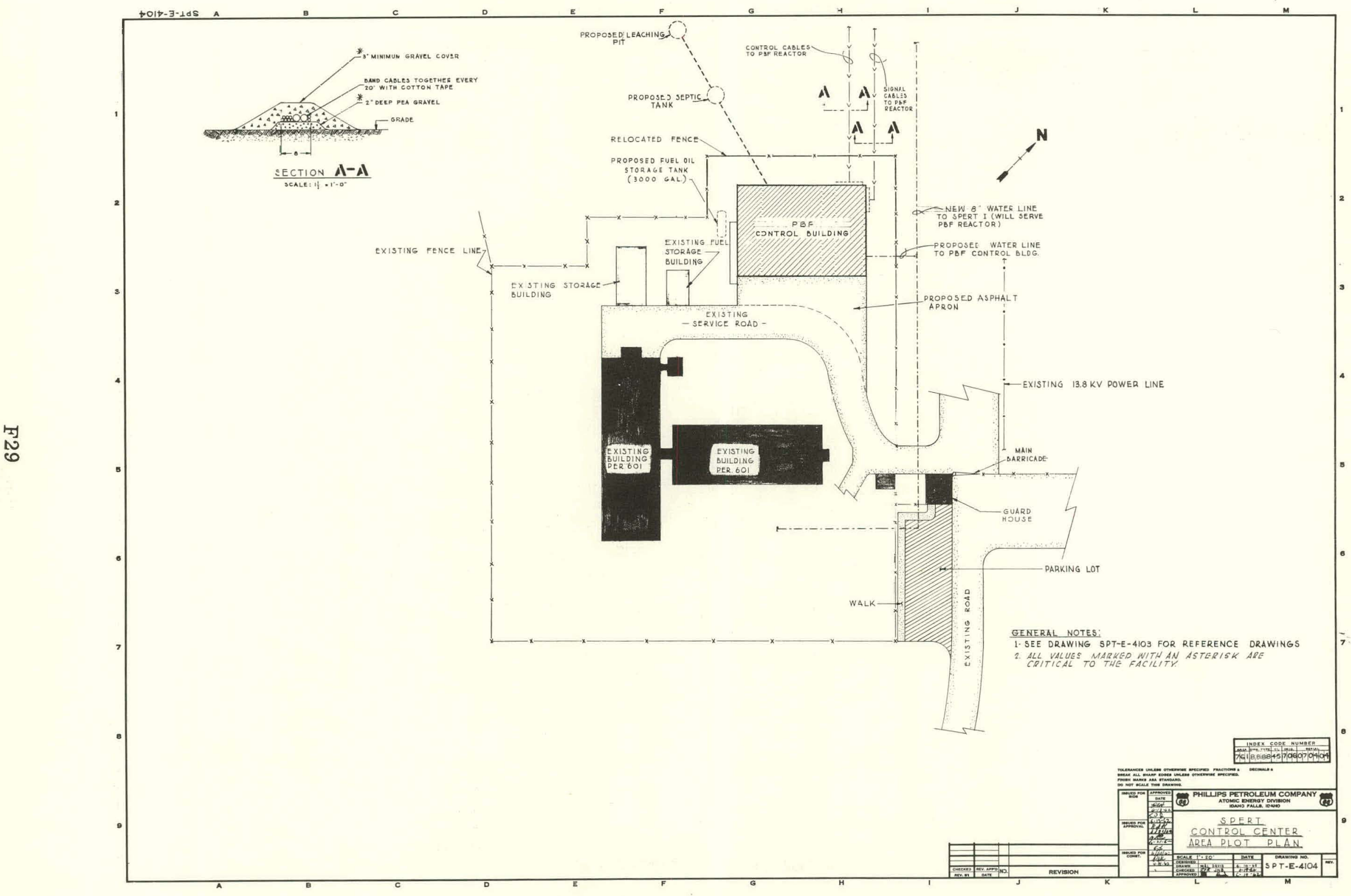

FIG. 29 SPERT CONTROL CENTER AREA. 


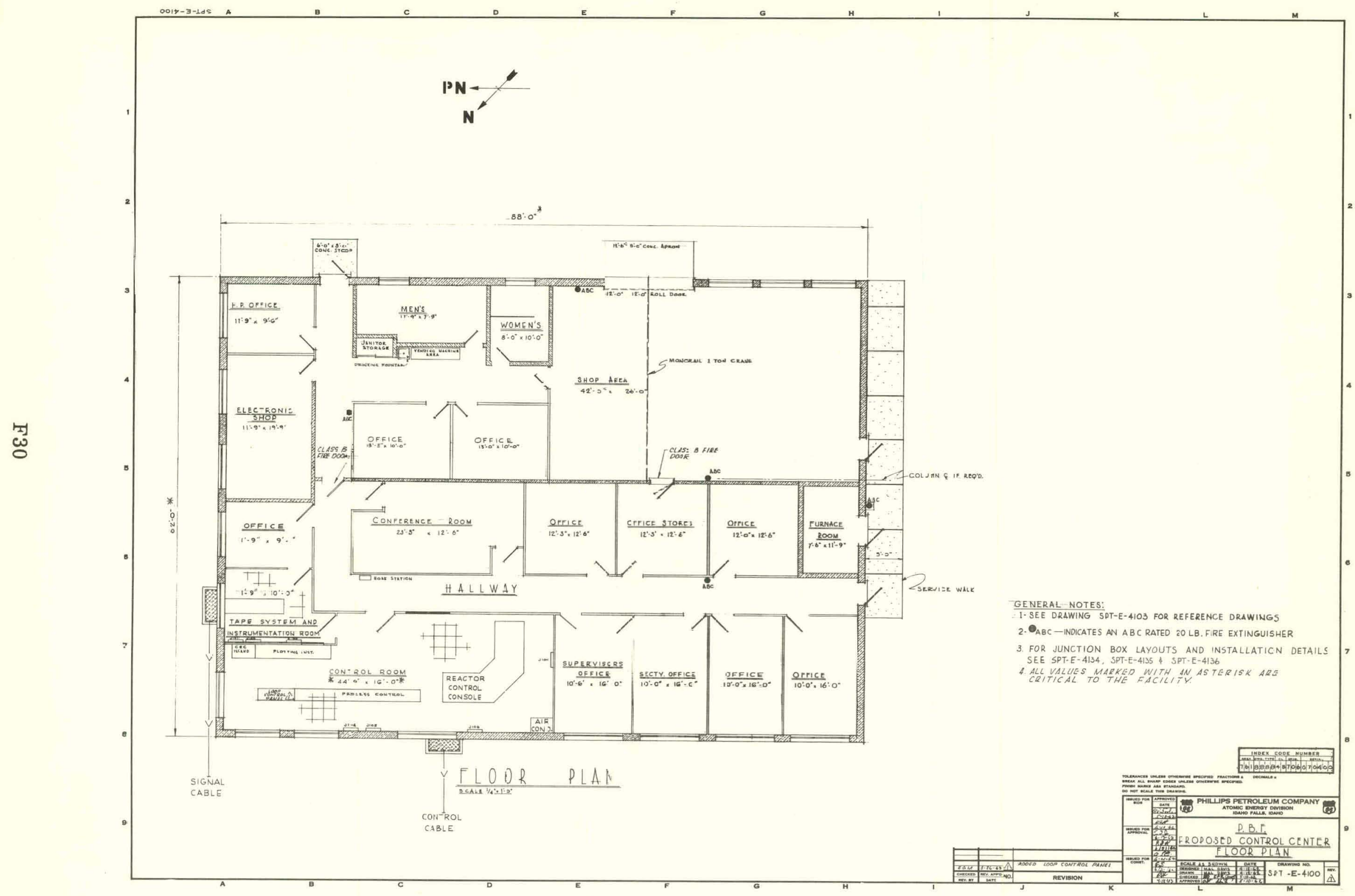

FIG. 3C PROPOSED CONTROL CENTER FLOOR PLAV, 


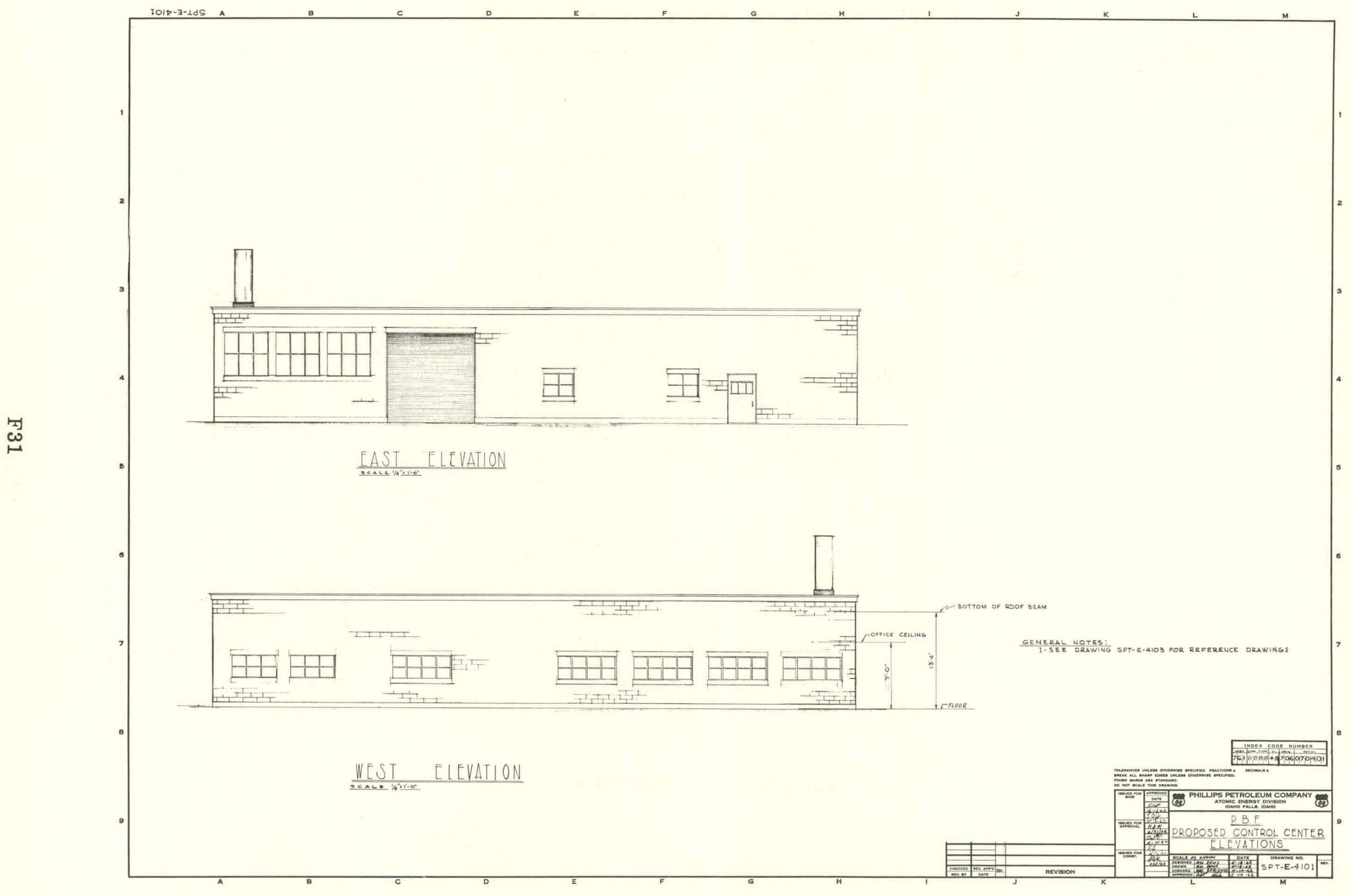

FIG. 31 PROPOSED CONTROL CENTER ELEVATIONS. 


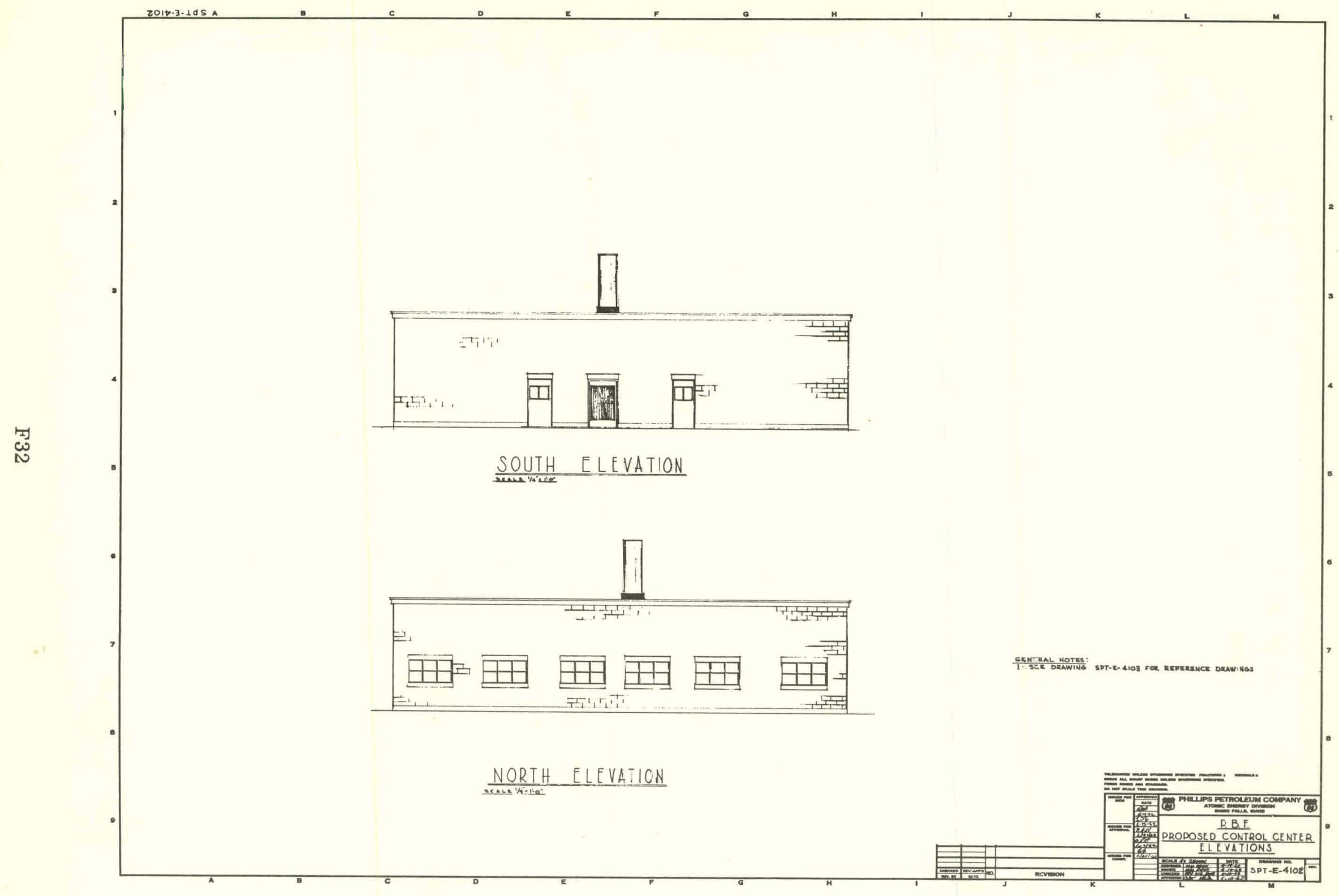

FIG. 32 PROPOSED CONTROL CENTER ELEVATIONS. 


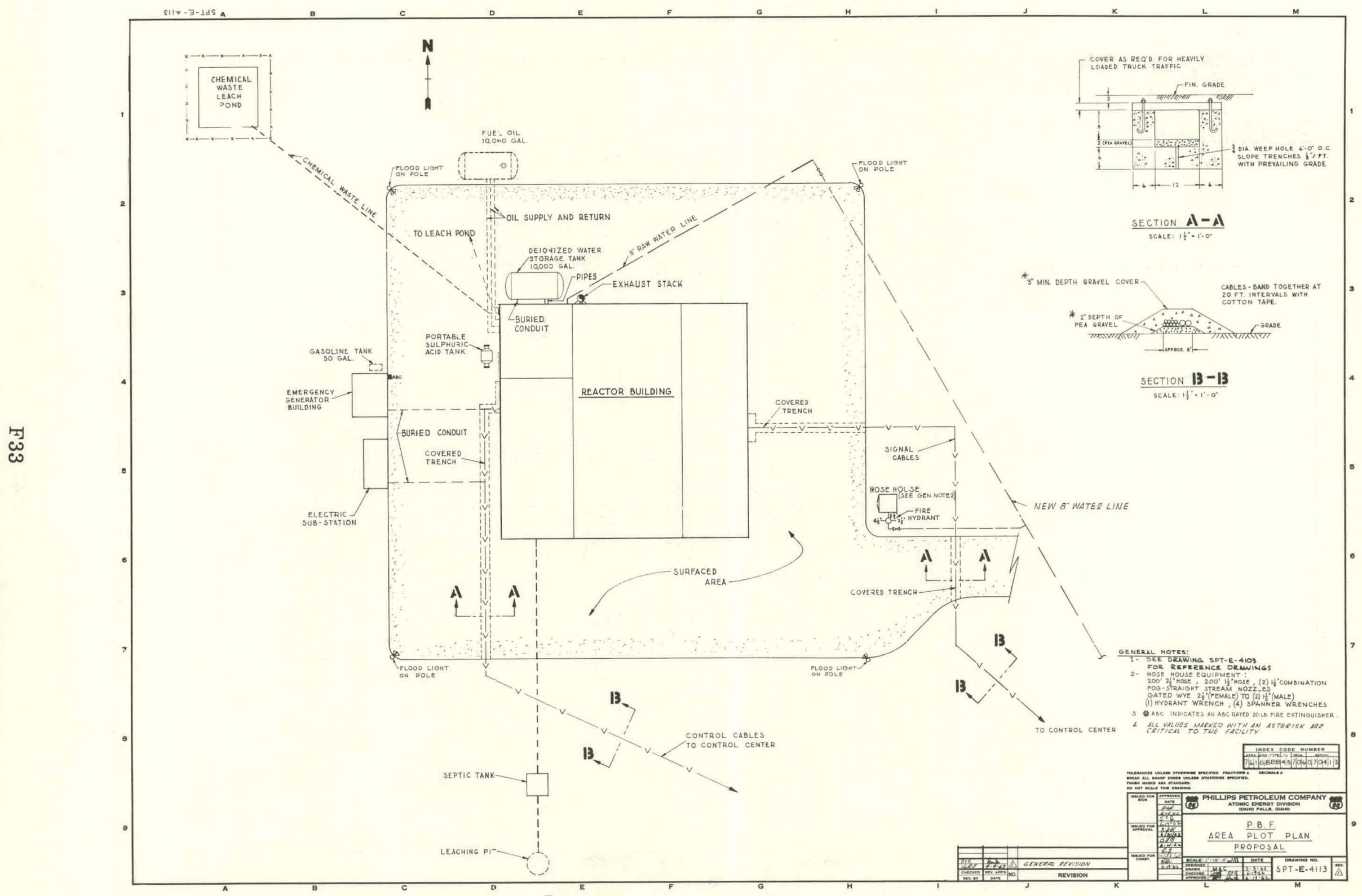

FIG. 33 PBF AREA PLAN. 


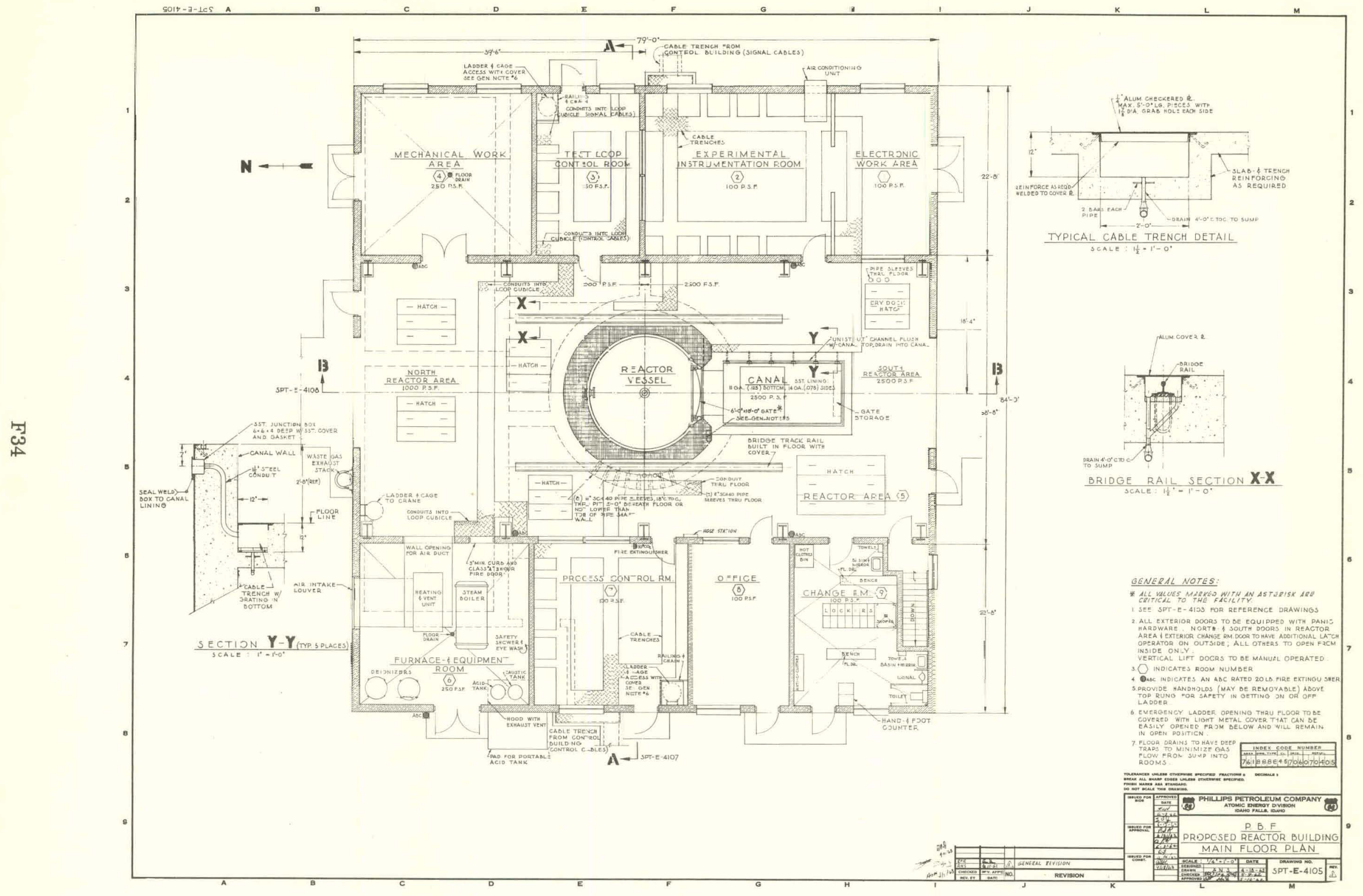

FIG. 34 REACTOR BUI_DING MAIN FLOO $₹$ PLAN. 


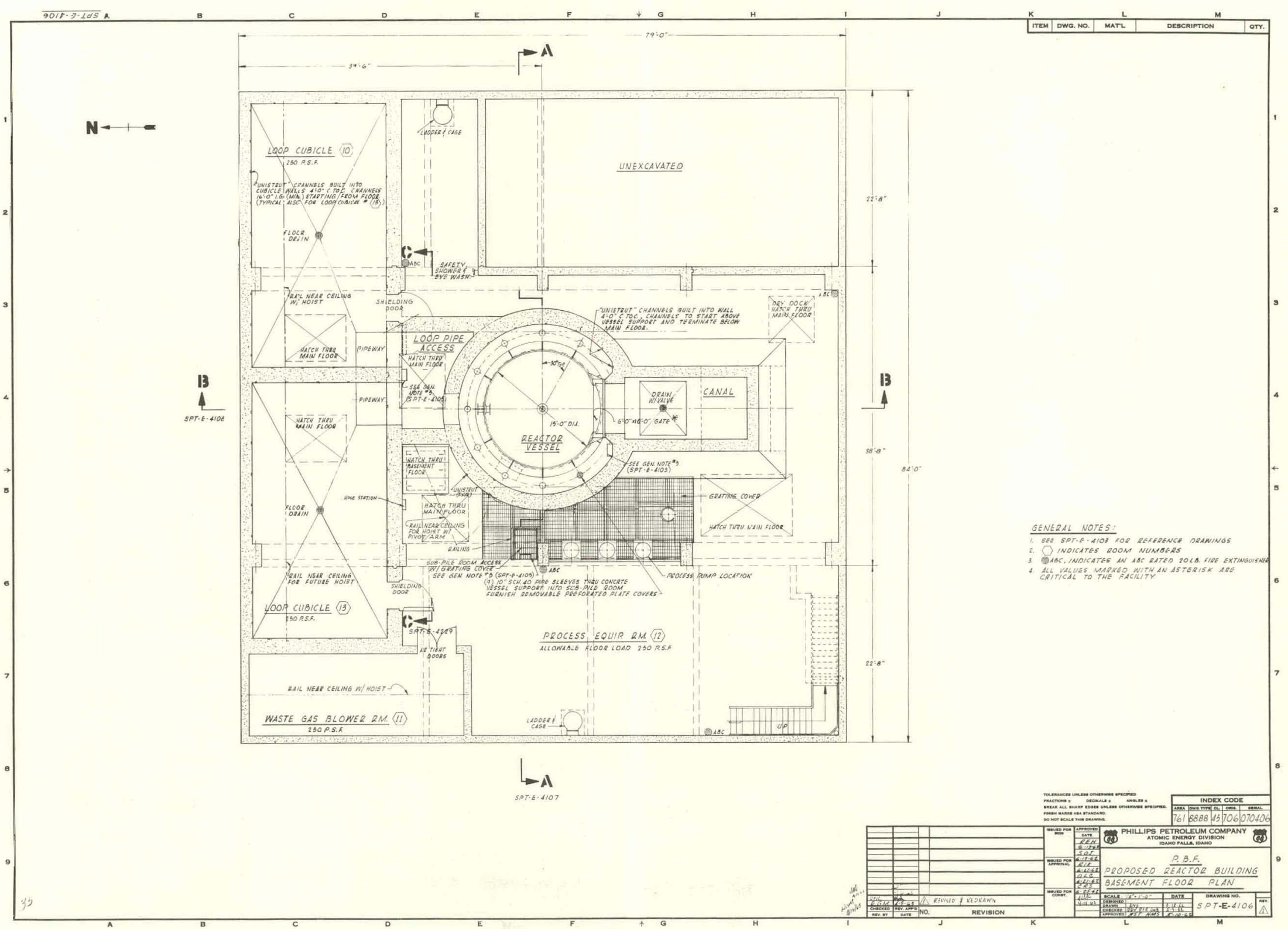

FIG. 35 REACTOR BUILDING BASEMENT FLOOR PLAN. 


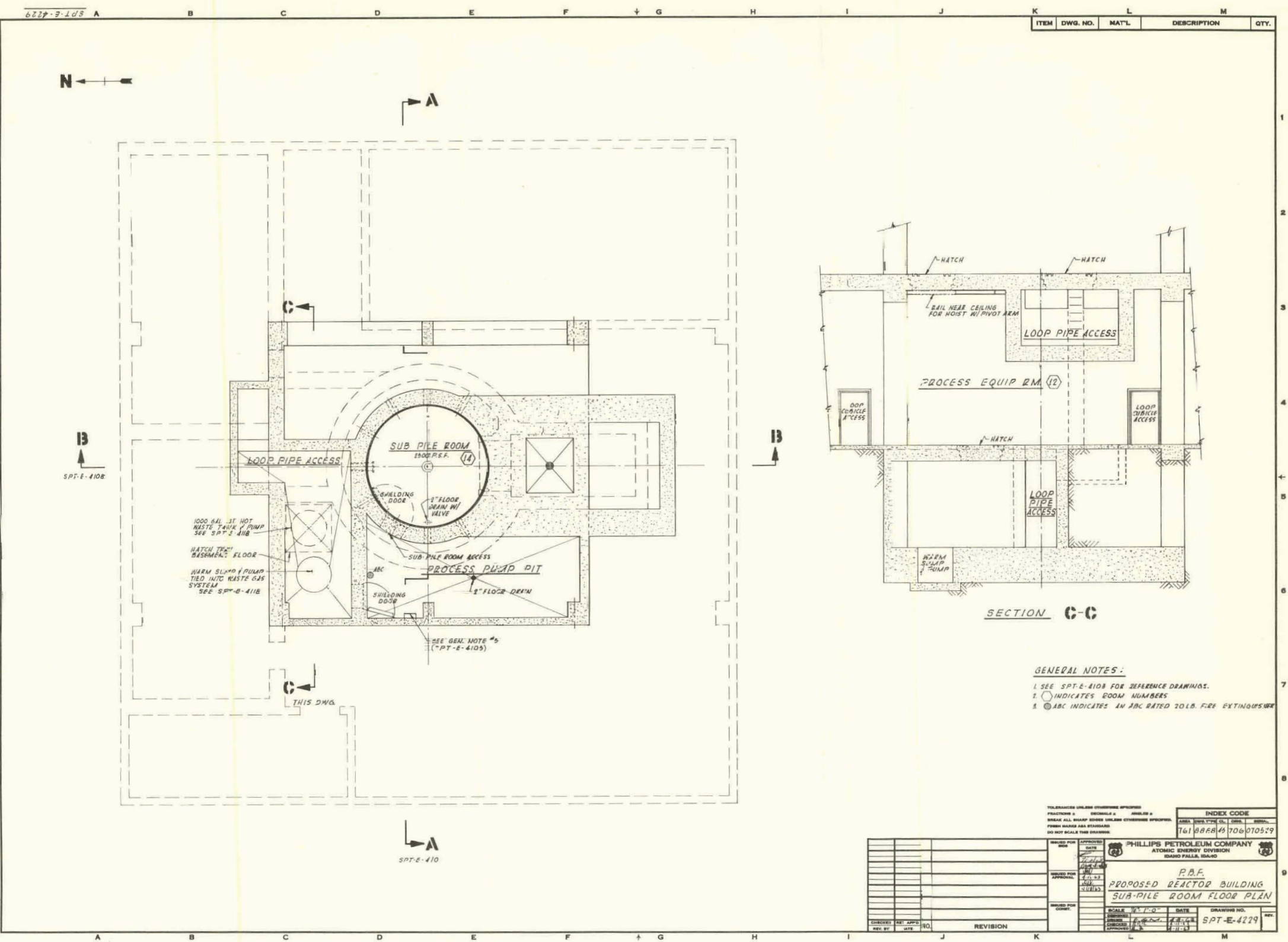

FIG, 36 REA_TOR EUILDING SUE-PILE ROOM FLOOR PLAN. 


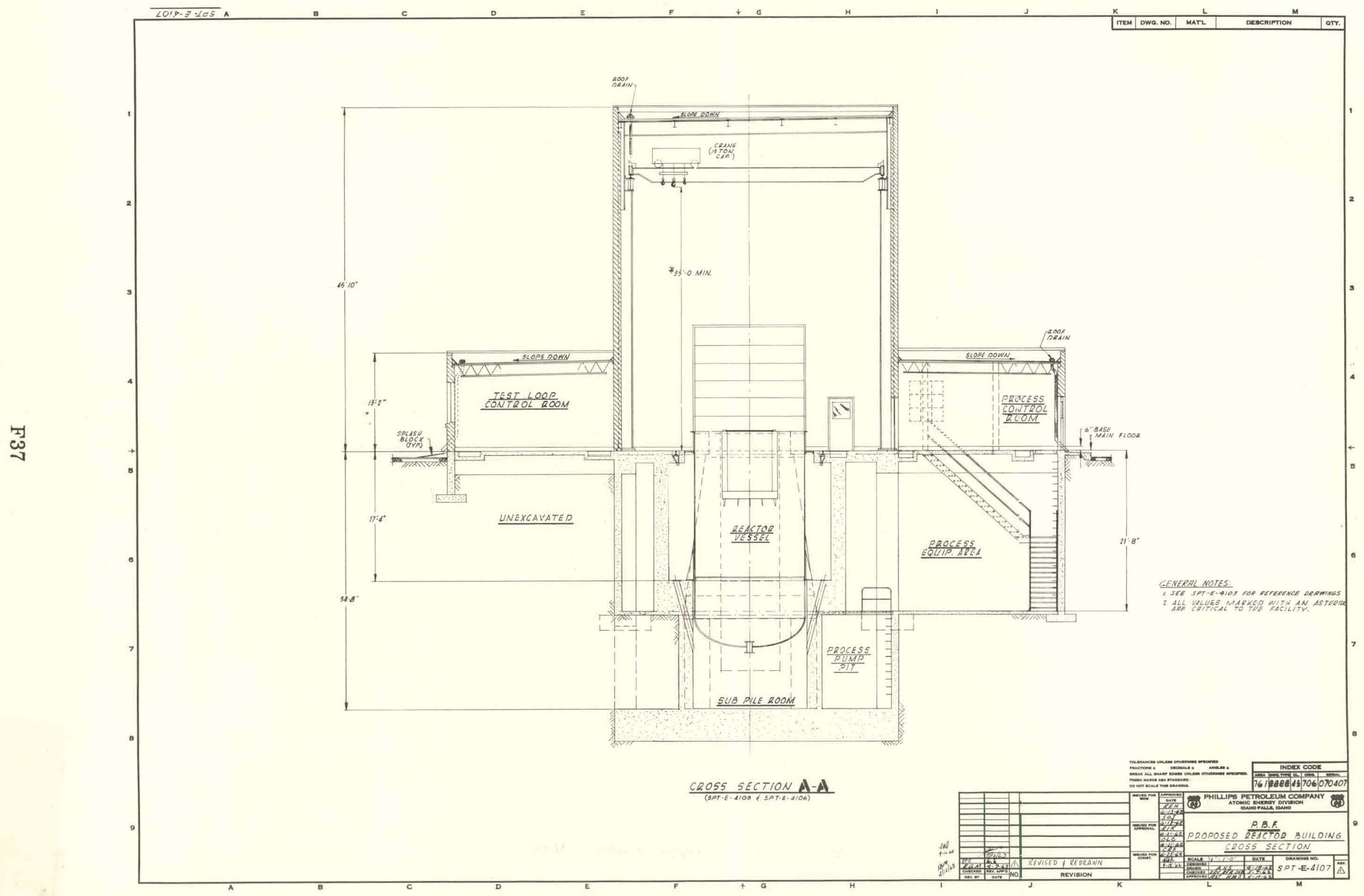

FIG. 37 REACTOR BUILDING CROSS SECTION. 


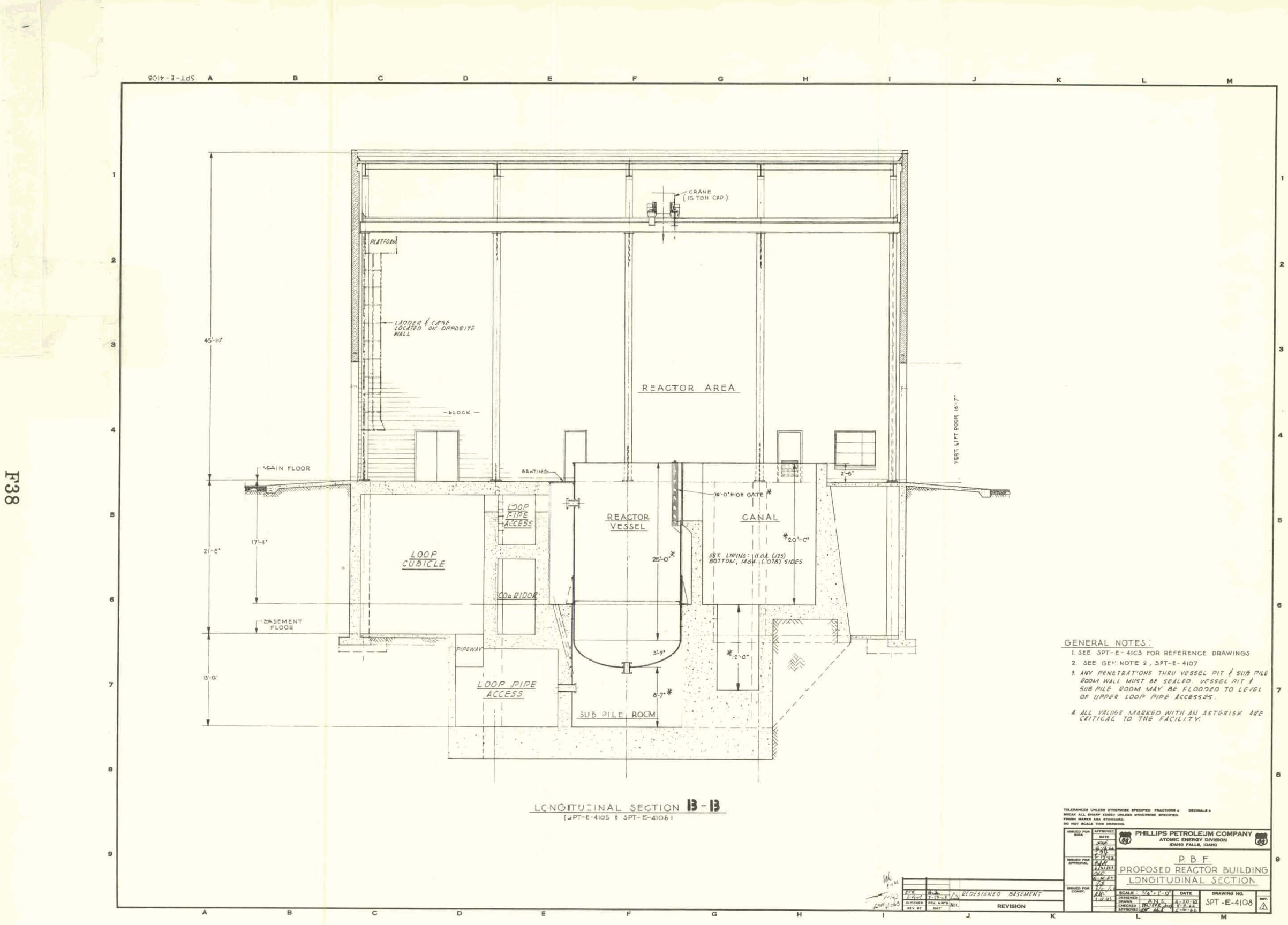

FIG. 38 REACTOR BUILIING LONGITUDINA_ SECTION. 


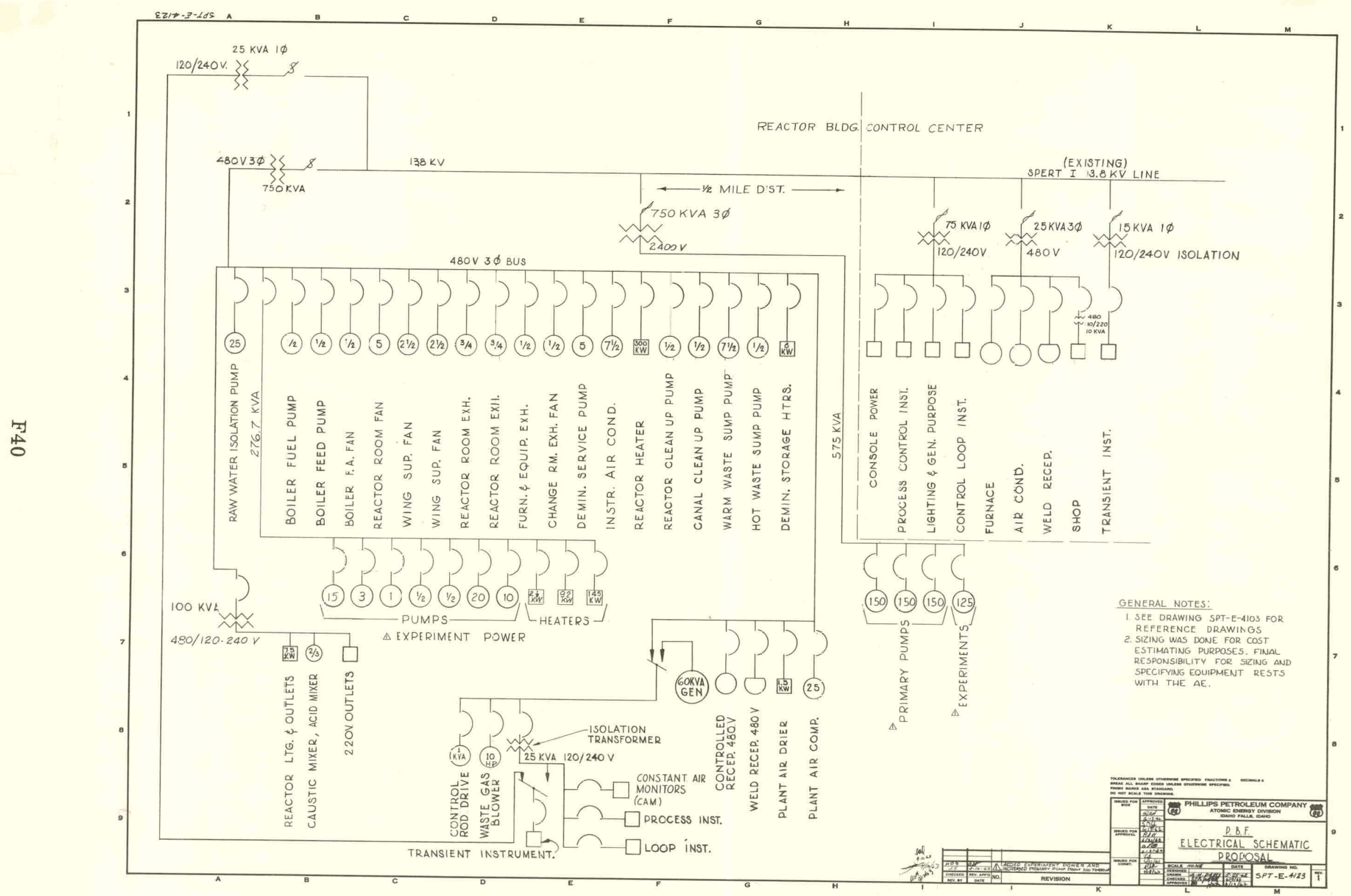

Fig. 40 ELECTRICAL SCHEMATIC. 


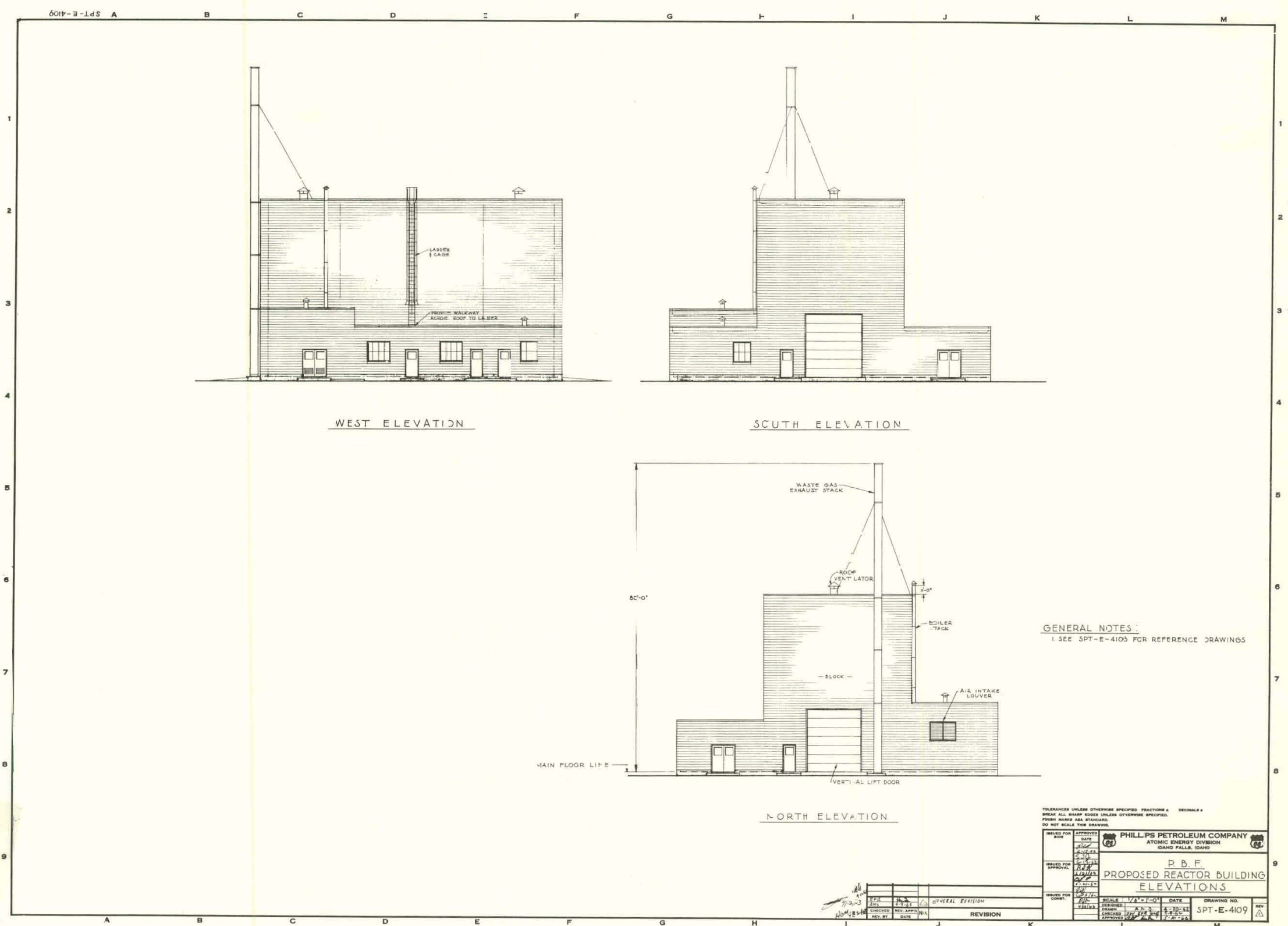

FIG. 39 REACTOR BUILDING ELEVATION. 


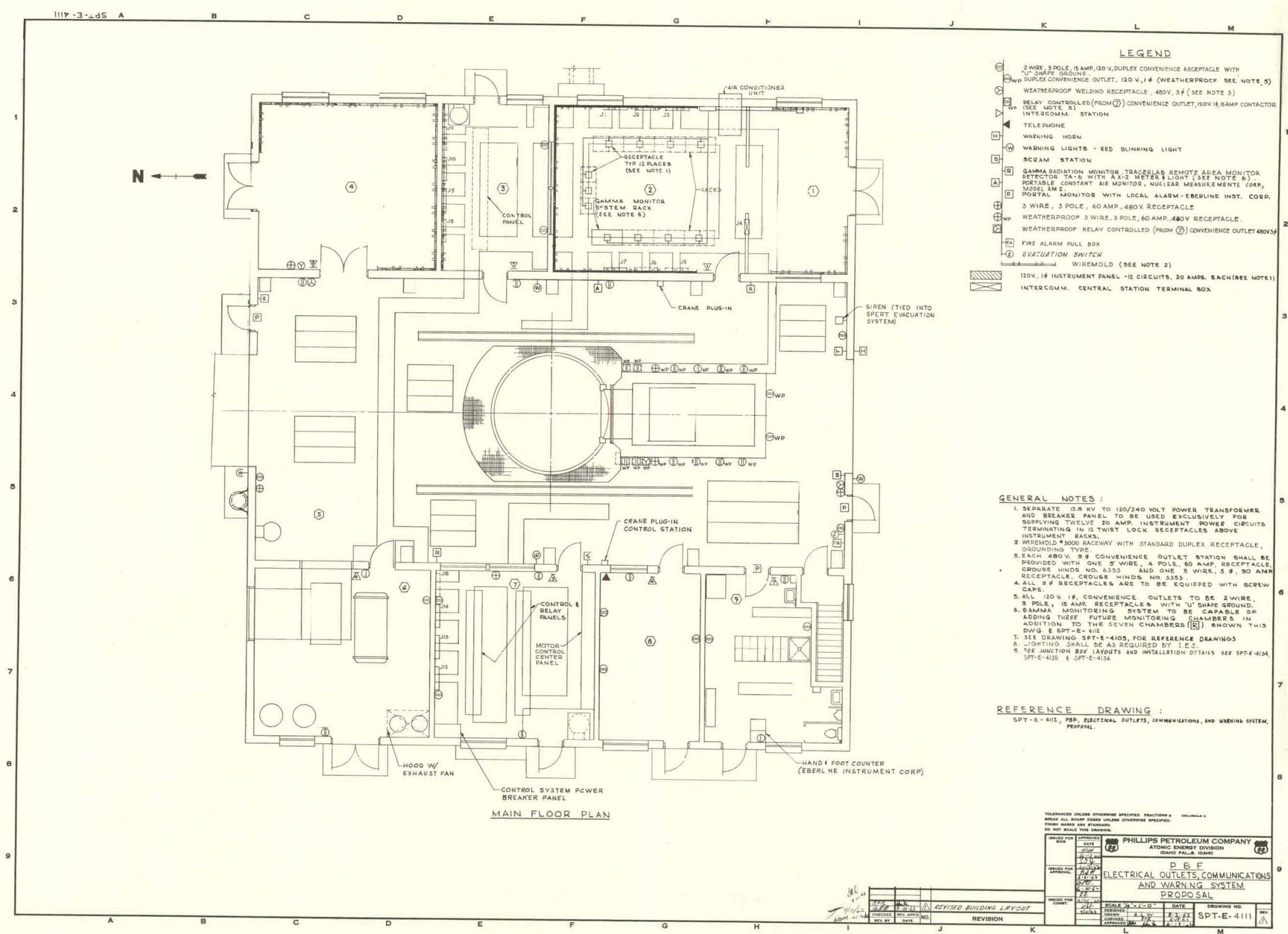

FIG. 41 ELECTRICAL OUTLETS, COMMUNICATIONS, AND WARNING SYSTEM. 


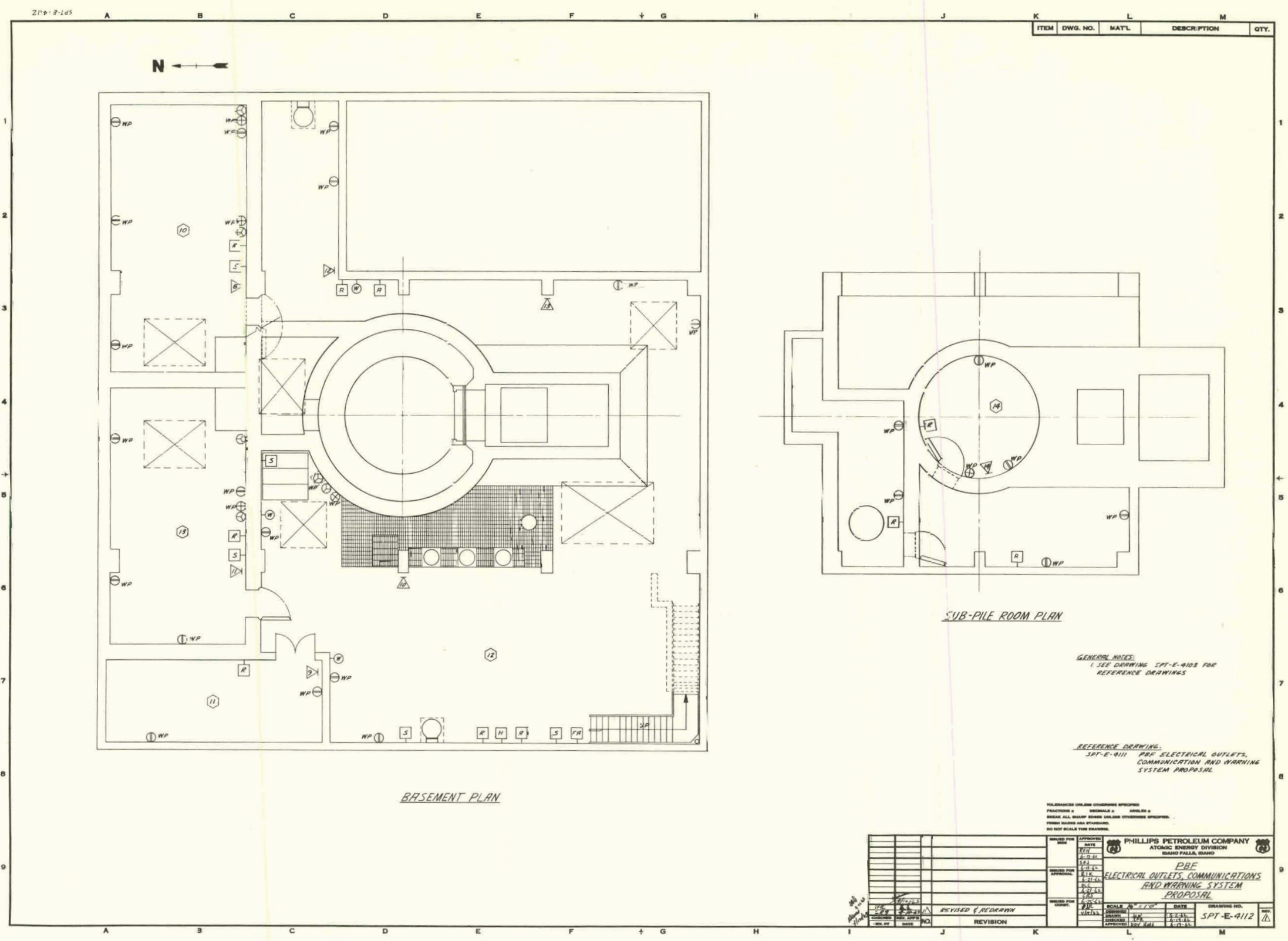

FIG. 42 ELECTRICAL OUTLETS, COMMUNICATIONS, AND WARNING SYSTEM. 


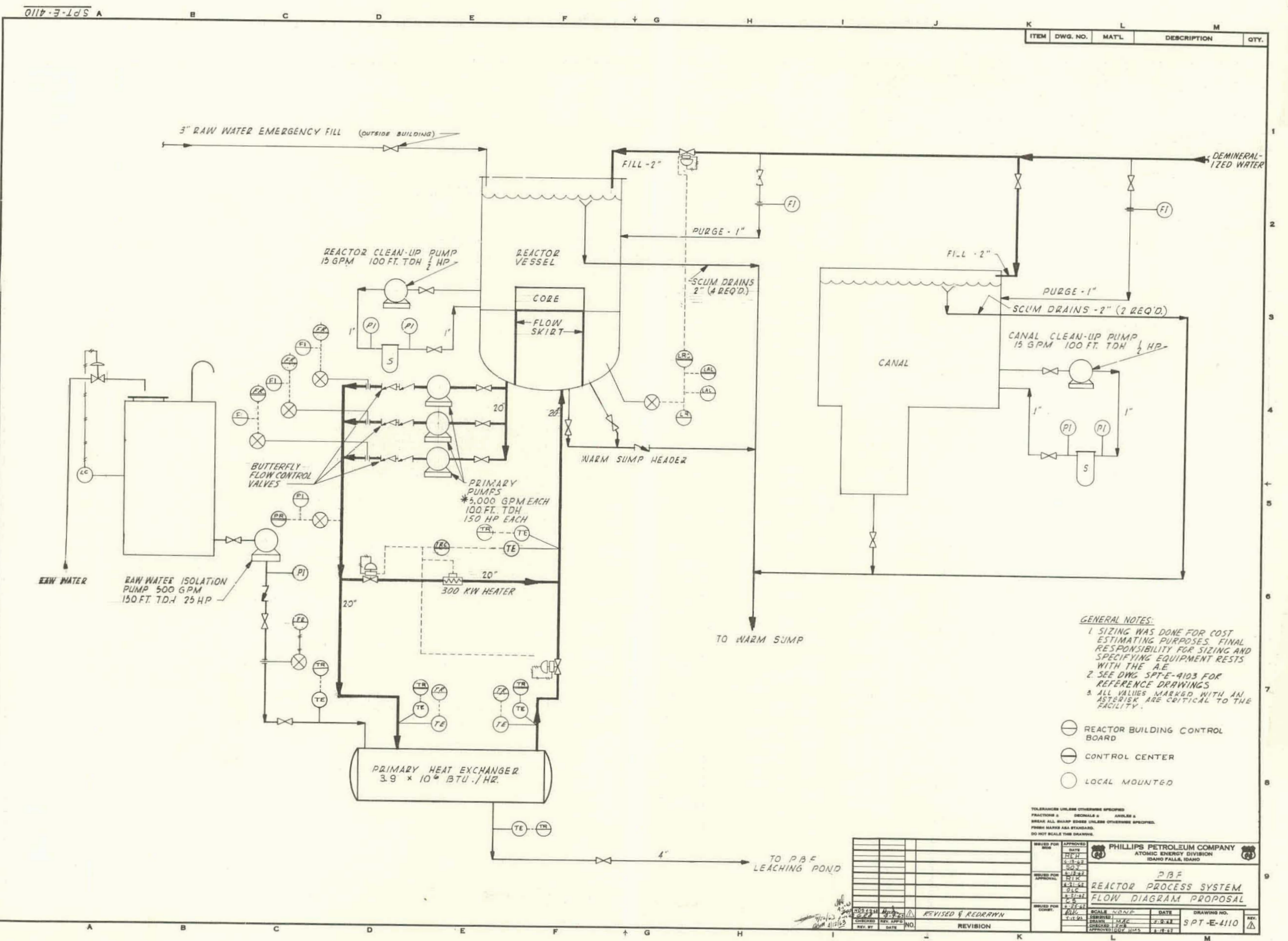

FIG. 43 REACTOR PROCESS SYSTEM FLOW DIAGRAM, 


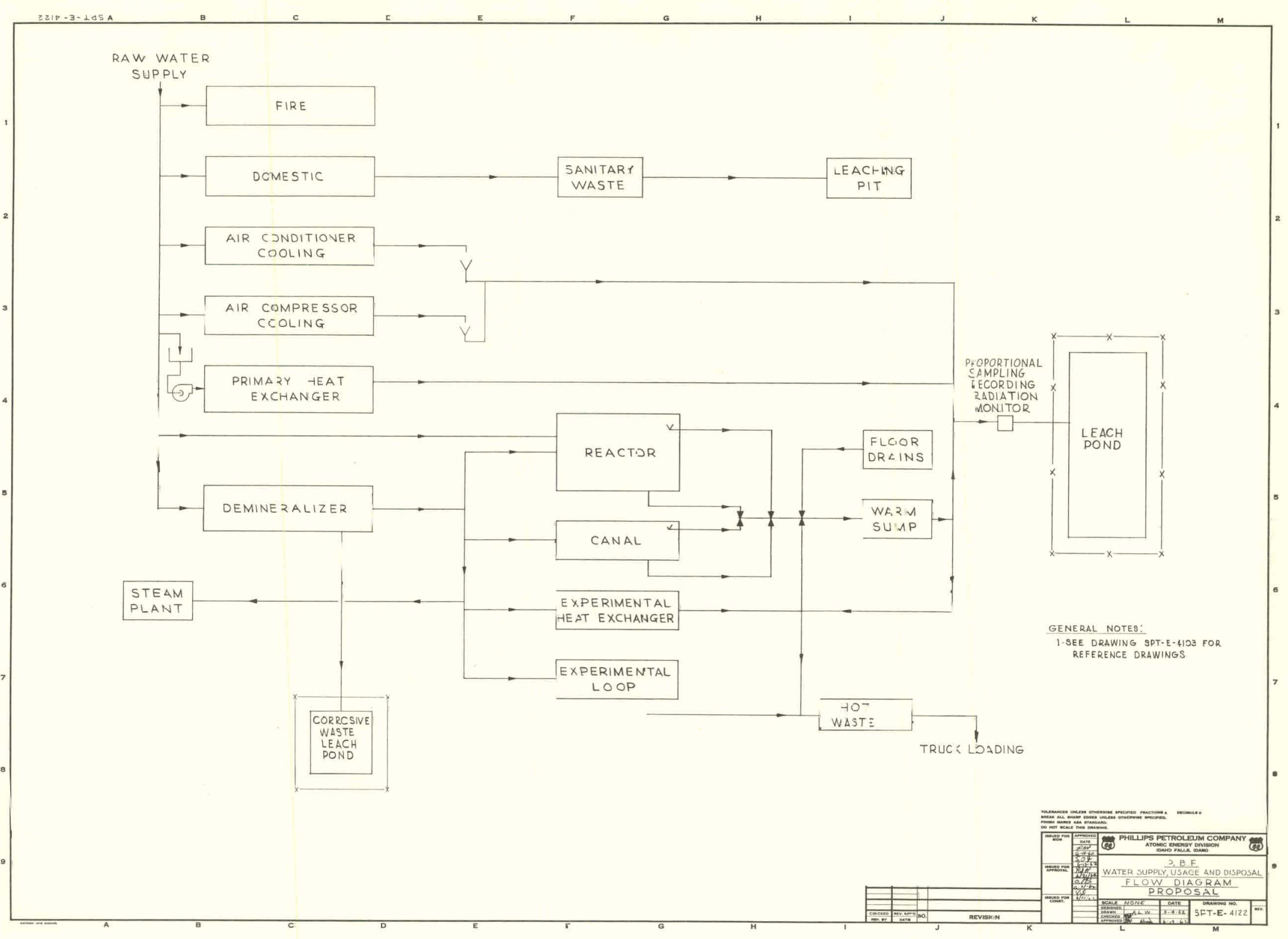

FIG. 44 WATER SUPPLy, USAGE, AND DisPosal Flow DIAGRAM. 


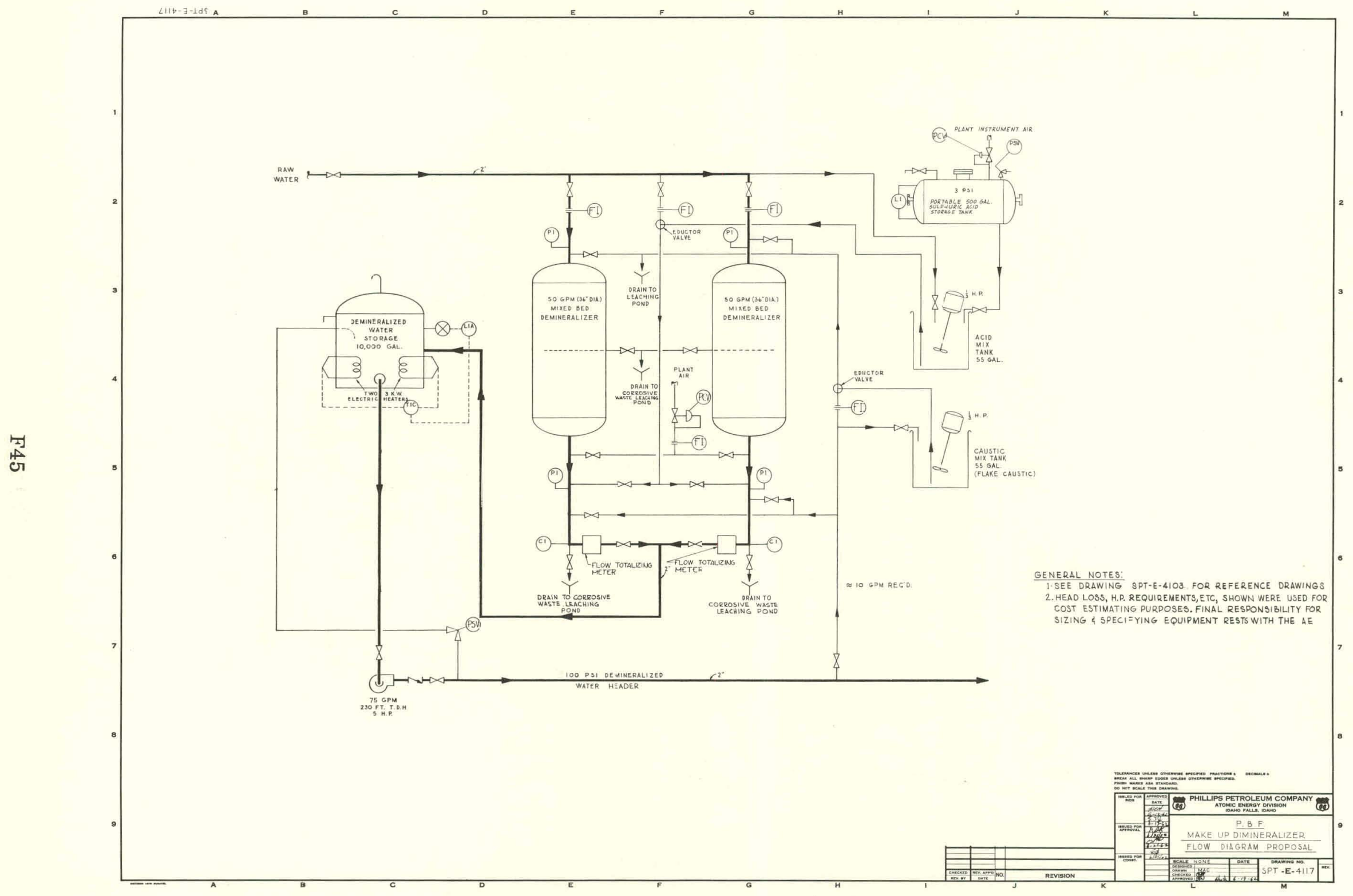

FIG, 45 MAKE-UP DEMINERALIZER FLOW DIAGRAM. 


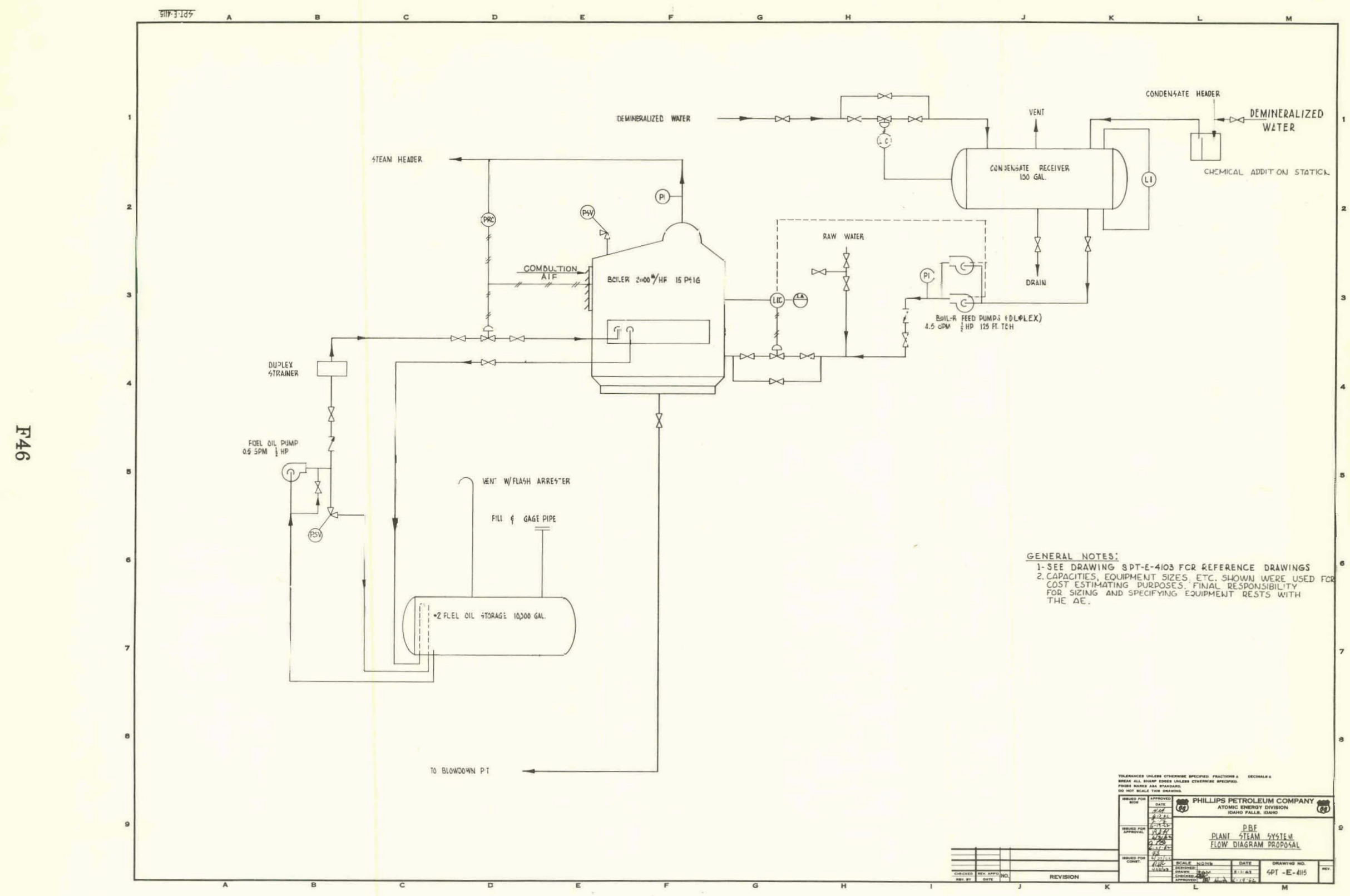

FIG. 46 PLANT STEAM SYSTEM FLOW DIAGRAM. 


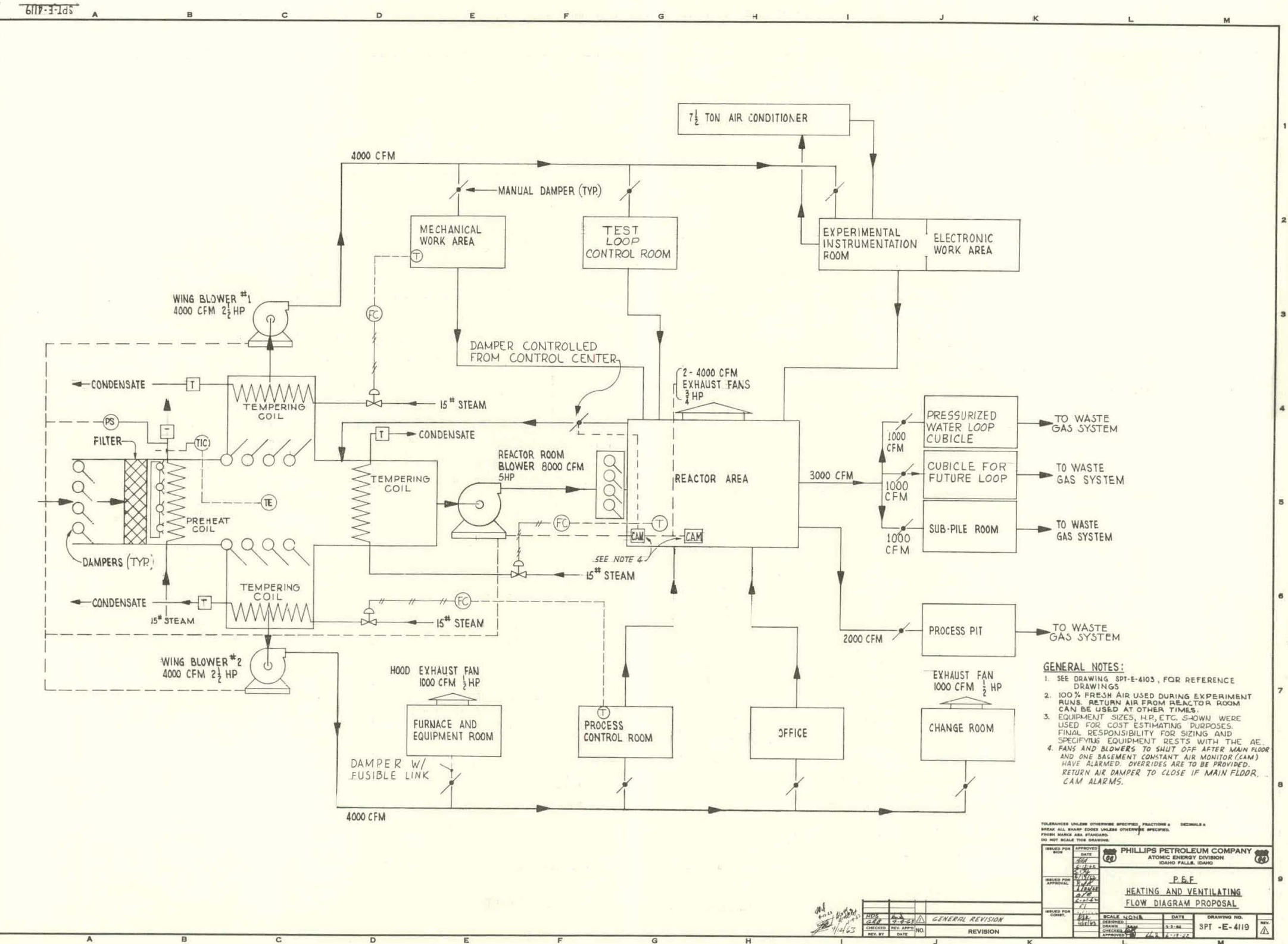

FIG. 47 HEATING AND VENTILATING FLOW DIAGRAM, 


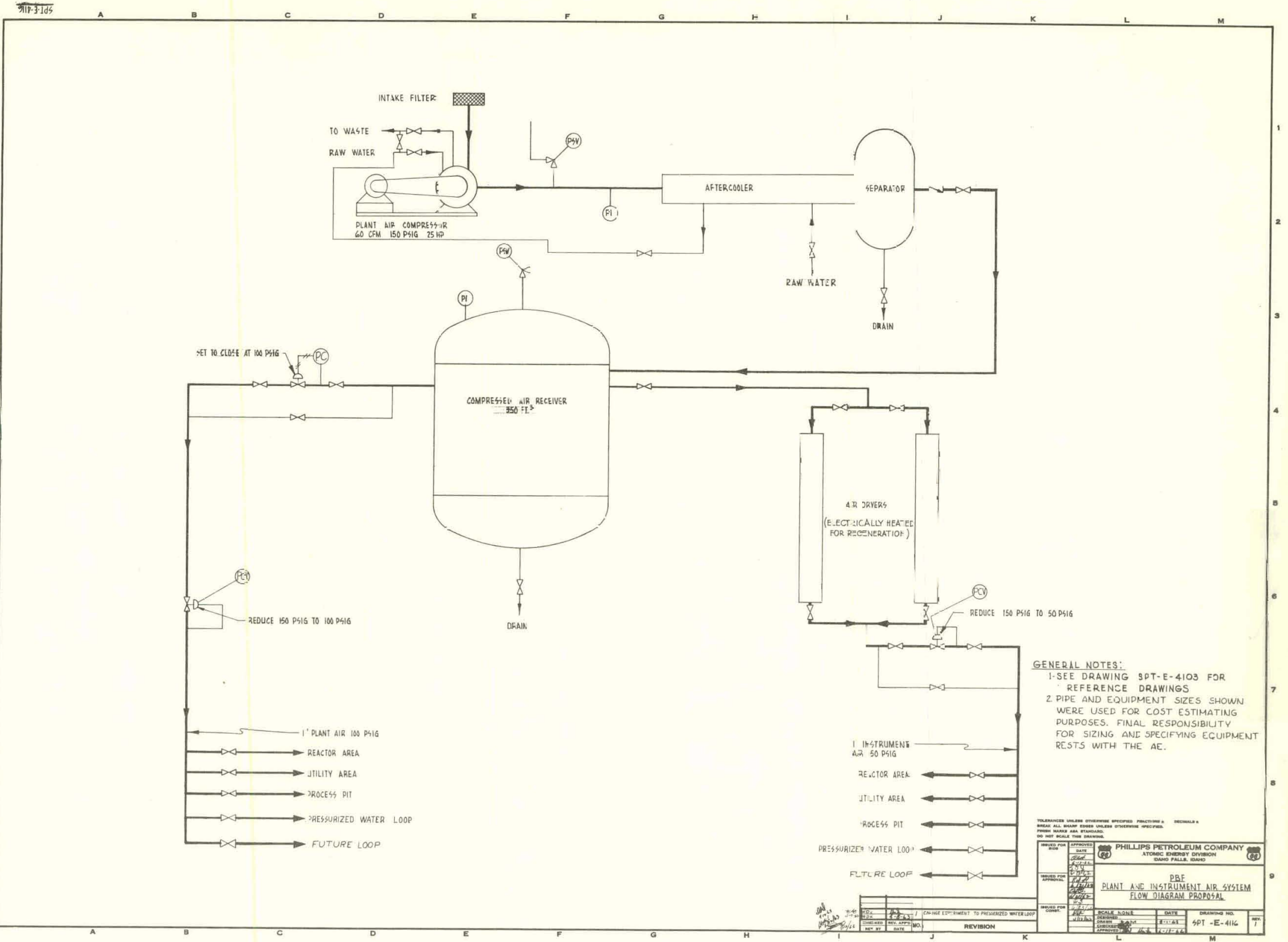

FIG. 48 PLANT AND INSTRUMENT AIR SYSTEM FLJW DIAGRAM. 


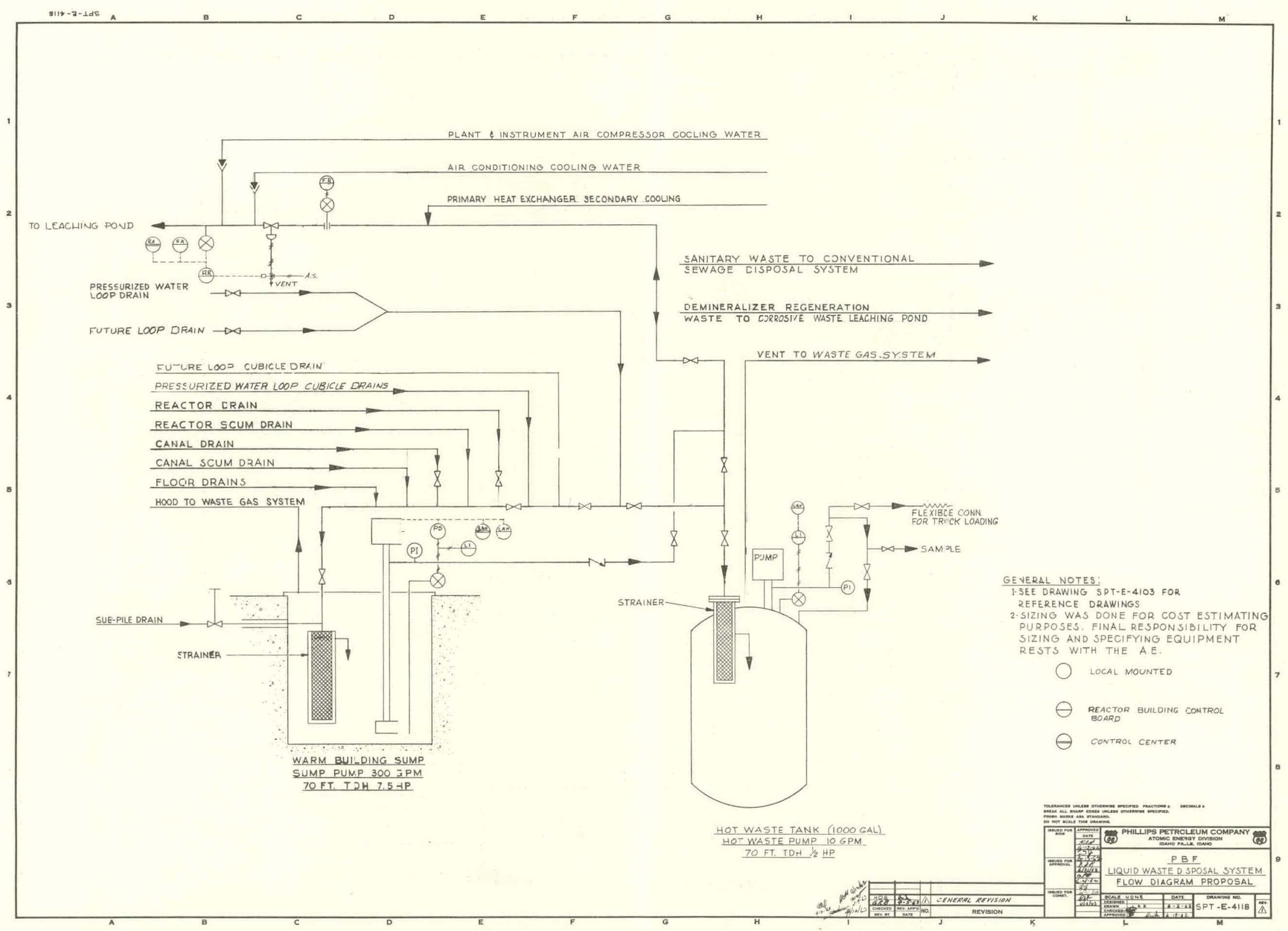

FIG. $4 \exists$ LIQUID WASTE DISPOSAL SYSTEM FLOW DIAGRAM. 


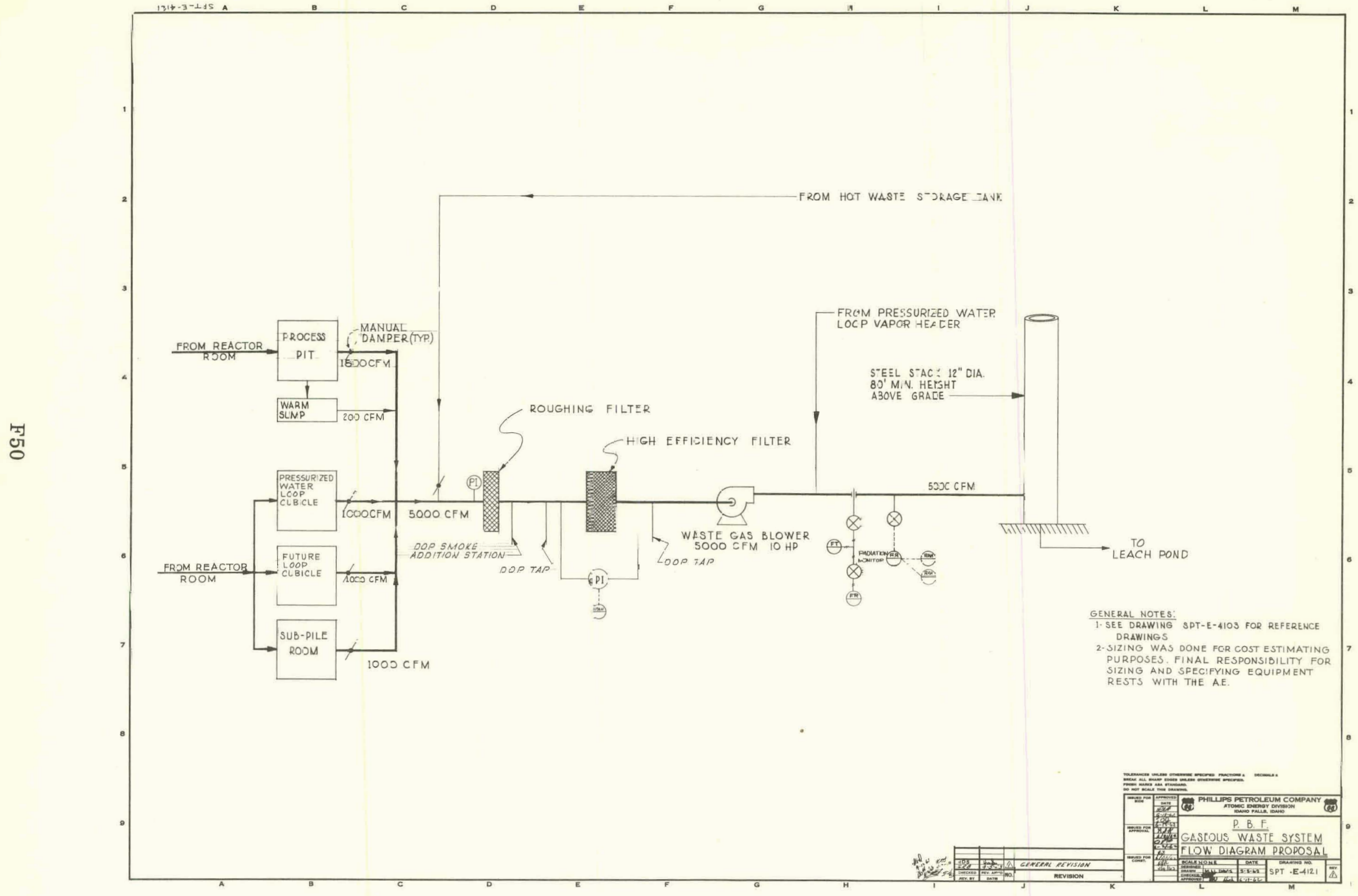

FIG, 50 GASEOUS WASTE SYSTEM FLOW DIAGR.AM. 


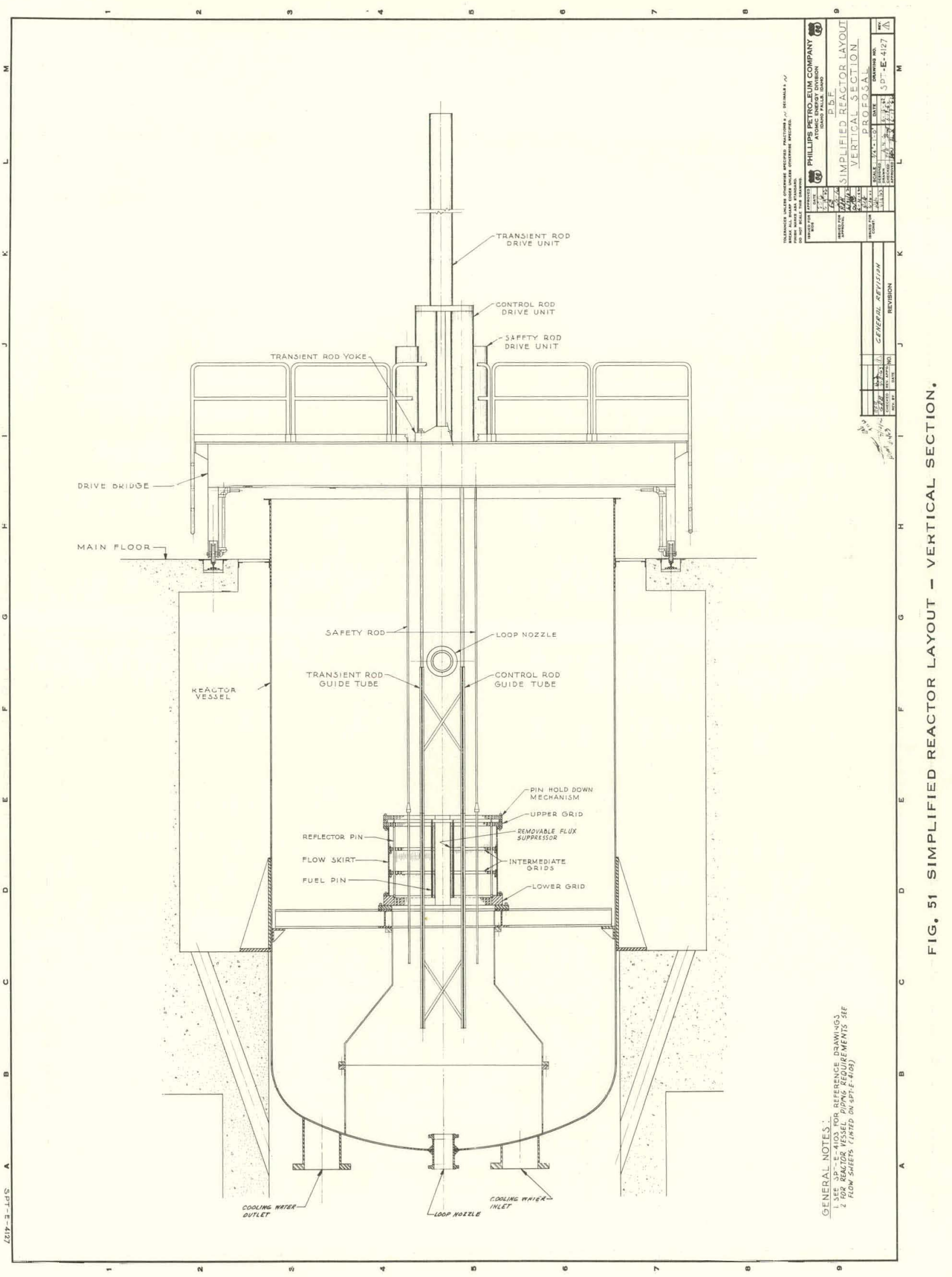




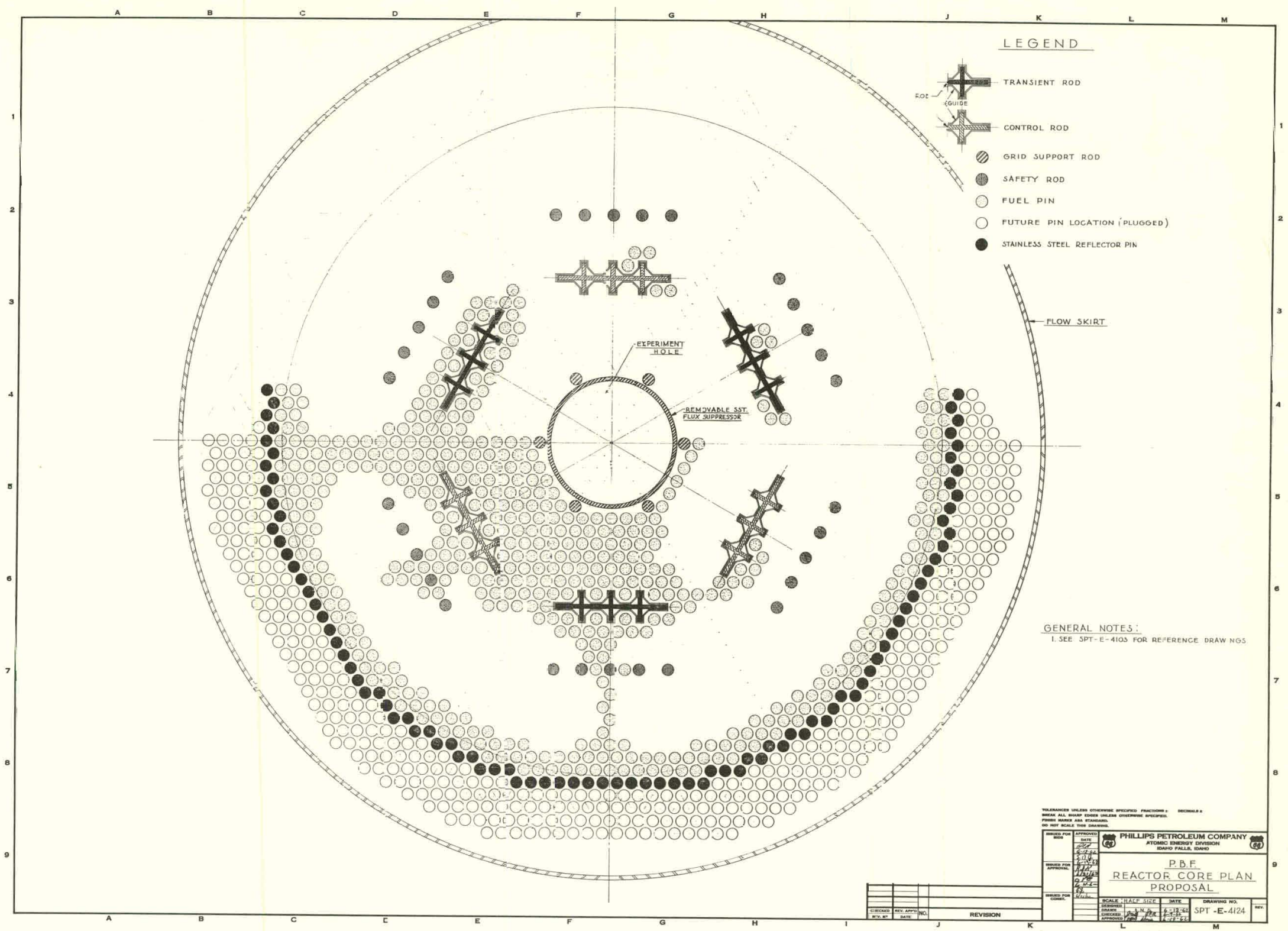

FIG. 52 REACTOR CORE PLAN. 


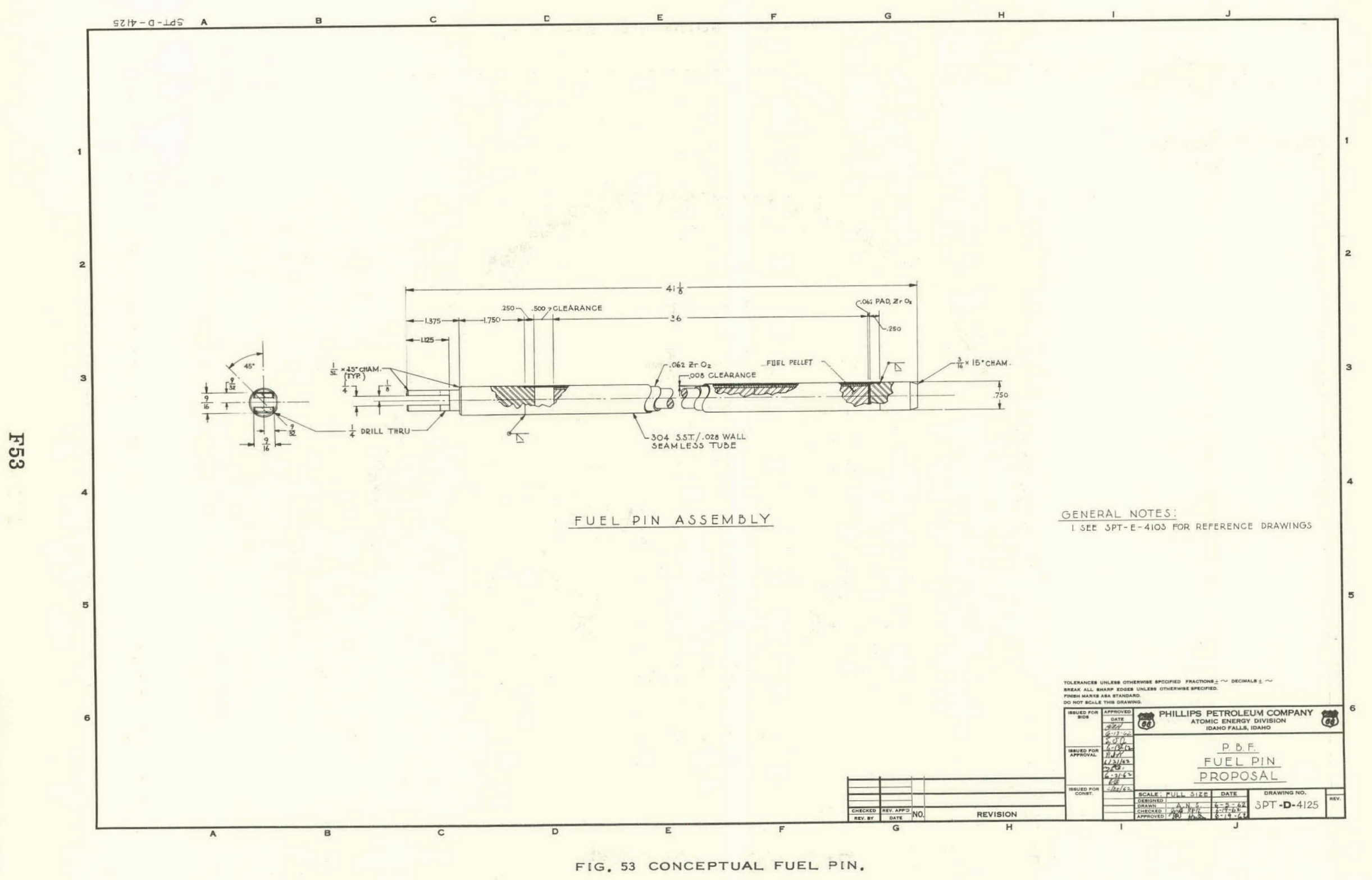




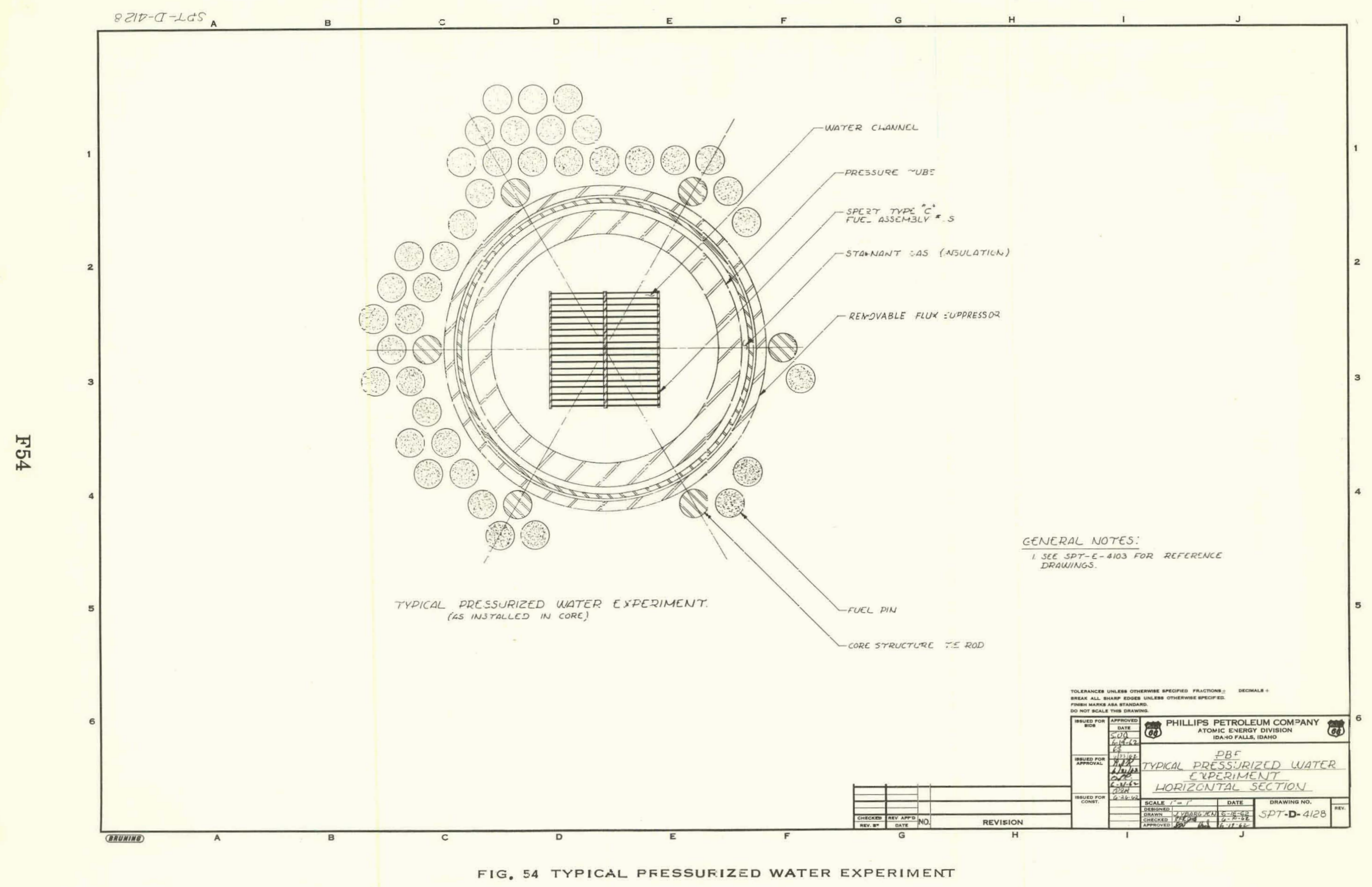




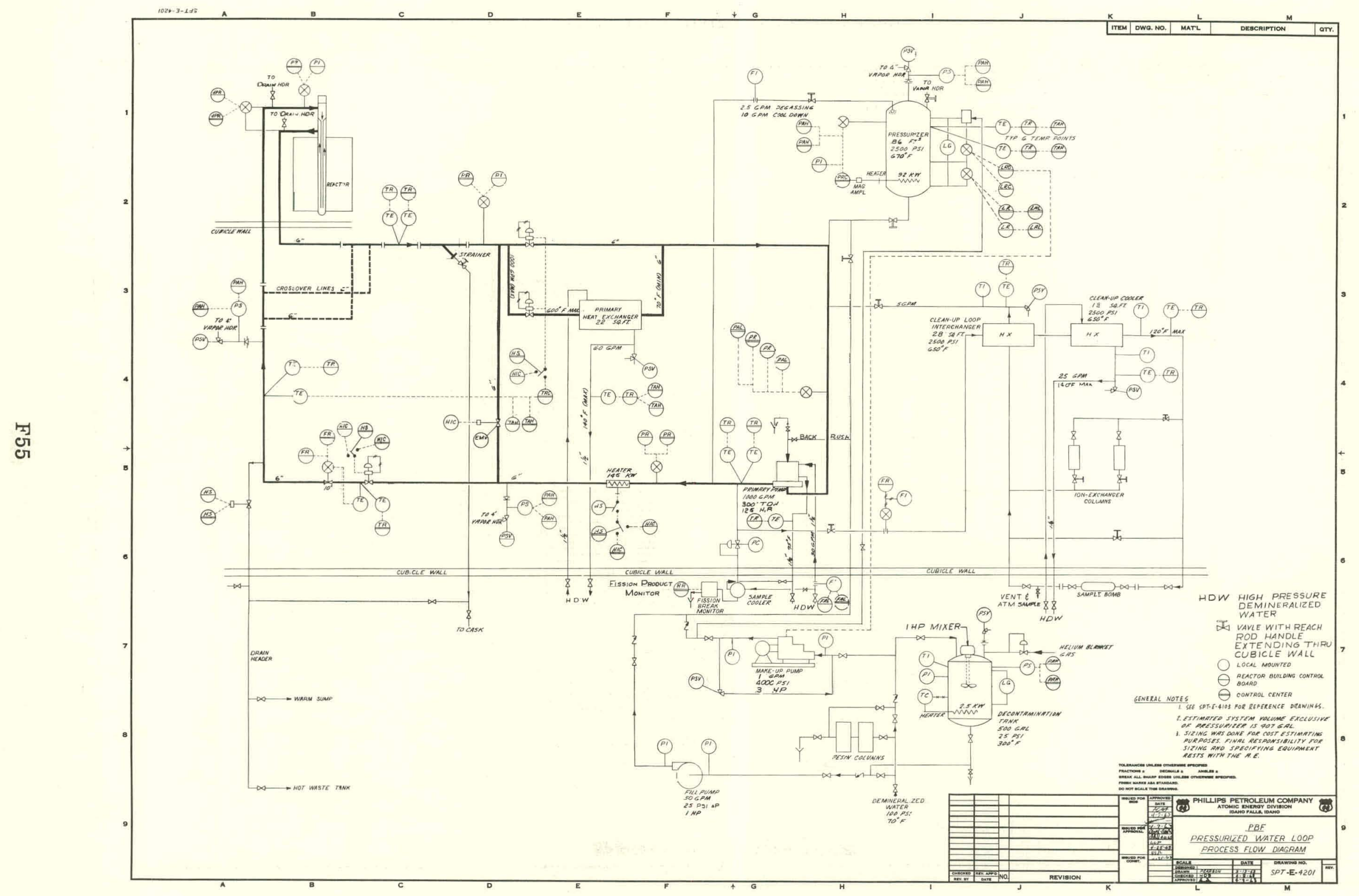

FIG. 55 PRESSURIZED WATER LOOP PROCESS FLOW DIAGRAM. 


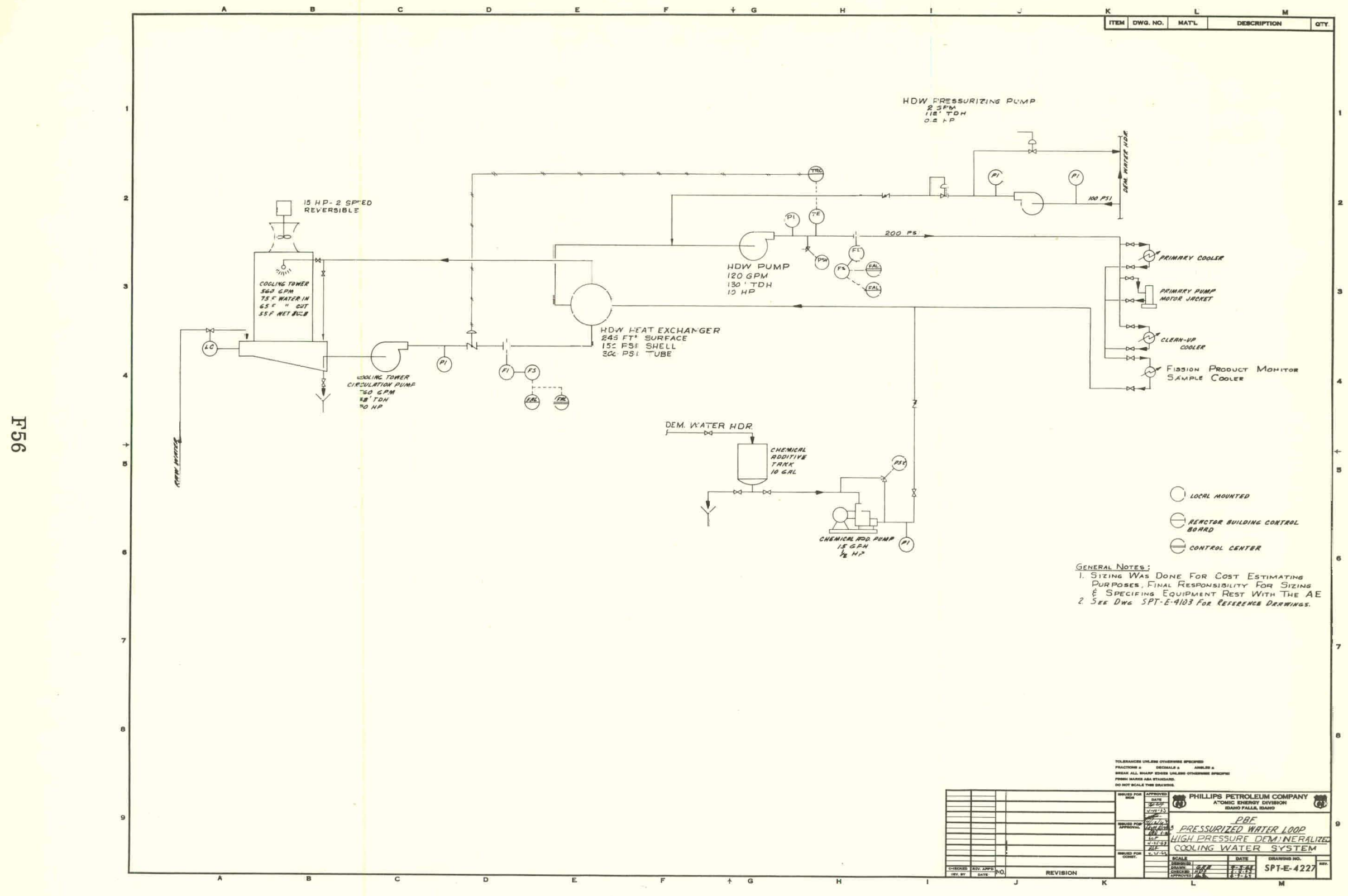

FIG. 56 FLOW DIAGRAM OF HIGH-PRESSURE DENINERALIZED COOLING WATER SYSTEM FIF PRESSURIZED WATER LOOP. 


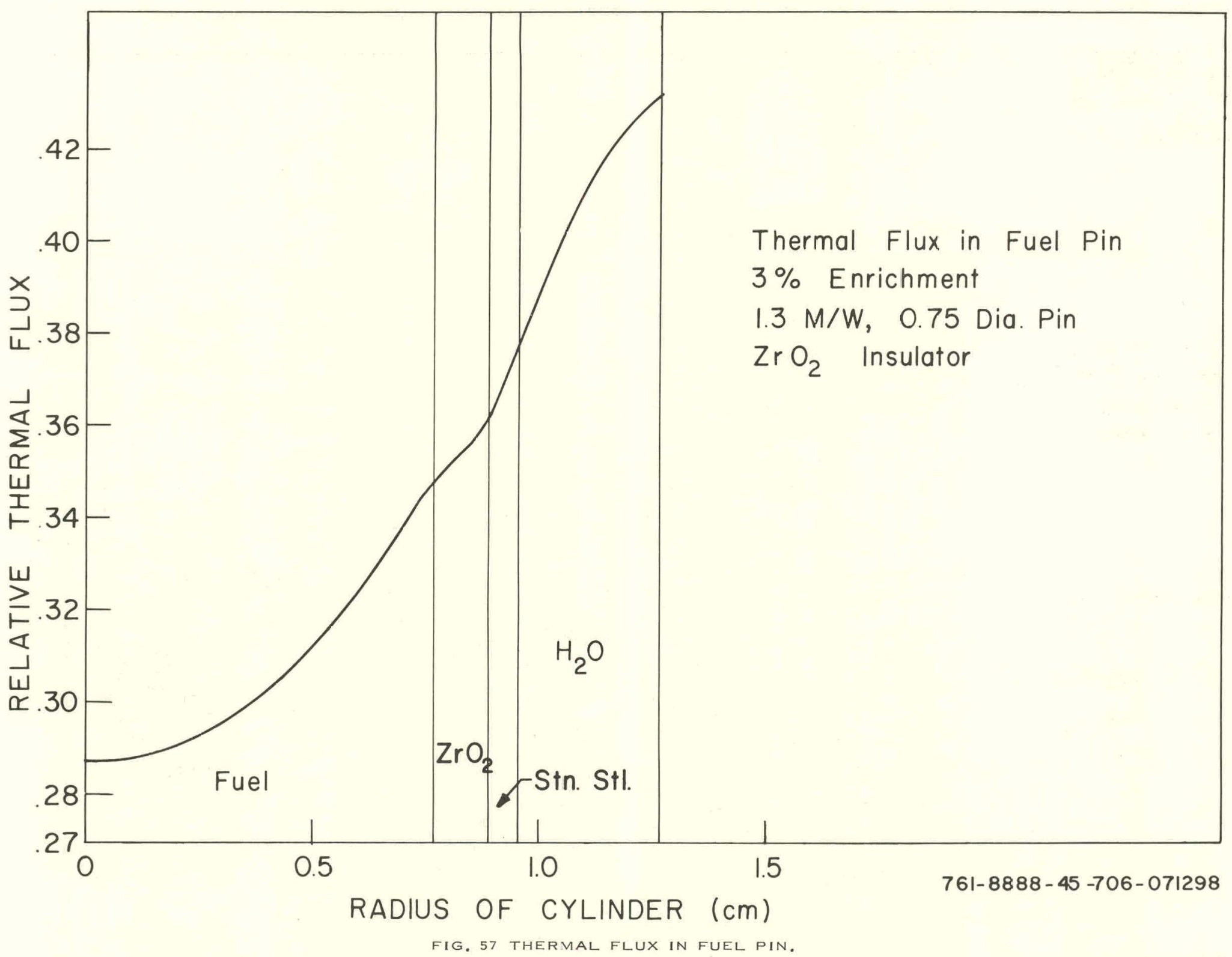




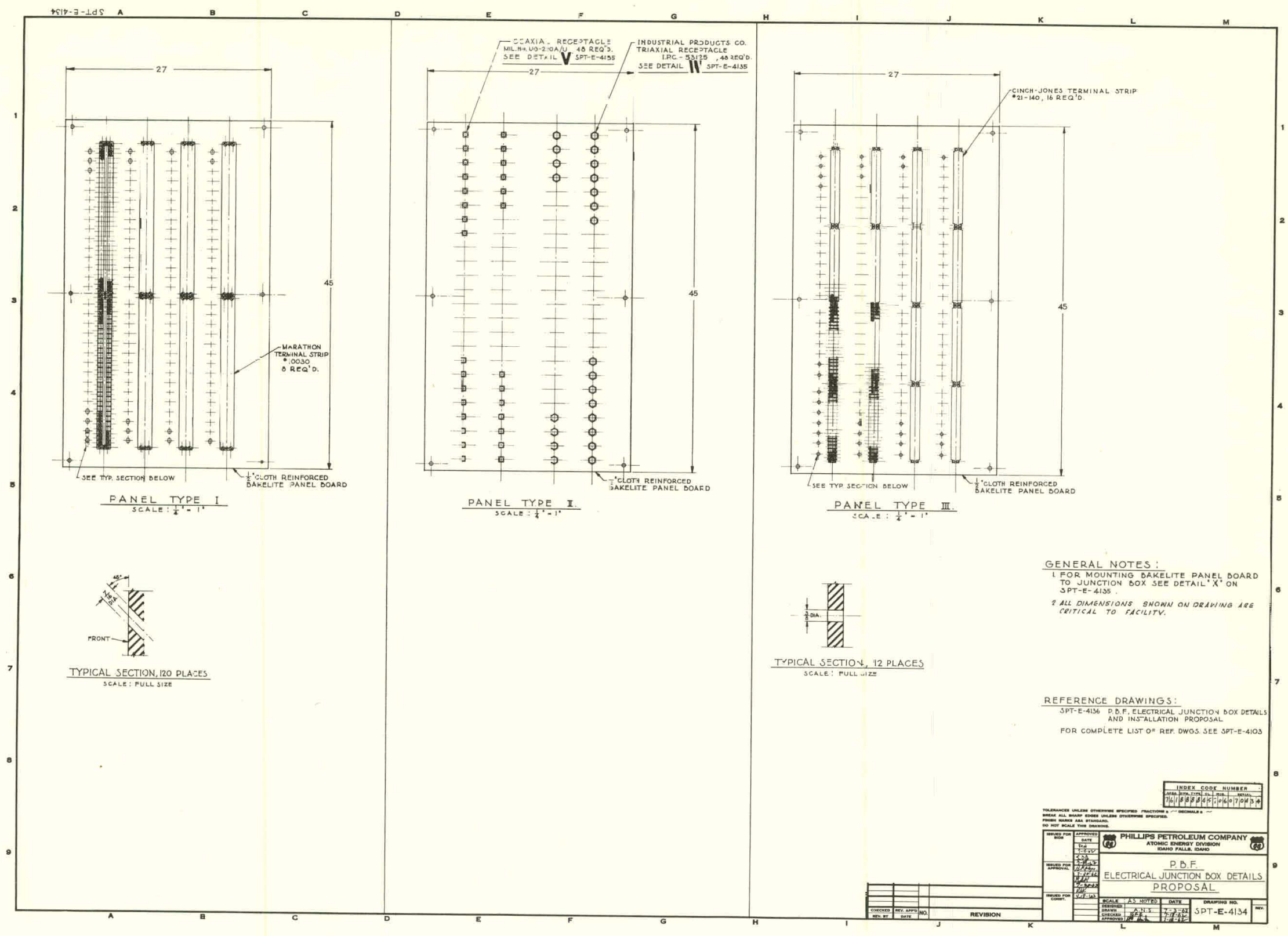

FIG. 58 ELECTRICAL JUNCTION BOX DETAILS 


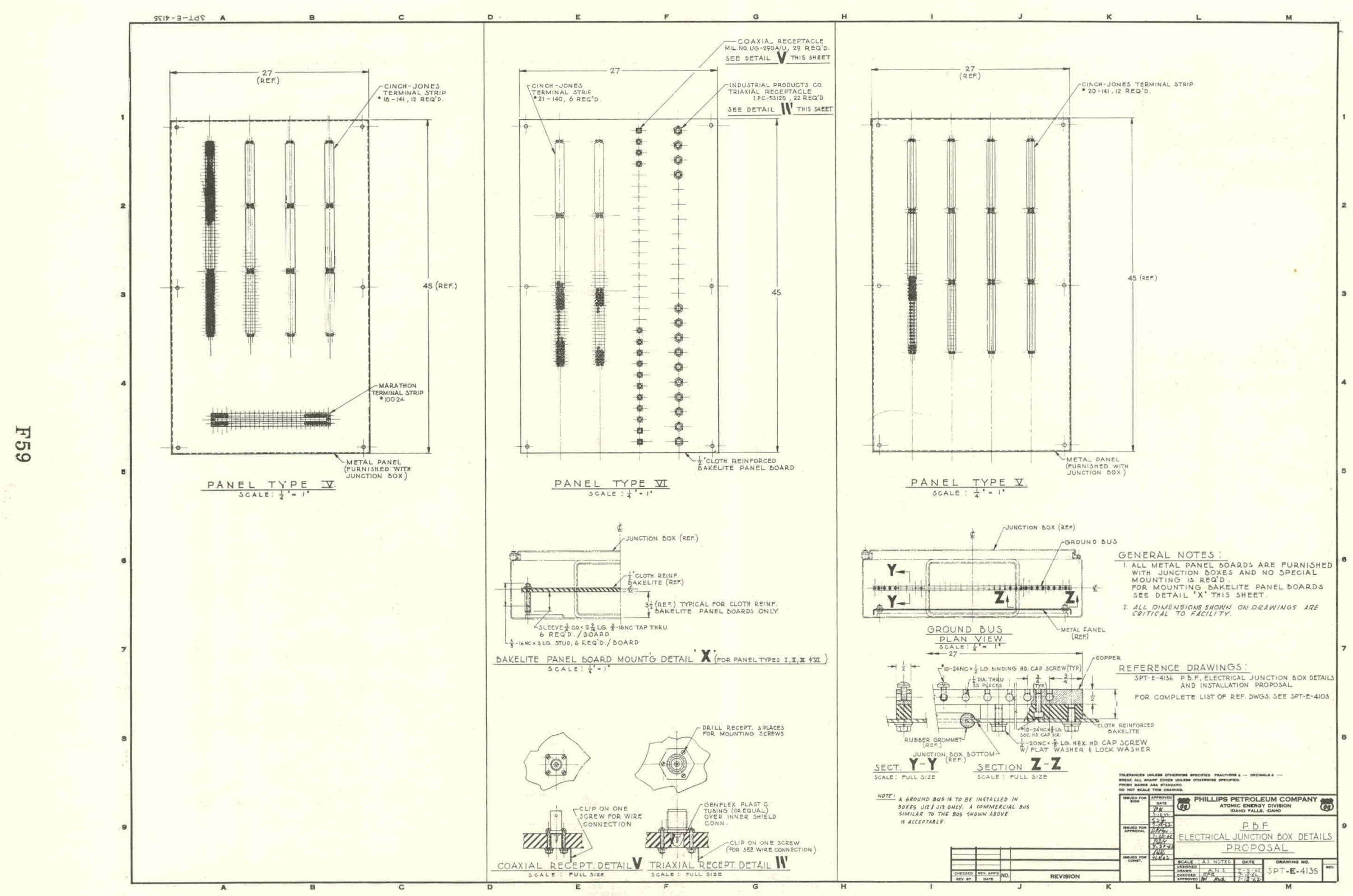

FIG, 59 ELECTRICAL JUNCTION BOX DETAILS. 


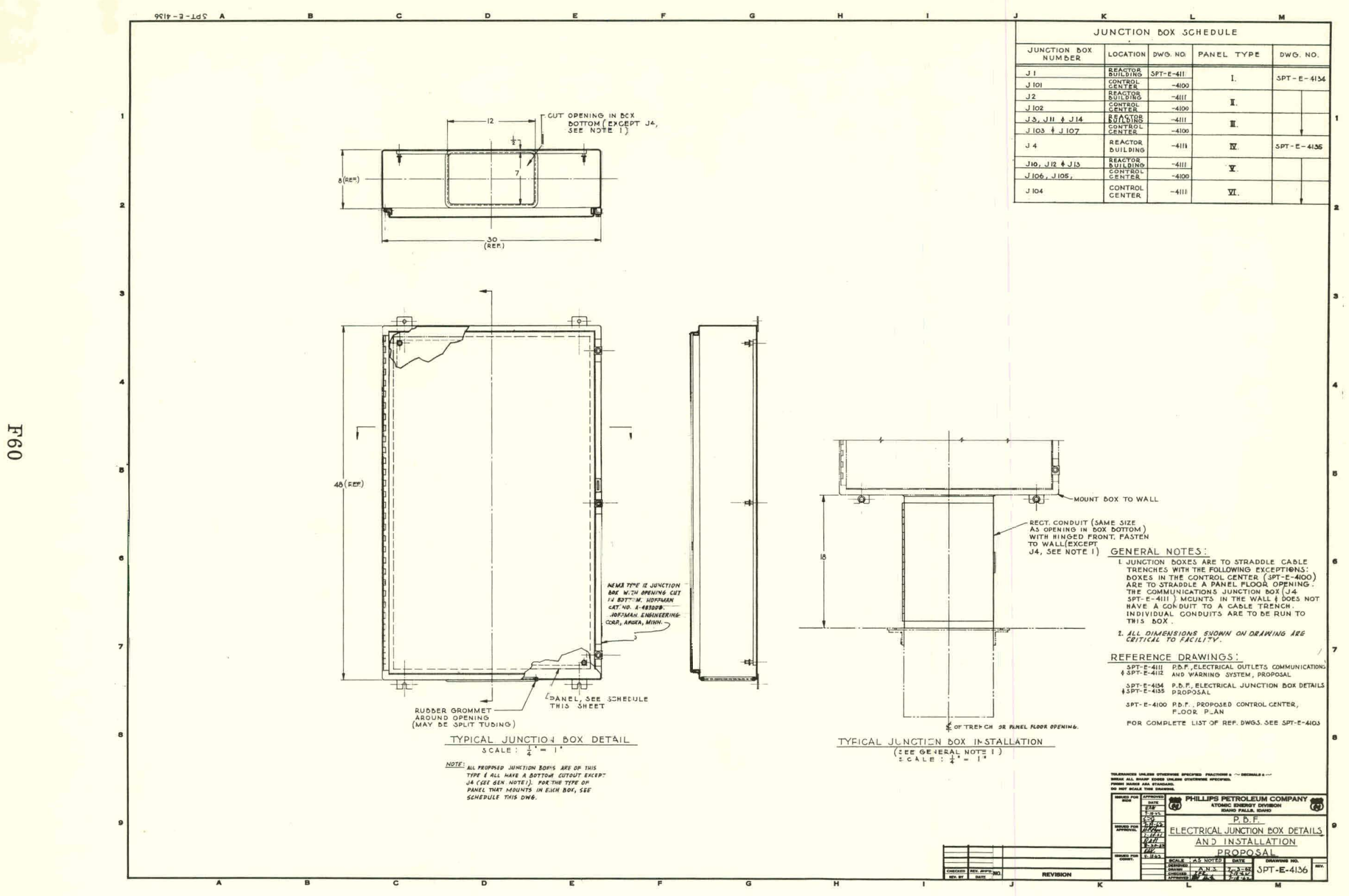

FIG. 60 ELECTRICAL JUNCTION BOX DETAILS AND INSTALLATION. 


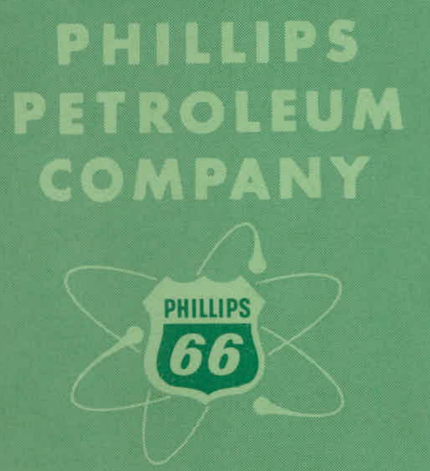

ATOMIC ENERGY DIVISION 